GABRIELA WERNER CESCHINI

\title{
PROPOSTA DE EXTENSÕES A MÉTODOS E FERRAMENTAS DE DESENVOLVIMENTO DE SISTEMAS DE AUTOMAÇÃO DISTRIBUÍDOS BASEADOS EM MODELOS DADOS PELA UML E PELA IEC 61499
}

Dissertação apresentada à Escola

Politécnica da Universidade de São Paulo para obtenção do título de Mestre em Engenharia. 

GABRIELA WERNER CESCHINI

\section{PROPOSTA DE EXTENSÕES A MÉTODOS E FERRAMENTAS DE DESENVOLVIMENTO DE SISTEMAS DE AUTOMAÇÃO DISTRIBUÍDOS BASEADOS EM MODELOS DADOS PELA UML E PELA IEC 61499}

Dissertação apresentada à Escola

Politécnica da Universidade de São Paulo para obtenção do título de Mestre em Engenharia.

Área de Concentração:

Sistemas Digitais

Orientador:

Prof. Livre-Docente Carlos Eduardo

Cugnasca 
AUTORIZO A REPRODUÇÃO E DIVULGAÇÃO TOTAL OU PARCIAL DESTE TRABALHO, POR QUALQUER MEIO CONVENCIONAL OU ELETRÔNICO, APENAS PARA FINS DE ESTUDO E PESQUISA, DESDE QUE CITADA A FONTE.

\section{FICHA CATALOGRÁFICA}

\section{Ceschini, Gabriela Werner}

Proposta de extensöes a métodos e ferramentas de desenvolvimento de sistemas de automação distribuídos baseados em modelos dados pela UML e pela IEC 61499 / G.W. Ceschini. -São Paulo, 2008.

$193 \mathrm{p}$.

Dissertação (Mestrado) - Escola Politécnica da Universidade de São Paulo. Departamento de Engenharia de Computação e Sistemas Digitais.

1. Automação predial 2. Metodologia e técnicas de computação 3. Normas técnicas 4. Softwares I. Universidade de São Paulo. Escola Politécnica. Departamento de Engenharia de Computação e Sistemas Digitais II. t. 
Dedicado à Família, aos Amigos e aos Professores, que constituem as minhas verdadeiras riquezas e são aqueles em quem encontro apoio para seguir adiante, hoje e sempre. 


\section{AGRADECIMENTOS}

Sem dúvida, esta é a minha parte favorita da dissertação: é um dos poucos momentos em que eu tenho a oportunidade de mostrar meu carinho por todos aqueles que me ajudaram a alcançar mais esta vitória. Sendo assim, agradeço:

Em primeiro lugar, à minha família, em especial a meus pais, Mary e Carlos, e ao meu irmão, João Carlos, que sempre estiveram presentes ao meu lado, dandome a força necessária para prosseguir (principalmente quando o cansaço e a descrença pareciam prestes a me derrotar...). Obrigada por acreditarem em mim, e perdão pelas ausências que se fizeram necessárias. Amo a todos.

À família Martins - em especial ao Samuel, claro - pelo apoio, companhia, receptividade, palavras de alento e até pelos jantares! Foi muito importante contar com o amor e carinho de todos vocês, os quais espero retribuir à altura.

Aos meus Professores - todos, absolutamente todos incluídos, desde a escola até a faculdade, de todas as disciplinas, e mesmo das atividades extraclasse - não somente por me instruírem, mas sobretudo por me ajudarem a ser uma pessoa melhor. Em particular:

- Ao Professor Carlos Eduardo Cugnasca, meu orientador, por me acompanhar durante este difícil percurso, pela paciência (apesar de todos os meus tropeços), e pela fé quase "inabalável" depositada em mim - e que me impulsionou sempre;

- Aos demais Professores do Laboratório de Automação Agrícola (Professores Antonio Saraiva, André Hirakawa e Pedro Corrêa), pelo incentivo e pela oportunidade de trabalhar nesse laboratório que eu adoro; e

- Aos Professores Selma Melnikoff, João José Neto e Moacyr Martucci Jr., pelo carinho de sempre e por me levarem a prosseguir mesmo nos momentos de aflição, cada um à sua maneira. 
Aos meus amigos, com quem tenho a felicidade de compartilhar a minha vida e muitos dos meus sonhos. Em especial:

- Ao Eduardo Bertassi, por se fazer presente em todos os momentos (independentemente da forma), pelas conversas de sempre (técnicas e nãotécnicas), pelas risadas infindáveis e também por repetir sempre que "a força é forte" em mim, mesmo que às vezes eu duvide (obrigada pela insistência);

- À Fabiana Nonogaki e ao Gustavo Marin, amigos a quem eu adoro e que, embora distantes, têm lugar cativo no meu coração;

- À Professora Márcia Menegatti, ao Francisco e a todos os membros do grupo de dança Formiga Amarela, pelo carinho e pela alegria que compartilhamos. Espero que fiquemos juntos durante muito e muito tempo;

- Aos colegas do Laboratório de Automação Agrícola e do Laboratório de Abelhas pela acolhida e pelo incentivo constante; e

- Ao José Garcia, por se interessar por meu trabalho e gentilmente me fornecer material para levá-lo adiante.

Por fim, à empresa IBM, à iniciativa BrOffice e a todas as universidades e pesquisadores citados no corpo desta dissertação, que me permitiram utilizar suas ferramentas e documentos para o desenvolvimento desta pesquisa. 
"If I have seen further it is by standing on ye shoulders of Giants". Isaac Newton 


\section{RESUMO}

A motivação para o presente trabalho foi o desejo de investigar métodos $\mathrm{e}$ ferramentas que fossem capazes de auxiliar engenheiros a desenvolver melhores projetos de sistemas de automação. Investigaram-se então quais seriam as contribuições da engenharia de software e da engenharia de controle para alcançar esse objetivo: a primeira destacou-se pelos métodos e ferramentas aplicáveis às fases de levantamento de requisitos e análise, em que os sistemas podem ser expressos através da UML; a segunda contribuiu com blocos funcionais, especialmente os orientados a eventos da norma IEC 61499, e ferramentas para implementação e testes. Diversos autores sugerem a unificação entre as técnicas de orientação a objetos expressas através da UML e o projeto de sistemas por meio de blocos funcionais orientados a eventos da norma IEC 61499, para que os engenheiros de cada uma das áreas citadas continuassem trabalhando com técnicas e ferramentas próprias no desenvolvimento de sistemas de automação, mas de maneira colaborativa. Nesta pesquisa estudou-se a maneira pela qual vêm sendo feitos os mapeamentos entre a UML e a norma IEC 61499 do ponto de vista teórico, embora com intenção de implementação de ferramentas para ajudar nessa conversão. Estudaram-se também as ferramentas criadas para automatizar essa transformação e para auxiliar no projeto de sistemas de automação distribuídos, principalmente segundo a visão da norma IEC 61499. A partir daí, pôde-se oferecer as seguintes contribuições: quanto aos métodos, sugerir um novo método de mapeamento UML-IEC 61499 simplificado, com o uso, em UML, de um vocabulário menos atrelado à norma IEC 61499 (ao contrário do que acontecia com os métodos estudados); e sugerir a expressão de requisitos temporais quanto aos sistemas de automação (também considerados no contexto da conversão UML-IEC61499); quanto às ferramentas, comparar o modelo lógico da IEC 61499 com o da tecnologia LonWorks; e, a partir daí, demonstrar a viabilidade de criação de uma ferramenta para implementar sistemas de automação LonWorks expressados primeiramente em abstrações da IEC 61499 (obtidas a partir das ferramentas vistas anteriormente). Concluiu-se que é possível, teoricamente, criar uma ferramenta para cobrir todo o ciclo de vida de desenvolvimento de um sistema de automação distribuído, com a 
implementação deste sendo feita em uma tecnologia de controle de grande aceitação no mercado. Apesar disso, identificou-se ainda que há várias oportunidades de estudo em continuidade a essa pesquisa, como aprofundamento da expressão dos requisitos de QoS e implementação da ferramenta idealizada.

Palavras-chave: sistemas de automação; modelagem; ferramentas de suporte a projetos; UML; IEC 61499; LonWorks. 


\section{ABSTRACT}

The main motivation of this research was to investigate tools and methods which could help engineers to develop better automation system projects. So, with this aim, the contributions of both software engineering and control engineering areas were investigated: the first offered methods and tools to be used in the requisite elicitation and system analysis project phases, in which the system could be designed in terms of UML models; the latter contributed mainly through implementation and test tools, related to the usage of function blocks, especially the IEC 61499 standard eventoriented ones. Many authors suggest the unification between object-orientation techniques expressed through UML and project methods done with the IEC 61499 event-driven function blocks, so that software engineers and control engineers could keep working with their own area techniques and tools, in the context of an automation system design, but in a collaborative sense. In this work, the mapping between UML and IEC 61499 standard concepts was investigated from a theoretical point of view, even though the intention behind that was to find or generate tools which could automate this kind of conversion. Additionally, other tools related to help engineers in the development of automation systems (particularly those which used IEC 61499 standard abstractions) were also analyzed. After all that, some contributions to this area could be proposed: as for the methods, a new simplified UML-IEC61499 mapping, whose main features are the usage, in UML, of a less IEC 61499-constrained vocabulary (opposite to what happened in the other studied techniques), and the way of expressing automation systems temporal requisites (still related to the UML-IEC61499 conversion context); as for the tools, a comparison between IEC 61499 and the LonWorks technology logical models, which led to the conclusion that it would be possible to implement LonWorks automation systems whose models were expressed at first through IEC 61499 abstractions (mainly those resultant from the usage of UML-IEC61499 conversion tools). The conclusion of this work is that with the development of all these tools and techniques it would be possible to aid engineers through all automation system development phases, and the implementation of such systems could be done with a broadly-accepted control system technology. It was also identified that many other study opportunities were 
raised by this research, such as discovering ways of expressing other QoS requisites in automation system models, and trying to implement more complete engineering project tools.

Keywords: automation systems; modeling; computer aided engineering; UML; IEC 61499; LonWorks. 


\section{LISTA DE ILUSTRAÇÕES}

Figura 1: Diferentes estruturas de sistemas: centralizada (a), hierárquico (b) e distribuído (c) - adaptado de Åström (1985).

Figura 2: Estrutura geral de um sistema de automação distribuído 43

Figura 3: Composição interna de um nó pertencente a um sistema de automação distribuído.

Figura 4: Exemplo de Diagrama de Classes .56

Figura 5: Exemplo de Diagrama de Estruturas Compostas. 57

Figura 6: Exemplo de Diagrama de Componentes 57

Figura 7: Exemplo de Diagrama de Distribuição (Deployment). .58

Figura 8: Exemplo de Diagrama de Pacotes. .59

Figura 9: Exemplo de Diagrama de Casos de Uso. 60

Figura 10: Exemplo de Diagrama de Máquinas de Estados (da classe Sensor)......61

Figura 11: Exemplo de Diagrama de Atividades (da classe Controlador)..... .62

Figura 12: Exemplo de Diagrama de Seqüência. 63

Figura 13: Exemplo de Diagrama de Colaboração/Comunicação. .64

Figura 14: Exemplo de Diagrama de Visão Geral das Interações. .64

Figura 15: Exemplo de outros elementos e mecanismos gerais da UML: nota, estereótipo, valor rotulado e restrição. .66

Figura 16: Composição de um IPMCS da norma IEC 61499 (em UML)..... 72 
Figura 17: Especificação estrutural de um tipo de bloco funcional da norma IEC 61499 (em UML)

Figura 18: Subclassificação dos tipos de blocos funcionais (em UML).

Figura 19: Bloco funcional básico da norma IEC 61499 - traduzido de Christensen (2002))

Figura 20: Diagrama de controle de execução de um bloco funcional básico da norma IEC 61499 - adaptado de Christensen (2002).

Figura 21: Bloco funcional composto da norma IEC 61499 - traduzido de Christensen (2002). .75

Figura 22: Bloco funcional de interface de serviços da norma IEC 61499 (aspecto externo idêntico aos dos demais blocos) e especificação da seqüência de primitivas de um serviço - adaptado de Christensen (2002)..... 76

Figura 23: Diagrama de Classes de um sistema de automação genérico para demonstração do uso dos estereótipos do mapeamento de Thramboulidis (estereótipos FB, IPT, SIFB e RWO). .88

Figura 24: Diagramas de Classes do sistema de automação de um condicionador de ar (fan coil) para demonstração do uso dos relacionamentos de agregação (a) e dependência (b), elaborado segundo o mapeamento de Thramboulidis. .90

Figura 25: Parte dos estereótipos ligados a blocos funcionais (modelo em UML) traduzido de Thramboulidis (2001).

Figura 26: Diagrama de Colaboração do sistema de automação de um condicionador de ar (fan coil), elaborado segundo o mapeamento de Thramboulidis e com os ícones dos estereótipos do CORFU ESS. .92

Figura 27: Diagrama de Seqüência do sistema de automação de um condicionador de ar (fan coil), elaborado segundo o mapeamento de Thramboulidis e com os ícones dos estereótipos do CORFU ESS. 
Figura 28: Diagrama de blocos funcionais obtido a partir do diagrama de seqüência descrito na Figura 27 (gerado com a ferramenta CORFU ESS)

Figura 29: Diagramas de Classes do sistema de automação de um condicionador de ar (fan coil) para demonstração do uso de relacionamentos de agregação e generalização, além de estereótipos e composições das classes, elaborado segundo o mapeamento de Dubinin e Vyatkin.

Figura 30: Diagrama de Colaboração do sistema de automação de um condicionador de ar (fan coil), elaborado segundo o mapeamento de Dubinin e Vyatkin.

Figura 31: Exemplo de hierarquia de objetos (a) e a sua estrutura implícita de blocos funcionais aninhados (b) - retirado de Dubinin, Vyatkin e Pfeiffer (2005). Note-se que as conexões dadas por uma linha tracejada são conexões locais, e a conexão dada por uma linha contínua - em (a) - é uma conexão de trânsito (transformada, em (b), em quatro conexões locais). 99

Figura 32: Diagrama de Componentes e sua transformação na interface externa de um bloco funcional segundo o mapeamento de Panjaitan e Frey - retirado de Panjaitan e Frey (2006a) 101

Figura 33: Diagrama de Estruturas Compostas e sua transformação na interface externa de um bloco funcional composto e na rede de blocos funcionais interna a ele, segundo o mapeamento de Panjaitan e Frey - retirado de Panjaitan e Frey (2006a)..................................................................102

Figura 34: Diagrama de Distribuição elaborado segundo o mapeamento de Panjaitan e Frey. 103

Figura 35: Diagrama de Máquinas de Estados segundo o mapeamento de Panjaitan e Frey - retirado de Panjaitan e Frey (2006a).....................................104

Figura 36: Diagrama de Seqüência segundo o mapeamento de Panjaitan e Frey adaptado de Panjaitan e Frey (2006a) 
Figura 37: Relação entre os estereótipos DataConnection e EventConnection com as metaclasses Connector e Informationltem da UML (a), e exemplo de Diagrama de Estrutura Composta segundo o mapeamento de Zhang, Diedrich e Halang - retirado de Zhang, Diedrich e Halang (2005)... 108

Figura 38: Diagrama mostrando a relação entre a classe SEQ_MVC (que representa um tipo de bloco funcional composto) e seus objetos internos ctrl:SEQ e v:SEQV (que cumprem o papel de instâncias de blocos funcionais) (a), e exemplo de Diagrama de Colaboração/Comunicação (entre uma instância anônima da classe SEQ_MVC e os dois objetos citados anteriormente) segundo o mapeamento de Zhang, Diedrich e Halang - retirado de Zhang, Diedrich e Halang (2005).....

Figura 39: Conexão entre objeto, FBA e bloco funcional - adaptado de Heverhagen, Tracht e Hirschfeld (2003) 110

Figura 40: Editor de Tipos de Blocos Funcionais (Function Block Type Editor) da ferramenta CORFU ESS - neste caso, exibindo a interface externa e o diagrama de controle de execução (ECC) de um bloco funcional..........123

Figura 41: Rede de blocos funcionais descrita no Editor de Diagramas de Blocos Funcionais (Function Block Diagram Editor) da ferramenta CORFU ESS.

Figura 42: Execução da rede de blocos funcionais através do Editor de Diagramas de Blocos Funcionais (Function Block Diagram Editor) da ferramenta CORFU ESS .125

Figura 43: Sistema de dispositivos e IPT projetado por meio do Editor da Camada de Sistema (System Layer Editor) da ferramenta CORFU ESS.

Figura 44: Gerenciador do Recurso de Transformação (Transformation Facility Manager) da ferramenta CORFU ESS.

Figura 45: Representação do efeito dos conversores UML-FB. 130

Figura 46: Interface da ferramenta FBench (exibindo a execução de um sistema).134 
Figura 47: Interface da ferramenta FBDK (exibindo um bloco funcional de interface de serviços). 135

Figura 48: Distribuição de uma aplicação em dois dispositivos através da ferramenta 4DIAC-IDE. 137

Figura 49: Distribuição de uma aplicação da norma IEC 61499 na ferramenta ISaGRAF - adaptado de Chouinard e Brennan (2006).... 139

Figura 50: Exemplo de Diagrama de Classes segundo o mapeamento UMLIEC61499 simplificado.

Figura 51: Exemplo de conversão de método com parâmetros e valor de retorno para uma rede de blocos funcionais (a) e detalhe da interface externa de um dos blocos funcionais (b), segundo o mapeamento UML-IEC61499 simplificado.

Figura 52: Exemplos de blocos funcionais de interface de serviços, para interações iniciadas pela aplicação (a) e para interações iniciadas pelo recurso (b) retirado de International Electrotechnical Commission (2005a). 151

Figura 53: Diagrama de Seqüência (da UML 2.X) com ênfase nas observações de tempo e duração, e nas restrições de tempo e duração - traduzido de Object Management Group (2007). .157

Figura 54: Diagrama de Temporização (da UML 2.X) com ênfase nas observações de tempo e duração, e nas restrições de tempo e duração - traduzido de Object Management Group (2007).... 158

Figura 55: Representação teórica de um bloco funcional LonWorks. .162

Figura 56: Representação de um perfil funcional LonWorks. .164

Figura 57: Relacionamento entre modelos lógicos LonWorks. .166

Figura 58: Arquitetura de um dispositivo 192 


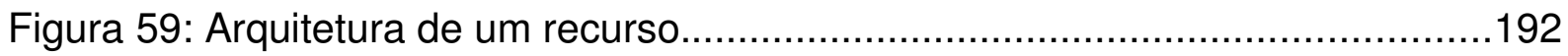

Figura 60: Arquitetura de um sistema distribuído segundo a norma IEC 61499......193 


\section{LISTA DE TABELAS}

Tabela 1: Identificação dos diagramas da UML utilizados para expressar os conceitos da norma IEC 61499 segundo os mapeamentos de Thramboulidis, de Dubinin e Vyatkin, de Panjaitan e Frey e de Zhang, Diedrich e Halang. 115

Tabela 2: Identificação dos principais elementos da UML utilizados para expressar os conceitos da norma IEC 61499 segundo os mapeamentos de Thramboulidis, de Dubinin e Vyatkin, de Panjaitan e Frey e de Zhang, Diedrich e Halang.... 116

Tabela 3: Identificação dos principais relacionamentos da UML utilizados para expressar os conceitos da norma IEC 61499 segundo os mapeamentos de Thramboulidis, de Dubinin e Vyatkin, de Panjaitan e Frey e de Zhang, Diedrich e Halang 117

Tabela 4: Cobertura das ferramentas estudadas quanto às fases de desenvolvimento do projeto de sistemas de automação. 142 


\section{LISTA DE ABREVIATURAS E SIGLAS}

$\begin{array}{ll}\text { 4DIAC } & \text { Framework for Distributed Industrial Automation and } \\ & \text { Control } \\ \text { ANSI } & \text { American National Standard Institute } \\ \text { AXE } & \text { Archimedes eXecution Environment } \\ \text { BFB } & \text { Basic FB } \\ \text { BNF } & \text { Backus-Naur Form } \\ \text { CD } & \text { Control-Dependency } \\ \text { CEA } & \text { Consumer Electronics Association } \\ \text { CFB } & \text { Composite FB } \\ \text { CLP } & \text { Controlador Lógico Programável } \\ \text { CORBA } & \text { Common Object Request Broker Architecture } \\ \text { CORFU } & \text { Common Object-oriented Real-time Framework for the } \\ & \text { Unified development of distributed IPMCS applications } \\ \text { CP } & \text { Configuration Property } \\ \text { CPT } & \text { CP Type } \\ \text { CPAS } & \text { Collaborative Process Automation Systems } \\ \text { CSIFB } & \text { Communication SIFB } \\ \text { DD } & \text { Data-Dependency } \\ \text { DDC } & \text { Digital Direct Control } \\ \text { DTD } & \text { Document Type Definition } \\ \text { ECC } & \text { Execution Control Chart } \\ \text { EIA } & \text { Electronic Industries Alliance } \\ \text { Enhanced-4LCA } & \text { Enhanced four Layer CORFU Architecture } \\ \text { ESS } & \text { Engineering Support System } \\ \text { FB } & \text { Function Block } \\ \text { FBA } & \text { Function Block Adapter } \\ \text { FBDK } & \text { Function Block Development Kit } \\ \text { FDCML } & \text { Field Device Configuration Markup Language } \\ \text { FORTE } & \text { 4DIAC-Run-time Environment } \\ \text { FP } & \text { Functional Profile } \\ \text { FPT } & \text { FP Template } \\ \text { Fuber } & \text { FUnction Block Execution Runtime } \\ \text { HVAC } & \text { Heating, Ventilating and Air Conditioning } \\ \text { LD } & \text { Ladder Diagram } \\ \text { IDE } & \text { Integrated Development Environment } \\ \text { IEC } & \text { International Electrotechnical Commission } \\ \text { IPMCS } & \text { Industrial-Process Measurement and Control Systems } \\ & \\ & \end{array}$




$\begin{array}{ll}\text { IPP } & \text { Industrial Process Parameter } \\ \text { IPT } & \text { Industrial Process Terminator } \\ \text { ISO } & \text { International Organization for Standardization } \\ \text { NCES } & \text { Net Condition/Event Systems } \\ \text { NV } & \text { Network Variable } \\ \text { NVT } & \text { Network Variable Type } \\ \text { OCL } & \text { Object Constraint Language } \\ \text { OMG } & \text { Object Management Group } \\ \text { OMT } & \text { Object Modeling Technique } \\ \text { OOONEIDA } & \text { Open, Object-Oriented kNowedge Economy for } \\ & \text { Intelligent Distributed Automation } \\ \text { OOSE } & \text { Object-Oriented Software Engineering } \\ \text { OSI } & \text { Open Systems Interconnection } \\ \text { PSIFB } & \text { Process SIFB } \\ \text { QOS } & \text { Quality of Service } \\ \text { RAM } & \text { Random Access Memory } \\ \text { RedeBF } & \text { Rede de Blocos Funcionais } \\ \text { ROM } & \text { Read-Only Memory } \\ \text { RTE } & \text { Run-time Environment } \\ \text { RTL } & \text { Real-Time Logic } \\ \text { RWO } & \text { Real-World Object } \\ \text { SCPT } & \text { Standard CPT } \\ \text { SFC } & \text { Sequential Function Chart } \\ \text { SFPT } & \text { Standard FTP } \\ \text { SIFB } & \text { Service Interface Function Block } \\ \text { SNVT } & \text { Standard NVT } \\ \text { ST } & \text { Structured Text } \\ \text { TFM } & \text { Transformation Facility Manager } \\ \text { TIC } & \text { Target Independent Code } \\ \text { TSIFB } & \text { Timer SIFB } \\ \text { UML } & \text { Unified Modeling Language } \\ \text { ViEd } & \text { Visual Editor } \\ \text { ViVe } & \text { Visual Verifier } \\ \text { VLSI } & \text { Very Large Scale Integration } \\ \text { XML } & \text { EXtensible Markup Language } \\ & \end{array}$




\section{SUMÁRIO}

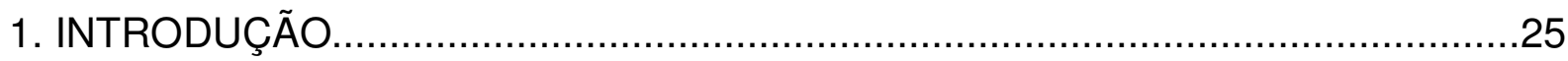

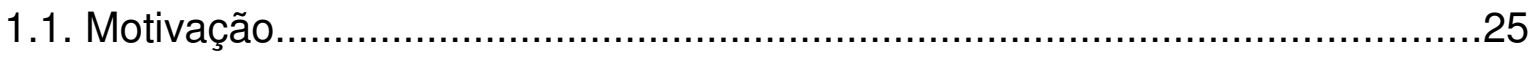

1.2. Justificativa

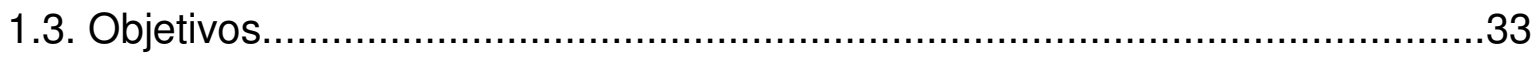

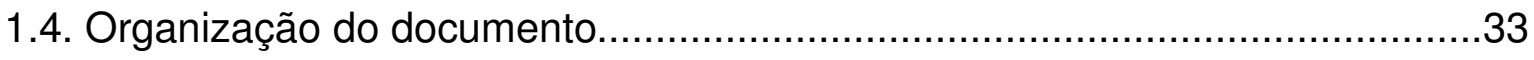

1.5. Considerações sobre estilo e formatação do texto............................................34

2. PROJETO DE SISTEMAS DE AUTOMAÇÃO DISTRIBUÍDOS............................35

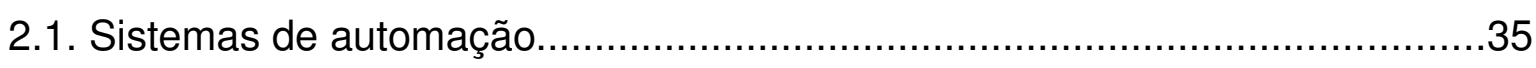

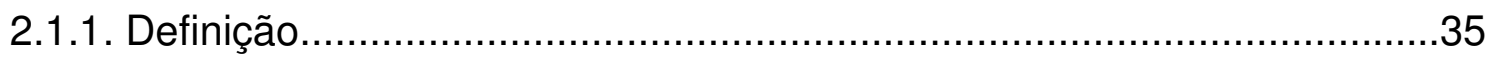

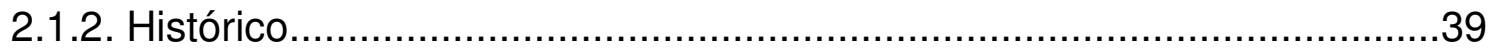

2.1.3. Necessidades latentes dos sistemas de automação distribuídos.............46

2.2. Ciclo de vida de projeto de sistemas de automação distribuídos....................47

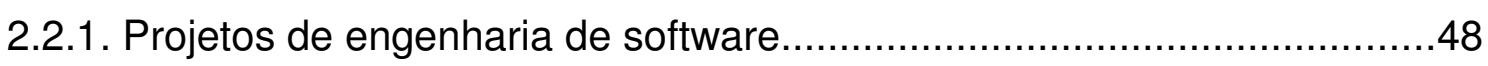

2.2.2. Projetos de engenharia de controle e automação..................................66

2.3. Comentários sobre os projetos de sistemas de automação distribuídos.........80

3. MAPEAMENTO DE DIAGRAMAS DA UML EM DIAGRAMAS DE ABSTRAÇÕES

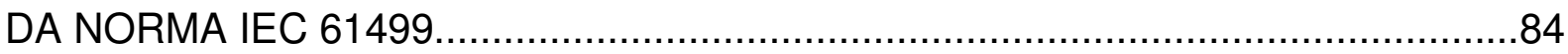

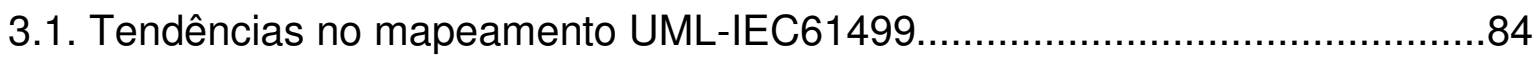

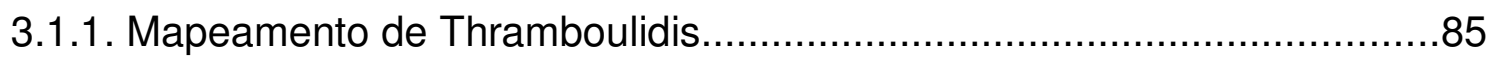

3.1.2. Mapeamento de Dubinin e Vyatkin........................................................94

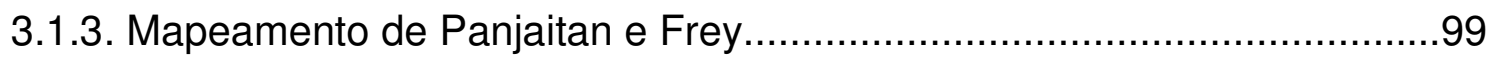

3.1.4. Mapeamento de Zhang, Diedrich e Halang.......................................106

3.1.5. Mapeamento de Heverhagen, Tracht e Hirschfeld..............................110

3.2. Comparação entre mapeamentos UML-IEC61499 e comentários................113 
4. FERRAMENTAS COMPUTACIONAIS PARA SUPORTE ÀS ATIVIDADES DE ENGENHARIA VOLTADAS AO DESENVOLVIMENTO DE SISTEMAS DE AUTOMAÇÃO DISTRIBUÍDOS .............................................................. 118

4.1. Apresentação geral das ferramentas.............................................118

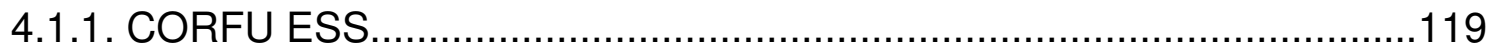

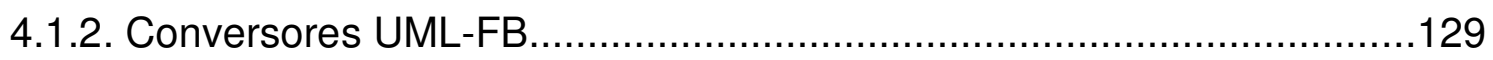

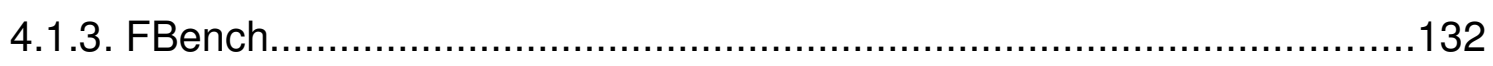

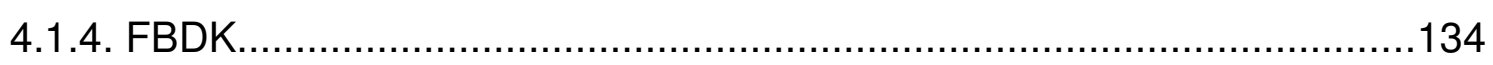

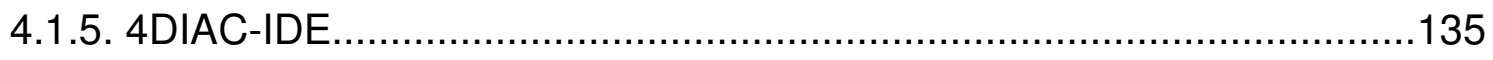

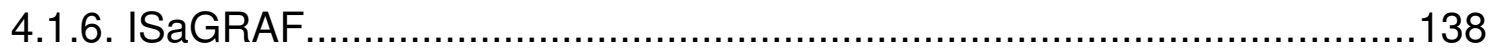

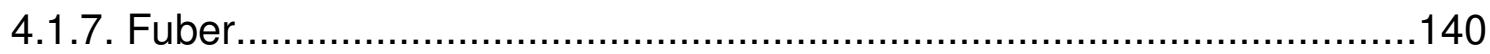

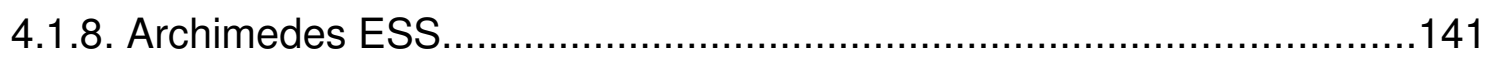

4.2. Comparação entre as ferramentas................................................... 142

5. PROPOSTA DE EXTENSÕES AOS MAPEAMENTOS UML-IEC61499 E

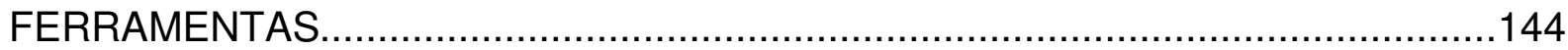

5.1. Extensões aos mapeamentos UML-IEC61499....................................144

5.1.1. Mapeamento UML-IEC61499 simplificado....................................144

5.1.2. Mecanismos para representação de parâmetros temporais em modelos de sistemas de automação.............................................................. 154

5.2. Extensões das ferramentas computacionais para suporte às atividades de engenharia voltadas ao desenvolvimento de sistemas de automação distribuídos

5.2.1. Compatibilidade entre as abstrações da norma IEC 61499 e das abstrações previstas pela tecnologia LonWorks para o projeto de sistemas de automação distribuídos

5. Implementação de ferramenta computacional para suporte ao desenvolvimento de sistemas de automação distribuídos LonWorks. 


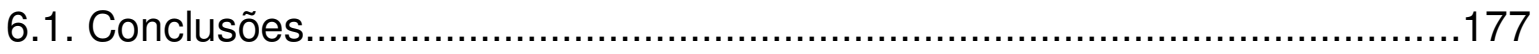

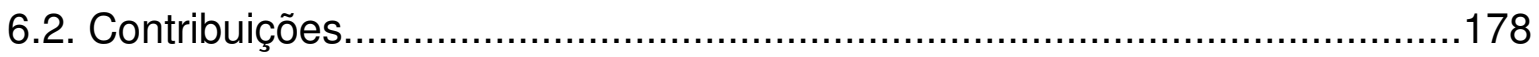

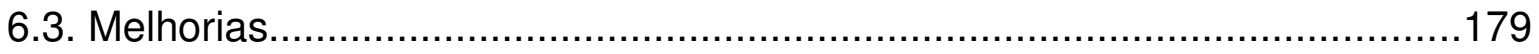

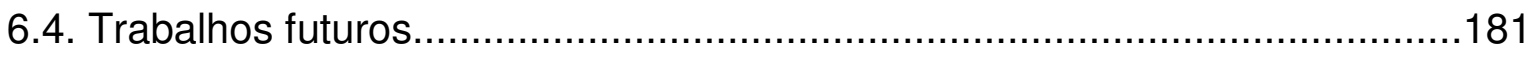

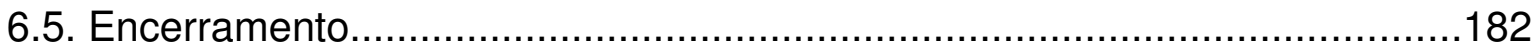




\section{INTRODUÇÃO}

Neste capítulo, apresenta-se a motivação, a justificativa e os objetivos da dissertação. Para isso, descreve-se brevemente o que é um sistema de automação distribuído, quais são algumas das abordagens provenientes das áreas de engenharia de sistemas e de software, e de engenharia de controle e automação, que podem ser usadas para guiar 0 desenvolvimento desses sistemas (correspondendo, respectivamente, à descrição dos mesmos em Unified Modeling Language (UML) durante as fases iniciais do ciclo de vida - que abrangem desde 0 levantamento de requisitos ao projeto, e à caracterização dos sistemas em termos de abstrações da norma International Electrotechnical Commission (IEC) 61499 durante as etapas finais, ou seja, do projeto à manutenção), e, a partir daí, quais são os trabalhos mais relevantes a respeito da integração dessas técnicas. Por fim, o foco do trabalho é posto na investigação e expansão de métodos para o mapeamento entre descrições de sistemas em UML e descrições em termos de modelos da norma IEC 61499, assim como no estudo e aprimoramento de ferramentas que tratam tanto dessa transposição quanto do suporte às atividades de engenharia em geral.

\subsection{MOTIVAÇÃO}

Segundo Samad, McLaughlin e Lu (2007), os sistemas de automação de processos (ou simplesmente sistemas de automação) são os responsáveis por monitorar, controlar e supervisionar, de forma precisa e conveniente, a operação de um sistema físico complexo e dinâmico, usualmente representado por um processo industrial ou planta (sendo essa aplicação o que o distingue de um sistema de automação de escritórios). Uma das áreas em que se utilizam os sistemas de automação é na integração de sistemas prediais (como sistemas de condicionamento de ar e iluminação, por exemplo) para a obtenção de edifícios inteligentes (aqueles em que se constrói um ambiente eficiente, produtivo e seguro 
por um custo mínimo) (GUSTIN, 2005).

Os sistemas de automação podem ser divididos, segundo sua topologia, em três tipos principais: sistemas de automação centralizados, hierárquicos ou distribuídos. Conforme citado por Åström (1985), enquanto nos sistemas centralizados o responsável pelo tratamento das medições é um processador central, em um sistema hierárquico o processamento das informações é descentralizado, e, em um sistema distribuído, é feito localmente em cada laço de controle. Neste último, as entidades computacionais autônomas responsáveis pelo tratamento das informações são chamadas nós ou módulos.

Apesar da existência dessas três topologias principais, os sistemas distribuídos têm sido preferidos por oferecerem algumas características muito desejáveis em um sistema de automação: segundo Samad, McLaughlin e Lu (2007), devido à multiplicidade de nós de processamento, tais sistemas são mais confiáveis (pela inexistência de um ponto central de falha); possibilitam simplificação do cabeamento (XIE; PU; MOORE, 1998); facilitam a manutenção e alteração do sistema (SAMAD; MCLAUGHLIN; LU, 2007) e, por serem escaláveis, causam menor impacto nos custos iniciais de implementação.

Embora apresentem tais vantagens, os sistemas de automação distribuídos caracterizam-se também por serem de difíceis concepção e implementação: a modularidade dos mesmos, tanto física quanto lógica, ao mesmo tempo em que é um de seus trunfos, aumenta a complexidade do projeto por demandar o particionamento da aplicação e sua distribuição nos nós - tarefa em que diversos fatores influenciam as decisões dos projetistas, entre eles os requisitos funcionais e não-funcionais do sistema, as características dos módulos (quanto a entradas e saídas físicas conectadas a eles e capacidade de processamento, por exemplo) e a própria experiência do pessoal responsável. Devido a isso, tais sistemas provocam a necessidade de haver processos de desenvolvimento que guiem os projetos de engenharia, para que, ao fim, obtenham-se sistemas de boa qualidade (sendo esta considerada em diversos sentidos, como para garantir que se obtenham projetos que satisfaçam às necessidades do usuário, que não fiquem obsoletos rapidamente, que possam ser mantidos de forma adequada, que não ultrapassem limites de orçamento e prazo de execução, entre outros aspectos).

Frente ao cenário exposto e às afirmações tanto de Mahalik e Lee (2002) quanto de Xie, Pu e Moore (1998) sobre a falta de ferramentas para apoiar o 
processo de descentralização das aplicações, surge o interesse pela investigação do estado atual da pesquisa nessa área, de forma a garantir que todo o ciclo de vida de desenvolvimento dos sistemas de automação seja coberto (abrangendo as fases de levantamento de requisitos, análise, projeto, implementação, testes, instalação e manutenção do sistema). Parte-se, então, para dois caminhos: verificar as técnicas existentes na área de engenharia de sistemas e de software e aquelas fornecidas pela engenharia de controle e automação.

Sob o prisma da engenharia de sistemas e de software, percebe-se uma abundância de ferramentas e de descrições na literatura sobre como tratar as fases de levantamento de requisitos, análise e projeto, em que se realizam o entendimento das necessidades e a modelagem dos sistemas em geral (aplicáveis também aos sistemas de automação).

Para a divisão da funcionalidade global dos sistemas de automação distribuídos entre componentes de software autônomos e cooperativos durante a modelagem do sistema (cujos potenciais benefícios são o reuso, a escalabilidade e a possibilidade de realizar modificações e manutenção nas aplicações, entre outros (MAHALIK; LEE, 2003)), uma das abordagens mais populares é o uso de técnicas de orientação a objetos, principalmente pela fácil comparação e passagem "intuitiva" de objetos do mundo real para objetos de software: segundo Armstrong (2006), objetos são itens individuais e identificáveis, tanto reais quanto abstratos, que contêm dados sobre si e descrições da forma pela qual os mesmos devem ser manipulados.

No âmbito das técnicas de orientação a objetos, a UML tornou-se o padrão de facto para a representação de sistemas (BORDBAR; DERRICK; WATERS, 2002), destacando-se por ser expressiva, extensível, de aplicação geral e fácil compreensão. De acordo com Booch, Rumbaugh e Jacobson (1998), a UML é uma linguagem gráfica que pode ser utilizada para visualizar, especificar, construir e documentar artefatos de sistemas dos mais diversos domínios, cobrindo a descrição tanto de seu comportamento quanto de sua estrutura. Devido a todas essas características, a UML tem provocado crescente interesse por parte dos pesquisadores da área de sistemas de automação distribuídos, em que começam a surgir trabalhos relacionados à geração de seus modelos como apoio às fases de levantamento de requisitos, análise e projeto (ainda que inicial) dos sistemas. Quanto ao suporte dessas atividades de projeto por meio de ferramentas, ele ocorre 
predominantemente através do uso das ferramentas de aplicação geral para modelagens em UML já existentes no mercado (ou seja, não se tem informações sobre a existência de ferramentas que visem especialmente ao mercado de sistemas de automação).

A partir da fase de implementação, no entanto, a área de software não possui muitos elementos com os quais contribuir para os projetos específicos de sistemas de automação distribuídos: em geral, as linguagens e técnicas de programação não se revelam adequados para a obtenção do software dos módulos funcionais desses sistemas, nem para a sua distribuição. Também não parece haver ferramentas que ajudem na implementação e na manutenção, tanto das aplicações quanto da estrutura física, dos sistemas de automação: portanto, vê-se que, até então, a área de software ofereceria suporte somente às fases de levantamento de requisitos, análise e projeto de tais sistemas.

Segue-se, então, para a verificação das técnicas oferecidas pela área de engenharia de controle e automação para descrever os sistemas de automação distribuídos: além de teorias adequadas para o bom projeto dos laços de controle (incluindo sua modelagem matemática), observa-se a existência de abundantes ferramentas para permitir o desenvolvimento de software, a especificação da arquitetura física do sistema (ou seja, quais são e como estão interligados os nós de automação), a passagem de softwares para os módulos de processamento, a configuração e a manutenção da rede de controle e dos nós, a interligação lógica dos módulos de software (entre si, e com as entradas e saídas físicas de seus nós), e a supervisão da aplicação de automação, conforme pode ser visto em Echelon Corporation (2006), Honeywell International Inc. (2005), TourAndoverControls (2006) e VisualControl, LLC (2003).

Nesse âmbito, nota-se que, em grande parte dos casos, a modularização do software dos sistemas de automação é feita por meio de blocos funcionais, que são, segundo Lewis ${ }^{1}$ (2001 apud TRANORIS; THRAMBOULIDIS, 2003a), mecanismos de abstração que permitem o encapsulamento de algoritmos industriais de forma que os mesmos possam ser rapidamente entendidos e aplicados pelos engenheiros, mesmo que eles não sejam especialistas na implementação de algoritmos complexos. Dai, Shih e Vyatkin (2006), por sua vez, descrevem o bloco funcional

1 LEWIS, R. Modeling control systems using IEC 61499. [S.I.]: The Institute of Electrical Engineers, 2001. 
como uma cápsula (normalmente de software, mas, de maneira geral, uma propriedade intelectual), que consiste de variáveis de entrada e saída, variáveis internas e descrição de seu comportamento interno, cuja interligação resulta na aplicação a ser posta em um dispositivo. Nesse contexto, uma das normas que padronizam o uso de blocos funcionais em sistemas de automação distribuídos é a IEC 61499, publicada em 2005, que define, além disso, uma arquitetura genérica e apresenta recomendações específicas para cobrir desde a fase de projeto até a fase de implementação desses sistemas por meio de modelos apropriados.

Dessa forma, observa-se que a área de engenharia de controle e automação tem oferecido bastantes recursos em termos de procedimentos e ferramentas para auxiliar nas etapas de desenvolvimento que vão da implementação à manutenção dos sistemas de automação distribuídos, ainda que se deva ressaltar a falta de suporte às fases de levantamento de requisitos, análise e projeto. No entanto, como visto anteriormente, estas fases são justamente aquelas que podem ser supridas pelas técnicas de engenharia de sistemas e de software.

\subsection{JUSTIFICATIVA}

Embora houvesse a possibilidade de estender as técnicas de software ou de controle para as fases de projeto em que ainda apresentam deficiências, tem-se notado que muitos autores começam a propor a unificação dessas diferentes abordagens, tanto para reaproveitamento de legado quanto para que os profissionais dessas áreas passem a colaborar entre si (mesmo mantendo os recursos e linguagens próprios de suas áreas). Percebe-se, especificamente, uma tendência em se aproximar os elementos de orientação a objetos, com modelos gerados em UML, das descrições de sistemas por meios de blocos funcionais, em especial daquelas dadas segundo a norma IEC 61499 (já que esta especifica um modelo de bloco funcional especial, orientado a eventos). Portanto, justifica-se assim o interesse pelos estudos tanto do mapeamento entre diagramas da UML e diagramas de abstrações da norma IEC 61499, quanto de ferramentas que facilitem essa transposição, bem como as demais atividades de engenharia, visando à disponibilidade de técnicas e ferramentas que cubram todo o ciclo de 
desenvolvimento de projeto de sistemas de automação.

A seguir, são listadas as principais referências que revelam o estado da arte da pesquisa nessa área. Para clareza, optou-se pelo uso de tópicos e pela apresentação das mesmas em ordem cronológica:

- Mapeamento de diagramas da UML em diagramas de abstrações da norma IEC 61499:

- Tranoris e Thramboulidis (2002): sugere extensões à UML e regras de transformação de diagramas da UML para diagramas de abstrações da norma IEC 61499, além de mostrar um exemplo de como essa transformação é feita;

- Heverhagen, Tracht e Hirschfeld (2003): mostra os adaptadores para blocos funcionais (Function Block Adapters - FBA), que permitem a compatibilização entre classes dos diagramas da UML e blocos funcionais da norma IEC 61499;

- Dubinin e Vyatkin (2004): descreve a linguagem UML-Function Block (UML-FB), que estende a UML de forma a tornar possível a representação de abstrações da norma IEC 61499;

- Dubinin, Vyatkin e Pfeiffer (2005): expõe brevemente a linguagem UMLFB, mostra um exemplo de aplicação e indica a existência de ferramentas conversoras UML-FB, disponíveis para download;

- Zhang, Diedrich e Halang (2005): explica como estender e usar a UML para fazer a modelagem de aplicações baseadas em abstrações da norma IEC 61499; e

- Panjaitan e Frey (2006): propõe o uso da UML para a modelagem de sistemas de automação e a posterior passagem desses modelos para diagramas de abstrações da norma IEC 61499. Por fim, os autores apresentam sua própria ferramenta para executar tal transformação.

- Ferramentas para o suporte às atividades de engenharia de sistemas de automação distribuídos (incluindo a transformação de diagramas da UML em diagramas de abstrações da norma IEC 61499):

- Thramboulidis (2003): expõe a ferramenta Common Object-oriented Real-time Framework for the Unified development of distributed Industrial-Process Measurement and Control Systems (IPMCS) applications-Function Block Development Kit (CORFU-FBDK), que dá 
suporte ao ciclo de vida de projeto de aplicações voltadas a sistemas de automação distribuídos e que, para isso, segue uma arquitetura chamada enhanced four Layer CORFU Architecture (enhanced-4LCA) e está inserida no contexto de um processo de desenvolvimento incremental (o CORFU development process);

- Tranoris e Thramboulidis (2003a): mostra a ferramenta CORFU Engineering Support System (ESS), que pode ser dividida em dois subsistemas: uma ferramenta para auxílio à engenharia de software, que nesse caso é a IBM Rational Rose, e outra chamada CORFU-FBDK, que é composta por: biblioteca de blocos funcionais pré-definidos, editor de blocos funcionais, editor de diagramas de blocos funcionais, editor da camada de sistema e pelo gerenciador do recurso de transformação (Transformation Facility Manager - TFM).

- Tranoris e Thramboulidis (2003b): exibe outros aspectos da ferramenta CORFU ESS, cuja função é fazer interface com a ferramenta IBM Rational Rose, transformar seus diagramas em modelos baseados em abstrações da norma IEC 61499 (através da aplicação de um conjunto de regras de transformação) e fornecer meios para a continuidade do desenvolvimento de projetos em um ambiente que emprega somente os conceitos de sistemas de automação vistos na norma IEC 61499;

- Dubinin, Vyatkin e Pfeiffer (2005): cita os conversores UML-FB e FBUML, que passam as descrições de sistemas em UML para diagramas de abstrações da norma IEC 61499 e vice-versa (segundo o que é descrito na linguagem UML-FB);

- Software Engineering Group (2005): mostra o funcionamento da ferramenta Archimedes ESS, a qual fornece suporte ao desenvolvimento de modelos baseados nas abstrações da norma IEC 61499 e sua subseqüente transformação para sistemas executáveis;

- Čengić, Ljungkrantz e Åkesson (2006): mostra a ferramenta FUnction Block Execution Runtime (Fuber), a qual pode ser utilizada para descrever e executar sistemas baseados em abstrações da norma IEC 61499. Seu principal diferencial em relação às outras ferramentas é que o comportamento de uma aplicação pode ser modificado durante a sua execução, já que os seus algoritmos não são previamente compilados, e 
sim interpretados;

- Chouinard e Brennan (2006): descreve algumas das funcionalidades da ferramenta comercial ISaGRAF, que permite o desenvolvimento de sistemas baseados em abstrações da norma IEC 61499, assim como a simulação do sistema e a distribuição dos blocos funcionais entre os dispositivos, por exemplo;

- Dai, Shih e Vyatkin (2006): mostra o estado do projeto Open, ObjectOriented kNowledge Economy for Intelligent Distributed Automation (OOONEIDA) Workbench, cujo objetivo é a criação de uma ferramenta (chamada FBench), de código aberto, para dar suporte ao desenvolvimento de aplicações compatíveis com o padrão IEC 61499 para sistemas de automação distribuídos;

- Holobloc, Inc. (2006b): oferece diversos tutoriais sobre a norma IEC 61499 e abundante material sobre a ferramenta Function Block Development Kit (FBDK), usada no suporte a projetos de sistemas de automação distribuídos que utilizam os blocos funcionais da IEC 61499 como abstrações principais;

- The University of Auckland, Research Centre for Embedded Intelligence - CEMBI (2007): apresenta a ferramenta FBench, cujo objetivo é auxiliar no processo de engenharia de sistemas e componentes baseados no padrão IEC 61499. Ela permite a exibição, a edição e a interconexão de blocos funcionais de forma gráfica, e também realiza a transformação dos mesmos para a linguagem Java (o que viabiliza a simulação da aplicação como um todo); e

- Zoitl e Strasser (2007): explica a função das ferramentas Framework for Distributed Industrial Automation and Control-Integrated Development Environment (4DIAC-IDE) - ambiente de engenharia em que a descrição de hardware de um sistema de automação é feita em Field Device Configuration Markup Language (FDCML) e a descrição de software é feita em blocos funcionais da norma IEC 61499 - e 4DIAC-Run-time Environment (4DIAC-RTE ou FORTE) - ambiente de execução em tempo real para o software citado anteriormente. 


\subsection{OBJETIVOS}

Diante desse cenário, os objetivos a serem alcançados nesta dissertação são:

- Detalhar as principais técnicas recentemente disponibilizadas para fazer o mapeamento entre diagramas da UML e diagramas de abstrações da norma IEC 61499, bem como seus pré-requisitos e restrições, fornecendo, ao fim, uma comparação entre elas e sugestões de extensão quanto à possibilidade de expressão de requisitos relacionados a qualidade de serviço (Quality of Service-QoS); e

- Estudar as ferramentas descritas na Justificativa (item 1.2) para entender quais são suas funcionalidades, como elas se inter-relacionam, e qual seu nível de cobertura quanto à norma IEC 61499 e, além de fornecer uma comparação entre elas, propor extensões a essas ferramentas, seja para melhorar a expressividade do mapeamento entre diagramas da UML e diagramas de abstrações da norma IEC 61499, seja para cobrir outras necessidades relativas a ferramentas de suporte ao desenvolvimento de sistemas de automação distribuídos (como a sua interação e aplicação a redes de automação específicas - por exemplo, à tecnologia LonWorks).

\subsection{ORGANIZAÇÃO DO DOCUMENTO}

O presente documento é organizado através dos seguintes capítulos:

- Capítulo 1 - Introdução: mostra a introdução, a justificativa e os objetivos da dissertação;

- Capítulo 2 - Projeto de sistemas de automação distribuídos: faz o detalhamento do que são sistemas de automação distribuídos e mostra como as áreas de engenharia de sistemas e de software, e de engenharia de controle e automação podem ser unificadas para cobrir todo o processo de desenvolvimento desses sistemas; 
- Capítulo 3 - Mapeamento de diagramas da UML em diagramas de abstrações da norma IEC 61499: exibe as principais tendências para a execução da transformação de diagramas da UML em diagramas de abstrações da norma IEC 61499;

- Capítulo 4 - Ferramentas computacionais para suporte às atividades de engenharia voltadas ao desenvolvimento de sistemas de automação distribuídos: mostra algumas das ferramentas usadas para suporte às atividades de engenharia dos sistemas de automação descritos através de abstrações da norma IEC 61499, e descreve quais as suas principais funcionalidades;

- Capítulo 5 - Proposta de extensões aos mapeamentos UML-IEC61499 e ferramentas: sugere extensões aos mapeamentos entre abstrações da UML e da norma IEC 61499 e às ferramentas estudadas anteriormente (com destaque para uma nova proposta de mapeamento UML-IEC61499, a representação de requisitos de QoS em sistemas de automação descritos através de diagramas da UML e de diagramas da norma IEC 61499, e para a criação de uma ferramenta que permitisse a transposição entre os elementos da norma IEC 61499 e as abstrações da tecnologia LonWorks); e

- Capítulo 6 - Considerações finais: exibe as conclusões, contribuições, melhorias e trabalhos futuros a serem realizados a partir desta pesquisa.

\subsection{CONSIDERAÇÕES SOBRE ESTILO E FORMATAÇÃO DO TEXTO}

Para facilitar a leitura, optou-se por:

- Repetir o termo completo referente a cada sigla utilizada no texto a partir do início de cada capítulo (como Unified Modeling Language para UML); e

- Não traduzir termos ou siglas consagrados em língua estrangeira (como gateways e métodos get, por exemplo, ou FB para bloco funcional (function block)).

Além disso, escolheu-se não adotar plural em caso de utilização de siglas (por exemplo, Function Blocks é abreviado por FB, e não FBs). 


\section{PROJETO DE SISTEMAS DE AUTOMAÇÃO DISTRIBUÍDOS}

Apresenta-se neste capítulo a definição de sistemas de automação, incluindo a distinção entre sistemas centralizados, hierárquicos e distribuídos, e a viabilidade de uso da tecnologia LonWorks para a implementação desses últimos. A partir de então, discutem-se abordagens, técnicas e ferramentas para o desenvolvimento de projetos, primeiramente do ponto de vista da engenharia de sistemas e de software (em que são mostrados o paradigma de orientação a objetos e a Unified Modeling Language (UML)), e posteriormente do ponto de vista da engenharia de controle e automação (em que são expostas a modularização de sistemas por meio de blocos funcionais e a norma International Electrotechnical Commission (IEC) 61499). Por fim, conclui-se que tais abordagens, técnicas e ferramentas, embora não sejam isoladamente suficientes, podem ser usadas de forma complementar para fornecer cobertura completa às atividades de engenharia do ciclo de vida de projetos de sistemas de automação. Entre diversos aspectos, mostra-se a possibilidade de aproximação entre as modelagens dadas em UML daquelas fornecidas em termos de abstrações da norma IEC 61499, por exemplo.

Ressalva-se que, embora este capítulo tenha se tornado extenso, optou-se por expor de forma abrangente todos os conceitos que fundamentam o restante da dissertação (a fim de dispensar consulta constante a outras referências).

\subsection{SISTEMAS DE AUTOMAÇÃO}

\subsubsection{Definição}

Segundo Samad, McLaughlin e Lu (2007), uma planta de processamento é uma organização estruturada de elementos físicos, controlada por critérios específicos da área de aplicação a que está vinculada, e que possui diversos interessados ou envolvidos que podem afetar ou ser afetados por sua operação. Entre os interessados ou envolvidos citados anteriormente, estão desde os 
investidores da indústria, que visam ao seu alto rendimento, até aqueles que trabalham nelas: segundo Åström (1985), os seres humanos participam desse contexto agindo como operadores ou gerentes da planta.

No entanto, a ação do homem em ambientes complexos (muitas vezes com restrições críticas de temporização), como o de uma planta de processamento, pode não ser desejável:

O controle de um sistema complexo por um operador humano não é eficiente devido às inúmeras inter-relações entre as diversas variáveis. Note que mesmo em um sistema simples um controlador automático eliminará quaisquer erros humanos de operação. Se for necessária alta precisão de controle, o controle deve ser automático. (OGATA, 1982)

Dessa forma, justifica-se o interesse pelo uso de sistemas de automação no controle de processos. Segundo Samad, McLaughlin e Lu (2007), o sistema de automação é vital para a operação das plantas de processamento, pois ele é responsável por controlá-la e por desempenhar outras funções avançadas, como otimização, agendamento e planejamento de produção. O sistema de automação assegura que os parâmetros apropriados sejam medidos, que as situações operacionais sejam analisadas, que oportunidades mais rentáveis sejam exploradas, que ações de controle sejam calculadas e tomadas, que situações anormais sejam identificadas e solucionadas, que os processos sejam integrados e que o pessoal da planta seja sempre mantido informado sobre seu estado, e que seu conhecimento e capacidades sejam utilizados de maneira adequada.

Todas as funções descritas acima são cumpridas tipicamente por duas partes diferentes de um sistema de automação: o subsistema de controle de processos e o subsistema de supervisão e gerenciamento. Este último, além de realizar as funções de otimização, comunicação e planejamento, permite a visão e a gestão global da planta e do subsistema de controle de processos por parte dos operadores: as informações relevantes sobre os mesmos (como equipamentos em modo de falha, exibidas através de interfaces homem-máquina, por exemplo), ajudam em que o sistema de automação cumpra seus objetivos.

O sistema de controle de processos, por sua vez, no qual este trabalho concentra seu foco, possui diversos componentes, e dentre esses os principais são (AIHKISALO, 2002; ÅSTRÖM, 1985; SANTOS, 1979):

- Sensores, que medem variáveis relevantes, ou seja, revelam o estado de um objeto ou processo automatizado; 
- Atuadores, que executam ações, modificando o estado dos objetos; e

- Controladores (ou unidades de processamento), que tomam decisões baseados nas informações dadas pelos sensores, cumprindo assim tarefas de regulação (ou seja, comparam as medidas dadas pelos sensores com os valores desejados, executam operações matemáticas e geram sinais de correção, enviados para os atuadores).

Os sensores e atuadores são ligados às unidades de entradas e saídas de sinais do sistema de controle de processos, que podem estar integradas com os dispositivos controladores ou podem ser disponibilizadas em módulos (que permitem sua fácil substituição). As unidades de entrada são usadas para levar os sinais dos sensores aos controladores, enquanto as unidades de saída exportam o sinal dos controladores para os atuadores. Ambas partes fazem conversão e adequação dos sinais por meio de transdutores, e sua escolha depende do tipo e quantidade de sinais a serem tratados no sistema (sendo os principais tipos o analógico e o digital).

Finalmente, o sistema de comunicação interliga todos os componentes do sistema.

A partir deste ponto, o trabalho direciona seu foco apenas ao sistema de controle de processos, e essa deve ser a interpretação dada à expressão "sistema de automação". Enquanto isso, o sistema de supervisão continuará sendo citado da mesma maneira, caso necessário.

Conforme pode ser visto em Åström (1985), a principal motivação para o uso de controle de processos centraliza-se nas promessas de melhor qualidade dos produtos, melhor uso de matérias-primas e energia, maiores volumes de produção, melhores relatórios gerenciais, menores custos e menor poluição ambiental. No entanto, todas essas vantagens são difíceis de se justificar quantitativamente, ao contrário do que ocorre com a verificação de uma melhor regulação do sistema, menores tempos de mudança em sua funcionalidade e melhor controle da planta e seus subprocessos. Já em Ogata (1982), vê-se que, desde que os avanços na teoria e na prática de controle automático propiciam meios para atingir-se desempenho ótimo de sistemas dinâmicos e eliminação de operações manuais repetitivas (levando a menos erros no sistema), a maioria dos engenheiros e cientistas que atuam nesta área devem entender e conhecer bem este campo. 


\subsubsection{Sistemas de automação predial}

Uma das áreas de aplicação dos sistemas de automação é em edifícios inteligentes, cujos principais objetivos, segundo Clements-Croome (1997), Gustin (2005) e Wong, Li e Wang (2005), podem ser agrupados da seguinte maneira:

- Quanto a aspectos de requisitos de usuário: oferecer ambientes produtivos, confortáveis, saudáveis, seguros (em termos patrimoniais, individuais e de dados, contra danos por incêndios, terremotos, desastres e danos estruturais, entre outros), flexíveis (quanto ao uso do espaço), eficientes e eficazes, de maneira a assegurar satisfação, bem-estar e suporte às atividades criativas, intelectuais e espirituais de seus ocupantes; ser aderentes à realidade cultural e social em que estão inseridos, além de adaptáveis a mudanças nesse âmbito; ser ambientalmente sustentáveis (pela otimização do uso de recursos - incluídos a utilização de insumos (como energia elétrica) e a devolução de dejetos ao meio ambiente); minimizar seus custos em investimento, operação e manutenção; e passar a idéia de avanço tecnológico (para aumentar seu valor de mercado); e

- Quanto a aspectos tecnológicos: permitir o controle automatizado, a monitoração, o gerenciamento, a operação local e/ou remota e a manutenção dos diferentes sistemas do edifício, de forma integrada e mantendo alto desempenho, confiabilidade, robustez, adaptabilidade (às exigências do ambiente e dos ocupantes), flexibilidade e escalabilidade (para possibilitar a incorporação de novos sistemas e/ou modificação das funções); e ter projeto e implementação consistentes com seus requisitos tecnológicos e de uso, de curto e longo prazo, levantados junto a todos os interessados, para garantir que não ocorra sua obsolescência antes de se obter o retorno do investimento.

Para alcançar todas essas metas com elevado grau de autonomia, os edifícios inteligentes devem garantir o inter-relacionamento e a integração entre todos os seus componentes, incluindo sua estrutura (arquitetura interior e exterior), sistemas (construídos a partir de tecnologias das áreas mecânica, elétrica, mecatrônica, civil e da computação ou informação), serviços, elementos de gerenciamento e ocupantes, no sentido de que os mesmos atuem cooperativamente como uma entidade coesa. 
Um dos sistemas que participa dessa integração é o sistema de automação predial, cuja função é permitir a troca de informações e a atuação conjunta de diversos subsistemas que dão suporte à operação dos edifícios, como os de aquecimento, ventilação e condicionamento de ar (Heating, Ventilating and Air Conditioning - HVAC), segurança (contra incêndios e para proteção da vida), transporte, elevadores, iluminação, drenagem e abastecimento de água, controle de acesso, telecomunicações e processamento de dados.

\subsubsection{Histórico}

A evolução tecnológica dos sistemas de automação é detalhada a seguir a partir das descrições de Åström (1985) e Samad, McLaughlin e Lu (2007):

- Passagem dos sistemas pneumáticos à utilização de padrões elétricos (como a norma 4-20mA) na interligação de sensores e atuadores aos seus respectivos controladores, sendo estes constituídos por componentes elétricos discretos;

- Separação dos sistemas de automação, até então monolíticos, em diversos dispositivos (como sensores, transdutores, reguladores e atuadores) intercambiáveis e produzidos em larga escala, a partir de componentes padronizados;

- Uso de computadores nos sistemas de automação, embora inicialmente para fins de supervisão, alarme, armazenamento de dados, estabelecimento de boas condições de operação (otimização estática), agendamento de tarefas, planejamento de produção e geração de relatórios (anos 50);

- Uso de computadores para controle dos sistemas de automação (constituindo o que se conhece por controle digital direto, ou Digital Direct Control-DDC) (anos 60);

- Surgimento dos controladores lógicos programáveis (CLP), computadores especiais para a realização de funções seqüenciais e lógicas no campo, e posteriormente dos primeiros sistemas de automação distribuídos, em que cada um de seus dispositivos computacionais espalhados pela planta realizava parte do processamento atribuído ao sistema. Paralelamente, dáse o início do uso de redes de controle para unir as possíveis unidades de entrada e de saída dos CLP aos mesmos (substituindo as interligações 
elétricas tradicionais) e para conectar os módulos dos sistemas distribuídos ${ }^{2}$ (anos 70);

- Integração e constituição de sistemas abertos baseados em redes (anos 80);

- Uso de padrões da tecnologia da informação e arquiteturas centradas em aplicação nos sistemas de automação (anos 90); e

- Previsão, a partir deste ponto, do uso intensivo de redes de comunicação sem fio, da disponibilização de infraestrutura para aplicações avançadas, e do surgimento de sistemas colaborativos de automação de processos (Collaborative Process Automation Systems - CPAS), em que informações contextuais são diretamente intercambiadas entre as aplicações de um sistema de automação em tempo real.

Devido a essa evolução histórica, surgiu a distinção entre sistemas de automação centralizados, hierárquicos e distribuídos, sendo essa segmentação referente à localização tanto das aplicações lógicas quanto dos módulos físicos dos sistemas. No entanto, ressalta-se que, entre esses, o parâmetro mais importante para a classificação é a distribuição do processamento nos sistemas de automação.

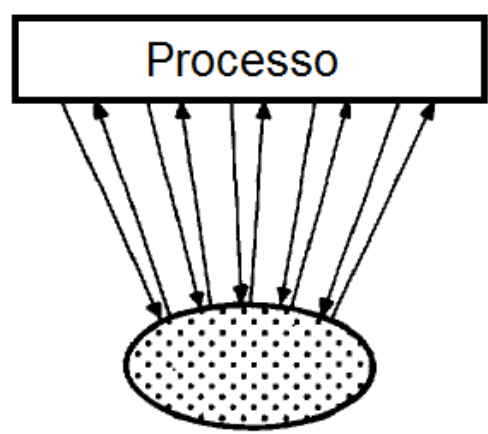

(a)

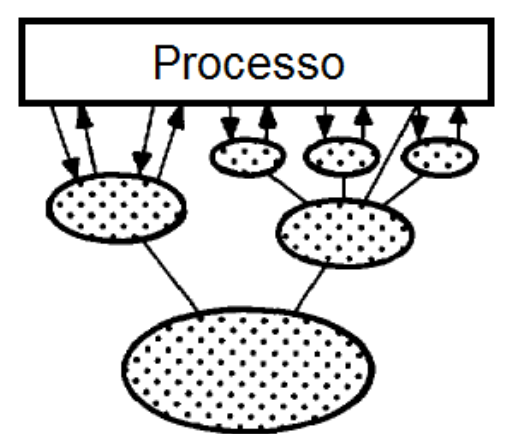

(b)

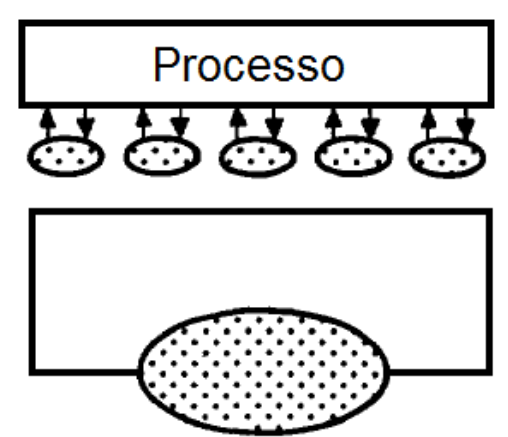

(c)

Figura 1: Diferentes estruturas de sistemas: centralizada (a), hierárquico (b) e distribuído (c) adaptado de Åström (1985).

2 De acordo com Echelon Corporation (1999), redes de controle são sistemas digitais de comunicação que permitem a um grupo de dispositivos intercambiar mensagens curtas, em topologia ponto-a-ponto, e se caracterizam principalmente pela confiabilidade e segurança. As redes de controle, assim, são similares a redes comuns de transmissão de dados, mas são otimizadas para o custo, o desempenho, o tamanho e as restrições temporais próprias de seu domínio de aplicação. 


\subsubsection{Sistemas de automação centralizados e hierárquicos}

Em um sistema de automação centralizado, todos os sensores e atuadores fazem interface direta com um sistema central (MAHALIK; LEE, 2002). Os controladores possuem microprocessadores de alto desempenho que processam a aplicação, em que é implementada a lógica de controle para todos os pontos de entrada e saída conectados a ele (já que sensores e atuadores não possuem por si nenhum processamento interno ou capacidade de comunicação), e podem, algumas vezes, trocar informações entre si (ECHELON CORPORATION, 1999). Como visto em Aihkisalo (2002), um dos exemplos de sistemas desse tipo são aqueles implementados com CLP, computadores de pequeno porte, com sistema operacional de tempo real, dedicados apenas à automação de processos.

Apesar dos sistemas de automação centralizados serem adequados para casos em que é necessária sincronização em tempo real ou grande fluxo de dados entre dispositivos (XIE; PU; MOORE, 1998) e de terem a seu favor o fato de suas aplicações serem mais fáceis de se conceber - já que neste caso, segundo Åström (1985), é mais simples implementar as interações entre os laços de controle, Mahalik e Lee (2002) afirmam que o uso de sistemas de automação centralizados também acarreta algumas desvantagens, como o problema de falha central (em que o sistema de automação falharia ou pararia por completo se o controlador fosse de alguma forma danificado) e a impossibilidade de atender os sinais e mensagens provenientes dos dispositivos de campo, dentro de certos requisitos temporais, caso fosse mal dimensionado. Adicionalmente, os sistemas centralizados apresentam problemas quanto ao cabeamento (já que este é extenso e, além de caro, pode provocar perdas de informação) (AIHKISALO, 2002).

Por outro lado, os sistemas de automação hierárquicos são aqueles em que controladores supervisórios (gateways) intercambiam informações entre si, usualmente através de uma rede de controle, para conectar sistemas de automação isolados (ECHELON CORPORATION, 1999).

Apesar de representar uma vantagem em termos de distribuição de funcionalidade e pela integração de sistemas antes independentes (como os sistemas legados), as desvantagens dos sistemas hierárquicos, segundo Echelon Corporation (1999) e Wang et al. (2004), centralizam-se no fato dos gateways serem soluções proprietárias, de difícil construção, configuração e manutenção, que não 
somente diminuem o tempo de resposta dos sistemas como ainda não permitem comunicação entre/com os dispositivos da planta (o que dificulta a implementação dos algoritmos de controle). Portanto, nota-se que os sistemas de automação hierárquicos ainda oferecem dificuldades quando da necessidade de expansão, já que não são tão flexíveis quanto o ideal.

\subsubsection{Sistemas de automação distribuídos}

Finalmente, um sistema de automação distribuído consiste de dispositivos ditos inteligentes, os quais se comunicam diretamente entre si através de um ou mais canais de comunicação (normalmente uma rede de controle), usando um protocolo comum (AIHKISALO, 2002; ECHELON CORPORATION, 1999; CAUFFRIEZ et al., 2004). Neste contexto, assim como definido em Xie, Pu e Moore (1998), o termo "dispositivo inteligente" refere-se à existência de uma unidade de processamento no dispositivo, que lhe permite responder a eventos externos em uma forma pré-definida, seja matemática ou lógica. Assim, em um sistema descentralizado é possível realizar o processamento dos dados localmente em cada laço de controle (ÅSTRÖM, 1985). Vale destacar ainda que, além da capacidade de cumprir requisitos de tempo real, Mahalik e Lee (2002) ressaltam a importância dos sistemas de automação distribuídos possuírem, normalmente, dispositivos com capacidade de auto-diagnóstico e auto-manutenção.

A partir dessa descrição inicial, segue-se para a listagem dos principais componentes de um sistema distribuído, que compreende, segundo Echelon Corporation (1999), Mahalik e Lee (2002) e Xie, Pu e Moore (2002):

- Os dispositivos de campo, que são sensores e atuadores sem capacidade de processamento;

- Os módulos ou nós computacionais, que são os dispositivos responsáveis por realizar o processamento de dados e a implementação de protocolos de comunicação, quando necessário. Eles se caracterizam por possuir um ou mais microprocessadores, transceptores para o meio de comunicação, dispositivos para armazenamento de dados (memórias), portas de entrada e saída de dados (para interconectá-los aos dispositivos de campo) e módulos para adaptação ou conversão de sinais. Os módulos ou nós contém aplicações (software), que, conjunta e cooperativamente, cobrem todas as 
funcionalidades necessárias ao sistema de automação. Por fim, vale destacar que principalmente quando tais módulos estão encapsulados junto a um dispositivo de campo, provendo a este capacidade de processamento, os mesmos são conhecidos por dispositivos inteligentes - smart devices ou intelligent devices;

- O meio ou canal de comunicação, que serve como base para a troca de dados entre todos os dispositivos do sistema de automação (seja de forma digital ou analógica). De acordo com o seu tipo (por exemplo, fibra óptica, cabo coaxial, par trançado, etc.), o meio de comunicação oferece características físicas distintas - que impactam na topologia da rede e na velocidade e distância de transmissão, por exemplo, condicionando a escolha do projetista do sistema.

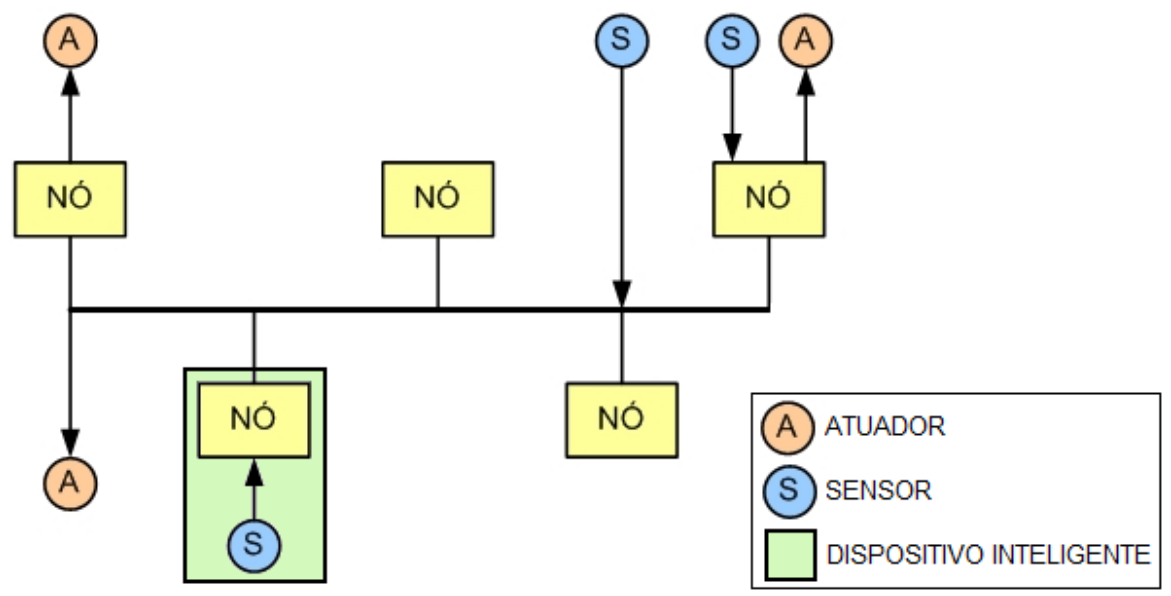

Figura 2: Estrutura geral de um sistema de automação distribuído.
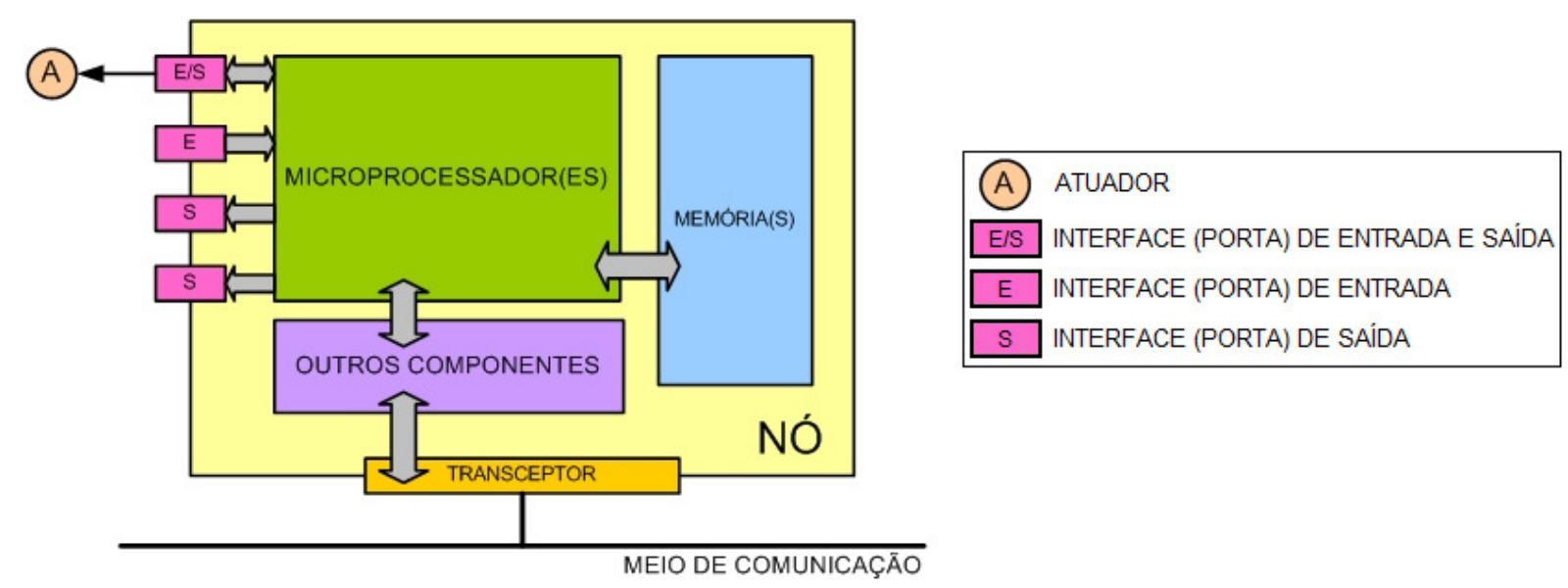

Figura 3: Composição interna de um nó pertencente a um sistema de automação distribuído. 
De acordo com as características apresentadas anteriormente, as principais vantagens dos sistemas de automação distribuído, a partir dos textos de Aihkisalo (2002), Echelon Corporation (1999), Mahalik e Lee (2002), Samad, McLaughlin e Lu (2007) e Xie, Pu e Moore (1998) concentram-se em: cabeamento simplificado; maior eficiência, robustez e disponibilidade devido à diminuição dos atrasos de controle (dada a execução local das aplicações de controle), além de facilidade de implementação e bom desempenho (em termos de sincronização e consistência das aplicações); maior confiabilidade (pela multiplicidade de nós de processamento (cada qual com segmentos da aplicação de controle), que minimiza as chances de haver um ponto central de falha que afete todo o sistema); maior escalabilidade (já que aceitam a inserção de novos nós para a expansão gradual de suas capacidades, o que causa menor impacto nos custos iniciais de implementação); e maior flexibilidade para a adaptação ou alteração do sistema para uma grande variedade de aplicações, já que a troca ou modificação dos módulos individuais de software não afeta o seu funcionamento global. Por fim, deve-se ressaltar que os contínuos estudos sobre de redes de controle que garantam boa qualidade de serviço - como pode ser visto em Neumann ([2006]) - ajudam a afastar preocupações com a possibilidade desses sistemas não atenderem restrições estritas de temporização. Portanto, devido a todas essas vantagens dos sistemas distribuídos sobre os sistemas centralizados ou hierárquicos, este trabalho direciona seu foco para os primeiros.

\subsection{A tecnologia LonWorks}

Segundo Mahalik e Lee (2002), a tecnologia LonWorks (ou simplesmente LON), desenvolvida pela empresa Echelon Corporation entre as décadas de 80 e 90, tem como objetivo fornecer uma solução completa para o projeto, a implantação e a manutenção de sistemas de controle e automação distribuídos. Para que isso seja possível, estão previstos pela tecnologia LonWorks, conforme Mahalik e Lee (2003), o microprocessador denominado Neuron Chip, transceptores para diversos meios de comunicação (como cabo coaxial, par trançado, rede de transmissão de energia elétrica e fibra ótica) e múltiplas taxas de transmissão, além de ferramentas de desenvolvimento (que abrangem desde a geração das aplicações ao gerenciamento da rede). 
Em um sistema LonWorks, diversos nós, responsáveis pela execução das tarefas de controle e automação, interagem através de uma rede digital e bidirecional. Tais dispositivos são usualmente constituídos pelo processador Neuron Chip, um transceptor para o meio de comunicação, e circuitos eletrônicos específicos para a sua aplicação (HUR; KIM; PARK, 2005).

Segundo Hur, Kim e Park (2005), o Neuron Chip, processador de 8 bits de muito alta escala de integração (Very Large Scale Integration - VLSI), é composto internamente por memória somente para leitura (Read-Only Memory - ROM), três subprocessadores, interface de comunicação e interfaces (portas) de entrada e saída configuráveis. Ele também possui ou interage com uma memória de acesso randômico (Random Access Memory - RAM).

A ROM contém o firmware do Neuron Chip, que inclui o seu sistema operacional (agendador de tarefas), o protocolo de comunicação entre dispositivos padronizado pela tecnologia LonWorks (chamado LonTalk) e uma biblioteca para facilitar o uso das portas de entrada e saída do processador, a ser empregada pelo usuário ao elaborar a aplicação do Neuron Chip (HUR; KIM; PARK, 2005; XIE; PU; MOORE, 1998). O protocolo de comunicação LonTalk permite que os dispositivos do ambiente de controle possam se comunicar uns com os outros, por meio do intercâmbio de pacotes, em uma topologia ponto a ponto. Para isso, cada dispositivo pode ser endereçado por um endereço físico - o Neuron ID, atribuído a cada Neuron Chip, ou lógico - configurado através de ferramentas de gerenciamento de rede (AIHKISALO, 2002). O protocolo LonTalk é aberto, padronizado (padrão American National Standard Institute / Electronic Industries Alliance / Consumer Electronics Association 709.1 - ANSI/EIA/CEA 709.1), e provê os serviços essenciais de todas as sete camadas do modelo de referência para interconexão de sistemas abertos especificada pela International Organization for Standardization (International Organization for Standardization / Open Systems Interconnection - ISO/OSI).

Quanto aos processadores internos do Neuron Chip, verifica-se, segundo Xie, Pu e Moore (1998), que os mesmos possuem diferentes funções: o processador de acesso ao meio provê os serviços referentes às camadas um e dois do modelo ISO/OSI (incluindo o controle do hardware de comunicação e a execução do algoritmo de evitação de colisões), o processador de rede implementa das camadas de três a seis do modelo ISO/OSI (ou seja, responsabiliza-se pelo processamento das variáveis de rede intercambiadas entre as aplicações dos dispositivos, pelo 
endereçamento dessas mensagens, pelo processamento de transações, pela autenticação, pelo diagnóstico, pelos temporizadores de software, pelo gerenciamento da rede e por funções de roteamento), e, por fim, o processador de aplicações executa o código escrito pelo usuário, vinculado às tarefas de automação e controle.

Já a aplicação de automação e controle dos dispositivos fica guardada na memória RAM do Neuron Chip, que também grava seus dados de configuração. Todos esses dados são descarregados por meio da própria rede de comunicação LonWorks no dispositivo, com a ajuda de ferramentas de gerenciamento de rede e desenvolvimento de aplicações (HUR; KIM; PARK, 2005).

Do ponto de vista lógico, em um sistema LonWorks cada dispositivo deve executar as suas próprias funções e intercambiar dados com os demais para que o sistema de automação cumpra seu objetivo. Como será visto em maiores detalhes no capítulo 5, a aplicação de cada dispositivo é modularizada em blocos funcionais, e cada bloco funcional possui variáveis de entrada e saída denominadas variáveis de rede (network variables - NV). Essas variáveis de rede, quando do mesmo tipo e sentidos opostos, podem ser conectadas logicamente através de um processo chamado binding, para permitir a intercomunicação das aplicações. Adicionalmente, cada bloco funcional pode conter propriedades de configuração (configuration properties - CP), que são variáveis para a configuração de variáveis de rede, blocos funcionais ou dispositivos.

Do ponto de vista de elaboração das aplicações, Mahalik e Lee (2003) afirmam que o Neuron Chip pode ser programado utilizando a linguagem Neuron C, derivada da linguagem ANSI C. Essa linguagem de programação é orientada a objetos, e possui comandos de comunicação específicos para o envio de mensagens do protocolo LonTalk (AIHKISALO, 2002). Outras ferramentas permitem a programação para dispositivos LonWorks sem a escrita de código em Neuron C (ou seja, de maneira gráfica), como é o exemplo da ferramenta TAC Menta (TOURANDOVERCONTROLS, 2006).

\subsubsection{Necessidades latentes dos sistemas de automação distribuídos}

Nota-se neste ponto que a modularidade dos sistemas de automação distribuídos é um de seus grandes trunfos, e se baseia na divisão da funcionalidade 
global do sistema: as subaplicações são distribuídas entre nós de processamento, e assim, ao invés de existir uma única aplicação monolítica, lida-se na verdade com diversos módulos de software, descritíveis por uma interface bem definida, que interagem e cooperam entre si para que o sistema como um todo atinja seus objetivos. Ao mesmo tempo em que é extremamente benéfico, vê-se que o particionamento da aplicação é uma tarefa muito complexa, já que diversos fatores influenciam as decisões dos projetistas, entre eles os requisitos funcionais e nãofuncionais do sistema (como necessidade de manutenibilidade e qualidade de serviço), as características dos nós (quanto a entradas e saídas físicas conectadas a eles e capacidade de processamento, por exemplo) e a própria experiência do pessoal responsável.

Como a escolha incorreta dessas subdivisões pode levar o sistema de automação a não ser concebido da melhor maneira e apresentar os mesmos inconvenientes de sistemas de automação centralizados, percebe-se a necessidade de que tal processo seja guiado adequadamente: Além disso, é fundamental que ferramentas adequadas forneçam suporte a esse processo. Alguns trabalhos na área de sistemas de automação embasam estas idéias: a necessidade de abordagens de modelagem e análise de sistemas de automação prediais, por exemplo, é levantada por Gustin (2005); a necessidade de ferramentas de projeto para guiar a distribuição da "inteligência" nos sistemas de automação, e o uso provável de componentes para a geração de software (conceito de orientação a objetos) é manifestada por Xie, Pu e Moore (1998); e a necessidade de ferramentas e técnicas para a realização da descentralização das tarefas de controle também é destacada por Mahalik e Lee (2002).

\subsection{CICLO DE VIDA DE PROJETO DE SISTEMAS DE AUTOMAÇÃO DISTRIBUÍDOS}

Para analisar quais os métodos e as ferramentas que poderiam assistir o processo de desenvolvimento de sistemas de automação distribuídos, podemos tentar encontrar respostas em duas áreas: na própria área de engenharia de 
controle e automação, e também na área de engenharia de software (e de sistemas em geral). Cada uma dessas áreas apresenta uma maneira distinta de tratar o problema de desenvolvimento de um sistema, possuindo ciclos de vida, métodos para divisão do sistema (e do software) em módulos e linguagens peculiares. No entanto, como será visto adiante, nenhuma dessas áreas consegue oferecer uma solução completa para tratar todo o projeto de desenvolvimento de um sistema de automação. Apesar disso, é possível encontrar fatores comuns entre as abordagens dessas duas áreas, o que permite aproximá-las e fazer com que uma complemente as deficiências da outra.

Apresenta-se, a partir de então, as abordagens da engenharia de software e da engenharia de controle e automação para o projeto de sistemas de automação distribuídos.

\subsubsection{Projetos de engenharia de software}

2.2.1.1. Ciclos de vida de engenharia de software e suas atividades

No desenvolvimento de sistemas, os termos método de desenvolvimento de sistemas, ciclo de vida de projeto e ciclo de desenvolvimento de sistemas podem ser usados alternativamente. Uma das principais funções de um método de desenvolvimento é estabelecer as atividades a serem executadas para que o sistema possa ser implementado (YOURDON, 1990). Alguns exemplos dos ciclos de vida que foram propostos para o desenvolvimento de sistemas de software, juntamente a suas características principais, são detalhados abaixo:

- Clássico, convencional ou em cascata: adota a abordagem de composição modular (bottom-up) para o projeto de sistema, com execução linear e seqüencial das atividades de projeto;

- Estruturado: uso da abordagem de decomposição modular (top-down) para o projeto do sistema, com possibilidade de desenvolvimento concorrente de atividades;

- Prototipação: construção de um modelo executável do sistema previamente à utilização do método clássico de desenvolvimento;

- Espiral: elaboração de um modelo evolutivo do projeto (dada pela construção de uma sucessão de protótipos e pela resolução incremental das 
especificações de projeto), até a obtenção de um sistema com nível de refinamento suficiente; e

- Processo Unificado: desenvolvimento iterativo e incremental do sistema, guiado por seus casos de uso, com foco na determinação da arquitetura e na resolução dos principais riscos de projeto nas fases iniciais do sistema. Independentemente das diferenças de enfoque de cada um desses métodos, algumas atividades técnicas (não-gerenciais) de desenvolvimento de projeto podem ser consideradas comuns (adota-se aqui uma simplificação das descrições de Yourdon (1990) para as mesmas):

- Levantamento (Eliciação) de requisitos: estudo inicial da viabilidade e das necessidades do projeto;

- Análise: especificação estruturada do projeto, envolvendo normalmente a modelagem do sistema, a partir dos dados obtidos durante o levantamento de requisitos;

- Projeto: determinação da forma pela qual o projeto deve ser implementado, com a obtenção (em nível lógico) da hierarquia e das interfaces dos módulos de software a representarem o sistema, além da previsão de sua distribuição em processadores;

- Implementação: codificação e integração progressiva do software;

- Testes: verificação e validação do sistema (ou seja, constatação de que as necessidades dos interessados, obtidas durante a atividade de levantamento de requisitos, estão correta e completamente atendidas pelo software); e

- Instalação: colocação do software no ambiente de execução previsto no projeto do sistema.

Apesar de não ser citada por Yourdon (1990), a atividade de manutenção pode ser incluída à lista acima: nesta, controla-se o estado do sistema instalado e se oferece suporte à sua utilização (não somente no sentido de auxílio ao uso, como para correção de falhas). Algumas vezes, essa fase é propícia para o levantamento de novas necessidades dos usuários e outros interessados tendo em vista o início de um novo projeto ou geração de uma nova versão do sistema. 
2.2.1.2. Separação de sistemas em módulos: orientação a objetos

De acordo com o disposto na descrição da atividade de análise, uma de suas tarefas é executar a divisão lógica do sistema em módulos e a determinação da hierarquia entre eles. Atualmente, uma das formas mais comuns de se realizar essa tarefa é adotando técnicas de orientação a objetos. Yourdon e Argila (1999) citam que essa abordagem sugere a estruturação dos programas de computador de acordo com o problema a ser resolvido, e destacam que, embora o termo "orientação a objetos" tenha sido empregado de muitas maneiras distintas, ele sempre sugere uma associação entre abstrações de elementos do mundo real e trechos correspondentes de software denominados objetos (entidades independentes, assíncronas e concorrentes que armazenam dados, encapsulam serviços e trocam mensagens entre si a fim de garantir a execução das funções pretendidas para o sistema como um todo). Complementarmente, Nerson (1992) observa que, na análise orientada a objetos, busca-se identificar os tipos de objetos que podem ser mapeados nos elementos do domínio de aplicação as ser representado, o que facilita o levantamento dos principais relacionamentos entre os diferentes tipos de objetos. A vantagem mais relevante do uso das técnicas de orientação a objetos é a possibilidade de reuso, não somente da codificação do software, mas também dos demais componentes do ciclo de vida de um projeto como os requisitos levantados e arquiteturas projetadas (YOURDON; ARGILA, 1999). No artigo de Armstrong (2006), são identificados oito conceitos fundamentais da orientação a objetos:

- Objeto: item individual e identificável, real ou abstrato, que contém dados sobre si e descrições de suas possibilidades de manipulação desses dados;

- Classe: descrição da organização e das ações apresentadas por um ou mais objetos similares;

- Abstração: ato de criar classes para simplificar aspectos da realidade usando distinções inerentes ao problema;

- Herança: mecanismo que permite que os dados e o comportamento de uma classe sejam incluídos ou usados como base de uma nova classe;

- Método: mecanismo que permite acessar, registrar ou manipular as informações de um objeto;

- Passagem de mensagem: processo pelo qual um objeto envia dados a outro 
objeto ou solicita a esse objeto a execução de um método;

- Polimorfismo: habilidade em que diferentes classes respondem a uma mesma mensagem e implementam seu método apropriadamente; e

- Encapsulamento: técnica para projetar classes e objetos que restrinjam acesso a seus dados e comportamento por meio da definição de um conjunto estrito de mensagens que estejam habilitados a receber.

Para facilitar o entendimento do tema, Armstrong (2006) propõe também uma taxonomia para a orientação a objetos, em que os citados conceitos são separados em dois grupos e relacionados entre si:

- Os termos objeto, classe, abstração, herança e encapsulamento, centrados no relacionamento entre classes e objetos e os mecanismos que dão suporte à estrutura classe/objeto, são agrupados do conjunto Estrutura (já que uma classe é uma abstração de um objeto; uma classe ou um objeto encapsulam dados e comportamento; e a herança permite que os dados e comportamentos encapsulados de uma classe sejam baseados em uma outra classe existente); e

- Os termos método, passagem de mensagem e polimorfismo, dirigidos à descrição das ações dos objetos no sistema, são agrupados no conjunto Comportamento, já que a passagem de mensagem é um processo em que um objeto envia informações para outro objeto ou invoca um de seus métodos; e o polimorfismo permite que diferentes objetos respondam a uma mesma mensagem e implementem o método apropriado para aquele objeto.

\subsubsection{Modelagem dos conceitos de orientação a objetos: UML}

Uma das linguagens que permitem a representação de sistemas concebidos segundo técnicas de orientação a objetos é a UML. A UML é uma linguagem visual e, embora usualmente seja empregada para modelar sistemas de software, pode ser utilizada para visualizar, especificar, construir e documentar artefatos de sistemas dos mais diversos domínios (BOOCH; RUMBAUGH; JACOBSON, 1998). Ainda que sua criação deva-se, inicialmente, aos pesquisadores Booch, Jacobson e Rumbaugh - os quais unificaram seus métodos de modelagem, chamados, respectivamente, Booch, Object-Oriented Software Engineering (OOSE) e Object Modeling Technique (OMT), a UML foi adotada como padrão em 1997 pelo Object Management Group 
(OMG) e é atualmente mantida por esse órgão. Segundo Bordbar, Derrick e Waters (2002), ela se tornou o padrão de facto na representação de sistemas concebidos segundo as técnicas de orientação a objetos.

A modelagem em UML é independente de um processo de desenvolvimento em particular (embora encaixe-se mais adequadamente em um processo centrado em arquitetura, guiado por casos de uso e iterativo e incremental, como é o caso do Processo Unificado). A UML também prevê mecanismos para estender sua capacidade de expressão, o que a torna bastante flexível: ela tanto pode ser personalizada para domínios de aplicação definidos quanto pode ser associada a outras linguagens. Por fim, deve-se ressaltar que há uma grande quantidade de ferramentas de mercado que dão suporte à geração de modelos da UML (tais como o IBM Rational Rose e o Microsoft Visio).

O destaque da UML nos campos da engenharia de sistemas e de software deve-se ao fato de ser uma linguagem expressiva, muito conhecida, de aplicação geral e fácil compreensão (mesmo entre pessoal não técnico). Conforme pode ser visto em Booch, Rumbaugh e Jacobson (1998), através dos diagramas definidos pela UML pode-se modelar aspectos estáticos e dinâmicos dos sistemas, e organizar os elementos de interesse segundo as perspectivas de casos de uso, de projeto, de processo, de implementação e de distribuição (deployment) (cinco visões complementares).

\subsection{Diagramas da UML}

Os diagramas da UML podem ser subdivididos em duas categorias: diagramas estruturais (utilizados para a visualização das partes estáticas de um sistema) e diagramas comportamentais (utilizados para a visualização das partes dinâmicas de um sistema).

Até a UML versão 1.X, estavam definidos nove diagramas básicos: quatro diagramas estruturais, sendo eles o Diagrama de Classes, o Diagrama de Objetos, o Diagrama de Componentes e o Diagrama de Distribuição (Deployment), e cinco diagramas comportamentais, dentre os quais estão o Diagrama de Casos de Uso, o Diagrama de Máquinas de Estados, o Diagrama de Atividades, e, finalmente, o Diagrama de Seqüência e o Diagrama de Colaboração - sendo esses dois isomorfos e denominados coletivamente como Diagramas de Interação $(\mathrm{BOOCH}$; 
RUMBAUGH; JACOBSON, 1998). A partir da publicação da UML versão 2.X, no entanto, ficaram definidos, ao todo, treze diagramas fundamentais: seis diagramas estruturais (já que surgem o Diagrama de Estruturas Compostas e o Diagrama de Pacotes) e sete diagramas comportamentais (pois são adicionados dois Diagramas de Interação - o Diagrama de Visão Geral das Interações e o Diagrama de Temporização, enquanto que o Diagrama de Colaboração passa-se a chamar Diagrama de Comunicação) (SPARX SYSTEMS PTY LTD., 2008).

Foge ao escopo deste trabalho apresentar um estudo aprofundado da UML, especialmente se considerarmos a grande abrangência do tema. Dessa maneira, prefere-se somente expor os conceitos da UML relevantes para os capítulos subseqüentes deste trabalho, explorados através de alguns diagramas da UML. As referências utilizadas para a elaboração das seguintes seções foram as de Booch, Rumbaugh e Jacobson (1999) para os conceitos gerais da UML e UML1.X, e de Sparx Systems Pty Ltd. (2008), para as abstrações da UML 2.X.

\subsection{Diagramas Estruturais}

\subsection{Diagrama de Classes}

O Diagrama de Classes é usado para mostrar uma visão estática de um sistema. Os elementos primordiais nesse tipo de diagrama são as classes, sendo que cada uma dessas descreve um conjunto de objetos que compartilham os mesmos atributos, operações, relacionamentos e semântica.

Uma classe é um tipo de classificador da UML: em geral, um classificador é um elemento de modelagem que pode possuir instâncias e que descreve características estruturais (na forma de atributos) e comportamentais (na forma de operações), comuns a todas elas. Outros classificadores são: interfaces, sinais, tipos de dados, componentes, nós, casos de uso e subsistemas.

Por sua vez, uma instância é uma manifestação concreta de uma abstração, para a qual um conjunto de operações podem ser aplicadas e possuidora de um estado interno que guarda os efeitos de suas operações. As instâncias das classes, especificamente, são chamadas de objetos.

Já um atributo representa uma propriedade de um classificador (um tipo de dado ou estado compartilhado entre todas suas instâncias), além de apresentar 
normalmente o intervalo de valores que as instâncias dessa propriedade podem assumir.

Por outro lado, uma operação é a implementação de um serviço que pode ser requisitado a qualquer instância de um certo classificador para modificar seu comportamento - dado que, na maioria das vezes, invocar uma operação implica modificação dos dados ou estados internos da instância. O nome da operação e seus parâmetros (variáveis passadas na chamada do método ou retornadas por ele - neste caso, denominadas mais especificamente de valores de retorno) são conhecidos por assinatura da operação. Vale destacar que a UML distingue os termos operação e método: este último representa a implementação de uma operação, e fornece, portanto, um algoritmo executável para a mesma (geralmente dado em uma linguagem de programação ou texto estruturado).

Finalmente, um detalhe importante associado a atributos e operações é a sua visibilidade: a visibilidade caracteriza se o atributo ou operação pode ser utilizada por outros classificadores da UML. Estão especificados três níveis de visibilidade:

- Visibilidade pública (public): determina que qualquer classificador externo visível ao presente classificador pode usar seu atributo ou operação (símbolo usual: +);

- Visibilidade protegida (protected): especifica que qualquer descendente do classificador pode usar seu atributo ou operação (símbolo usual : \#); e

- Visibilidade privada (private): denota que somente o próprio classificador pode usar seu atributo ou operação (símbolo usual: -).

Outros classificadores de interesse, comuns em Diagramas de Classe, são as interfaces. Uma interface restringe-se a prescrever uma coleção de operações usadas para especificar os serviços de uma classe ou componente. Ressalta-se, no entanto, que as mesmas não especificam estruturas (ou seja, não incluem atributos), nem qualquer tipo de implementação (como métodos, por exemplo). Quando uma interface é implementada por uma classe ou componente, ela pode ser chamada de interface exposta. Uma interface exposta fornecida por um classificador é mostrada pela notação reduzida que se assemelha a um plugue (ou a um "pirulito" - lollipop), e indica um relacionamento de realização entre eles. Já uma interface aceita por um classificador (que especifica a aptidão do mesmo em se comunicar com outro classificador que implemente essa interface) é dada pela notação reduzida parecida 
a um soquete, e indica um relacionamento de dependência entre os mesmos.

Entre diversos elementos da UML podem ser especificadas conexões denominadas relacionamentos. Dentre eles, podem ser citadas as dependências, as generalizações, as associações e as realizações.

Uma dependência é um relacionamento de uso que indica que a modificação na especificação de um elemento pode afetar o elemento que o utiliza, mas não necessariamente o contrário. É denotada visualmente por uma seta de ponta aberta e linha tracejada.

Uma generalização, por outra parte, é um relacionamento entre um classificador mais geral e um classificador mais específico (os classificadores em que há herança mais comumente são as classes, interfaces e pacotes). No caso das classes, a generalização significa que a subclasse (ou classe filha) é um tipo específico da superclasse (ou classe mãe), e que esta pode ser substituída pela primeira. Quando uma classe possui exatamente uma classe mãe, diz-se que a herança é simples; se houver mais de uma superclasse, a herança é dita múltipla. Uma subclasse sempre herda as propriedades de sua(s) superclasse(s), especialmente seus atributos e operações, mas freqüentemente as classes filhas possuem atributos e operações a mais que as classes mães. Se a subclasse possuir uma operação de mesma assinatura que a da superclasse, esta operação prevalece à da superclasse (ocorrência chamada polimorfismo).

Uma associação é um relacionamento estrutural que especifica que instâncias de um tipo estão conectadas a instâncias de outro tipo. Entre as classes, as associações mais comuns conectam exatamente duas classes (associação binária), mas pode haver associações conectando duas ou mais classes (ainda que isso seja mais raro). Algumas características de uma associação são seu nome (usado para descrever a natureza da relação), os papéis (que indicam qual o papel que a classe ao final da associação representa perante a(s) outra(s) classe(s) envolvida(s)) e a multiplicidade (que indica quantos objetos podem estar conectados através de uma instância de uma associação). Um tipo especial de associação é a agregação, a qual modela um relacionamento de uma classe representante de uma parte para uma classe representante do todo.

Por fim, uma realização é um relacionamento semântico entre classificadores, em que um deles especifica um contrato que o outro garante satisfazer. Conforme visto anteriormente, esse tipo de relacionamento é comum, por 
exemplo, entre classes e interfaces (significando que a classe implementa os serviços especificados pela interface).

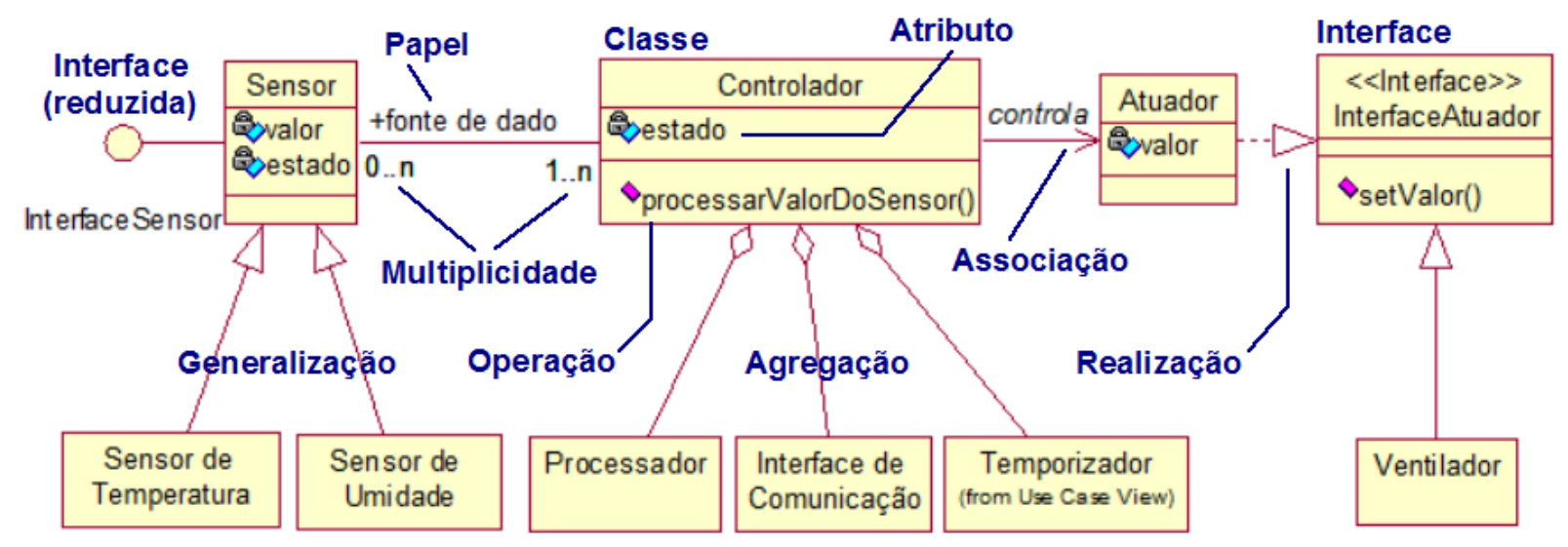

Figura 4: Exemplo de Diagrama de Classes.

\subsection{Diagrama de Estruturas Compostas}

Um Diagrama de Estruturas Compostas exibe a estrutura interna de um classificador (ou seja, a configuração e o relacionamento entre seus elementos internos, que, juntos, realizam o seu comportamento), além dos pontos de interação desse classificador com outros elementos do sistema. Assim, tal diagrama é normalmente composto por classificadores, partes, portas e conectores.

Uma parte é um elemento pertencente ao classificador modelado que representa um papel, uma superclasse abstrata ou uma classe concreta a ser implementada por uma ou mais instâncias no momento de execução (dependendo da multiplicidade - opcional - associada à parte).

Uma porta, por outro lado, é um elemento que representa uma parte externa visível de uma instância de um classificador, definindo a interação entre o classificador e suas partes ou ambiente através da especificação dos serviços que ele requer ou provê - o que pode ser feito por meio de interfaces, nas notações soquete (requeridas) ou plugue (fornecidas). Ao receber uma requisição, uma porta pode entregá-la diretamente ao classificador que a contém (sendo o tratamento da requisição descrito no comportamento desse classificador) ou pode delegá-la a uma ou mais de suas partes internas.

Finalmente, um conector liga duas ou mais entidades, permitindo a elas interagir no momento de execução, e é mostrado como uma linha entre algumas combinações de partes, portas e classificadores estruturados. 


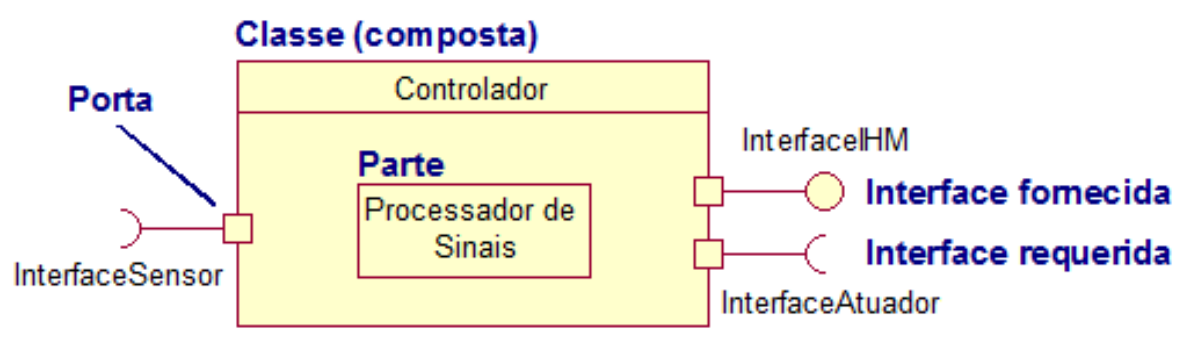

Figura 5: Exemplo de Diagrama de Estruturas Compostas.

\subsection{3. Diagrama de Componentes}

Um componente é uma parte física e substituível de um sistema. Em muitos aspectos, componentes assemelham-se a classes: possuem nomes, realizam um conjunto de interfaces e podem ser aninhados, ter instâncias, participar em interações e participar em relacionamentos de dependência, generalização e associação. No entanto, enquanto classes são apenas lógicas, os componentes podem ser mapeados em nós do sistema pois representam o encapsulamento físico de componentes lógicos (ou seja, estão em outro nível de abstração).

Outra característica especial é que os atributos e operações de um componente só podem ser acessados através de sua interface. Uma interface realizada por um componente é chamada de interface de exportação (export interface), e indica uma interface que o componente provê como um serviço para outros. Já uma interface usada por um componente é chamada de interface de importação (import interface).

Assim, a função do Diagrama de Componentes é explicitar uma visão estática do sistema ao mostrar os seus componentes e relacionamentos.

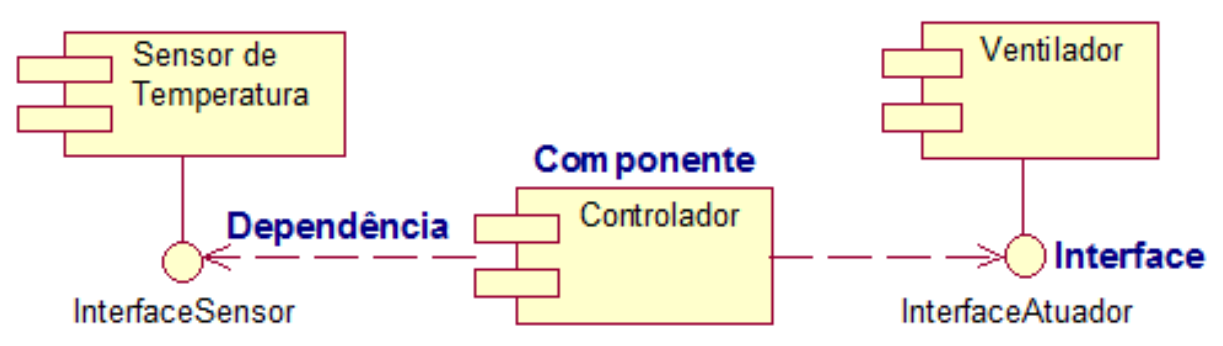

Figura 6: Exemplo de Diagrama de Componentes. 


\subsection{4. Diagrama de Distribuição (Deployment)}

O Diagrama de Distribuição (Deployment) ilustra aspectos estáticos da visão de distribuição de um sistema através da exibição de seus nós e relacionamentos.

Um nó é um elemento físico do sistema, representante de um recurso computacional (possuindo, normalmente, memória e capacidade de processamento), em que componentes são distribuídos e executados. O conjunto de objetos ou componentes executados por um nó é chamado de unidade de distribuição (distribution unit).

Como os componentes, os nós também se parecem a classes: possuem nomes e podem ser aninhados, ter instâncias, participar em interações, ter atributos e métodos, e participar em relacionamentos de dependência, generalização e associação. Desses relacionamentos, o tipo mais comum encontrado nos Diagramas de Distribuição é a associação, que representa conexão física entre os nós, e, embora mais rara, a dependência é usada para vincular os nós aos componentes que executam.

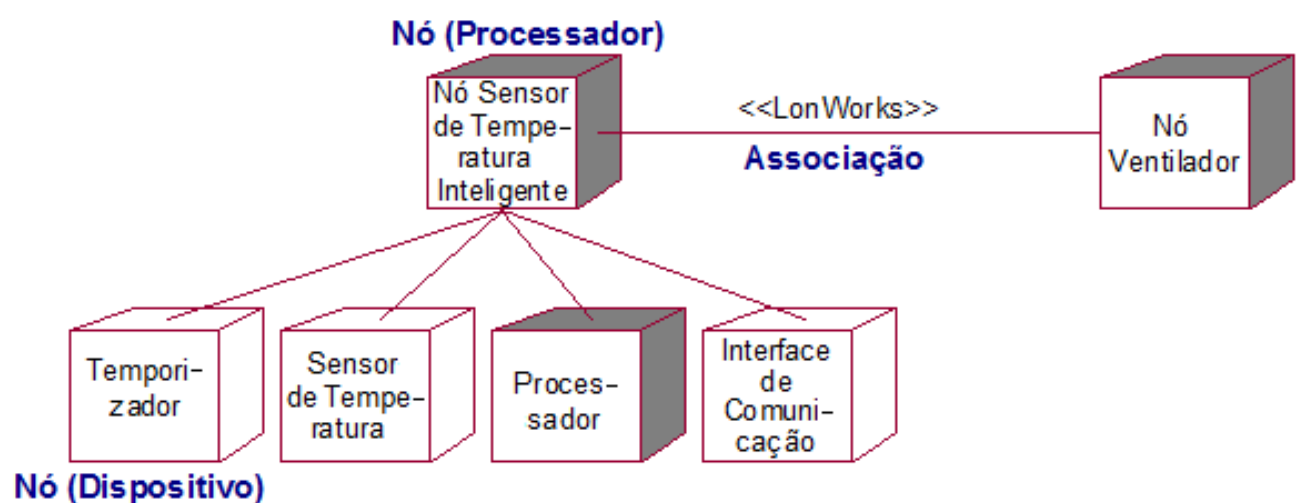

Figura 7: Exemplo de Diagrama de Distribuição (Deployment).

\subsection{5. Diagrama de Pacotes}

O Diagrama de Pacotes é usado para refletir quais são e como estão relacionados os pacotes de um sistema.

Um pacote é um mecanismo de propósito geral utilizado para organizar elementos (incluindo classes, interfaces, componentes, nós, colaborações, casos de uso, diagramas e mesmo outros pacotes) em grupos, representando tanto 
relacionamentos lógicos como físicos entre eles.

Entre os pacotes pode haver dois tipos principais de relacionamentos: generalizações (usadas para especificar famílias de pacotes) ou dependências do tipo import ou access (usadas para designar que um pacote usa (importa) elementos dados por outros pacotes (seus elementos exportados)). Outro relacionamento é dado pelo conector de aninhamento (nesting), que implica que o pacote de origem está completamente contido pelo pacote de destino.

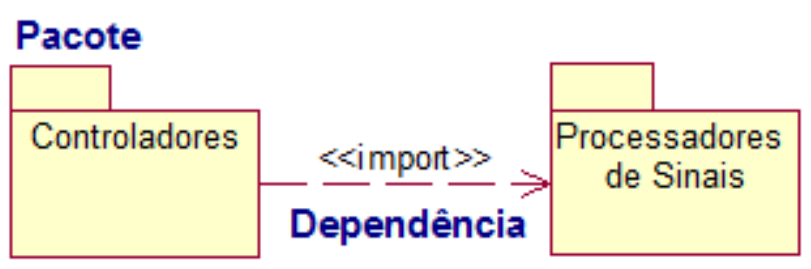

Figura 8: Exemplo de Diagrama de Pacotes.

\subsection{Diagramas Comportamentais}

\subsection{Diagrama de Casos de Uso}

O Diagrama de Casos de Uso é utilizado para organizar e modelar as funcionalidades esperadas de um sistema através da representação de casos de uso, atores e seus relacionamentos.

O principal componente desse tipo de diagrama é o caso de uso, o qual representa a descrição de um conjunto de seqüências de ações, normais e exceções, que um sistema executa para fornecer um resultado observável a um ator. Um caso de uso deve ser complementado pelo fluxo de eventos (texto que descreve detalhadamente como o caso de uso ocorre, inclusive suas seqüências anormais). Cada seqüência específica de ações que ilustra comportamento (uma instância de um caso de uso) é chamada cenário. Um ator, por sua vez, representa um conjunto coerente de papéis que os usuários dos casos de uso (humanos, dispositivos de hardware ou outros sistemas, por exemplo) podem desempenhar ao interagir com esses casos de uso. 

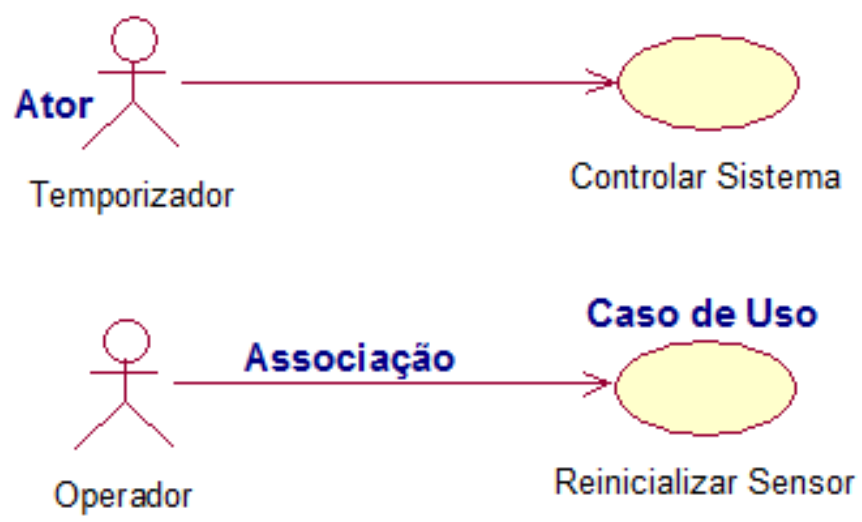

Figura 9: Exemplo de Diagrama de Casos de Uso.

\subsection{Diagrama de Máquinas de Estados e Diagrama de Atividades}

O Diagrama de Máquinas de Estados mostra o comportamento de instâncias - normalmente objetos de uma classe - diante da recepção de eventos, o que é especialmente útil em sistemas reativos.

Nesse caso, uma máquina de estados designa uma seqüência de estados pelos quais um objeto transita, exibindo os eventos que causam tais transições e as ações tomadas pelo objeto frente à recepção desses eventos. Um estado é uma condição ou situação durante a vida de um objeto durante o qual ele permanece por um estado finito de tempo, seja executando atividades, seja esperando por algum evento.

Atividades, no contexto acima, são processamentos não-atômicos (ou seja, passíveis de interrupção por eventos) que, em última instância, podem ser decompostos em ações (processamentos atômicos - por exemplo, a chamada a uma operação, o envio de um sinal, a criação ou destruição de um objeto ou a execução de um processamento puro, como o cálculo de uma expressão - que pode agir sobre o próprio objeto da máquina de estados ou indiretamente sobre outros objetos visíveis àquele objeto, resultando em uma mudança de estado do sistema ou o retorno de um valor).

Observa-se que um estado é usualmente composto pelas seguintes partes (nem todas obrigatórias): nome, ações de entrada e saída (ações executadas ao se entrar ou sair do estado), transições internas (transições que não causam a modificação do estado do objeto), subestados (estados internos que compõem uma estrutura aninhada do estado original, abrangendo subestados disjuntos - 
seqüencialmente ativos - ou concorrentes - concorrentemente ativos), atividades e eventos adiados (lista de eventos não tratados nesse estado, mas sim adiados e postos em uma fila para posterior tratamento - ou seja, feito quando o objeto atingir outro estado). Dois casos especiais de estados são os chamados estado inicial (que marca o local de começo de uma máquina de estado ou subestado) e estado final (que indica a finalização da execução da máquina de estados ou do estado composto).

Por sua vez, uma transição é um relacionamento entre dois estados, indicando que um objeto no primeiro estado (estado de origem) executará certas ações e entrará no segundo estado (estado de destino) quando um determinado evento ocorrer e certas condições forem satisfeitas - dessa forma, em tal mudança de estado, diz-se que a transição foi disparada. Uma transição possui cinco partes (nem todas obrigatórias): estado de origem (estado afetado pela transição), estado de destino (estado ativo após o término da transição), gatilho (ou trigger - evento cuja recepção pelo objeto permite o disparo da transição, desde que a condição de guarda seja satisfeita), condição de guarda (expressão booleana avaliada na recepção do evento de gatilho: se for verdadeira, a transição pode ocorrer; se for falsa, a transição não é disparada, e caso nenhuma outra transição possa ser disparada pelo mesmo evento, o evento se perde) e ação.

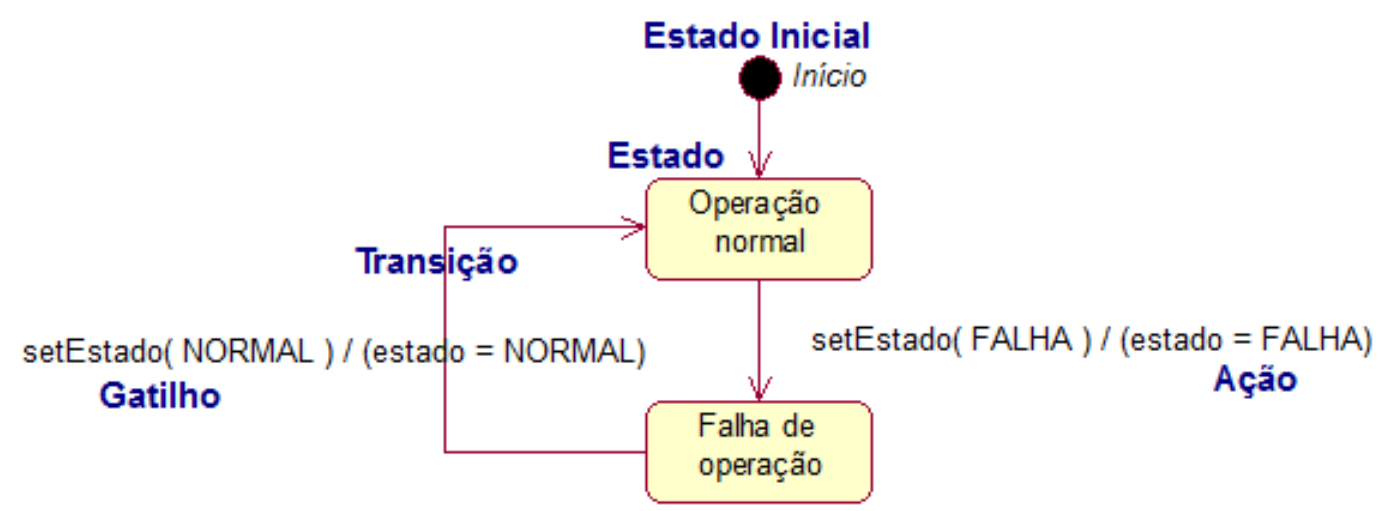

Figura 10: Exemplo de Diagrama de Máquinas de Estados (da classe Sensor).

O Diagrama de Atividades é um caso especial de Diagrama de Estados, ou seja, todas as características do último aplicam-se ao primeiro. No entanto, nesse caso particular os estados representam atividades (estados de atividade - activity states) ou ações (estados de ação - action states), e o término da execução desses 
estados provoca automaticamente o disparo de transições para outros estados (ou seja, não há há evento de gatilho nas transições). Os estados de atividade podem ser interpretados como elementos compostos, já que são formados por um conjunto de ações (inclusive de entrada e saída) e podem conter subestados. Assim, o desmembramento desses estados poderia gerar iterativamente novos Diagramas de Atividades até que todos os estados do diagrama fossem estados de ação.

Além do que foi descrito sobre Diagramas de Estados, outros elementos comuns dos Diagramas de Atividades são as transições condicionais (ou branches, em que uma transição de entrada pode ser desviada por caminhos alternativos de acordo com a condição de guarda das transições de saída), as divisões (ou forks, em que um fluxo de controle é dividido entre dois ou mais fluxos de controle concorrentes) e as junções (ou joins, que representam a sincronização de dois ou mais fluxos de controle concorrentes).

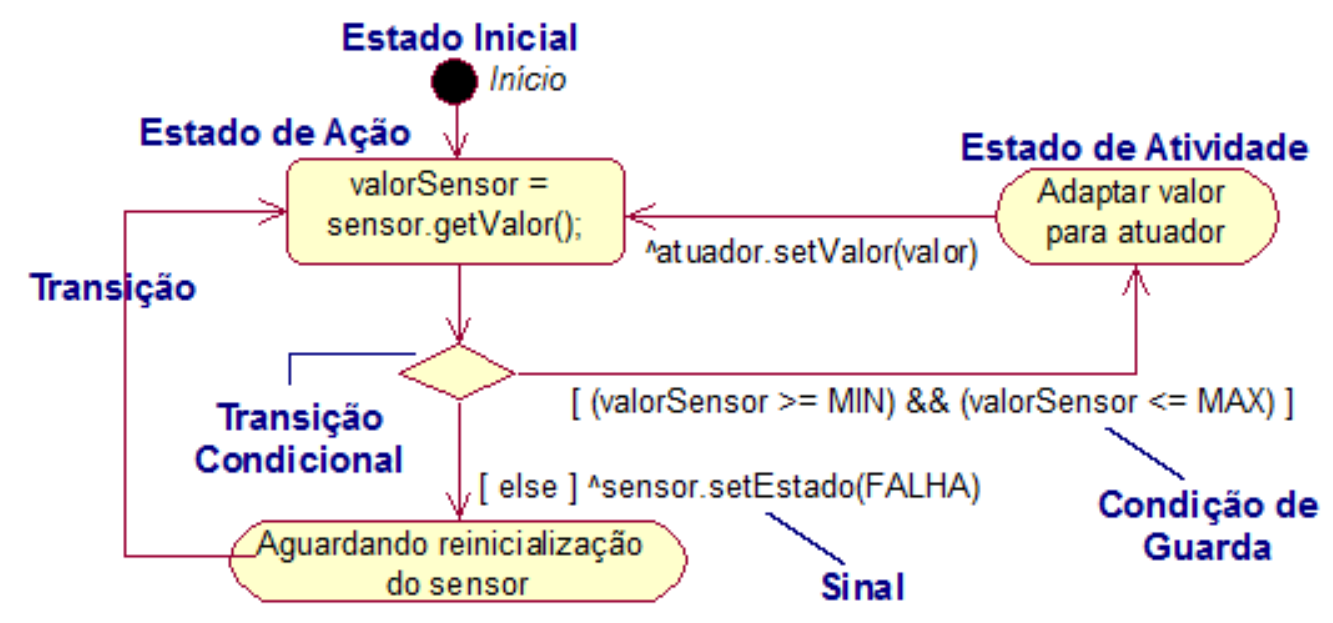

Figura 11: Exemplo de Diagrama de Atividades (da classe Controlador).

2.2.1.3.1.2.3. Diagramas de Interação (Diagrama de Seqüência, Diagrama de Colaboração/Comunicação e Diagrama de Visão Geral das Interações)

Um Diagrama de Interação (Diagrama de Seqüência, Diagrama de Colaboração/Comunicação, Diagrama de Visão Geral das Interações ou Diagrama de Temporização) mostra um grupo de instâncias (de classes, componentes, nós ou casos de uso) e seus relacionamentos, além das mensagens que elas trocam entre si. As instâncias que participam em uma interação tanto podem ser representantes de elementos concretos (pertencentes ao mundo real) quanto elementos prototípicos 
(uma instância qualquer de um classificador, expressando, nesse caso, um certo papel de um elemento no sistema).

Por sua vez, uma mensagem é a especificação de uma comunicação entre instâncias, com passagem de informações entre as mesmas (por parâmetros ou valor de retorno, por exemplo), e prováveis mudança de estado e/ou disparo de uma atividade (procedimento computacional) no sistema - já que a recepção de uma mensagem pode ser considerada como a chegada de um evento. O tipo mais comum de mensagem modelada é chamada função, em que um objeto invoca a operação de um outro (ou de si próprio). O conjunto de mensagens trocadas entre diversos objetos forma uma seqüência. Vale lembrar que nos Diagramas de Interação representam-se normalmente fluxos diretos e seqüenciais de controle, mas também podem ser modeladas seqüências mais complexas, envolvendo interações e condicionais.

O Diagrama de Seqüência, especificamente, enfatiza a ordenação temporal das mensagens trocadas entre instâncias. Alguns de seus elementos são a representação da linha de vida (lifeline) de uma instância (que representa a existência da mesma durante um período de tempo, possivelmente mostrando sua criação ou destruição), e o seu foco de controle (que indica o período de tempo em que o objeto está realizando alguma ação).

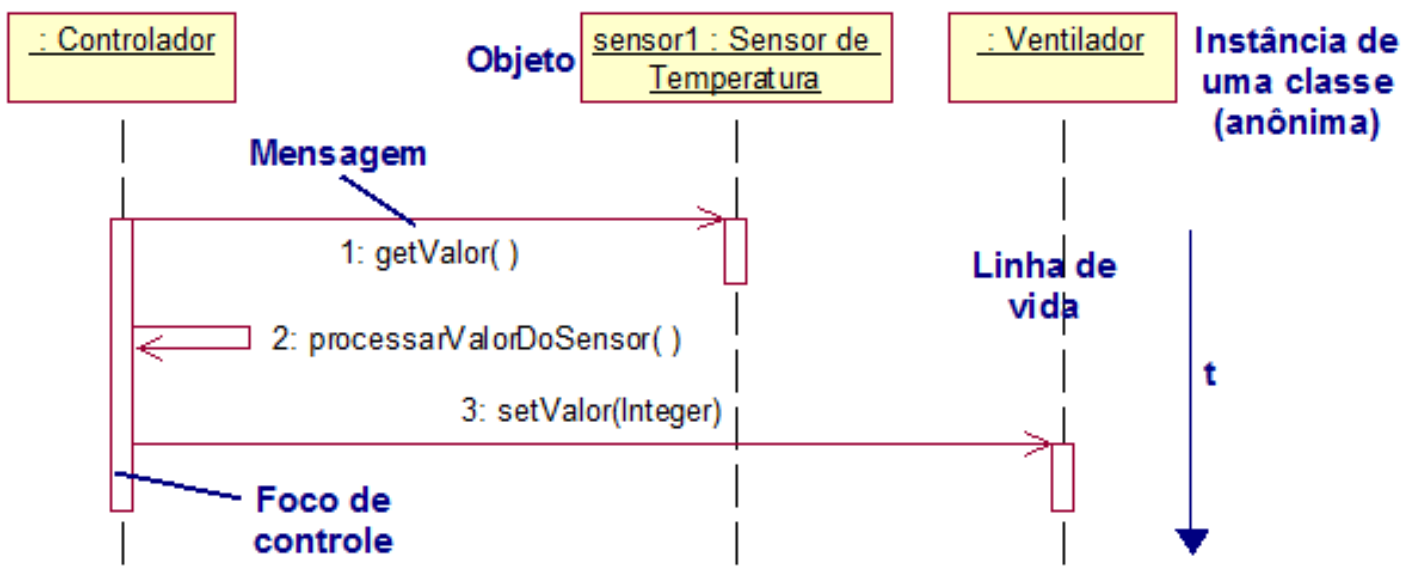

Figura 12: Exemplo de Diagrama de Seqüência.

Por sua vez, o Diagrama de Colaboração/Comunicação ressalta a organização estrutural das instâncias que participam em uma interação (enviando ou recebendo mensagens), dada usualmente pela modelagem das ligações (links) entre 
as instâncias (conexões semânticas que constituem caminhos através dos quais uma instância pode enviar mensagens para outra ou para si, geralmente concretizadas por instâncias de uma associação). As mensagens transmitidas através de uma ligação podem ser prefixadas por um número de seqüência único, o que lhes confere ordenação temporal.

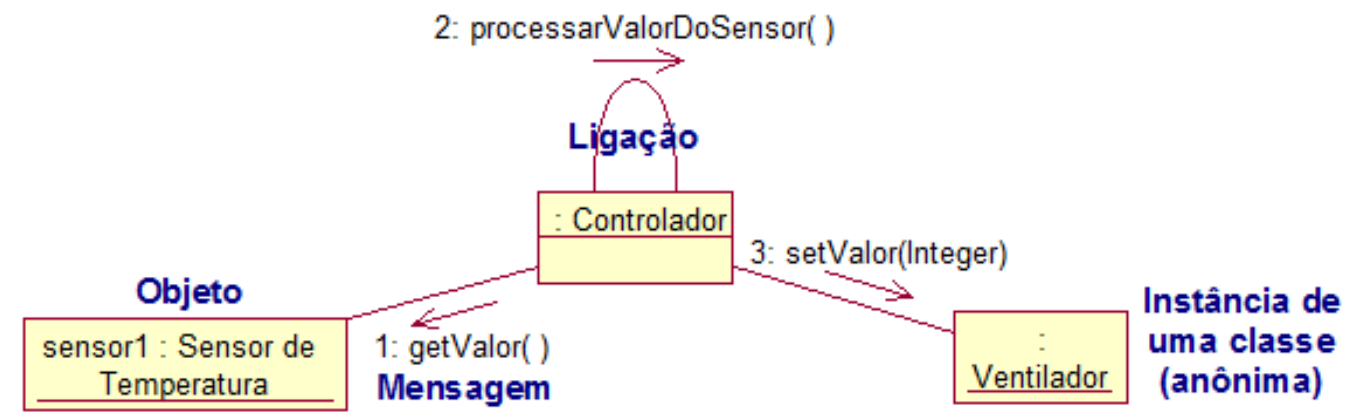

Figura 13: Exemplo de Diagrama de Colaboração/Comunicação.

Por fim, o Diagrama de Visão Geral das Interações é um tipo de Diagrama de Atividades em que os nós representam Diagramas de Interação, expressos por meio de dois elementos especiais:

- Ocorrência de Interação (Interaction Ocurrence): referência a um diagrama existente, cujo nome é posto no meio de um quadro de referência (elemento que o representa); e

- Elemento de Interação (Interaction Element): representação explícita de um Diagrama de Interação no quadro.

Deve-se enfatizar que, por ser um tipo de Diagrama de Atividades, todos os controles desse tipo de diagrama (como condicionais (branches), divisões (forks) e junções (merges), entre outros) aplicam-se a um Diagrama de Visão Geral de Interações.

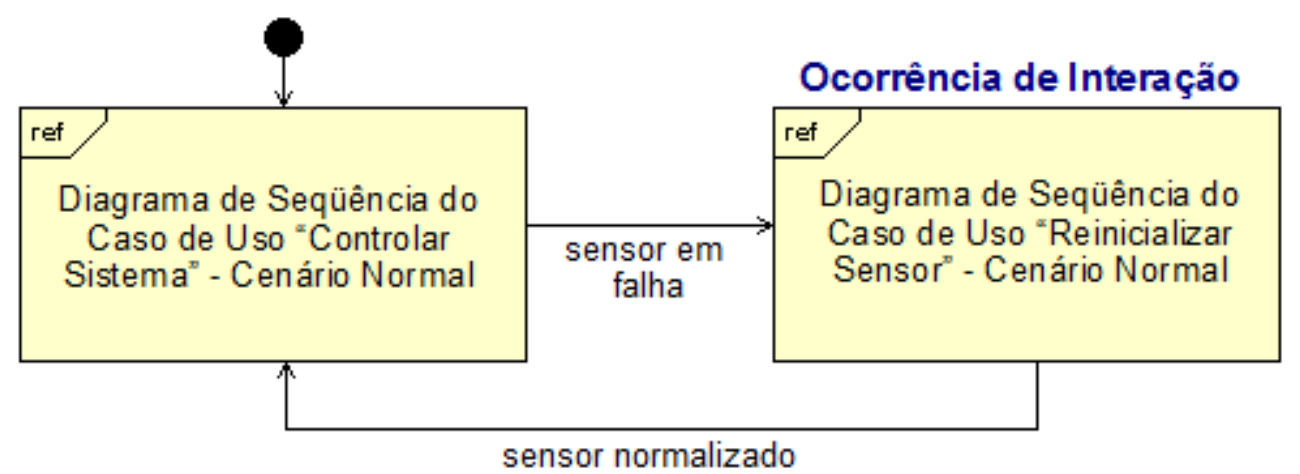

Figura 14: Exemplo de Diagrama de Visão Geral das Interações. 
2.2.1.3.2. Outros elementos e mecanismos gerais da UML

\subsection{Nota}

Uma nota, em qualquer diagrama, é um símbolo gráfico usado para descrever restrições ou fazer comentários relativos a um elemento ou coleção de elementos.

\subsection{Mecanismos de extensão}

\subsection{1. Valor rotulado}

Um valor rotulado (tagged value) permite a criação de novas propriedades em um elemento pré-existente da UML ou em um estereótipo (lembrando que um exemplo de propriedades são os atributos e operações de uma classe, por exemplo). No entanto, lembra-se que o valor rotulado assemelha-se a um metadado - já que o mesmo é aplicado a um elemento da UML, e não a suas instâncias.

\subsection{2. Restrição}

Uma restrição (constraint) é uma extensão da semântica de um elemento da UML que permite adicionar-lhe novas regras ou modificar suas regras pré-existentes (ou seja, uma restrição especifica condições que devem ser mantidas verdadeiras para que o modelo construído com esse elemento esteja bem formado). Uma restrição pode ser dada em texto simples, ou, caso necessário, em uma linguagem de semântica mais precisa, como a Object Constraint Language (OCL). Por fim, vale ressaltar que algumas das restrições mais comuns estão associadas a valores de tempo e espaço.

\subsection{3. Estereótipo}

Um estereótipo é uma extensão do vocabulário da UML, que permite a criação de novos elementos da UML, similares aos já existentes, mas com propriedades, semântica e notação especiais (já que cada estereótipo pode prover 
seu próprio conjunto de valores rotulados, restrições e ícone, respectivamente). Pode-se idealizar um estereótipo como um metatipo, dado que ele cria o equivalente a um novo bloco de construção no metamodelo UML.

\subsection{Perfil (Profile)}

Finalmente, um perfil é uma coleção de estereótipos, valores rotulados e restrições que, em conjunto, podem descrever um determinado problema particular de modelagem e facilitam a construção de modelos nesse domínio.

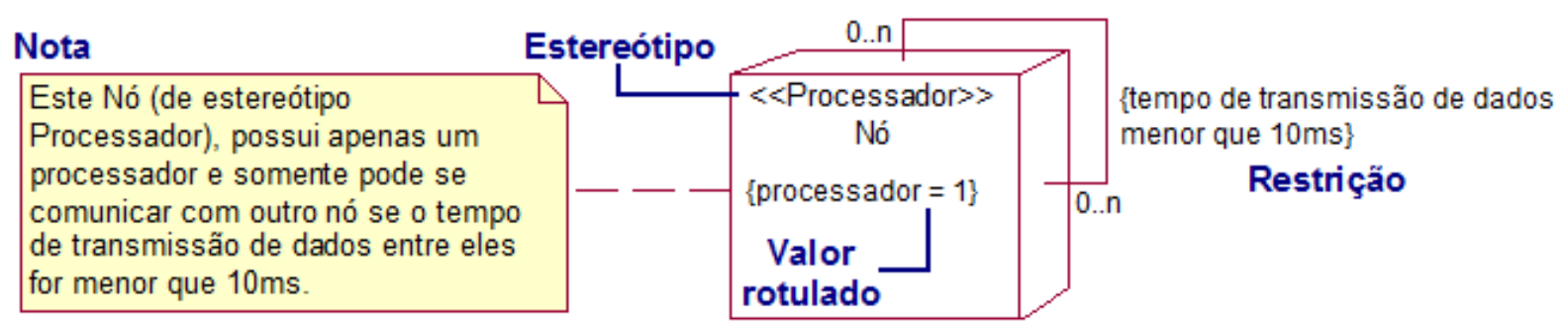

Figura 15: Exemplo de outros elementos e mecanismos gerais da UML: nota, estereótipo, valor rotulado e restrição.

\subsubsection{Projetos de engenharia de controle e automação}

2.2.2.1. Ciclos de vida de engenharia de controle e automação e suas atividades

Quanto aos ciclos de vida de engenharia de controle e automação para sistemas de automação distribuídos, Mahalik e Lee (2002) afirmam que, independentemente da complexidade envolvida, tais métodos envolvem a especificação ou identificação do problema, e a segmentação (ou descentralização), o desenvolvimento e os testes do sistema. Em Echelon Corporation (1999) pode-se encontrar o detalhamento de algumas subatividades que corresponderiam ao desenvolvimento de um sistema distribuído baseado na tecnologia LonWorks:

- Projeto do sistema: consiste da seleção dos dispositivos e da rede que deve compor o sistema. Os dispositivos devem conter os pontos de entrada e saída necessários ao sistema (ou fazer interface com pontos legados), e implementar as funções de controle apropriadas em suas aplicações. Por sua vez, a rede de comunicação deve ser selecionada de acordo com as 
características próprias dos meios físicos disponíveis (como a taxa de transmissão de dados): assim, são determinados o tipo e a quantidade de canais, assim como seus elementos de interconexão (roteadores, por exemplo);

- Configuração de rede: inclui a escolha do endereçamento lógico para os dispositivos a serem instalados; a interconexão lógica das aplicações de cada dispositivo; e a configuração do protocolo de comunicação dos dispositivos de acordo as características e desempenho desejados (como a forma de confirmação da recepção e a autenticação de mensagens);

- Configuração da aplicação: abrange a personalização da aplicação de cada dispositivo para que ele execute as funcionalidades desejadas dentro de certos parâmetros estipulados; e

- Instalação: consiste da instalação dos canais da rede de comunicação, dos dispositivos e dos elementos de interconexão da rede; da interligação dos possíveis pontos de entrada e saída legados aos dispositivos que os tratarão; e do uso de ferramentas apropriadas para descarregar os dados de configuração da rede e da aplicação de cada dispositivo (além da própria aplicação, caso necessário). Por fim, vale lembrar que pode seguir-se a esta uma etapa de manutenção do sistema.

Como descrito por Mahalik e Lee (2002), no entanto, a decisão sobre a segmentação do sistema ocorre previamente ao desenvolvimento do projeto em si. Do ponto de vista da descentralização das aplicações (necessária, inclusive, para a decisão dos dispositivos a serem utilizados no sistema), ela pode ser realizada através de abstrações denominadas blocos funcionais.

\subsubsection{Separação de sistemas em módulos: blocos funcionais}

De maneira geral, um bloco funcional é uma cápsula (usualmente de software, mas, de forma mais geral, de alguma propriedade intelectual) que consiste de variáveis de entrada e de saída, variáveis internas e descrição de comportamento interno (DAI; SHIH; VYATKIN, 2006).

Segundo a descrição do modelo generalizado de bloco funcional dado Heverhagen, Tracht e Hirschfeld (2003), aderente à descrição acima, as variáveis de entrada somente podem ser escritas externamente e lidas internamente ao bloco 
funcional. Por sua vez, as variáveis de saída podem ser lidas e escritas internamente, e somente lidas externamente ao bloco funcional. Finalmente, os autores definem, além dessas, variáveis especiais de entrada e saída (through variables), que são compartilhadas entre diversos blocos funcionais: assim, se diversos blocos funcionais estão interconectados por meio dessas variáveis, todos os blocos funcionais acessam o valor da variável conectada à primeira entrada da cadeia. Ressalta-se neste ponto que as variáveis de interface de um bloco funcional (de entrada, de saída e through variables) podem ser interconectadas exclusivamente se seus tipos de dados forem compatíveis, e que elas constantemente têm um valor atribuído que pode ser recebido ou enviado a outro bloco funcional (portanto, esta característica contrapõe-se ao modelo de comunicação da orientação a objetos, em que os objetos se comunicam pelo intercâmbio de mensagens). Quanto ao comportamento interno dos blocos funcionais, os mesmos podem ser especificados para atender a tempo contínuo, a tempo discreto ou a eventos, e suas instâncias possuem persistência das informações de seu estado interno.

O uso de blocos funcionais para a divisão de aplicações de sistemas é muito comum na área de engenharia de controle e automação, e é suportado por diversas ferramentas (como pode ser visto em Echelon Corporation (2006), Honeywell International Inc. (2005), TourAndoverControls (2006) e VisualControl, LLC (2003)). No entanto, visando a uma possível aproximação entre conceitos de orientação a objetos e de blocos funcionais, tem-se interesse especial no estudo de blocos funcionais orientados a eventos (já que essa característica permitiria que o comportamento dos blocos funcionais se assemelhasse ao que é visto em objetos, em que um evento de chegada de mensagem dispara determinadas atividades). Nesse contexto, justifica-se o interesse no estudo da norma IEC 61499, descrita a seguir.

2.2.2.3. Modelagem dos conceitos de blocos funcionais: norma International Electrotechnical Commission 61499 (IEC 61499)

Uma das normas relacionadas ao uso de blocos funcionais orientados a eventos no projeto de sistemas distribuídos de controle e medição para processos industriais (Industrial-Process Measurement and Control Systems - IPMCS) é a IEC 
61499. Para isso, ela está organizada em quatro partes (INTERNATIONAL ELECTROTECHNICAL COMMISSION, 2005a):

- Parte 1 - Arquitetura (Architecture): contém requisitos gerais (incluindo escopo, referências normativas, definições e modelos de referência) e regras para a declaração de tipos de blocos funcionais, para o comportamento das instâncias desses tipos e para o uso dos blocos funcionas na configuração, no atendimento aos requisitos de comunicação e no gerenciamento de aplicações, recursos e dispositivos dos IPMCS distribuídos;

- Parte 2 - Requisitos das Ferramentas de Software (Software Tool Requirements): define os requisitos gerais de ferramentas de software que auxiliem 0 desenvolvimento das atividades de engenharia de IPMCS distribuídos (incluindo a especificação de tipos de blocos funcionais, recursos e dispositivos; a especificação, análise, validação, configuração, implementação, operação e manutenção desses sistemas; e a troca de informações entre dadas ferramentas);

- Parte 3 - Tutorial (Tutorial Information): esclarece dúvidas freqüentes sobre a norma (em todas as suas partes) e fornece exemplos de uso de seus conceitos no contexto de problemas comuns de engenharia de controle e automação; e

- Parte 4 - Regras para Perfis de Aderência à Norma (Rules for Compliance Profiles) - especifica as características das partes 1 e 2 da norma IEC 61499 a serem implementadas para permitir a interoperabilidade entre os dispositivos, a portabilidade do software e a configurabilidade dos dispositivos através das ferramentas de software, mesmo quando produzidos por diferentes fabricantes.

Considerando as restrições de escopo desta dissertação, a seguir serão detalhadas somente as partes 1 e 2 da norma.

\subsection{Parte 1 - Arquitetura (Architecture)}

A parte 1 da norma IEC 61499 define uma arquitetura genérica - dada em termos de modelos de referência, sintaxes textuais e representações gráficas - e apresenta recomendações para o uso de blocos funcionais no projeto de sistemas 
distribuídos de controle e medição para processos industriais (IPMCS).

\subsection{Modelos de referência (abstrações) da norma IEC 61499}

Conforme descrito em International Electrotechnical Commission (2005a), os modelos de referência da norma IEC 61499 (que podem ser entendidos como suas abstrações ou conceitos primordiais) são ${ }^{3}$ :

- Sistema (IPMCS): é dado por uma coleção de dispositivos interconectados e em comunicação através de uma rede (que consiste de segmentos - trechos de rede - e ligações - conexões dos dispositivos à rede). Qualquer função desempenhada pelo IPMCS é modelada por uma aplicação, que deve estar contida em um ou mais dispositivos;

- Dispositivo: deve conter ao menos uma interface (seja de processo, seja de comunicação), e pode conter zero ou mais recursos. Uma interface de processo realiza um mapeamento entre uma planta física (da qual se obtém uma medida analógica, por exemplo) e os recursos, sendo as informações obtidas do processo dadas a esses recursos como eventos ou dados. Já uma interface de comunicação faz um mapeamento entre os recursos e as informações intercambiadas através de uma rede. Seus serviços podem incluir: fornecer as informações trocadas através da rede aos recursos, na forma de eventos ou dados; ou prover suporte a atividades de programação, configuração e diagnóstico dos dispositivos (entre outras);

- Recurso: é considerado uma unidade funcional em que as aplicações do sistema são postas. Um recurso sempre fica contido em um dispositivo e possui controle independente (assim, entre outras operações, um recurso pode ser criado, configurado, parametrizado, iniciado ou apagado, sem afetar outros recursos do dispositivo). As suas funções são aceitar dados e/ou eventos das interfaces de comunicação e de processo, tratá-los por meio das aplicações e fornecer a tais interfaces dados e/ou eventos correspondentemente. Além disso, uma outra função é controlar a execução e a transferência de dados entre blocos funcionais da aplicação, de acordo com as interconexões entre blocos funcionais, a ordem de ocorrência de

3 Algumas figuras referentes aos modelos de referência da norma IEC 61499 podem ser vistas no ANEXO A. 
eventos e outras informações de temporização (como períodos e prioridades de execução);

- Aplicação: consiste de uma rede de blocos funcionais (ou diagrama de blocos funcionais) cujos nós são blocos funcionais ou subaplicações (e seus parâmetros), e cujos arcos são conexões de dados ou de eventos entre eles - sendo que as subaplicações, como as aplicações, também são redes de blocos funcionais. Uma aplicação pode ser distribuída entre diversos recursos de um mesmo ou de diferentes dispositivos, e um recurso usa as relações causais especificadas pela aplicação para determinar as ações apropriadas a serem dadas em resposta aos eventos que recebe de suas interfaces (como o agendamento e a execução de algoritmos dos blocos funcionais; a modificação de valores de variáveis; a geração de outros eventos; e novas interações com as interfaces de processamento e de comunicação);

- Bloco funcional: é uma unidade funcional de software que possui, como características mais importantes, uma interface externa (composta por entradas de eventos, que afetam a execução de um ou mais algoritmos internos; saídas de eventos, que provocam eventos em uma conexão de acordo com algum de seus algoritmos ou outra capacidade funcional do recurso em que o bloco funcional está instalado; entradas de dados, mapeáveis em variáveis de entrada; e saídas de dados, mapeáveis em variáveis de saída); dados internos (mapeáveis em variáveis internas); e especificações funcionais (dadas pela combinação dos dados e/ou do estado interno, persistentes e inacessíveis exteriormente, com um conjunto de capacidades funcionais do recurso associado e/ou algoritmos internos, normalmente inacessíveis pelo exterior da interface). Pode fazer parte da definição de interface externa do bloco funcional a associação de eventos e dados por meio do qualificador WITH: por meio desse artifício, uma entrada de evento e um conjunto de entradas de dados podem ser ligados entre si para especificar quais variáveis devem ser amostradas na ocorrência de um determinado evento; e podem ser unidos uma saída de evento e um conjunto de saídas de dados para indicar que evento aponta a modificação de certas variáveis (enfatizando-se que todas essas associações são feitas para garantir a consistência de dados das aplicações); 
- Distribuição: refere-se à colocação dos blocos funcionais de uma aplicação ou subaplicação em um ou mais recursos, de um ou mais dispositivos. Vale lembrar que, embora distribuídos, os blocos funcionais - elementos atômicos de uma aplicação - mantêm entre si suas relações originais;

- Gerenciamento: pode ser entendido como a monitoração e o controle do estado dos recursos e dispositivos de um sistema, que pode ser realizado de maneira compartilhada ou distribuída, por aplicações específicas para essa função; e

- Estado operacional: refere-se a um estado de uma unidade funcional (dispositivo, recurso ou aplicação) que controla as ações que a mesma pode realizar, de acordo com a etapa do ciclo de vida em que esteja (projeto, comissionamento, operação ou manutenção), e também ajuda a manter a sua integridade em relação às demais unidades funcionais. Assim, alguns exemplos de estados operacionais são "operacional", "configurável", "carregado" e "parado", por exemplo.

Embora não esteja explícito anteriormente, as abstrações dispositivo, recurso, subaplicação e bloco funcional possuem tipos e instâncias (com uma relação muito semelhante a classes e objetos, no paradigma de orientação a objetos). Assim, um tipo de bloco funcional, por exemplo, estabelece um modelo para as suas correspondentes instâncias.

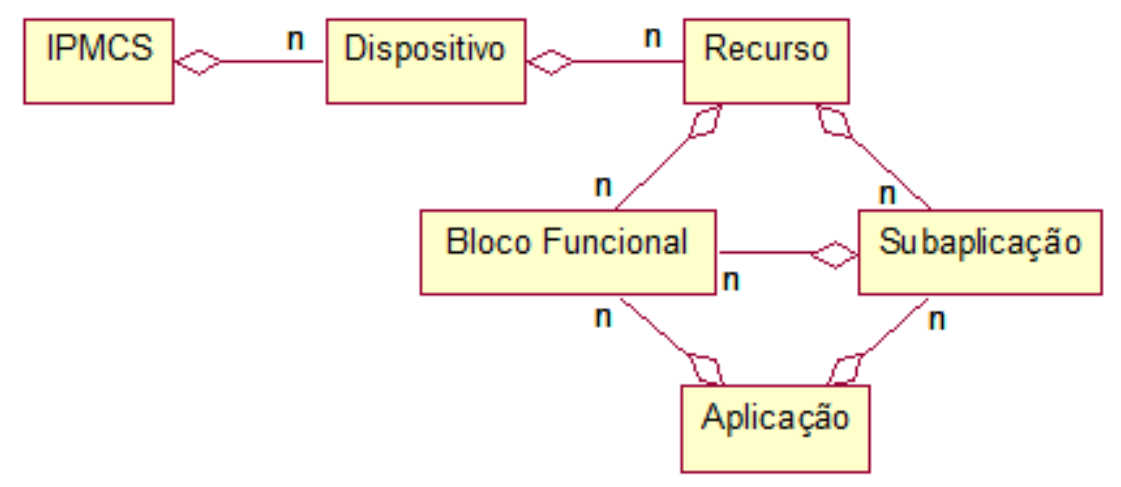

Figura 16: Composição de um IPMCS da norma IEC 61499 (em UML).

A partir deste ponto, serão detalhados alguns elementos da norma IEC 61499, como os tipos de blocos funcionais, os tipos de interfaces adaptadoras e o que é a configuração de unidades funcionais e sistemas, a fim de dar subsídios ao entendimento do restante da dissertação. 
2.2.2.3.1.2. Tipos de blocos funcionais

A especificação de um tipo de bloco funcional define as características de todas as suas instâncias, incluindo o nome desse tipo e a sua interface externa (dada pelo número, nomes, tipos e ordem dos eventos de entrada e de saída; o número, nomes, tipos e ordem dos dados de entrada, de saída e internos; e as eventuais associações WITH entre entradas e saídas de eventos e de dados).

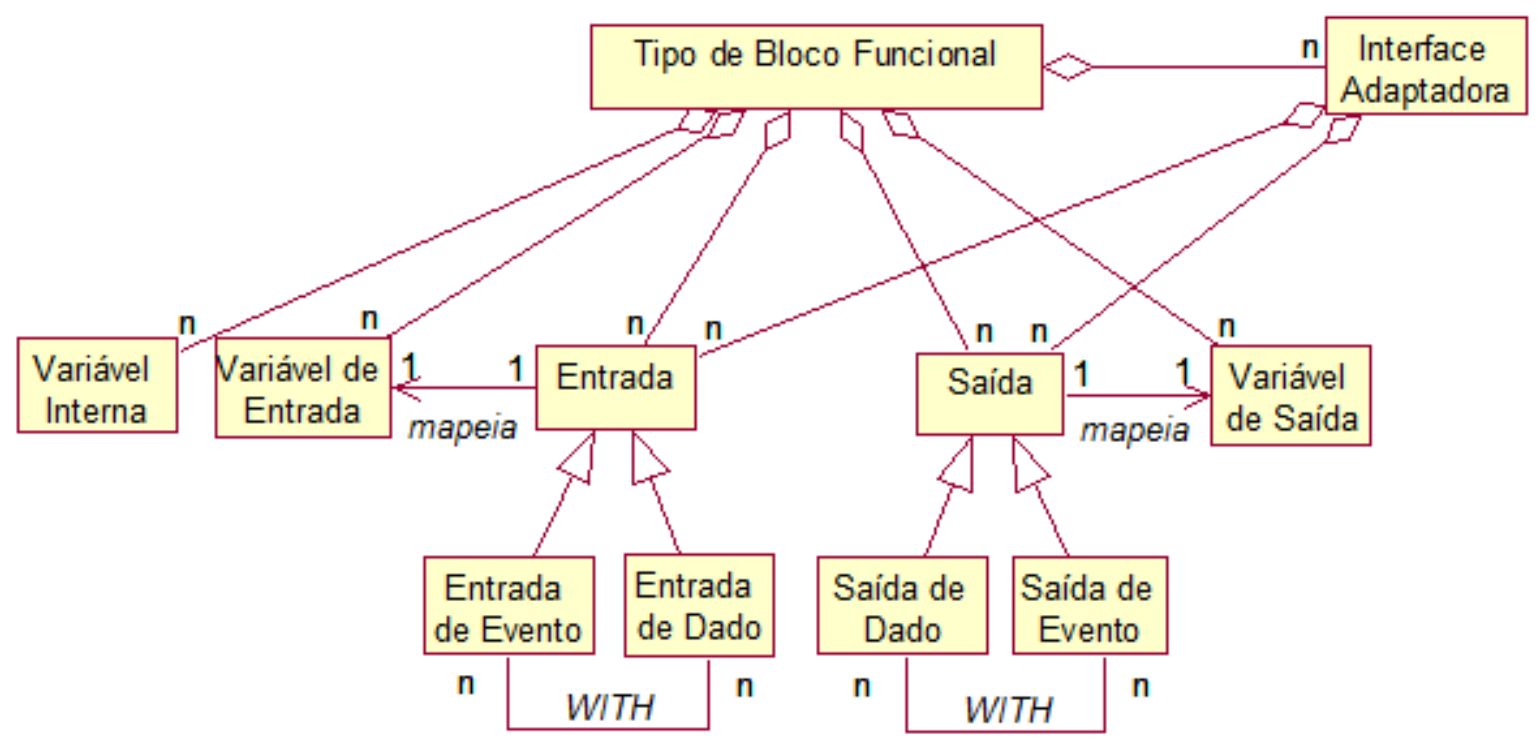

Figura 17: Especificação estrutural de um tipo de bloco funcional da norma IEC 61499 (em UML).

A descrição do funcionamento de um bloco, no entanto, pode ser dada por maneiras gerais (como através do uso de linguagem natural), ou depende da espécie do bloco funcional: na norma, são descritos os blocos funcionais básicos, os blocos funcionais compostos e os blocos funcionais de interface de serviços (Service Interface Function Blocks - SIFB), vistos a seguir.

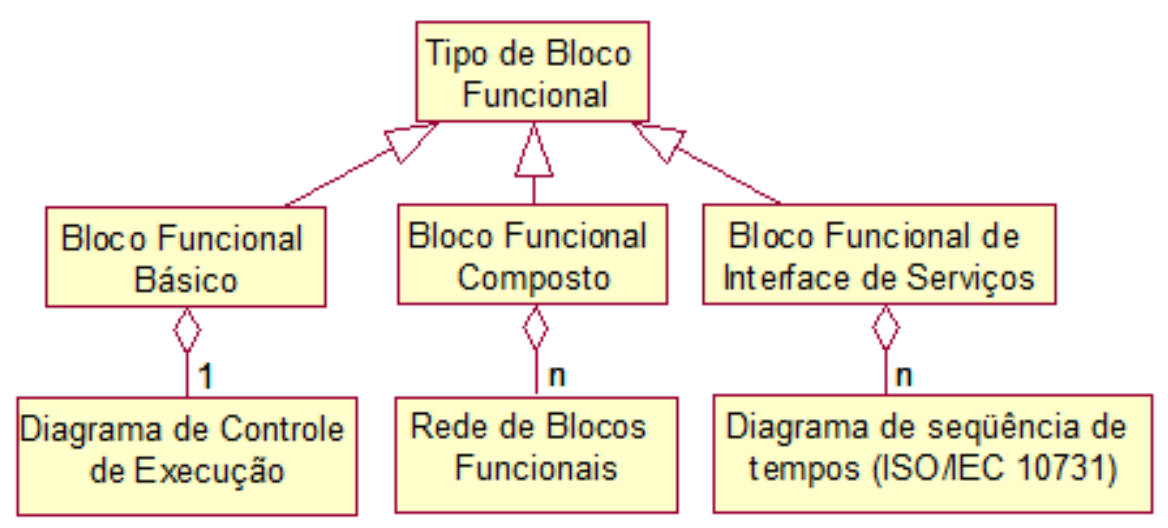

Figura 18: Subclassificação dos tipos de blocos funcionais (em UML). 
Os blocos funcionais básicos são os elementos atômicos de uma aplicação. O comportamento desses blocos é definido através de seus algoritmos - que especificam uma seqüência finita de operações, responsável por lidar com os valores de variáveis de entrada, de saída e internas e transformá-las em novos valores das variáveis de saída e internas - e de seu Diagrama de Controle de Execução (Execution Control Chart - ECC) - que relaciona a ocorrência de eventos nas entradas correspondentes do bloco funcional à invocação e execução dos algoritmos.

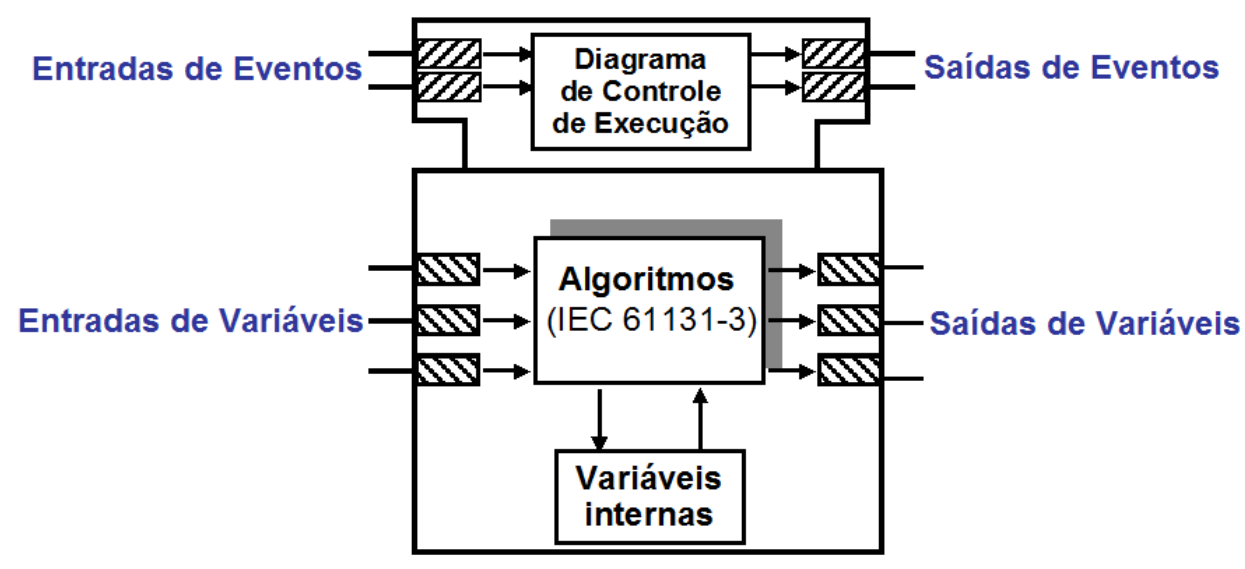

Figura 19: Bloco funcional básico da norma IEC 61499 - traduzido de Christensen (2002)).

O ECC possui ações, estados e transições. Uma ação é composta por um algoritmo e, opcionalmente, por um evento que indica o término da execução desse algoritmo. Um estado, por sua vez, pode ter zero ou mais ações vinculados a ele, com exceção do estado inicial do ECC (único, e sempre denominado START), que não deve possuir ação alguma. Por fim, uma transição é uma ligação que denota uma migração entre um estado de origem e um estado de destino, disparada pelo cumprimento de uma condição booleana (expressão construída em torno dos valores de uma ou mais variáveis de entrada de evento ou de dado, variáveis de saída ou variáveis internas pertencentes a um bloco funcional). Caso a transição deva ocorrer de qualquer maneira, independentemente do valor das variáveis do bloco funcional, a condição booleana é denotada por "1". Dessa maneira, pode-se ver que o ECC leva o bloco funcional a ter o seguinte comportamento: os algoritmos do estado corrente (estado ativo) são executados, e, conseqüentemente, são 
modificadas algumas variáveis do bloco funcional; a partir dessas alterações, pode ser disparada uma transição, que causa a desativação do estado corrente e ativação de um novo estado (para o qual essa seqüência se repete).

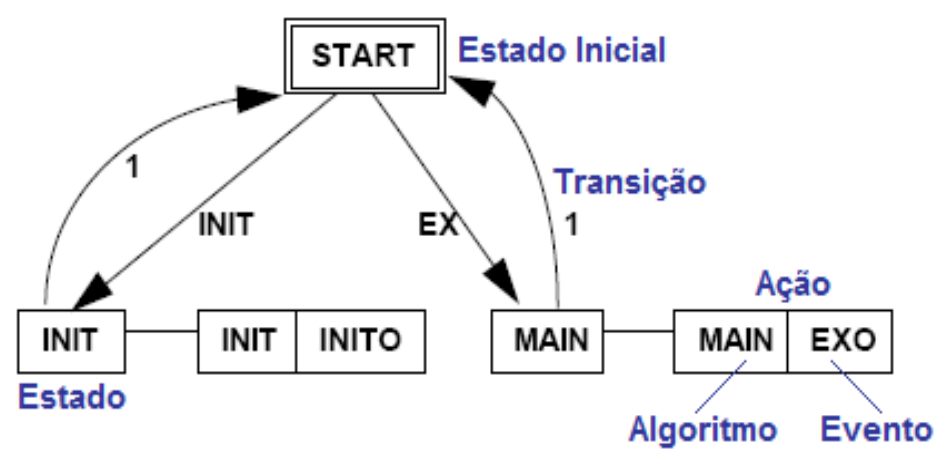

Figura 20: Diagrama de controle de execução de um bloco funcional básico da norma IEC 61499 adaptado de Christensen (2002).

\subsection{2. Blocos funcionais compostos}

Os blocos funcionais compostos têm como objetivo encapsular uma rede de blocos funcionais. Assim, o comportamento desses blocos é dado por sua rede de blocos funcionais (interna), e pela forma como essa rede se interconecta com suas entradas e saídas, de eventos e de dados (ou seja, sua interface). Dessa forma, blocos funcionais compostos assemelham-se a subaplicações, embora estas diferenciem-se dos primeiros principalmente por seus blocos funcionais poderem estar distribuídos em diversos recursos, por poderem conter outras subaplicações, e por não poderem ter, em sua interface, eventos ligados a dados por qualificadores WITH.

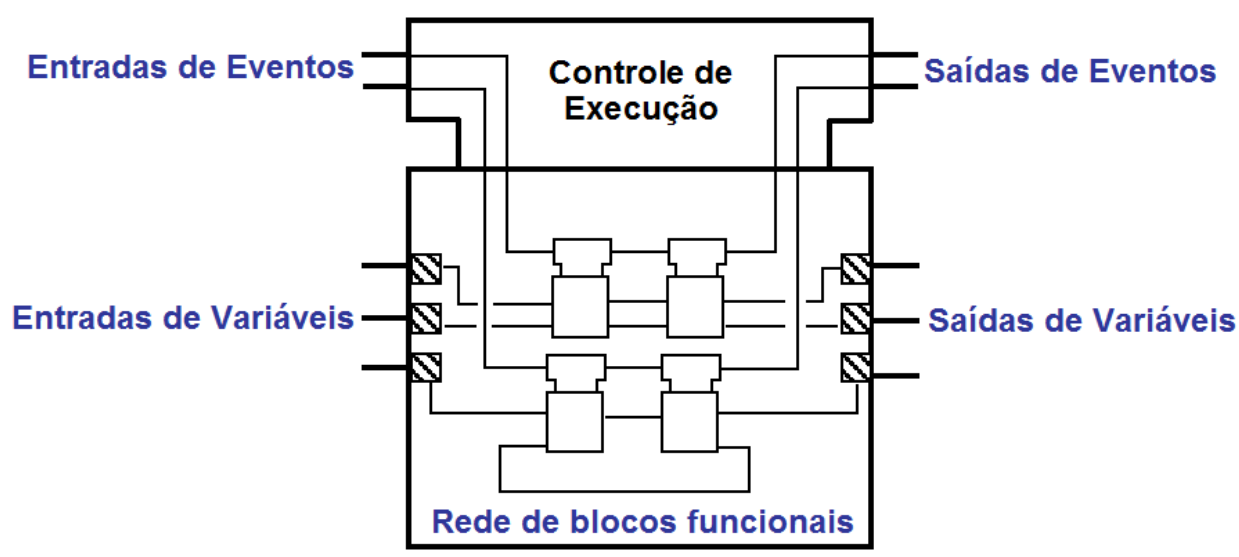

Figura 21: Bloco funcional composto da norma IEC 61499 - traduzido de Christensen (2002). 
2.2.2.3.1.2.3. Blocos funcionais de interface de serviços

Os blocos funcionais de interface de serviços (service interface function blocks) fornecem um ou mais serviços para uma aplicação, baseados no mapeamento de primitivas de serviço às suas entradas e saídas de dados e de eventos (as quais, muitas vezes, possuem semântica específica). O comportamento desse tipo de bloco é definido pelas seqüências de primitivas dos serviços (que fornecem ou requisitam da outra parte envolvida na interação), as quais podem ser dadas por uma notação gráfica especial: os Diagramas de Seqüência de Tempos da norma ISO/IEC 10731.

É possível encontrar duas subclassificações desses blocos funcionais:

- Blocos funcionais de comunicação: provêem interfaces entre as aplicações e as funções de mapeamento de comunicação de seus recursos; e

- Blocos funcionais de gerenciamento: implementam funções que permitem:

- Em um recurso, criar, inicializar, iniciar, parar, apagar, questionar a existência, requisitar os atributos ou prover notificação de mudanças de disponibilidade ou de estado:

- Dos tipos de dados;

- Dos tipos de blocos funcionais (e instâncias); ou

- Das conexões entre instâncias dos blocos funcionais.

- Em um dispositivo, criar, inicializar, iniciar, parar, apagar, questionar a existência, requisitar os atributos ou prover notificação de mudanças de disponibilidade ou do estado dos recursos.
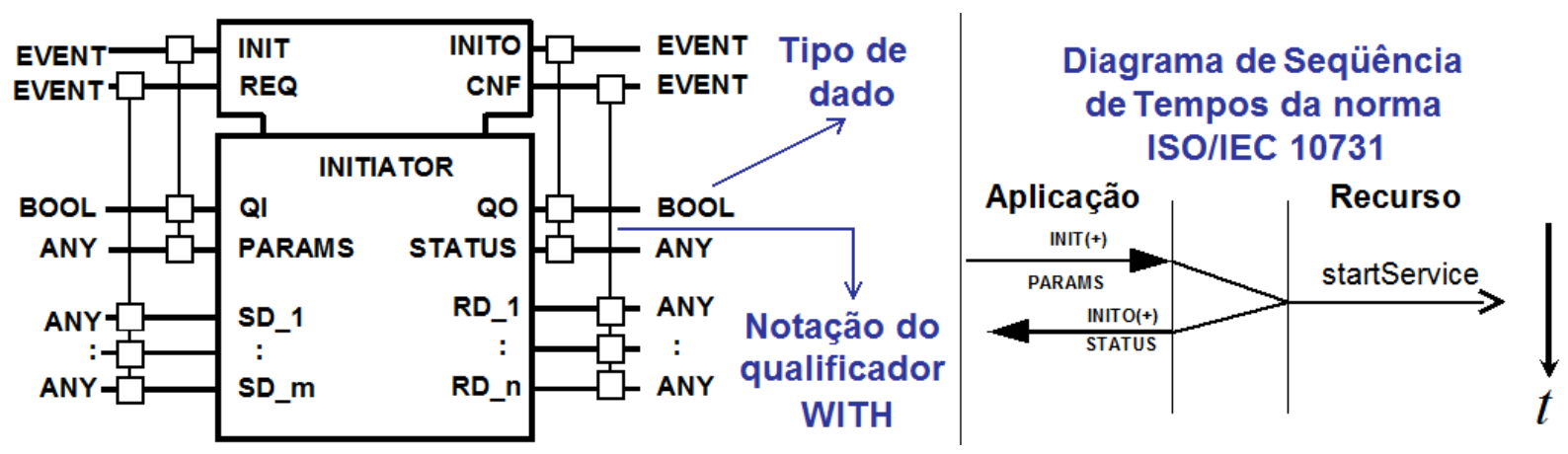

Figura 22: Bloco funcional de interface de serviços da norma IEC 61499 (aspecto externo idêntico aos dos demais blocos) e especificação da seqüência de primitivas de um serviço - adaptado de Christensen (2002). 


\subsection{Tipos de interfaces adaptadoras}

Os tipos de interfaces adaptadoras podem ser usados para fornecer um modelo de representação compacta de uma interface de um bloco funcional (conjunto de entradas e saídas de eventos e de dados) e dos caminhos usados por ela para fornecer ou receber um serviço. Ressalva-se que:

- Quando um bloco funcional provê um serviço para outro bloco funcional, ele é denominado bloco funcional provedor (provider). Ao utilizar uma instância de um determinado tipo de adaptador para expressar a interface usada para esse serviço, tal instância é chamada adaptador plugue (plug);

- Quando um bloco funcional aceita um serviço de outro bloco funcional, ele é denominado bloco funcional aceitador (acceptor). Ao utilizar uma instância de um determinado tipo de adaptador para expressar a interface usada para esse serviço, tal instância é chamada adaptador soquete (socket);

- Um adaptador soquete e um adaptador plugue só podem ser interconectados se forem do mesmo tipo; e

- O padrão da interação entre um bloco funcional provedor e outro aceitador pode ser representado por seqüências de primitivas de serviço (ou seja, por Diagramas de Seqüência de Tempos da norma ISO/IEC 10731).

\subsection{Configuração de unidades funcionais e sistemas}

A configuração de um IPMCS, atividade prévia à sua operação, conta, de forma geral, com as seguintes etapas:

- Configuração das aplicações, com a determinação dos nomes, tipos e conexões (de dados, de eventos e de adaptadores) de cada bloco funcional;

- Configuração dos dispositivos, com a escolha de valores específicos para seus parâmetros, e a determinação de seus recursos, blocos funcionais e conexões (de dados, de eventos e de adaptadores);

- Configuração dos recursos, com a escolha dos tipos de dados suportados, e tipos e instâncias de blocos funcionais (e suas respectivas conexões de dados, de eventos e de adaptadores); e

- Configuração da rede, com a atribuição de valores específicos para os parâmetros dos segmentos de rede, e a determinação dos dispositivos ou 
recursos unidos a cada segmento por meio de ligações (assim como o valor dos parâmetros destas).

\subsection{Anexos}

Por fim, os anexos da parte 1 da norma IEC 61499 apresentam as seguintes informações:

- Anexo A (normativo): mostra os blocos funcionais de eventos (Event Function Block), que podem ser usados para a geração e o processamento de eventos;

- Anexo B (normativo): expressa a descrição da sintaxe textual através da qual podem ser descritos todos os elementos da norma (como blocos funcionais, por exemplo) de maneira mais formal;

- Anexo C (informativo): fornece modelos de orientação a objetos para guiar a criação de ferramentas computacionais para suporte ao ciclo de vida (projeto, implementação, comissionamento e operação) dos IPMCS;

- Anexo D (informativo): mostra a relação entre a norma IEC 61499 e a norma IEC 61131-3 (que também trata de blocos funcionais, mas não orientados a eventos);

- Anexo $E$ (informativo): especifica aspectos relacionados à transferência de informações entre processos de aplicação (recursos), segundo a norma ISO/ IEC 7498-1, feita pelos blocos funcionais de comunicação;

- Anexo $F$ (normativo): especificações em sintaxe textual de todas as figuras apresentadas nessa parte da norma; e

- Anexo G (informativo): mostra a função dos atributos, que, associados a tipos de dados, variáveis, aplicações, e a tipos e instâncias de blocos funcionais, dispositivos e recursos (assim como a seus elementos componentes), possuem valores que podem ser acessados e/ou modificados em algum momento do ciclo de vida desses elementos. São postos em atributos dados como versão, permissão de escrita e descrição de algoritmos de blocos funcionais, por exemplo. 
2.2.2.3.2. Parte 2 - Requisitos das Ferramentas de Software (Software Tool Requirements)

A norma IEC 61499, na seção principal de sua parte 2, estabelece que uma ferramenta de software para o desenvolvimento das atividades de engenharia de IPMCS distribuídos deve ser capaz de:

- Permitir o intercâmbio dos elementos de sua biblioteca (que contém declarações de tipos de blocos funcionais, recursos, dispositivos, subaplicações, adaptadores, e dados, além das configurações de sistemas) com outras ferramentas de software;

- Mostrar as declarações dos elementos de sua biblioteca de uma forma conveniente às tarefas de engenharia (seja por texto ou graficamente, seguindo a norma IEC 61499-Parte 1, seja adotando um formato próprio);

- Permitir a alteração das declarações dos elementos de sua biblioteca (incluindo a adição, a exclusão ou a alteração de seu conteúdo - como, por exemplo, variáveis e algoritmos de tipos de blocos funcionais), textual, graficamente ou de ambas formas;

- Viabilizar a validação (ou seja, a verificação sintática ou semântica, ou simulação e teste de operação, por exemplo) de um elemento da biblioteca;

- Permitir a implementação das declarações (como a produção de código executável, por exemplo, e a ligação das instâncias dos blocos funcionais a recursos e dispositivos); e

- Fornecer meios para a operação, teste e manutenção do IPMCS, caso isso seja necessário para dar suporte a alguma etapa de engenharia desse sistema.

\subsection{Anexos}

Por sua vez, os anexos da parte 2 da norma IEC 61499 exibem os seguintes assuntos:

- Anexo A (normativo): mostra as definições de tipos de documento (Document Type Definitions - DTD), dados na sintaxe definida pela especificação da eXtensible Markup Language (XML), para a troca de elementos entre bibliotecas de distintas ferramentas de software (o que 
permite, por exemplo, a portabilidade de descrições de tipos de blocos funcionais);

- Anexo B (informativo): fornece um modelo gráfico simples para a representação das abstrações da norma IEC 61499, independentemente da ferramenta utilizada; e

- Anexo C (informativo): exemplos referentes à parte 2 da norma IEC 61499.

\subsection{COMENTÁRIOS SOBRE OS PROJETOS DE SISTEMAS DE AUTOMAÇÃO DISTRIBUÍDOS}

Tendo como objetivo o entendimento das contribuições das áreas de engenharia de sistemas e de software e de engenharia de controle e automação para a obtenção de ciclos de vida, métodos para modularização, linguagens e ferramentas adequados para o desenvolvimento de sistemas de automação distribuídos, é possível sintetizar as informações vistas nas seções anteriores da seguinte maneira:

- Quanto à engenharia de software e sistemas:

- Os métodos de desenvolvimento de sistemas dessa área são muito bem documentados pela literatura e são aplicáveis a distintos tipos de projeto (não somente de software), muitos deles contando inclusive com processos de gerenciamento além dos fluxos de atividades técnicos. As principais etapas desses métodos compreendem o levantamento (eliciação) de requisitos, a análise, o projeto, a implementação, os testes, a instalação e a manutenção dos sistemas;

- Uma das formas de modularização mais comuns nessa área ocorre quando se adotam técnicas de orientação a objetos, em que o sistema ou software é representado por abstrações chamadas objetos, que estabelecem normalmente um paralelo entre si e um objeto do mundo real (como dispositivos, processadores ou mesmo pessoas, por exemplo). Essa característica e o fato de que os mecanismos de orientação a objetos permitem a representação de relações 
semanticamente complexas entre elementos facilita a sua aplicação a qualquer domínio;

- Das linguagens utilizadas para expressar conceitos de orientação a objetos uma das mais populares é a UML: através de seus modelos gráficos é possível representar de forma muito rica aspectos de diferentes níveis de abstração sobre um determinado sistema (desde idéias puras a elementos de implementação). Destacam-se também a sua facilidade de compreensão e flexibilidade (principalmente pela possibilidade de expansão da linguagem); e

- Finalmente, as ferramentas fornecidas pela área têm funcionalidades centradas na representação de sistemas (que podem ser de propósito geral, como aquelas que permitem a modelagem através da $U M L$ ) e na implementação específica de software (como as que são aplicadas para codificação em linguagens de computação - por exemplo, Java e C).

- Quanto à engenharia de controle e automação:

- Os ciclos de vida de projetos de automação em geral são direcionados às atividades de construção do sistema em si (contando com as fases de projeto (já de baixo nível de abstração), de configuração da rede de comunicação, da configuração de aplicações, da instalação - de dispositivos e de software - e da manutenção do sistema). Durante a fase de projeto, ou eventualmente um pouco antes dela, executa-se o entendimento do problema e sua modelagem, mas tais atividades não constituem normalmente uma etapa formal do método de desenvolvimento;

- O uso de blocos funcionais para a segmentação das aplicações dos sistemas de automação é bastante difundido. Em geral, essas abstrações representam apenas módulos de encapsulamento de funções, mas especificamente os blocos funcionais orientados a eventos assemelham-se a elementos reativos (no sentido de que executam funções internas e divulgam dados de acordo com a recepção de determinados eventos);

- A norma IEC 61499 contribui com a área ao padronizar blocos funcionais orientados a eventos para expressar aplicações de sistemas de automação distribuídos, além de oferecer outras abstrações (como 
dispositivos e recursos) para permitir também a representação da estruturas físicas referentes a esses sistemas. Adicionalmente, incentiva a criação de ferramentas computacionais para suporte às etapas de engenharia de desenvolvimento de sistemas que utilizem suas abstrações (normatizando-as e definindo características que levem à interoperabilidade entre elas); e

- As diversas ferramentas de engenharia de controle e automação direcionam-se preferencialmente à modelagem matemática de sistemas, verificação e validação de modelos e implementação de redes de controle específicas (incluindo testes, configuração de rede e dispositivos, e supervisão de campo, entre outras funções).

Assim, do ponto de vista de levantamento de requisitos e de análise conceitual (incluída aqui a atividade de modelagem), a engenharia de sistemas e software parece ter contribuições importantes a oferecer aos projetos de sistemas de automação distribuídos. Por sua vez, a de engenharia de controle e automação aporta, nesse contexto, ciclos de vida e ferramentas bem estabelecidos quanto ao projeto de baixo nível e implementação dos sistemas. Dessa maneira, mesmo com suas diferenças, parece interessante unir as técnicas dessas duas áreas, a fim de que uma cubra as deficiências da outra no desenvolvimento de projetos. Isso pode ser feito se considerarmos os seguintes aspectos:

- Possibilidade de unificação dos ciclos de vida: pode-se entender o desenvolvimento de software e de hardware como subprojetos dentro do projeto de um sistema de automação distribuído. Este poderia ser constituído das etapas de levantamento de requisitos, análise, projeto, implementação, testes, instalação e manutenção (como no ciclo de engenharia de software), mas com atividades específicas de software e hardware (como configuração de rede, por exemplo) distribuídas entre essas macro-atividades, que recebem ênfases diferentes de acordo com o momento do projeto geral (como ocorre com as atividades dentro das fases no Processo Unificado de desenvolvimento de sistemas, por exemplo); e

- Similaridade entre conceitos de orientação a objetos e de descrição de sistemas em termos de blocos funcionais orientados a eventos: uma vez que tanto objetos como blocos funcionais orientados a eventos representam, ao mesmo tempo, estrutura (interface externa) e comportamento (encapsulado 
pela interface), e que ambos respondem a estímulos externos (sejam eles chamados de mensagens ou eventos, que alteram seu estado interno e, opcionalmente, a condição de variáveis), tais abstrações parecem ser compatíveis entre si.

A partir desse ponto, então, torna-se coerente e desejável estabelecer uma correlação entre a UML e as abstrações da norma IEC 61499: com a UML ter-se-ia a possibilidade de expressar uma visão geral dos requisitos e da análise do sistema de automação distribuído (tanto sob a perspectiva da aplicação quanto do ambiente de implementação teórico), enquanto que as abstrações da norma IEC 61499 poderiam mostrar, além do projeto de baixo nível da aplicação (com a divisão do software em blocos funcionais), uma visão mais concreta do sistema de hardware subjacente. Os modelos de ambas linguagens conseguiriam, dessa maneira, mostrar visões distintas e complementares de todo o sistema, usadas nas diversas atividades do ciclo de vida do projeto de um sistema de automação.

Complementarmente, o estabelecimento de um mapeamento entre essas linguagens tornaria possível a automatização da transformação desses modelos, que poderia ser realizada por alguma ferramenta computacional. Dessa maneira, os engenheiros de software e sistemas e o engenheiros de controle e automação poderiam trabalhar cooperativamente, compartilhando as tarefas de especificação de um sistema e, ainda assim, utilizar para isso suas próprias linguagens e ferramentas (ou seja, sem a necessidade de estudar profundamente uma outra área de conhecimento) (PANJAITAN; FREY, 2006a).

Dado o interesse nessa linha de pesquisa, analisam-se no capítulo seguinte algumas das principais técnicas de mapeamento entre UML e abstrações da norma IEC 61499. 


\section{MAPEAMENTO DE DIAGRAMAS DA UML EM DIAGRAMAS DE ABSTRAÇÕES DA NORMA IEC 61499}

Este capítulo apresenta alguns dos principais trabalhos sobre o mapeamento de diagramas da Unified Modeling Language (UML) em diagramas de abstrações da norma International Electrotechnical Commission (IEC) 61499 (chamado, a partir deste ponto, de mapeamento UML-IEC61499). O interesse neste tópico justifica-se no fato de que o desenvolvimento de tal técnica leva à obtenção de regras para a transformação automática das descrições de sistemas de automação em UML para as descrições em termos de abstrações da norma IEC 61499, o que pode ser utilizado para a implementação de ferramentas computacionais de auxílio a projetos.

A partir deste ponto, fica subentendido que os termos relacionados a diagramas de blocos funcionais e outros conceitos correlatos referem-se somente àqueles tratados pela norma IEC 61499 (tornando opcional o uso deste complemento no texto).

\subsection{TENDÊNCIAS NO MAPEAMENTO UML-IEC61499}

As técnicas de mapeamento UML-IEC61499 a serem tratadas neste capítulo, por ordem de relevância, compreendem os seguintes trabalhos ${ }^{4}$ :

- Mapeamento de Thramboulidis: Thramboulidis (2001) e Tranoris e Thramboulidis (2002, 2003b);

- Mapeamento de Dubinin e Vyatkin: Dubinin e Vyatkin (2004) e Dubinin, Vyatkin e Pfeiffer (2005);

- Mapeamento de Panjaitan e Frey: Panjaitan e Frey (2005, 2006a, 2006b);

- Mapeamento de Zhang, Diedrich e Halang: Zhang, Diedrich e Halang (2005); e

4 Deve-se esclarecer que o nome do subtópico foi escolhido de acordo com o(s) nome(s) do(s) pesquisador(es) que aparece $(\mathrm{m})$ como autor(es) em todos os trabalhos correlatos, e que o critério usado para a sua ordem de apresentação é a aplicabilidade do mapeamento considerando os objetivos iniciais da dissertação e a existência de ferramentas para automatizá-lo. 
- Mapeamento de Heverhagen, Tracht e Hirschfeld: Heverhagen, Tracht e Hirschfeld (2003).

A seguir, passa-se à descrição de cada uma dessas técnicas.

\subsubsection{Mapeamento de Thramboulidis}

Para realizar o mapeamento UML-IEC61499, Thramboulidis (2001) e Tranoris e Thramboulidis (2002, 2003b) sugeriram extensões à UML especialmente através do mecanismo de estereótipos. Como será visto adiante, a base dessa transposição é a captura de dados das classes e de informações adicionais dos Diagramas de Interação para obter blocos funcionais e interconexões que descrevam completamente o sistema de automação determinado. Iterativamente, o projetista deve lidar com a passagem dos diagramas da UML para os diagramas de blocos funcionais, até que todos os diagramas de blocos funcionais gerados a partir dos Diagramas de Interação sejam unificados e todas as redundâncias de blocos funcionais sejam eliminadas.

A ferramenta computacional que automatiza as regras de transformação UML-IEC61499 de Thramboulidis é o Common Object-oriented Real-time Framework for the Unified development of distributed Industrial-Process Measurement and Control Systems (IPMCS) applications (CORFU) Engineering Support System (ESS), que dá suporte ao processo de desenvolvimento CORFU e cuja subaplicação chamada Transformation Facility Manager (TFM) executa o mapeamento referido.

\subsubsection{Diagramas da UML usados no mapeamento de Thramboulidis}

Os Diagramas de Classes, Pacotes, Estados e Interação são usados como fontes de dados para uma série de regras de transformação simples e automatizáveis que levam à obtenção dos diagramas de blocos funcionais do sistema. Os Diagramas de Casos de Uso, embora importantes para o estudo do sistema a ser desenvolvido, não oferecem dados para tal mapeamento. A seguir, são detalhadas as funções de cada tipo de diagrama. 


\subsubsection{Diagrama de Classes}

O Diagrama de Classes representa os tipos de blocos funcionais que compõem a aplicação do sistema de automação distribuído, além de seus relacionamentos. Isto é feito respectivamente por classes descritas com estereótipos adequados e por relacionamentos de agregação e dependência.

\subsection{Estereótipos das classes}

As classes podem assumir os seguintes papéis no sistema de automação especificado, de acordo com os seus estereótipos:

- Bloco Funcional (Function Block - FB);

- Bloco Funcional de Interface de Serviço (Service Interface Function Block SIFB);

- Terminador do Processo Industrial (Industrial Process Terminator - IPT); e

- Objeto do Mundo Real (Real-World Object-RWO).

A seguir, são explicadas as características de cada um desses estereótipos.

\subsection{Estereótipo FB}

O estereótipo FB determina que uma classe representa um tipo de bloco funcional.

Os atributos privados ou protegidos representam as variáveis internas do bloco funcional, enquanto os atributos públicos, ou obtidos por meio de operações get() e registrados através de métodos set(), indicam a existência de dados de entrada e de saída do bloco funcional, e se relacionam às dependências de dados entre blocos funcionais (detalhados adiante no texto, e que determinam a troca de dados entre os mesmos).

Os métodos públicos representam eventos de entrada dos blocos funcionais, e os possíveis parâmetros passados em tais métodos correspondem aos dados de entrada vinculados a esses eventos (e, nesse caso, eventos e dados são ligados pelo qualificador WITH quando da transformação da UML para os diagramas de blocos funcionais). Se houver um valor de retorno para um método, este deve ser considerado como um dado de saída do bloco funcional. Os métodos públicos das 
classes de estereótipo FB estão ligados aos relacionamentos de dependência de controle entre as classes (a serem vistas adiante, e que designam a transmissão de eventos de um bloco funcional a outro), enquanto os métodos privados destinam-se a maximizar as possibilidades de reuso de código dos blocos funcionais.

Por fim, vale lembrar que cada classe de estereótipo FB pode estar vinculada a um Diagrama de Máquinas de Estados se representar um bloco funcional básico (já que esses diagramas designam os Diagramas de Controle de Execução ou Execution Control Chart- ECC).

\subsection{2. Estereótipo SIFB}

Quando o sistema de automação precisa interagir com uma entidade externa, utiliza-se uma classe de estereótipo SIFB para especificar o elemento responsável pela interface entre as partes citadas (já que o SIFB é responsável por prover um ou mais serviços para o sistema de automação, como o mapeamento de serviços primitivos, entre eles os de comunicação, para facilitar a troca de eventos e dados entre o sistema de automação e a entidade externa).

\subsection{3. Estereótipo IPT}

As classes de estereótipo IPT representam as entidades do processo industrial que são monitoradas e controladas pela aplicação, já que os IPT fazem a interface entre o sistema de controle (entidades lógicas) e os elementos da planta (dados, por exemplo, por um objeto do mundo real, ou classe de estereótipo RWO). Assim, pode-se entender o IPT como a representação lógica dos elementos físicos previamente citados.

Os IPT, dependendo de servirem como interface para elementos fontes ou sorvedouros de dados, são discriminados como IPT de entrada (input-IPT), IPT de saída (output-IPT) ou IPT de entrada e saída (input/output-IPT). Os dados ou eventos (de entrada ou de saída) da aplicação, ligados à planta, são chamados de parâmetros do processo industrial (ou Industrial Process Parameters - IPP), sendo os dados de entrada vinculados a métodos set(), e os de saída a métodos get(). 
O estereótipo RWO representa os objetos relevantes do mundo real (ou seja, os dispositivos de entrada e saída, físicos, que fazem interface com o sistema de controle, fornecendo sinais de entradas e recebendo sinais de saída do mesmo).

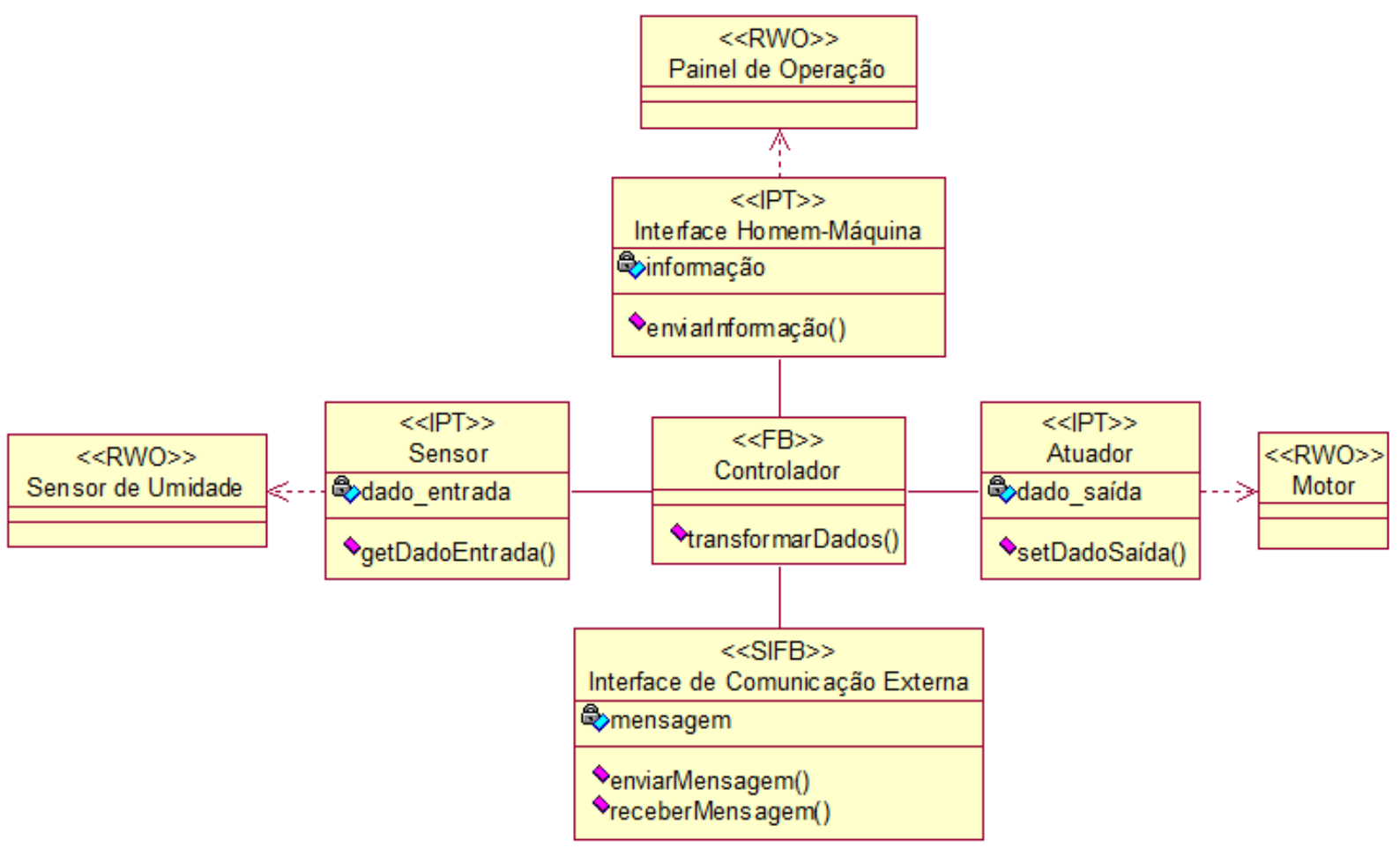

Figura 23: Diagrama de Classes de um sistema de automação genérico para demonstração do uso dos estereótipos do mapeamento de Thramboulidis (estereótipos FB, IPT, SIFB e RWO).

\subsection{Relacionamentos}

Os relacionamentos usados nos Diagramas de Classes restringem-se a relacionamentos de associação (agregação) ou a relacionamentos de dependência, conforme descrito a seguir.

\subsection{1 Associação (Agregação)}

Os tipos de blocos funcionais compostos (composite FB) e das subaplicações (sub-applications) devem ter relacionamentos de agregação com as classes que representam os tipos de blocos funcionais pertencentes a eles. Vale ressaltar que a única diferença entre bloco funcional composto e subaplicação é que 
no último os blocos funcionais componentes podem ser colocados em recursos diferentes do sistema.

\subsection{Dependência}

Os relacionamentos de dependência entre classes podem receber um dos estereótipos listados abaixo:

- Dependência de dados (DataDependency - DD): o estereótipo DD é colocado em relacionamentos de dependência entre as classes de blocos funcionais e blocos funcionais ou IPT para designar uma associação do tipo produtor-consumidor de dados entre as partes. É a partir desse estereótipo que são definidos os métodos set() e get() a serem postos nas classes: enquanto o elemento produtor no diagrama envia uma mensagem do tipo set(nome_do_atributo, valor_do_atributo), o elemento consumidor envia uma mensagem do tipo get(nome_do_atributo) para o produtor; e

- Dependência de controle (ControlDependency - CD): o estereótipo CD é posto em relacionamentos de dependência entre as classes de blocos funcionais e blocos funcionais ou IPT para designar a existência de propagação de eventos entre elas. A partir desses relacionamentos determina-se um método no bloco funcional receptor, chamado método de resposta (response method), que define o comportamento do bloco funcional frente à recepção do evento. Esse comportamento pode incluir: a execução de processos computacionais; a modificação de valores de atributos e disparo de transições no ECC; a habilitação ou desabilitação de métodos contínuos; o disparo de métodos de uma só execução (one-shot); e a habilitação ou desabilitação de relacionamentos de estereótipo DD ou CD.

A Figura 24 mostra os relacionamentos descritos anteriormente em relação ao exemplo de um sistema de automação de um condicionador de ar (fan coil): o fan coil deve receber a temperatura de dois sensores, posicionados em suas regiões de retorno e insuflamento de ar, e decidir qual a velocidade em que o seu ventilador deve funcionar (para resfriar $o$ ar, forçando a sua passagem através de uma serpentina de água gelada, por exemplo), ou se o ventilador deve ser desligado. Esse exemplo deve ser usado neste capítulo, quando necessário, para ilustrar os mapeamentos UML-IEC61499 pesquisados. 


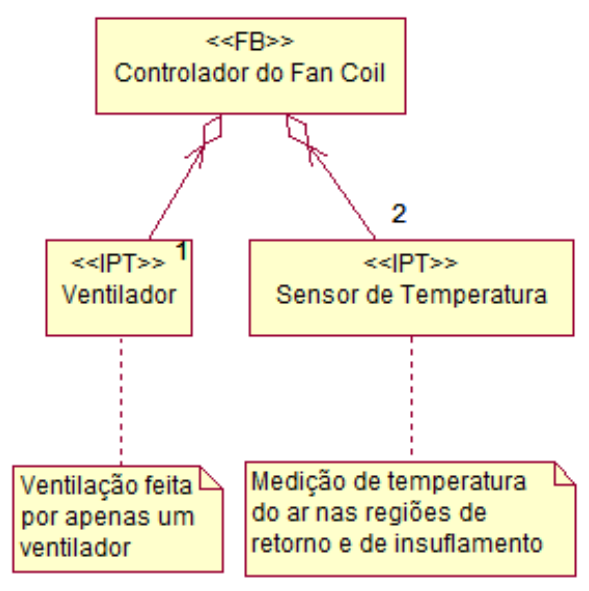

(a)

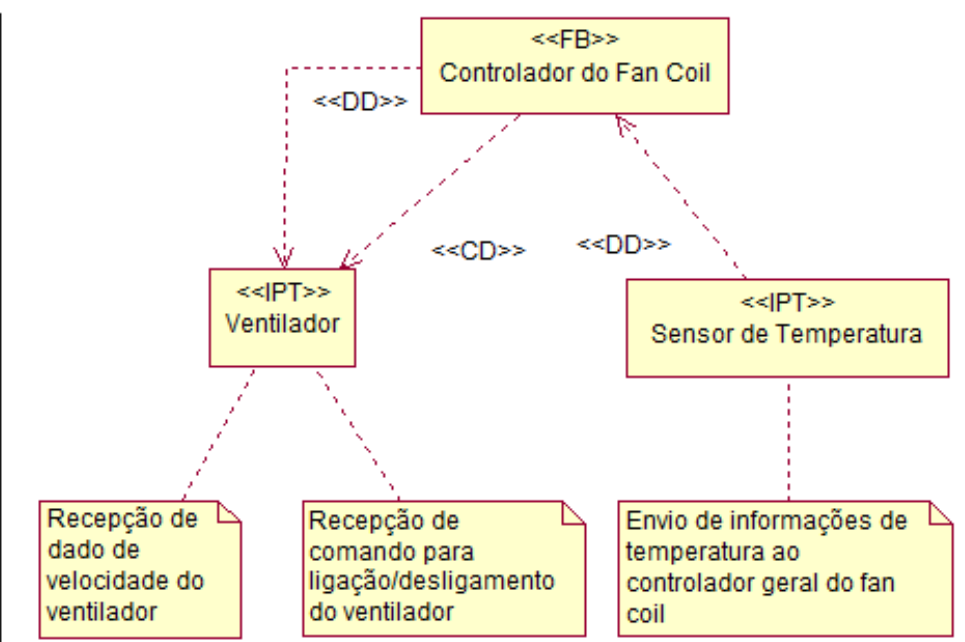

(b)

Figura 24: Diagramas de Classes do sistema de automação de um condicionador de ar (fan coil) para demonstração do uso dos relacionamentos de agregação (a) e dependência (b), elaborado segundo o mapeamento de Thramboulidis.

\subsubsection{Diagrama de Pacotes}

Apesar de ser uma das alternativas viáveis, o uso de pacotes para a representação de blocos funcionais compostos e de subaplicações não é recomendado, já que os mesmos não podem participar como elementos nos Diagramas de Interação da UML (dificultando a representação do interfaceamento dessas entidades com as demais). Ainda assim, se for esta a opção feita, o Diagrama de Classes do pacote define os blocos funcionais que compõem o bloco funcional composto ou subaplicação, além de seus relacionamentos.

\subsection{Diagrama de Máquinas de Estados}

O Diagrama de Máquinas de Estados ligado a uma classe representa o diagrama de controle de execução (Execution Control Chart - ECC) do bloco funcional básico descrito por ela. 


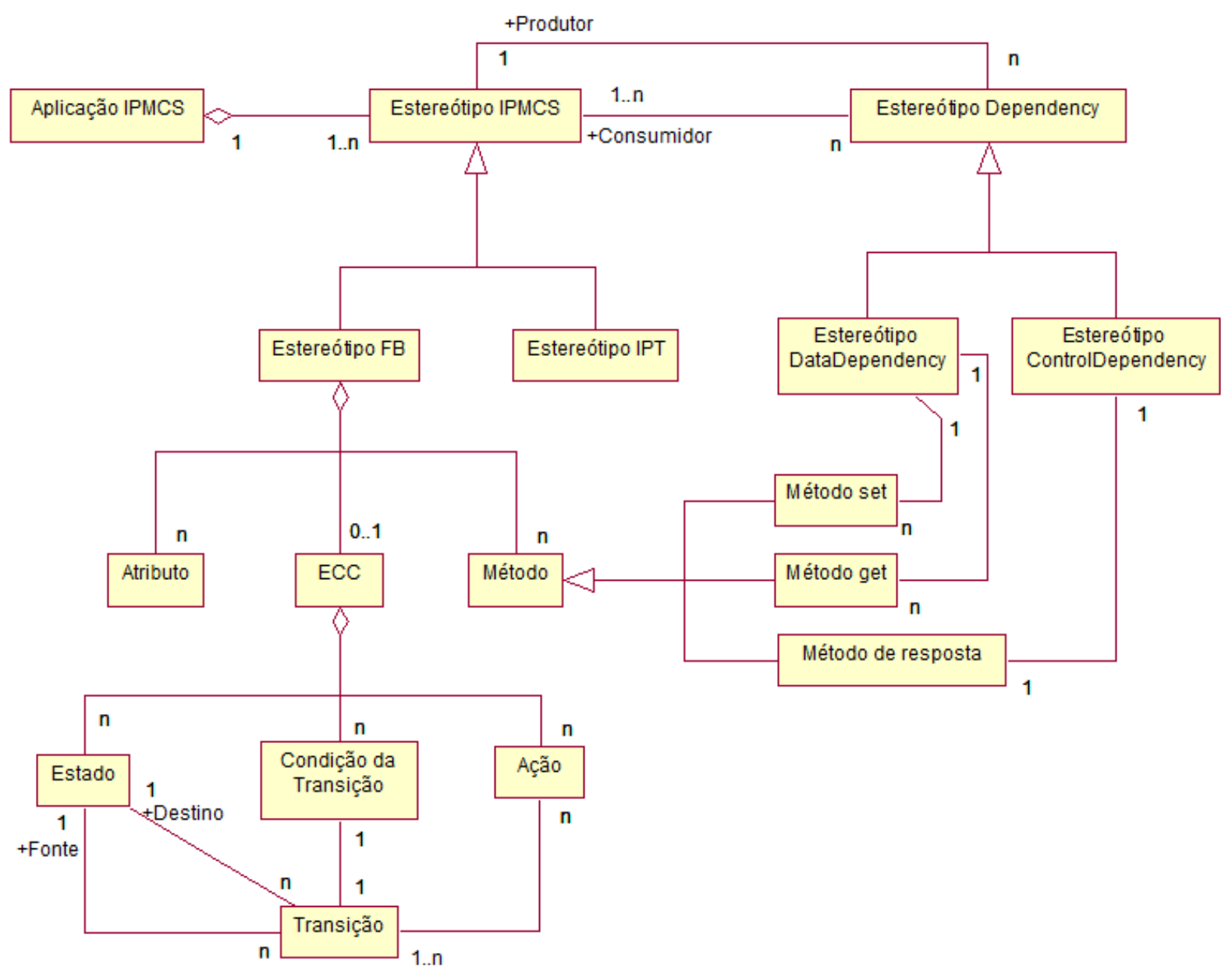

Figura 25: Parte dos estereótipos ligados a blocos funcionais (modelo em UML) - traduzido de Thramboulidis (2001).

\subsubsection{Diagrama de Interação}

Os Diagramas de Interação (Diagramas de Seqüência e de Colaboração) explicitam as conexões de dados ou eventos entre blocos funcionais, esclarecendo a função de cada relação de dependência descrita no Diagrama de Classes.

Em primeiro lugar, para cada Diagrama de Interação obtém-se um diagrama de blocos funcionais (que deve ser unificado aos demais ao final do processo de transformação). Cada objeto desses diagramas deve gerar uma instância de bloco funcional, de acordo com a classe a que o objeto pertence. Caso um objeto interaja com um elemento externo ao sistema, deve-se adicionar um bloco funcional de interface de serviços (SIFB) ao diagrama de blocos funcionais.

Logo, cada mensagem entre os objetos gera parte da interface de eventos dos blocos funcionais: neste caso, o nome da mensagem é posto como o nome do 
evento de saída do bloco funcional chamador, e também deve ser o nome do evento de entrada do bloco funcional chamado. Assim, formam-se as interconexões entre os eventos dessas duas instâncias de blocos funcionais (que possuem o mesmo nome do evento de entrada/saída). Se as interações entre blocos funcionais envolverem mensagens com parâmetros, tais parâmetros devem ser mapeados como entradas e saídas de dados dos blocos funcionais que estão interagindo. Além disso, tais parâmetros devem ser vinculados a seus eventos pelo qualificador WITH.

Em relação às mensagens trocadas entre blocos funcionais e IPT, os parâmetros passados entre eles revelam quais são os IPP em questão. O nome da mensagem vai ser mapeado como um IPP do tipo "evento" e os parâmetros possíveis da mensagem vão ser mapeados como IPP do tipo "dado". Se a direção da mensagem for de um bloco funcional para um IPT, temos um IPP de atuador (saída de dados). Caso contrário, temos um IPP de sensor (entrada de dados no sistema).

Por fim, se uma mensagem possui mais de um receptor, uma instância do bloco funcional divisor de eventos (Function Block Event Splitter) deve ser inserida no diagrama de blocos funcionais, enquanto que quando houver necessidade que dois ou mais eventos se encontrem (coincidam) para que o processo continue, uma instância do bloco funcional de reunião de eventos (Function Block Event Rendezvous) deve ser acrescentada ao diagrama.

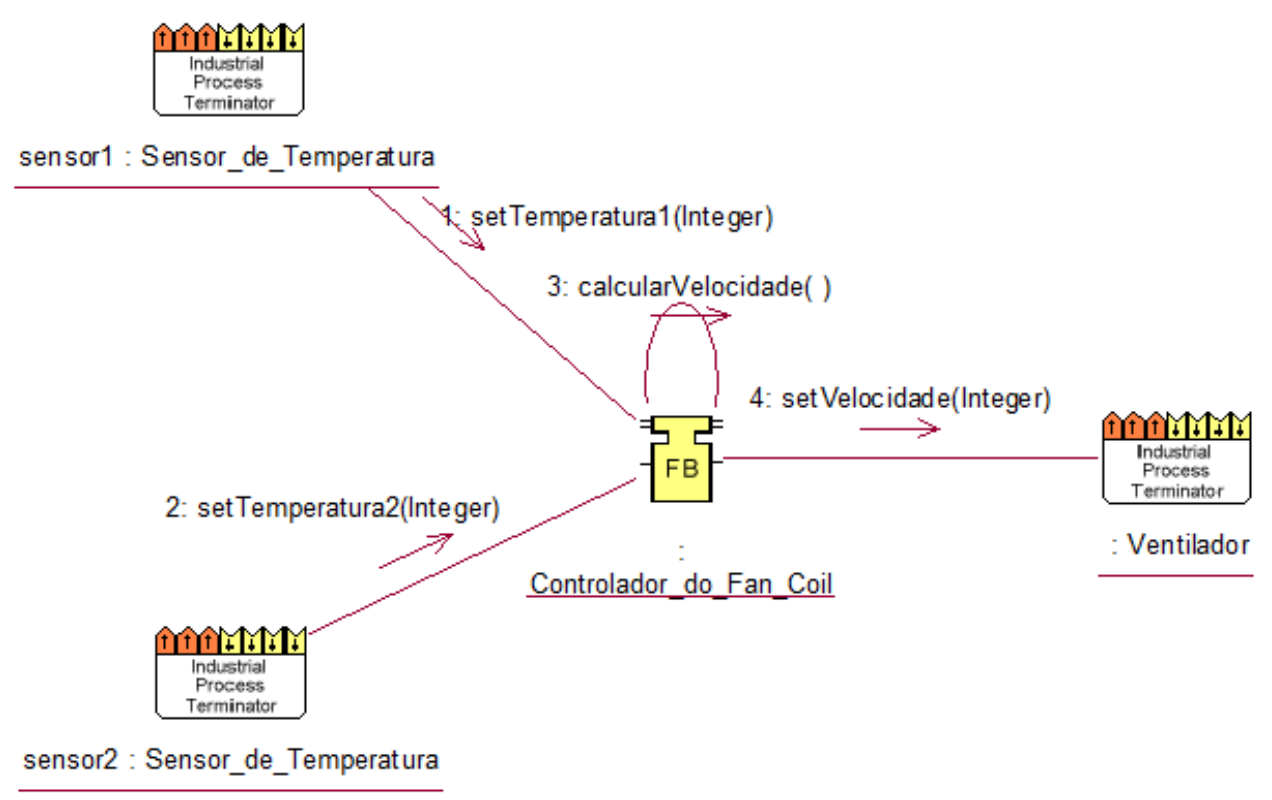

Figura 26: Diagrama de Colaboração do sistema de automação de um condicionador de ar (fan coil), elaborado segundo o mapeamento de Thramboulidis e com os ícones dos estereótipos do CORFU ESS. 


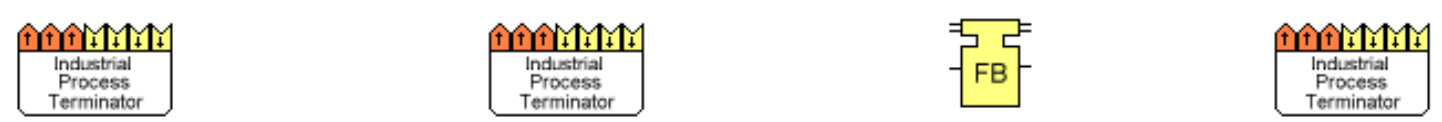

sensor 1 : Sensor_de_Temperatura sensor2: Sensor_de_Temperatura

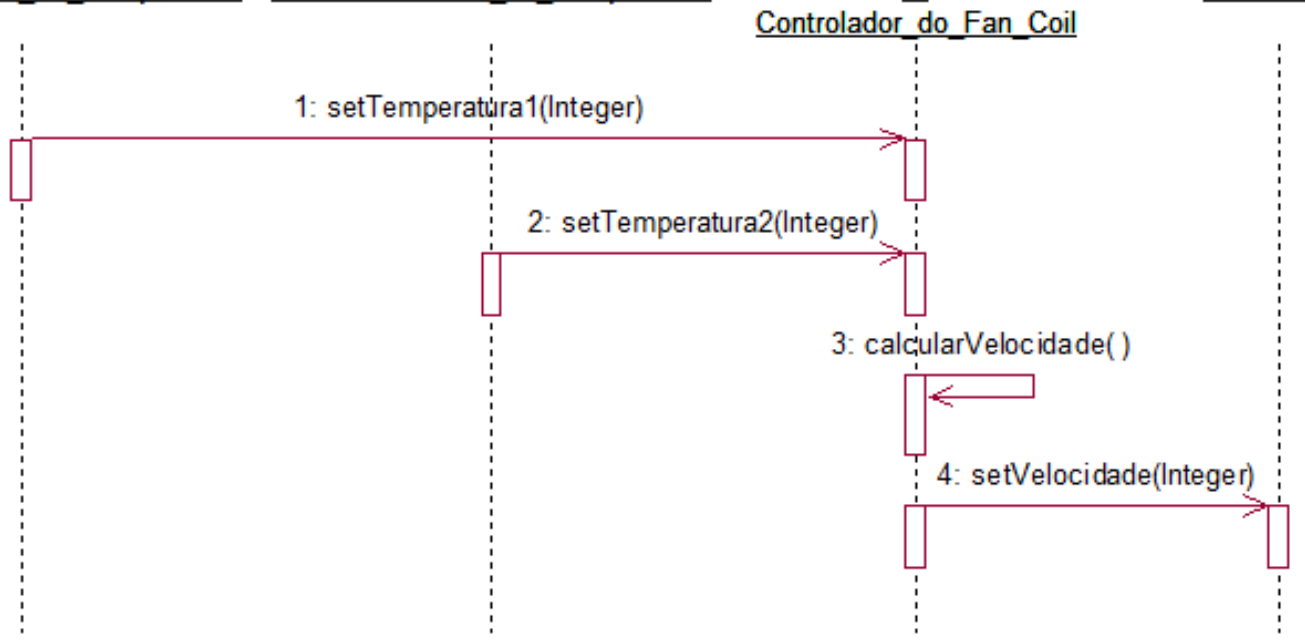

Figura 27: Diagrama de Seqüência do sistema de automação de um condicionador de ar (fan coil), elaborado segundo o mapeamento de Thramboulidis e com os ícones dos estereótipos do CORFU ESS.

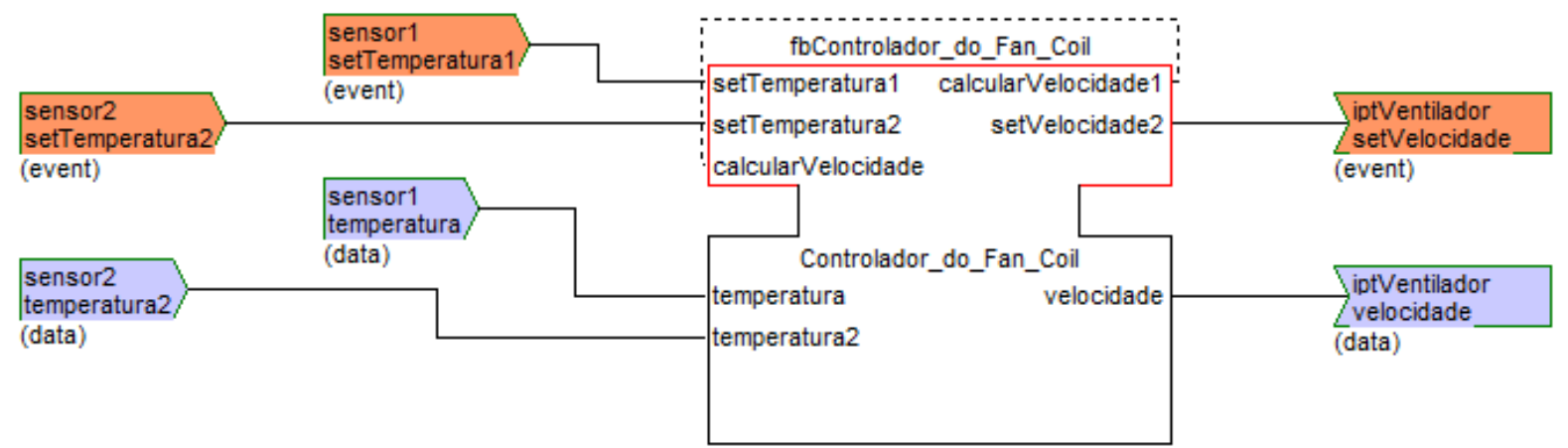

Figura 28: Diagrama de blocos funcionais obtido a partir do diagrama de seqüência descrito na Figura 27 (gerado com a ferramenta CORFU ESS).

\subsection{Diagrama de Casos de Uso}

Finalmente, os Diagramas de Casos de Uso, apesar de servirem para o estudo das funções a serem desempenhadas pelo sistema de automação, não são passíveis de mapeamento para elementos dos diagramas de blocos funcionais, conforme relatado anteriormente. 


\subsubsection{Mapeamento de Dubinin e Vyatkin}

A descrição de abstrações da norma IEC 61499 através da UML foi proposta por Dubinin e Vyatkin (2004) e Dubinin, Vyatkin e Pfeiffer (2005) em sua linguagem chamada UML-FB, a qual estende a UML através do mecanismo de estereótipos. $A$ linguagem UML-FB deve ser utilizada estritamente para a modelagem, o projeto e a manutenção de sistemas de automação (devido a suas regras de aplicação e semântica específicas).

A transformação dos diagramas da linguagem UML-FB para os diagramas de abstrações da IEC 61499 permite a obtenção de uma especificação executável de um sistema de controle, e é feita pelas ferramentas computacionais denominadas conversores UML-FB e FB-UML - esta última para a conversão inversa, ou seja, para a obtenção de diagramas da UML a partir de elementos da IEC 61499 (DUBININ; VYATKIN; PFEIFFER, 2005).

\subsubsection{Diagramas da linguagem UML-FB}

A UML-FB utiliza os Diagramas de Classes, de Seqüência, de Cooperação e de Máquinas de Estados apresentados na UML. A seguir, detalha-se a aplicação de cada um destes na descrição dos sistemas de automação.

\subsection{Diagrama de Classes}

Os Diagramas de Classes são usados para representar: os blocos funcionais, subaplicações, adaptadores, recursos e dispositivos do sistema; as interfaces dos blocos funcionais, incluindo suas entradas e saídas, tanto de dados quanto de eventos; as configurações do sistema, dos dispositivos e dos recursos; os dados constantes que representam parâmetros de entrada dos blocos funcionais, subaplicações, recursos e dispositivos; e, por fim, os relacionamentos e a hierarquia de todos esses componentes do sistema. A seguir, detalha-se como tais informações são dadas em UML-FB. 


\subsection{Estereótipos das classes}

Em primeiro lugar, deve-se esclarecer que as classes da UML correspondem aos tipos de blocos funcionais da IEC 61499, enquanto os objetos da UML correspondem às instâncias dos blocos funcionais. Assim, para a criação de estereótipos para as classes, utilizou-se a própria classificação da norma IEC 61499, em que o bloco funcional (FB) é a raiz de uma árvore de estereótipos. A partir dele, derivam-se o bloco funcional básico (basic FB - BFB), o bloco funcional composto (composite FB - CFB) e o bloco funcional de interface de serviços (service interface FB - SIFB). Dubinin e Vyatkin sugerem, ainda, uma subclassificação dos SIFB de acordo com sua aplicação: blocos funcionais de interface de serviços de processo (process SIFB - PSIFB), que fazem conexão com o objeto controlado (planta); blocos funcionais de interface de serviços com os equipamentos periféricos, como temporizadores ou timers (timer SIFB - TSIFB); e blocos funcionais de interface de serviços de comunicação (communication SIFB - CSIFB), para o encapsulamento de funções de comunicação.

Além desses, as classes podem ainda possuir os seguintes estereótipos: SUB (subaplicações), ADAPTER (adaptadores), CONSTANT (constantes), SERVICE (serviços de um SIFB), SYSTEM (sistema), DEVICE (dispositivo), DEVICE_TYPE (tipo de dispositivo), RESOURCE (recurso), RESOURCE_TYPE (tipo de recurso), APPLICATION (aplicação) e o estereótipo Interface (pré-definido na UML).

\subsection{Estereótipos de métodos e atributos}

Os métodos das classes da UML-FB podem receber os estereótipos INPUT (se estiverem se referindo à entrada de um evento), OUTPUT (se forem associados à saída de um evento desse bloco funcional) ou INTERNAL (caso sejam internos). Os atributos, por sua vez, designam entradas e saídas de dados, e, além de receberem esses estereótipos, podem ter também os estereótipos SOCKET ou PLUG (se estiverem associados à existência de adaptadores - soquetes e plugues, respectivamente) e são declarados como sendo de um tipo específico (booleano ou inteiro, por exemplo). 


\subsection{Relacionamentos}

O diagrama de classes da UML-FB identifica tanto os tipos de blocos funcionais, dispositivos e recursos (representados como classes) quanto suas instâncias (dadas por objetos). Para definir a hierarquia de classes e objetos, utilizam-se relacionamentos de generalização, associação e dependência.

\subsection{1 . Associação}

Os relacionamentos de associação são utilizados para determinar as conexões entre entradas e saídas de eventos, de dados e de adaptadores existentes entre os tipos de blocos funcionais interligados, estabelecendo assim uma correspondência de todos-para-todos (multiplicidade n-m) entre as instâncias desses blocos funcionais. Os relacionamentos de associação podem ser dos seguintes tipos: EVENT (para eventos), DATA (para dados), EVENT_WITH_DATA (para eventos relacionados a dados) ou ADAPTER (para adaptadores).

Por outro lado, os relacionamentos de agregação da UML-FB têm como propósito identificar quais são os blocos funcionais compostos utilizados no sistema, ou seja, tais relacionamentos determinam quais instâncias específicas de blocos funcionais são encapsuladas por um tipo de bloco funcional, subaplicação ou recurso. O nome do papel da parte contida, especificado por essa conexão, fornece o nome da instância do bloco funcional. Tal nome não pode ser repetido em outra conexão de agregação entre as mesmas classes.

\subsection{Generalização}

Os relacionamentos de generalização são utilizados para descrever que um tipo de bloco funcional herda de um outro suas entradas e saídas de eventos, dados e adaptadores, ou até mesmo interfaces completas.

Quando uma relação de generalização é rotulada com o estereótipo STR, isso significa que a classe filha designa, na verdade, uma instância de um tipo de dispositivo ou de recurso (herdando, mais precisamente, sua configuração - ou seja, sua composição interna). 
Os relacionamentos de dependência determinam ligações semânticas entre objetos (como cliente-servidor, por exemplo), mas não são transformados em nenhuma estrutura específica dos diagramas de abstrações da IEC 61499 (ou seja, não há geração de código a partir deles).

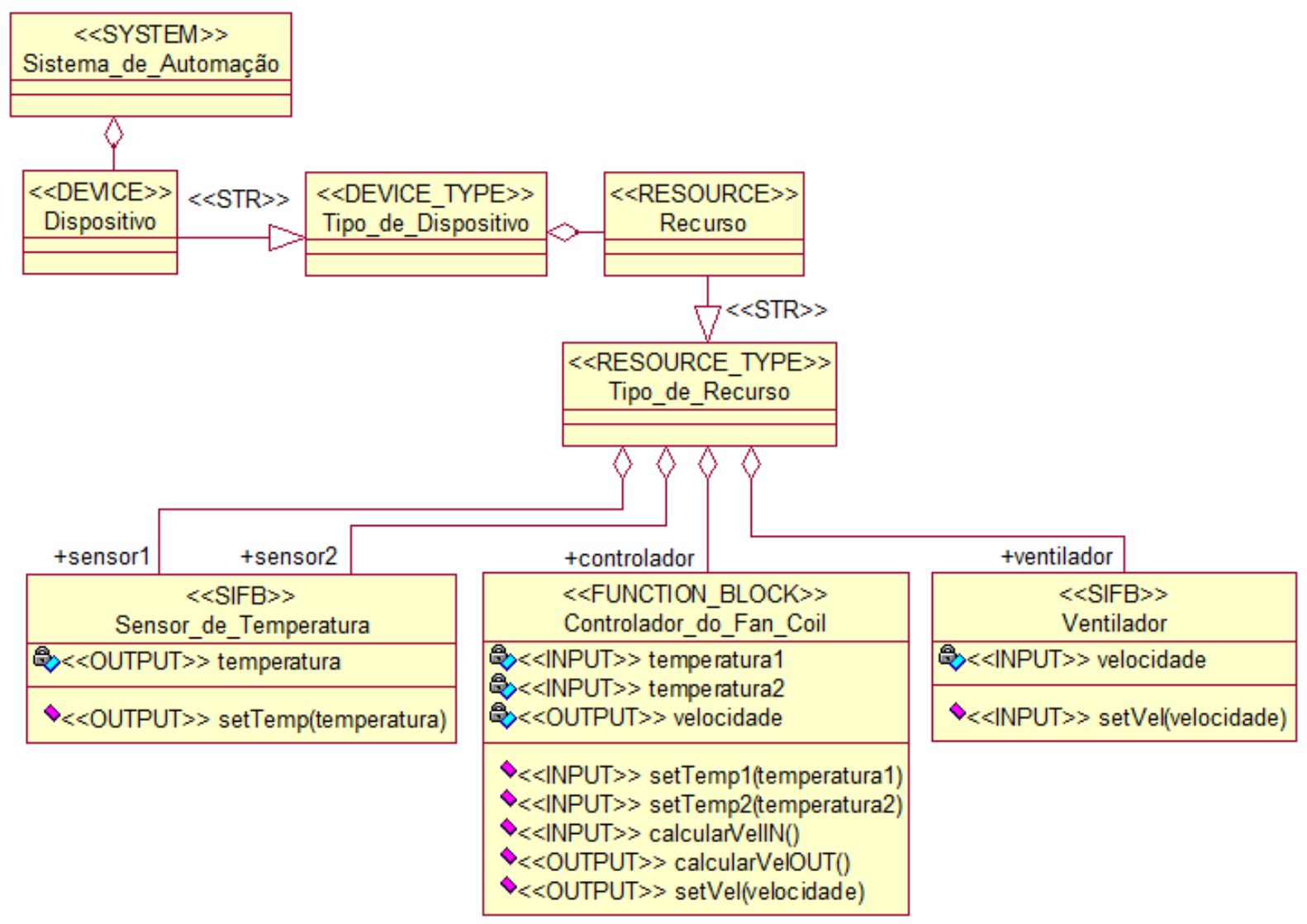

Figura 29: Diagramas de Classes do sistema de automação de um condicionador de ar (fan coil) para demonstração do uso de relacionamentos de agregação e generalização, além de estereótipos e composições das classes, elaborado segundo o mapeamento de Dubinin e Vyatkin.

\subsection{Diagrama de Interação}

Os Diagramas de Interação (Diagramas de Seqüência e de Colaboração) são utilizados para mostrar o comportamento dinâmico do sistema, ou seja, os eventos e dados intercambiados entre blocos funcionais, recursos e dispositivos, estabelecendo assim conexões ponto-a-ponto entre tais componentes do sistema.

Nos Diagramas de Colaboração, o formato das mensagens é definido por meio da linguagem Backus-Naur Form (BNF) como segue: <Nome da saída do bloco 
funcional $>-<$ Nome da entrada do bloco funcional $><$ Nome da conexão>. Já nos Diagramas de Seqüência, os métodos da UML representam eventos, e, caso os mesmos possuam parâmetros, tais eventos ficam vinculados a dados por meio do qualificador WITH da norma IEC 61499. Os Diagramas de Seqüência podem ser usados para a geração dos Diagramas de Seqüência de Tempos que seguem a International Organization for Standardization (ISO) TR 8509, os quais podem ser aplicados no paradigma de blocos funcionais da IEC 61499 para descrever o comportamento dos SIFB.

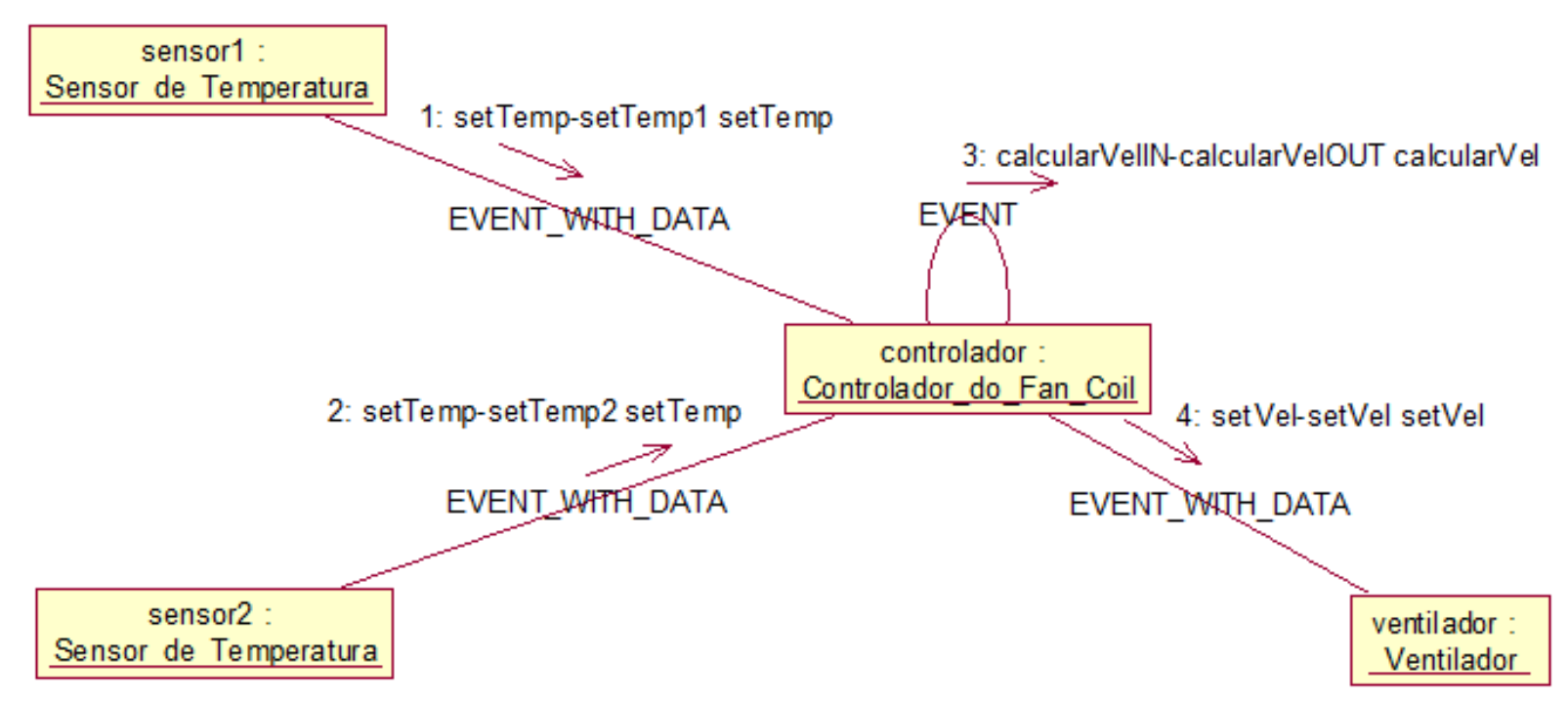

Figura 30: Diagrama de Colaboração do sistema de automação de um condicionador de ar (fan coil), elaborado segundo o mapeamento de Dubinin e Vyatkin.

\subsection{Diagrama de Máquinas de Estado}

Os Diagramas de Máquinas de Estado da UML-FB são usados para designar o comportamento de cada um dos tipos de bloco funcional básicos, já que devem ser mapeados diretamente em seus Diagramas de Controle de Execução (ECC). Para isso, os diagramas de estado da UML-FB mantêm-se muito simples, sem incluir estados históricos ou compostos, e nem transições complexas (com ações ou sinais, por exemplo). 
Os relacionamentos estabelecidos entre classes e objetos nos diversos diagramas da UML-FB determinam a hierarquia do sistema (que pode ser expressa através de diagramas de blocos funcionais aninhados) e as conexões entre as instâncias dos blocos funcionais. Essas conexões podem ser classificadas como locais ou de trânsito. As primeiras descrevem ligações diretas entre blocos funcionais de um mesmo nível hierárquico (ou seja, entre objetos irmãos) ou entre níveis diferentes, porém diretamente relacionados. Já as conexões de trânsito são aquelas que ocorrem entre blocos funcionais de níveis de hierarquia não relacionados entre si. Para implementar uma conexão de trânsito (que não é prevista pela IEC 61499) devem ser efetuadas diversas conexões locais e a redefinição das interfaces dos blocos funcionais através dos quais essa conexão é feita. Vale lembrar que a nomenclatura das entradas e saídas geradas é feita de acordo com o nome da conexão ou com os nomes dos papéis da conexão.

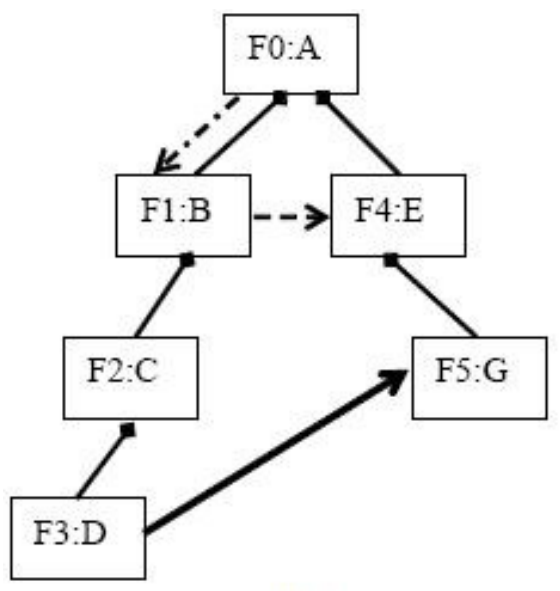

(a)

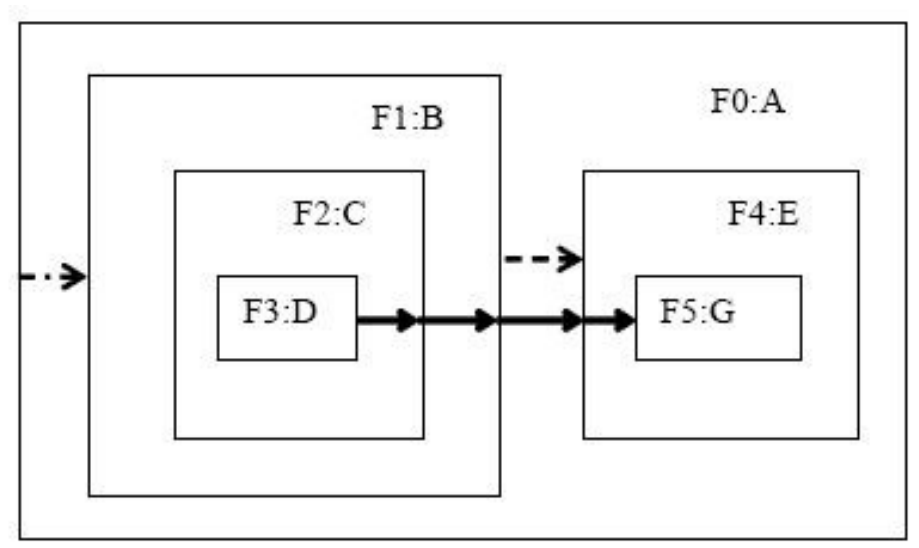

(b)

Figura 31: Exemplo de hierarquia de objetos (a) e a sua estrutura implícita de blocos funcionais aninhados (b) - retirado de Dubinin, Vyatkin e Pfeiffer (2005). Note-se que as conexões dadas por uma linha tracejada são conexões locais, e a conexão dada por uma linha contínua - em (a) - é uma conexão de trânsito (transformada, em (b), em quatro conexões locais).

\subsubsection{Mapeamento de Panjaitan e Frey}

Panjaitan e Frey $(2005,2006 \mathrm{a}, 2006 \mathrm{~b})$ propuseram um mapeamento de diagramas da UML em abstrações da norma IEC 61499, baseado em extensões à UML a partir do uso de estereótipos. 
Nesse mapeamento, apesar de todos os diagramas da UML servirem para a descrição de um sistema de automação, alguns deles são usados como dados de entrada para a transformação automática em abstrações da norma IEC 61499 por meio de uma ferramenta computacional (PANJAITAN; FREY, 2006a), enquanto outros servem apenas como simples artefatos de descrição (como os casos de uso, por exemplo).

\subsubsection{Diagramas da UML usados no mapeamento de Panjaitan e Frey}

Os Diagramas de Classes, de Componentes, de Estruturas Compostas, de Pacotes, de Distribuição (Deployment), de Atividades, de Máquinas de Estados, de Casos de Uso e de Interação da UML podem ser usados em tal mapeamento.

\subsection{Diagrama de Classes}

Os Diagramas de Classes são usados para definir os blocos funcionais, incluindo suas entradas e saídas de dados e eventos. Isso é feito através de estereótipos, como FBType (para as classes que designam tipos de blocos funcionais); input e output (para os atributos que representam entradas e saídas de dados); e event_input e event_output (para os métodos que representam entradas e saídas de eventos). Uma outra alternativa para indicar a configuração externa dos blocos funcionais é criar interfaces apropriadas para esses blocos funcionais, cujos métodos sejam designados pelo estereótipo signal. Se houver parâmetros nesses métodos (caso em que um evento de um bloco funcional estaria vinculado a um dado pelo qualificador WITH da norma IEC 61499), seu tipo deve ser determinado. Para que haja possibilidade de conexão entre dois blocos funcionais, suas interfaces devem ser compatíveis (complementares, quanto ao formato e tipo). Por fim, vale lembrar que as instâncias dos blocos funcionais são obtidas com a instanciação de suas classes correspondentes.

Por outro lado, os relacionamentos possíveis entre blocos funcionais são os de agregação e dependência. A agregação é utilizada para especificar quais tipos de blocos funcionais são compostos internamente por outros blocos funcionais. Já a dependência é usada para indicar o relacionamento entre dois blocos funcionais, seja entre seus eventos (com o estereótipo EventConnections), seja entre seus 
dados (com o estereótipo DataConnections). Essa interconexão leva à criação de redes de blocos funcionais.

\subsection{Diagrama de Componentes}

Ao invés de serem denotados por classes, os blocos funcionais também podem ser designados diretamente por componentes (quando são elementos físicos, intercambiáveis, que podem ser diretamente mapeados em nós). Neste caso, eles também podem implementar interfaces e estabelecer relações de dependência entre si, conforme descrito no item anterior. Usualmente, as interfaces fornecidas (implementadas) por um componente são colocadas na notação plugue, e as interfaces aceitas (usadas) são colocadas na notação soquete. A conexão entre os componentes permite a criação de redes de blocos funcionais.

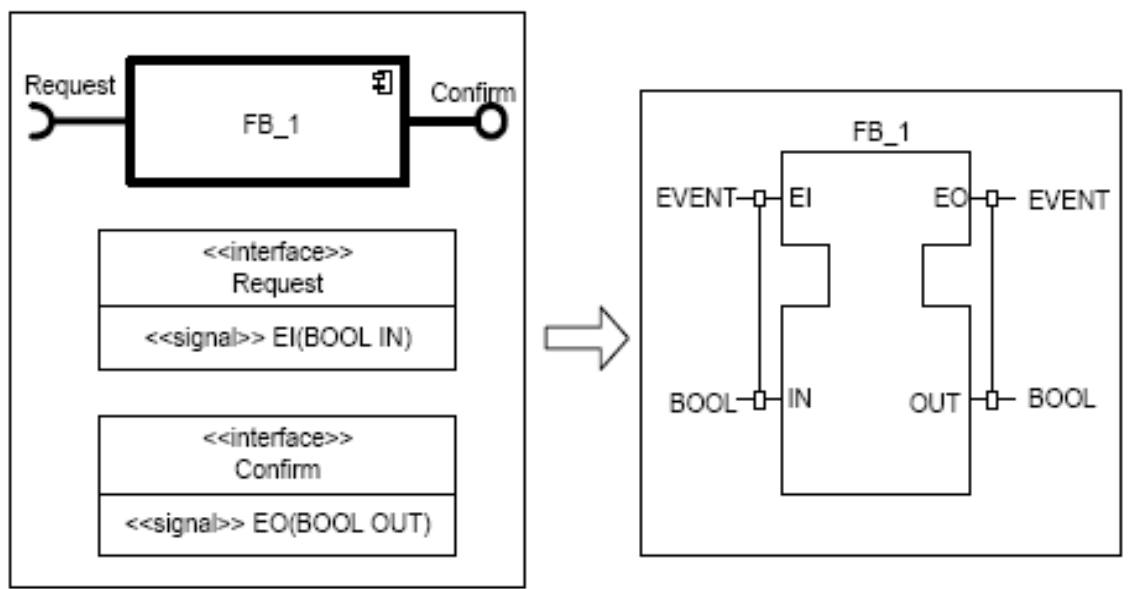

Figura 32: Diagrama de Componentes e sua transformação na interface externa de um bloco funcional segundo o mapeamento de Panjaitan e Frey - retirado de Panjaitan e Frey (2006a).

\subsection{Diagramas de Estruturas Compostas}

Apesar de não serem descritos explicitamente nas referências de Panjaitan e Frey, e sim mostrados em forma gráfica, relacionados a Diagramas de Componentes, os Diagramas de Estruturas Compostas podem ser usados para mostrar a composição interna de classes e componentes que representem blocos funcionais compostos, principalmente para a geração de redes de blocos funcionais, conforme pode ser visto na Figura 33. 


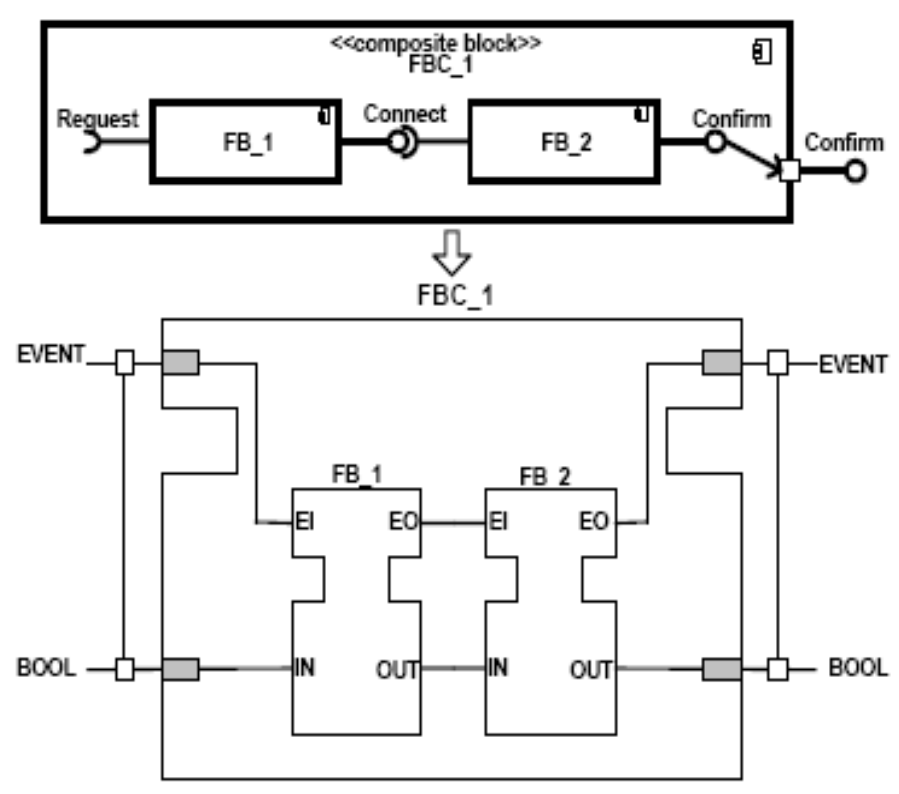

Figura 33: Diagrama de Estruturas Compostas e sua transformação na interface externa de um bloco funcional composto e na rede de blocos funcionais interna a ele, segundo o mapeamento de Panjaitan e Frey - retirado de Panjaitan e Frey (2006a).

\subsection{Diagrama de Pacotes}

Os Diagramas de Pacotes constituem uma das opções para mostrar quais blocos funcionais básicos e blocos funcionais de interface de serviços (classes ou componentes com estereótipos basic function block e service interface block) estão inseridos em blocos funcionais compostos (pacotes com estereótipo composite block) ou em recursos (pacotes com estereótipos resource), e também quais recursos estão inseridos em dispositivos (pacotes com estereótipos device), segundo o modelo da IEC 61499 desejado.

\subsection{Diagrama de Distribuição (Deployment)}

Os Diagramas de Distribuição (Deployment) da UML mostram, em uma visão de alto nível, as relações entre objetos, componentes e nós do sistema. No mapeamento UML-IEC61499, os blocos funcionais, descritos como classes ou componentes, podem ser vinculados a recursos (denotados como componentes, por exemplo), e estes, por sua vez, podem ser postos em seus correspondentes dispositivos (normalmente dados por nós). A interconexão dos dispositivos pode ser 
feita pela ligação entre suas interfaces, as quais são realizadas de fato através de blocos funcionais de interface de serviço (SIFB).

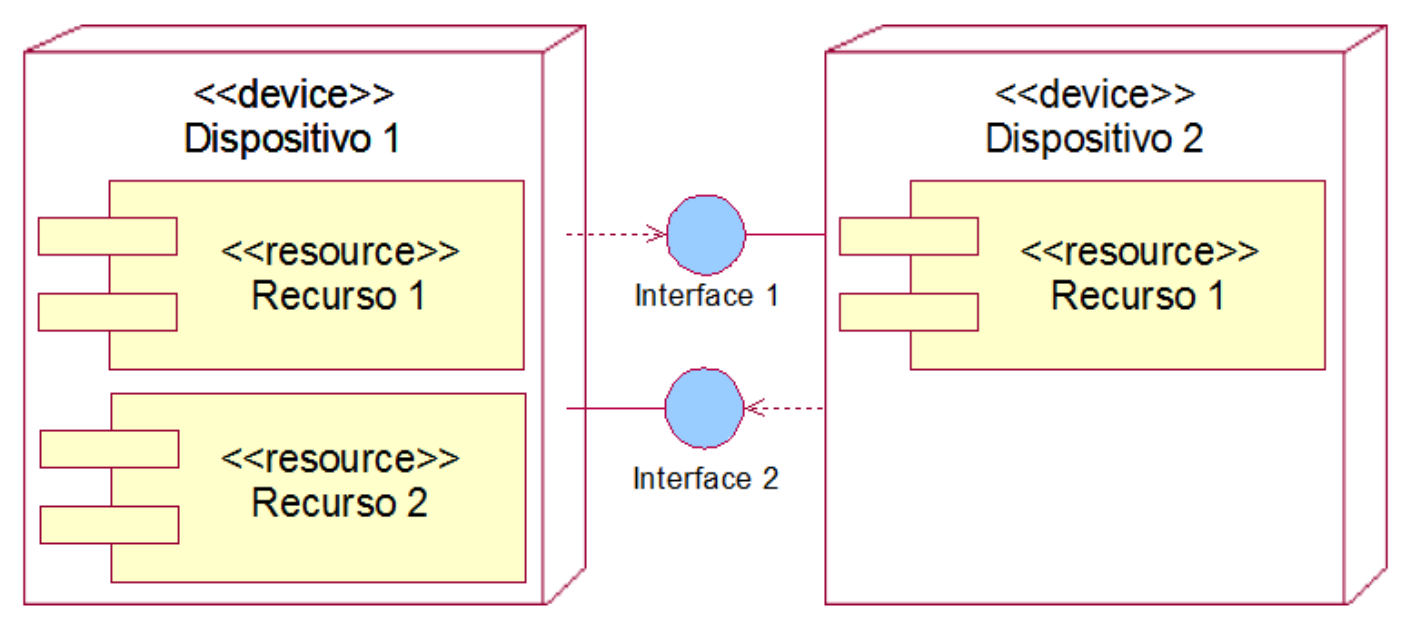

Figura 34: Diagrama de Distribuição elaborado segundo o mapeamento de Panjaitan e Frey.

\subsection{Diagrama de Atividades}

Os Diagramas de Atividades são utilizados para descrever, de forma gráfica, os algoritmos executados em um único bloco funcional ou mostrar o interrelacionamento entre as tarefas executadas por vários deles (independentemente de serem tarefas seqüenciais ou concorrentes). Como os Diagramas de Atividades são baseados na semântica da rede de Petri, eles podem ser futuramente usados para a modelagem e a verificação formal dos sistemas.

\subsection{Diagrama de Máquinas de Estados}

O comportamento de um bloco funcional básico, dado pelo diagrama de controle de execução (ECC) na norma IEC 61499, pode ser descrito em UML através do Diagrama de Máquinas de Estados. Para manter consistência com o ECC, os estados são indicados pelo estereótipo EC State, sendo sempre o estado inicial chamado START. As transições entre estados (EC Transition) representam os eventos, suas variáveis associadas, e as condições que provocam a passagem de um estado a outro (caso não haja nenhum destes, denota-se o fato com o símbolo "1", como na norma IEC 61499). Por fim, a ação executada em cada estado (dada pelo estereótipo EC Action) serve para designar o algoritmo que deve ser executado 
nesse estado e quais os eventos e dados de saída que devem ser atualizados quando do término da execução desse mesmo algoritmo.

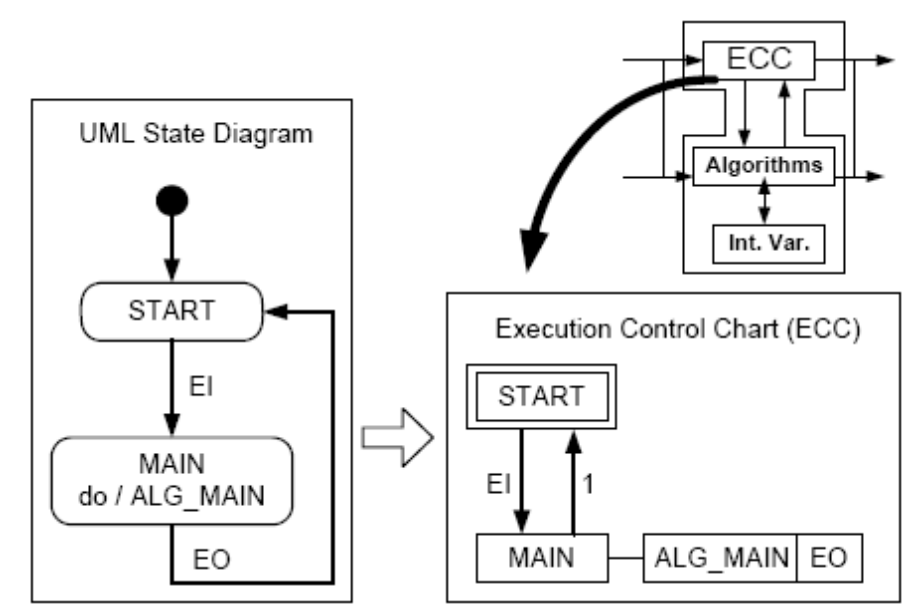

Figura 35: Diagrama de Máquinas de Estados segundo o mapeamento de Panjaitan e Frey - retirado de Panjaitan e Frey (2006a).

\subsection{Diagrama de Casos de Uso}

Os Diagramas de Casos de Uso, embora usados para descrever as principais funcionalidades oferecidas por um sistema (sem detalhes de implementação), assim como os cenários em que o mesmo está inserido, não encontram correspondência entre os modelos previstos pela norma IEC 61499. Portanto, apesar de serem usados para fornecer uma visão geral do sistema, tais diagramas não são usados no processo de transformação da UML para blocos funcionais.

\subsection{Diagrama de Interação}

Os Diagramas de Interação mostram o comportamento dinâmico entre objetos, representantes de blocos funcionais, por exemplo): enquanto os Diagramas de Seqüência são mais voltados para as descrições de temporização, os Diagramas de Colaboração/Comunicação têm maior vínculo com os papéis ou tarefas desempenhados por cada um dos objetos. Vale ressaltar que o nível de aprofundamento pode variar durante o processo de projeto: Panjaitan e Frey, nos artigos analisados, mostram o uso dos diagramas de seqüência, por exemplo, tanto 
para a simples captura de requisitos como para mostrar a ordem de ocorrência de eventos.

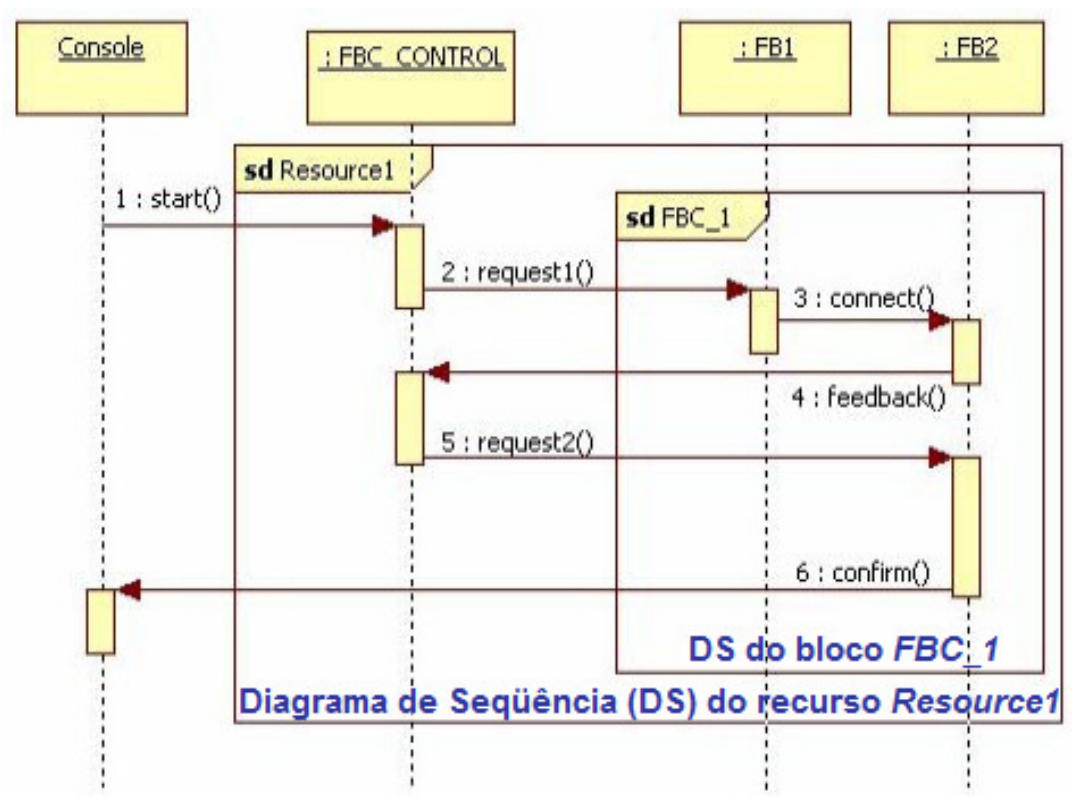

Figura 36: Diagrama de Seqüência segundo o mapeamento de Panjaitan e Frey - adaptado de Panjaitan e Frey (2006a).

\subsubsection{Processo de transformação da UML para blocos funcionais}

Por fim, uma vez que as descrições em UML tenham sido feitas com estereótipos dos tipos Data (dado), FBType (tipo de blocos funcionais), Adapter (adaptador), Subapplication (subaplicação), Resource (recurso), Device (dispositivo) e System (sistema), e que os mesmos sejam rastreáveis, pode-se passar tais modelos para descrições em eXtensible Markup Language (XML), segundo o que é disposto na Parte 2 da norma IEC 61499. Segundo Panjaitan e Frey (2006b), um exemplo de regra de tradução é dado a seguir. Essa conversão de modelos UML para modelos IEC 61499 pode ser implementada em uma ferramenta, tendo em vista um mapeamento automático UML-IEC61499. 


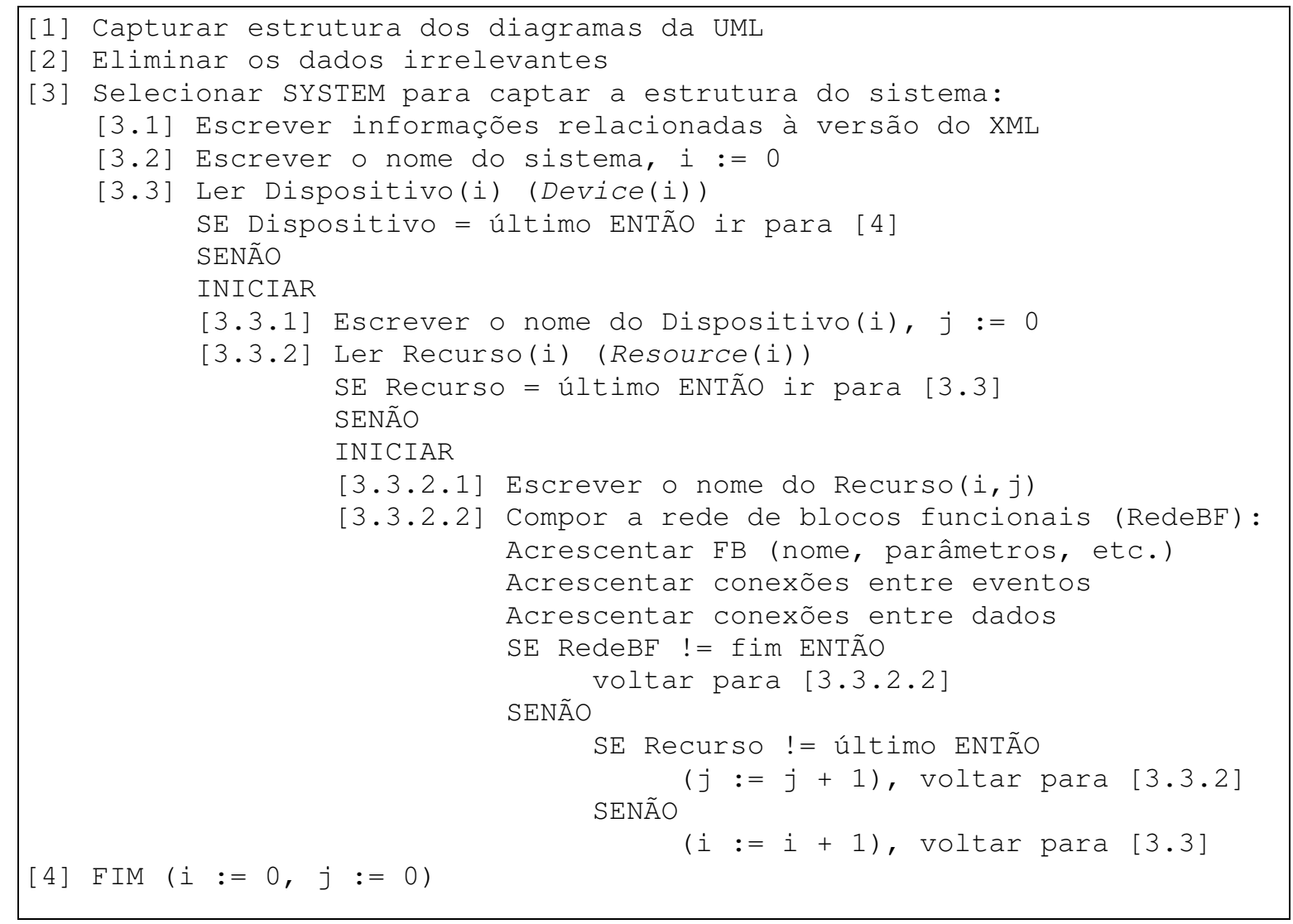

\subsubsection{Mapeamento de Zhang, Diedrich e Halang}

O paradigma $\mathrm{FB}^{\mathrm{UML}}$ proposto por Zhang, Diedrich e Halang (2005) prevê a extensão dos metamodelos da UML - ou seja, modelos em UML que definem essa mesma linguagem - através da definição de novos estereótipos, restrições e valores rotulados, agrupados em um perfil, os quais descrevem os principais conceitos relacionados à norma IEC 61499. Dessa maneira, a UML pode ser usada, junto aos diagramas de blocos funcionais e de configuração de dispositivos, para o projeto de um sistema de automação distribuído, sendo esses últimos responsáveis pela especificação arquitetural abstrata do sistema. A seguir, é detalhada a função de cada um dos diagramas da UML nesse mapeamento UML-IEC61499.

3.1.4.1. Diagramas da UML usados no mapeamento de Zhang, Diedrich e Halang

Os diagramas da UML usados nesse mapeamento são os Diagramas de Classes, de Estruturas Compostas, de Máquinas de Estado, de Atividades e de Interação. 


\subsubsection{Diagrama de Classes}

Os Diagramas de Classes representam os diferentes tipos de blocos funcionais e suas interfaces. Os blocos funcionais são representados por classes, que podem possuir os seguintes estereótipos: BasicFB (para blocos funcionais básicos), CompositeFB (para blocos funcionais compostos) e SIFB (para blocos funcionais de interface de serviços). A partir daí, as interfaces dos tipos de blocos funcionais são determinadas pelos elementos de sua classe representante: os eventos de entrada são métodos públicos de estereótipo EventInput; os eventos de saída são métodos privados de estereótipo EventOutput; os dados de entrada são atributos privados de estereótipo InputVariable; os dados de saída são atributos públicos de estereótipo OutputVariable; e as variáveis internas são atributos privados estereotipados como InternalVariable.

Para estabelecer uma associação entre eventos e dados, como ocorre na norma IEC 61499 ao se utilizar o qualificador WITH, emprega-se entre o evento e o dado um relacionamento de dependência de estereótipo AssociateWith. Já para estabelecer a relação entre um evento de entrada e seus dados e eventos de saída deve ser posto entre eles um relacionamento de dependência de estereótipo obsOutput (partindo do evento de entrada para as saídas), tanto no caso de blocos funcionais básicos como compostos.

Por fim, para a representação de redes de blocos funcionais (ou seja, de blocos funcionais compostos ou de subaplicações), são usadas classes com os estereótipos CompositeFB (para blocos funcionais compostos) ou Application e SubApplication (para aplicações e subaplicações), cujas interfaces externas são especificadas da mesma maneira descrita anteriormente. Tais classes são associadas às suas instâncias de blocos funcionais internas através de relacionamentos de agregação.

\subsection{Diagrama de Estruturas Compostas}

Uma alternativa para expressar os elementos internos de blocos funcionais compostos, aplicações ou subaplicações é fazer o Diagrama de Estrutura Composta da classe que representa o bloco funcional.

As conexões de eventos e dados entre os blocos funcionais (representados 
pelas partes da classe composta) podem ser especificadas como instâncias da metaclasse InformationFlow (fluxo de informação), sendo seus estereótipos, respectivamente, EventConnection ou DataConnection. Os estereótipos citados são definidos pela extensão das metaclasses Information/tem (item de informação) e Connector (conector). Como um InformationFlow pode transferir alguns Information/tem, eventos e dados (instâncias de Informationltem) são passados por uma mesma conexão de eventos e dados. Colaborações podem ser usadas para descrever mais detalhes das conexões entre as instâncias contidas em uma classe, e as conexões entre a classe composta e seus componentes pode ser especificada com o uso de instâncias de portas e conectores.

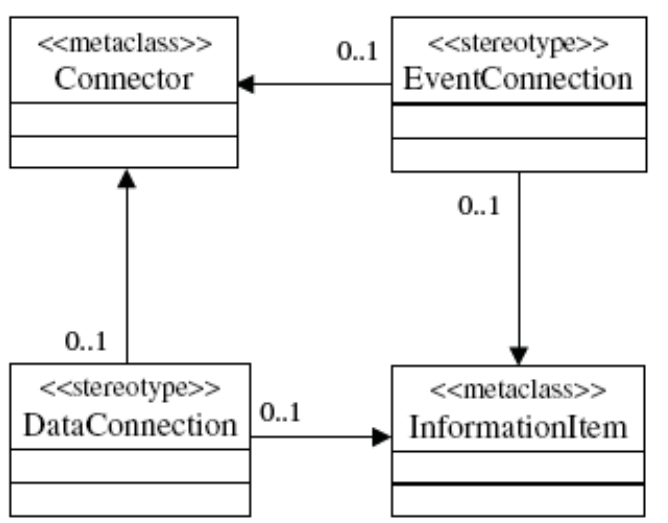

(a)

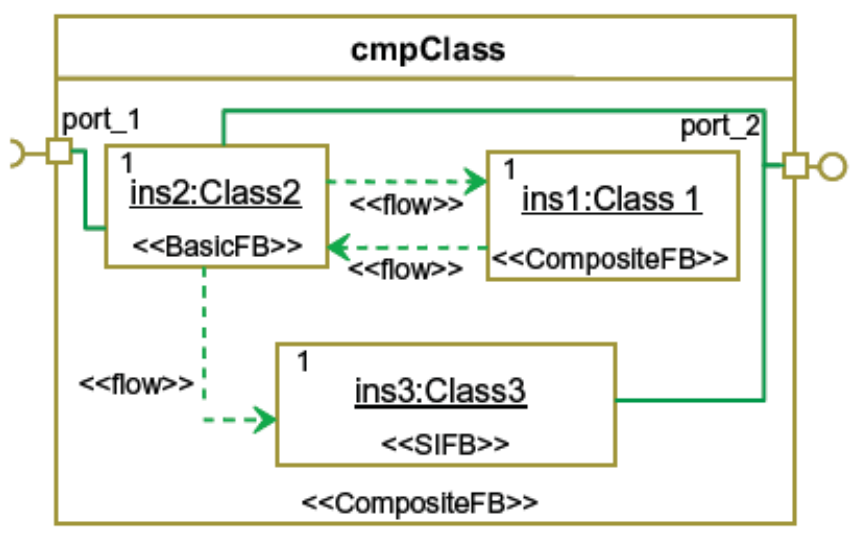

(b)

Figura 37: Relação entre os estereótipos DataConnection e EventConnection com as metaclasses Connector e Information/tem da UML (a), e exemplo de Diagrama de Estrutura Composta segundo o mapeamento de Zhang, Diedrich e Halang - retirado de Zhang, Diedrich e Halang (2005).

\subsection{Diagrama de Máquinas de Estados}

O Diagrama de Máquinas de Estados da UML é utilizado para a representação do diagrama de controle de execução de um bloco funcional, e, nesse caso, seu estereótipo denomina-se ECC. Os estados do ECC são marcados pelo estereótipo ECState, enquanto suas transições são de estereótipo ECTransition. Estas, por sua vez, podem ter apenas um evento como gatilho (não havendo guarda ou atividade na transição), ou podem ser disparadas por um evento e uma expressão booleana simultaneamente (caso em que a transição tem o evento por gatilho e a expressão por guarda). Por fim, vale lembrar que, para manter compatibilidade com a norma IEC 61499, o estereótipo ECC possui como restrições 
os fatos de que nem seus estados nem suas transições podem ser compostos, além de que seu estado inicial deve ser sempre denominado START.

\subsubsection{Diagrama de Atividades}

$\mathrm{O}(\mathrm{s})$ algoritmo(s) ligado(s) à(s) atividade(s) executada(s) na entrada a um estado do ECC pode(m) ser representado(s) na UML por um método privado. Assim, para cada um deles atribui-se o estereótipo Algorithm, que estende a metaclasse Operation e que possui visibilidade privada fixa. Por fim, como ocorre para qualquer método da UML, seu comportamento pode ser especificado através de um Diagrama de Atividades.

\subsection{Diagrama de Interação}

Os Diagramas de Interação da UML previstos para uso no mapeamento de Zhang, Diedrich e Halang são o Diagrama de Seqüência e o Diagrama de Colaboração/Comunicação.

Os Diagramas de Seqüência são responsáveis por indicar a interação entre as instâncias dos componentes de uma rede de blocos funcionais e suas conexões de eventos e dados, dando destaque à visão sobre os tempos de execução de tais interações. Os Diagramas de Colaboração/Comunicação, por sua vez, são empregados para mostrar a cooperação entre essas instâncias do ponto de vista estrutural. A conexão entre eventos (de entrada e saída) é descrita por uma mensagem (de estereótipo EventConnection), dirigida do objeto remetente ao objeto destinatário. Nesse contexto, os dados associados ao evento são passados como parâmetros das mensagens. Para não haver conflito na nomenclatura de tais mensagens, a seguinte regra é sugerida: "objeto_receptor evento_do_remetente evento_do_destinatário". Para os parâmetros, a regra aplicada deve ser: "objeto.variável" (sendo esse objeto o dono da variável declarada). Deve-se esclarecer que as mensagens das instâncias para a classe agregadora da rede de blocos funcionais são operações da classe (ou bloco funcional composto) que representam eventos de saída da mesma, enquanto aquelas que partem da classe para as instâncias identificam seus eventos de entrada. 


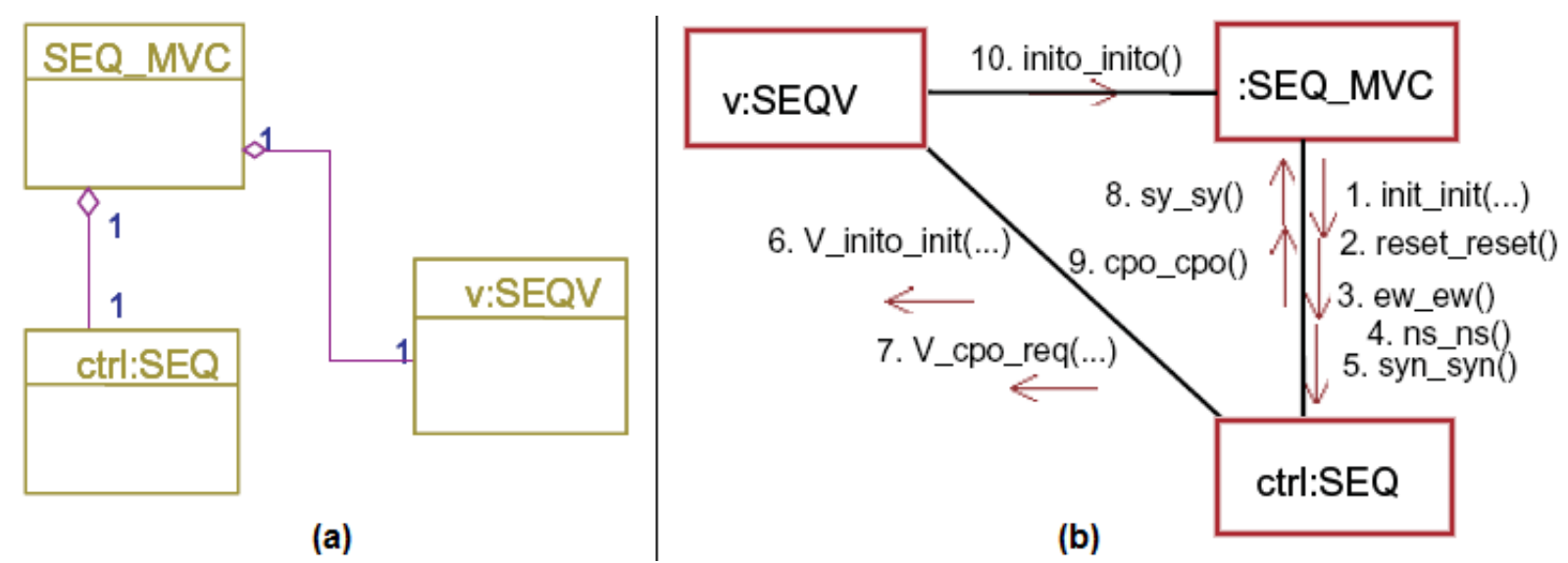

Figura 38: Diagrama mostrando a relação entre a classe SEQ_MVC (que representa um tipo de bloco funcional composto) e seus objetos internos ctrl:SEQ e v:SEQV (que cumprem o papel de instâncias de blocos funcionais) (a), e exemplo de Diagrama de Colaboração/Comunicação (entre uma instância anônima da classe SEQ_MVC e os dois objetos citados anteriormente) segundo o mapeamento de Zhang, Diedrich e Halang - retirado de Zhang, Diedrich e Halang (2005).

\subsubsection{Mapeamento de Heverhagen, Tracht e Hirschfeld}

A abordagem utilizada por Heverhagen, Tracht e Hirschfeld (2003) para o mapeamento entre diagramas da UML e diagramas de blocos funcionais é bastante diferente das anteriores. Neste caso, o objetivo é utilizar as extensões da UML - ou seja, estereótipos, restrições e valores rotulados, agrupados em um perfil (profile) denominado Adaptadores para Blocos Funcionais (ou Function Block Adapters FBA) - para permitir a descrição das interfaces externas de blocos funcionais (tanto da norma IEC 61499 como de outros padrões) e de um adaptador entre esses últimos e objetos da UML (também chamado FBA).

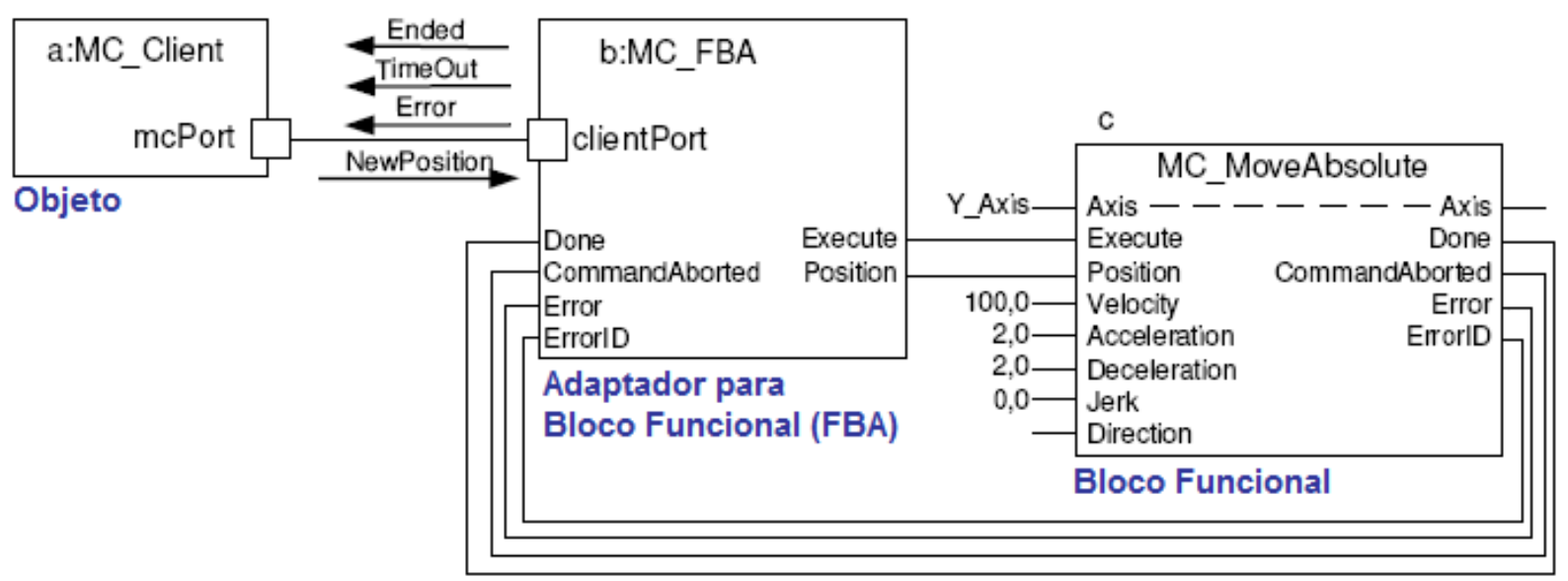

Figura 39: Conexão entre objeto, FBA e bloco funcional - adaptado de Heverhagen, Tracht e Hirschfeld (2003) 
Vale destacar, neste ponto, que o comportamento interno dos blocos funcionais não é mapeado em UML, mas mantido em sua linguagem original (orientada a blocos funcionais, como Matlab/Simulink e outras definidas pela norma IEC 61131-3).

Essa técnica tem como principal vantagem a integração entre componentes de software orientados a eventos (objetos) e componentes de software orientados a execução em tempo contínuo (blocos funcionais), obtendo-se, ao fim, a descrição de um sistema completamente orientado a eventos (em UML).

O perfil da UML denominado FBA conta com sete estereótipos:

- FunctionBlock - aplicado a Classes: uma classe de estereótipo FunctionBlock descreve um bloco funcional. Tal classe deve conter somente portas de estereótipo FBPort para comunicação;

- FBPort, FBInPort e FBOutPort - aplicados a Portas: designam portas, que representam os elementos para definição da estrutura externa dos blocos funcionais (entradas e saídas de eventos e de dados). FBInPort provê uma interface de estereótipo FBInterface, FBOutPort requer uma interface de estereótipo FBInterface e ambas herdam suas características de FBPort. Segundo os autores, as portas da UML são as melhores contrapartes para os componentes da interface externa de um bloco funcional, já que tais conceitos estão ligados à idéia de prover meios para exportação e importação de dados, além de ajudar a deixar encapsulado o comportamento interno de seus respectivos módulos;

- FBInterface - aplicado a Interfaces: é uma interface especial que possui apenas uma operação (ValueChanged), cujo parâmetro possui o valor de uma das variáveis de interface de um bloco funcional. $\mathrm{O}$ tipo do parâmetro deve pertencer ao conjunto permitido pela linguagem orientada a blocos funcionais a que o bloco funcional pertence, e esse tipo deve ser remodelado em UML como tipo de dado, tipo primitivo ou enumeração (datatype, primitivetype ou enumeration);

- FunctionBlockAdapter - aplicado a Classes: as classes de estereótipo FBA têm a função de interconectar classes da UML a blocos funcionais (representados por classes de estereótipo FunctionBlock). Para isso, os FBA possuem portas comuns (através das quais se comunicam com as classes da UML) e portas de estereótipo FBPort: por meio destas últimas, as 
interfaces das classes que designam blocos funcionais ligam-se às interfaces dos FBA. Para ser possível o mapeamento entre os protocolos da UML e dos blocos funcionais (ou seja, para que ambos consigam intercambiar variáveis e eventos), é definido um conjunto de traduções chamadas FBATranslations, que descrevem o funcionamento interno do FBA. Essas traduções são vinculadas a seus FBA através de um valor rotulado chamado translations (de estereótipo FBATranslation); e

- FBATranslation - aplicado a Classe: uma classe de estereótipo FBATranslation descreve o mapeamento entre os protocolos da UML e dos blocos funcionais. O estereótipo FBATranslation possui alguns valores rotulados:

- fba (tipo: FunctionBlockAdapter): indica a classe (FBA) a que essa tradução pertence (sendo esta uma e apenas uma);

- isOrthogonal (tipo: booleano): se estiver marcada como verdadeira, mostra que essa tradução é executada concorrentemente às demais de seu FBA;

- trigger (tipo: evento): designa um evento de sinal de uma porta ou mudança em uma variável de interface que dispara a execução de uma tradução;

- signals (tipo: sinal): abrange a listagem de todos os sinais da porta que devem ser acessados, recebidos ou enviados (inclusive o sinal de trigger, se for o caso);

- translationBody (tipo: string) e exceptionBody (tipo: string): dados na linguagem FBA, representam os programas de tradução entre os protocolos da UML e dos blocos funcionais. O software executado normalmente corresponde àquele contido no valor rotulado translationBody, enquanto que o exceptionBody só é executado em caso de erro no primeiro. Os programas citados anteriormente podem ser dados em Diagramas de Máquinas de Estados, já que a linguagem FBA é definida como um subconjunto da semântica desses diagramas; e

- fbProtocol (tipo: ProtocolStatechart): fornece um diagrama de estados que descreve todas as seqüências válidas de mudanças nas variáveis de interface acessadas pela tradução. 
Por fim, destaca-se que o mapeamento de Heverhagen, Tracht e Hirschfeld aplica-se de forma mais fácil a blocos funcionais da norma IEC 61499, já que os blocos funcionais definidos por ela são orientados a eventos por natureza.

\subsection{COMPARAÇÃO ENTRE MAPEAMENTOS UML-IEC61499 E COMENTÁRIOS}

Os mapeamentos UML-IEC61499 vistos anteriormente podem ser divididos em dois tipos: os quatro primeiros - o de Thramboulidis, o de Dubinin e Vyatkin, o de Panjaitan e Frey e o de Zhang, Diedrich e Halang - referem-se à passagem de modelos da UML para modelos da norma IEC 61499, conforme seria necessário para que as fases de levantamento de requisitos e análise de desenvolvimento de um sistema fossem realizadas em UML, e para que a tradução desses modelos (conforme descrevem os autores) levassem ao tratamento das demais fases de engenharia de um sistema diretamente em abstrações da norma IEC 61499. O mapeamento de Heverhagen, Tracht e Hirschfeld, no entanto, apesar de ser um tipo de mapeamento entre UML e qualquer tipo de bloco funcional (inclusive os da IEC $61499)$ - merecendo, por isso, ser citado neste trabalho - tem um outro propósito: compatibilizar módulos de software da orientação a objetos, dados em UML, com módulos de software orientados a linguagens de blocos funcionais. Sendo assim, centra-se agora o foco nos primeiros trabalhos, que serão analisados a seguir.

Conforme demonstrado pela Tabela 1, os principais diagramas da UML utilizados nos mapeamentos UML-IEC61499 citados previamente são o Diagrama de Classes, o Diagrama de Máquinas de Estado e os Diagramas de Seqüência e de Colaboração/Comunicação. Esse subconjunto de diagramas é muito representativo, não somente pelo fato de ser adotado por todos os autores estudados, mas também por expressar alguns dos pontos de vista mais importantes de um sistema de automação distribuído (em especial, de sua aplicação): estrutura - dado pelo Diagrama de Classes, que essencialmente mostra a composição de uma rede de blocos funcionais e o inter-relacionamento estático entre os blocos; comportamento de um módulo - dado pelo Diagrama de Máquinas de Estado, que descreve o 
diagrama de controle de execução (ECC) de um bloco funcional básico; e comportamento geral do sistema - exposto através dos Diagramas de Sequência e de Colaboração/Comunicação - usados para demonstrar a dinâmica do intercâmbio de eventos e dados entre blocos funcionais.

Por sua vez, a partir da Tabela 2 e da Tabela 3, que relacionam as abstrações da norma IEC 61499 a elementos e relacionamentos da UML, percebese a utilização intensiva de estereótipos para executar a extensão da linguagem UML (de forma a que ela cubra os conceitos da norma IEC 61499). Este fato, no entanto, parece ser um entrave se considerarmos que a utilização da UML seria prevista para engenheiros de sistemas e software que, embora pudessem ter conhecimentos gerais sobre sistemas de automação, não necessariamente estariam envolvidos com pesquisas sobre a norma IEC 61499: portanto, a extensão da UML para cobrir o vocabulário dessa norma poderia ser questionado.

Por outro lado, outras fortes tendências que podem ser observadas por meio dessas tabelas é a representação de tipos de blocos funcionais da IEC 61499 por meio de classes; instâncias de blocos funcionais através de objetos; conexões de eventos (associados a dados através do qualificador WITH) através de métodos ou mensagens (e seus parâmetros); entradas e saídas de dados por meio de atributos; e relacionamento entre blocos funcionais compostos e suas instâncias de blocos funcionais (componentes) através de relacionamentos de agregação.

De certa maneira, pode-se dizer que essas tendências estabelecem um conjunto mínimo de representações suficientes para exprimir a maioria dos conceitos sobre aplicações de sistemas de automação. Outros modelos da norma IEC 61499 (como os de dispositivos e recursos) foram representados apenas por alguns autores, e podem ser questionados, novamente, no sentido da necessidade de que os especificadores de requisitos e análise geral do sistema tenham de chegar a esse nível de abstração, se se pretende que equipes de engenharia de sistemas e software e de engenharia de controle e automação trabalhem cooperativamente: é possível que, na verdade, essa tarefa de refinamento do sistema caiba melhor a estes últimos que aos primeiros, já que eles detêm uma visão mais apurada sobre a implementação provável do sistema.

No capítulo seguinte, serão analisadas ferramentas de suporte ao desenvolvimento de projetos de sistemas de automação distribuídos, com foco naquelas que realizam conversões UML-IEC61499. 
Tabela 1: Identificação dos diagramas da UML utilizados para expressar os conceitos da norma IEC 61499 segundo os mapeamentos de Thramboulidis, de Dubinin e Vyatkin, de Panjaitan e Frey e de Zhang, Diedrich e Halang.

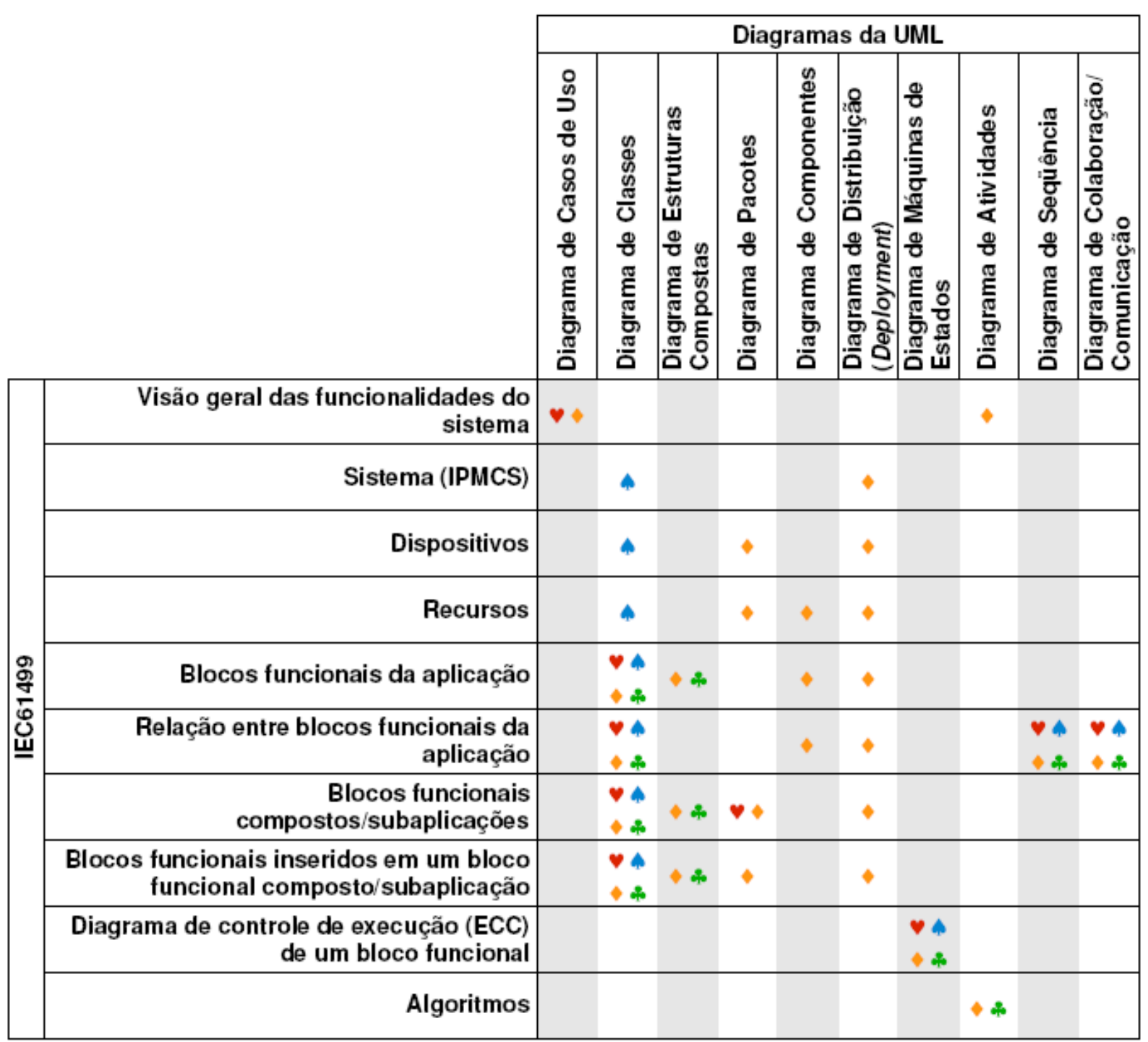

\section{Legenda:}

$\checkmark \quad$ Mapeamento de Thramboulidis

4 Mapeamento de Dubinin e Vyatkin

- Mapeamento de Panjaitan e Frey

* Mapeamento de Zhang, Diedrich e Halang 
Tabela 2: Identificação dos principais elementos da UML utilizados para expressar os conceitos da norma IEC 61499 segundo os mapeamentos de Thramboulidis, de Dubinin e Vyatkin, de Panjaitan e Frey e de Zhang, Diedrich e Halang.

\begin{tabular}{|c|c|c|c|c|c|c|c|c|c|c|c|}
\hline & \multicolumn{9}{|c|}{ Elementos da UML } \\
\hline & & & $\begin{array}{l}\stackrel{ }{\circ} \\
\circ \\
\frac{0}{9} \\
\frac{1}{0}\end{array}$ & $\begin{array}{l}\frac{9}{0} \\
\frac{0}{2}\end{array}$ & 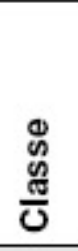 & 올 & 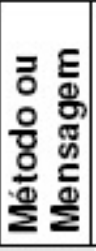 & 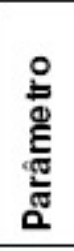 & 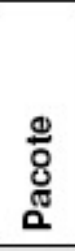 & 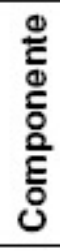 & 을 \\
\hline \multirow{15}{*}{ 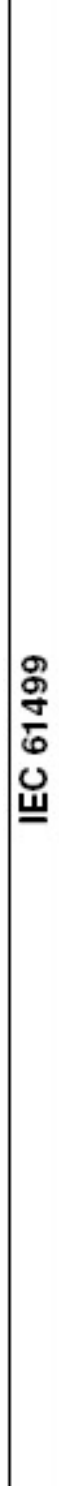 } & \multirow{8}{*}{ 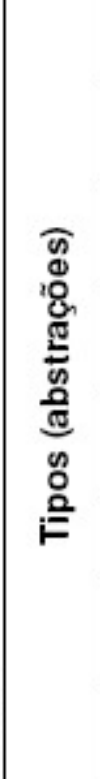 } & Sistema (IPMCS) & $\leftrightarrow$ & & $\uparrow$ & & & & & & \\
\hline & & Dispositivo & $\uparrow$ & & $\uparrow$ & & & & $\bullet$ & & $\bullet$ \\
\hline & & Recurso & $\leftrightarrow$ & & $\uparrow$ & & & & $\downarrow$ & $\bullet$ & \\
\hline & & $\begin{array}{l}\text { Aplicação (diagrama/rede } \\
\text { de blocos funcionais) }\end{array}$ & 44 & & $A 4$ & & & & & & \\
\hline & & $\begin{array}{r}\text { Bloco funcional } \\
\text { composto/subaplicação }\end{array}$ & 4 & & $4+$ & & & & $\bullet$ & & \\
\hline & & Bloco funcional básico & $\checkmark 4$ & & $\checkmark 4$ & & & & & $\bullet$ & \\
\hline & & $\begin{array}{l}\text { Bloco funcional de } \\
\text { interface de servico }\end{array}$ & $\checkmark 4$ & & 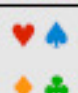 & & & & & & \\
\hline & & Adaptador & 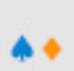 & & 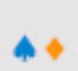 & & & & & & \\
\hline & \multirow{4}{*}{ 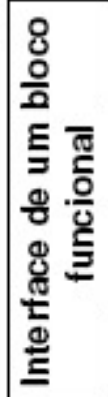 } & Entrada/Saída de eventos & $\$$ & & & & $\checkmark 4$ & & & & \\
\hline & & Entrada/Saída de dados & $\div$ & & & $\rightarrow 4$ & & $\nabla *$ & & & \\
\hline & & Qualificador WITH & 4 & & & & & 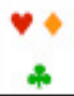 & & & \\
\hline & & Variável interna & $*$ & & & $\bullet *$ & & & & & \\
\hline & \multirow{3}{*}{ 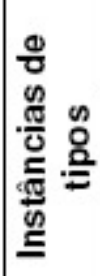 } & Bloco funcional & & $\forall 4$ & & & & & & & \\
\hline & & Dispositivo & $\uparrow$ & & 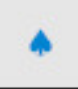 & & & & & & \\
\hline & & Recurso & $\uparrow$ & & 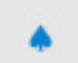 & & & & & & \\
\hline
\end{tabular}

Legenda:

v Mapeamento de Thramboulidis

- Mapeamento de Dubinin e Vyatkin

- Mapeamento de Panjaitan e Frey

* Mapeamento de Zhang, Diedrich e Halang 
Tabela 3: Identificação dos principais relacionamentos da UML utilizados para expressar os conceitos da norma IEC 61499 segundo os mapeamentos de Thramboulidis, de Dubinin e Vyatkin, de Panjaitan e Frey e de Zhang, Diedrich e Halang.

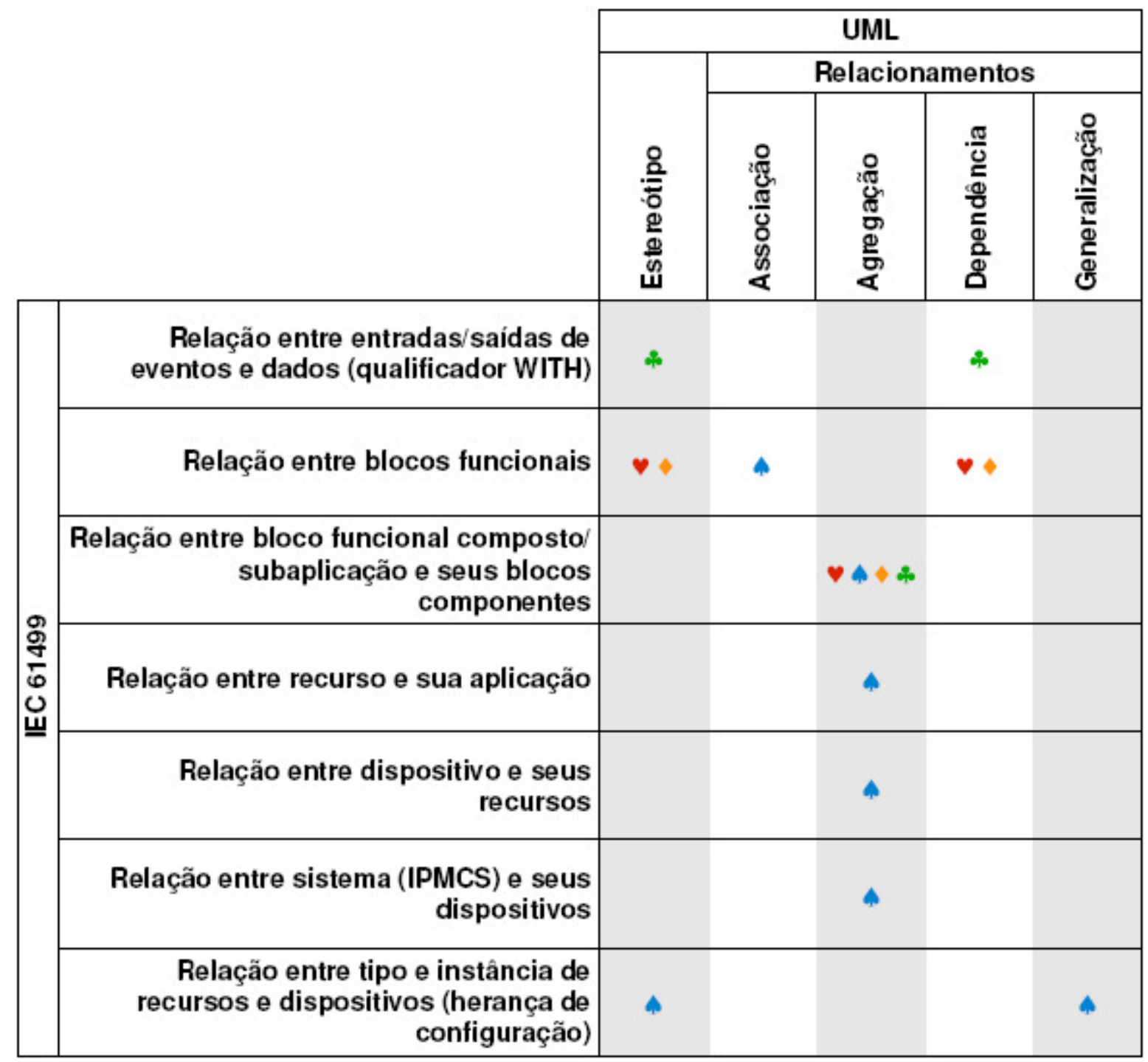

Legenda:

v Mapeamento de Thramboulidis

- Mapeamento de Dubinin e Vyatkin

- Mapeamento de Panjaitan e Frey

* Mapeamento de Zhang, Diedrich e Halang 


\title{
4. FERRAMENTAS COMPUTACIONAIS PARA SUPORTE ÀS ATIVIDADES DE ENGENHARIA VOLTADAS AO DESENVOLVIMENTO DE SISTEMAS DE AUTOMAÇÃO DISTRIBUÍDOS
}

\begin{abstract}
Mostram-se neste capítulo algumas das principais ferramentas computacionais para suporte às atividades de engenharia voltadas ao desenvolvimento de sistemas de automação distribuídos e que utilizam as abstrações da norma International Electrotechnical Commission (IEC) 61499 como modelos para o projeto de tais sistemas. A ênfase, no entanto, foi dada àquelas que implementam métodos de mapeamento UML-IEC61499, já que estas permitem a cobertura das fases de levantamento de requisitos e análise do projeto por meio de modelos da Unified Modeling Language (UML).
\end{abstract}

\subsection{APRESENTAÇÃO GERAL DAS FERRAMENTAS}

As ferramentas a serem apresentadas neste capítulo, por ordem de aprofundamento em sua análise, são citadas a seguir:

- CORFU ESS: Common Object-oriented Real-time Framework for the Unified development of distributed Industrial-Process Measurement and Control Systems (IPMCS) applications (CORFU) Engineering Support System (ESS) - versão 1.0.0 - Software Engineering Group, Electrical \& Computer Engineering, University of Patras;

- Conversores UML-FB: Converter from UML to IEC 61499 function blocks versão 1.0.1 e Converter from IEC 61499 function blocks to UML - versão 1.5 - University of Penza;

- FBench: IEC 61499 FBench - versão 0.5 (build 20070610) - Intelligent Mechatronics and Automation Group, Department of Electrical and Computer Engineering, The University of Auckland;

- FBDK: Function Block Development Kit (FBDK) - versão 20061017 Holobloc, Inc.; 
- 4DIAC-IDE: Framework for Distributed Industrial Automation and ControlIntegrated Development Environment (4DIAC-IDE) - versão 0.0.2 (build 2007-09-27) - 4DIAC Consortium;

- ISaGRAF: ISaGRAF - versão 5.0 - ICS Triplex;

- Fuber: FUnction Block Execution Runtime (Fuber); e

- Archimedes ESS: Archimedes ESS - versão 0.8 - Software Engineering Group, Electrical \& Computer Engineering, University of Patras.

\subsubsection{CORFU ESS}

O CORFU ESS (SOFTWARE ENGINEERING GROUP, 2006), ferramenta criada para automatizar o processo de desenvolvimento segundo o ciclo de vida de desenvolvimento CORFU para sistemas distribuídos de controle e monitoração de processos industriais (Industrial-Process Measurement and Control Systems IPMCS), está construído segundo a arquitetura chamada enhanced four Layer CORFU Architecture (enhanced-4LCA), e leva em consideração as recomendações da norma IEC 61499 quanto às ferramentas computacionais para auxílio a projetos de engenharia.

Segundo Thramboulidis (2003), a arquitetura enhanced-4LCA possui quarto camadas (ordenadas, a seguir, do nível mais baixo ao mais alto):

- Camada de processo industrial: abrange as representações de software dos componentes do mundo real (artefatos de implementação), que fazem parte dos diagramas de projeto das plantas de automação;

- Camada de sistema: fornece uma visão de engenharia do sistema de automação distribuído, ao mostrar as abstrações de software dos recursos computacionais que permitem a implementação da camada superior da arquitetura (camada de aplicação) - elementos físicos tais como dispositivos de campo e redes de comunicação, por exemplo, que fazem interface entre as aplicações e os dispositivos do mundo real;

- Camada de aplicação: conta com as representações necessárias à análise, projeto e implementação dos sistemas (como aqueles dados nos Diagramas de Casos de Uso, de Interação, de Contexto e de Classes (da UML), e nos diagramas de blocos funcionais (da norma IEC 61499)); e

- Camada de interface homem-máquina: reúne todas as abstrações para o 
desenvolvimento e operação de interfaces homem-máquina.

Por sua vez, conforme descrito por Tranoris e Thramboulidis (2002, 2003a), o ciclo de vida de desenvolvimento CORFU é iterativo e incremental, e procura expandir o processo de desenvolvimento definido pela norma IEC 61499, acrescentando a este algumas técnicas de desenvolvimento baseadas em componentes, orientação a objetos e modelagem em UML. As principais atividades desse ciclo de vida são:

- Captura de requisitos: definição dos casos de uso do sistema (segundo a definição de Ivar Jacobson), descritos através do Diagrama de Casos de Uso da UML;

- Captura do comportamento do sistema: levantamento do comportamento dinâmico do sistema por meio dos Diagramas de Colaboração e Seqüência da UML;

- Captura da visão estática do sistema: definição da estrutura do sistema, com o uso do Diagrama de Classes da UML;

- Projeto dos diagramas de blocos funcionais: obtenção dos diagramas de blocos funcionais da norma IEC 61499 a partir dos diagramas UML, usados na avaliação e refinamento do sistema, verificação de modelos e distribuição de blocos funcionais em dispositivos físicos.

Até o momento, o CORFU ESS implementa diversos editores das abstrações da camada de aplicação e um editor da camada de sistema da arquitetura enhanced-4LCA. Para isso, o CORFU ESS pode ser dividido, do ponto de vista estrutural, em dois subsistemas (TRANORIS; THRAMBOULIDIS, 2003b):

- Uma ferramenta arbitrária para auxílio à engenharia de software (papel cumprido até o momento pelo IBM Rational Rose), que cobre a captura de requisitos, de comportamento e de visão estática do sistema descritos pelo processo CORFU, segundo os conceitos da UML (abstrações pertencentes à camada de aplicação da arquitetura enhanced-LCA); e

- A ferramenta CORFU-FBDK, usada durante a atividade de projeto de diagramas de blocos funcionais do processo CORFU. O CORFU-FBDK pode ser subdividido em três editores e uma ferramenta auxiliar:

- Editor de Tipos de Blocos Funcionais (Function Block Type Editor): usado para criar novos tipo ou modificar tipos de blocos funcionais préexistentes na biblioteca do CORFU (vinculado às abstrações da camada 
de aplicação da arquitetura enhanced-4LCA);

- Editor de Diagramas de Blocos Funcionais (Function Block Diagram Editor): usado para a construção ou refinamento dos diagramas de blocos funcionais (e também vinculado às abstrações da camada de aplicação da arquitetura enhanced-4LCA)

- Gerenciador do Recurso de Transformação (Transformation Facility Manager (TFM)): automatiza a transposição dos diagramas UML para os diagramas de rede de blocos funcionais, segundo as normas UMLIEC61499 dispostas pelo mapeamento de Thamboulidis, conforme visto no Capítulo 3); e

- Editor da Camada de Sistema (System Layer Editor): utilizado para a distribuição da aplicação de controle nos elementos de software que representam os recursos computacionais do sistema (sendo um editor, portanto, de abstrações referentes à camada de sistema da arquitetura enhanced-4LCA).

A seguir, cada uma dessas partes será analisada separadamente.

\subsubsection{Subferramentas do CORFU ESS}

\subsection{Editor de Tipos de Blocos Funcionais (Function Block Type Editor)}

Segundo Tranoris (2003), o editor de tipos de blocos funcionais é utilizado principalmente para modificar tipos de blocos funcionais já existentes e para a criação de novos tipos de blocos funcionais (tanto básicos quanto compostos, a partir dos modelos básicos ou de outros blocos funcionais pré-existentes).

Ao se editar ou criar um tipo de bloco funcional básico, as principais informações exibidas são:

- Descrição geral do bloco funcional: expõe propriedades como o nome e a versão do bloco; mostra e permite a modificação das entradas e saídas de dados e eventos do bloco funcional (inclusive a determinação de tipos, a vinculação de dados e eventos pelo qualificador WITH e a criação de soquetes, plugues e variáveis internas); e exibe a representação gráfica do bloco funcional;

- Especificação do bloco funcional em eXtensible Markup Language (XML): 
mostra a estrutura do bloco funcional em XML, segundo a norma IEC 61499;

- Especificação do diagrama de controle de execução do bloco funcional (Execution Control Chart - ECC): permite o projeto do ECC de um bloco funcional, contando com:

- Criação de estados e indicação do estado inicial (chamado sempre START, de acordo com a norma IEC 61499) por uma linha de contorno dupla;

- Atribuição de um algoritmo e de um evento de saída (para indicação do término do processamento do algoritmo) a um estado, caso desejado; e

- Interligação dos estados através de transições simples ou complexas ou seja, com ou sem evento de gatilho (responsável pelo disparo da transição), condição de guarda (expressão booleana que, se verdadeira, habilita uma transição que tenha recebido seu evento) e ação (processamento atômico causado pela transição);

- Estrutura navegável, em árvore, das informações contidas no XML do bloco funcional;

- Detalhamento dos algoritmos citados no ECC: inclui o nome, a descrição e o funcionamento de cada algoritmo (que pode ser dado em texto estruturado, diagramas escada (ladder diagrams) ou em qualquer outra linguagem de alto nível, e pode manipular as variáveis internas e as variáveis de interface do bloco funcional); e

- Especificação das seqüências de serviço de um bloco funcional, caso ele seja um bloco funcional de interface de serviço (Service Interface Function Block - SIFB): exibe as transações entre as duas entidades participantes dessas seqüências, com o nome dos eventos e os parâmetros intercambiados entre elas.

No caso da edição ou criação de um bloco funcional composto, as informações disponíveis são praticamente as mesmas descritas para um bloco funcional básico, exceto a edição do ECC (que não se aplica, e é substituída pela determinação de um diagrama de blocos funcionais interno ao bloco funcional composto). 


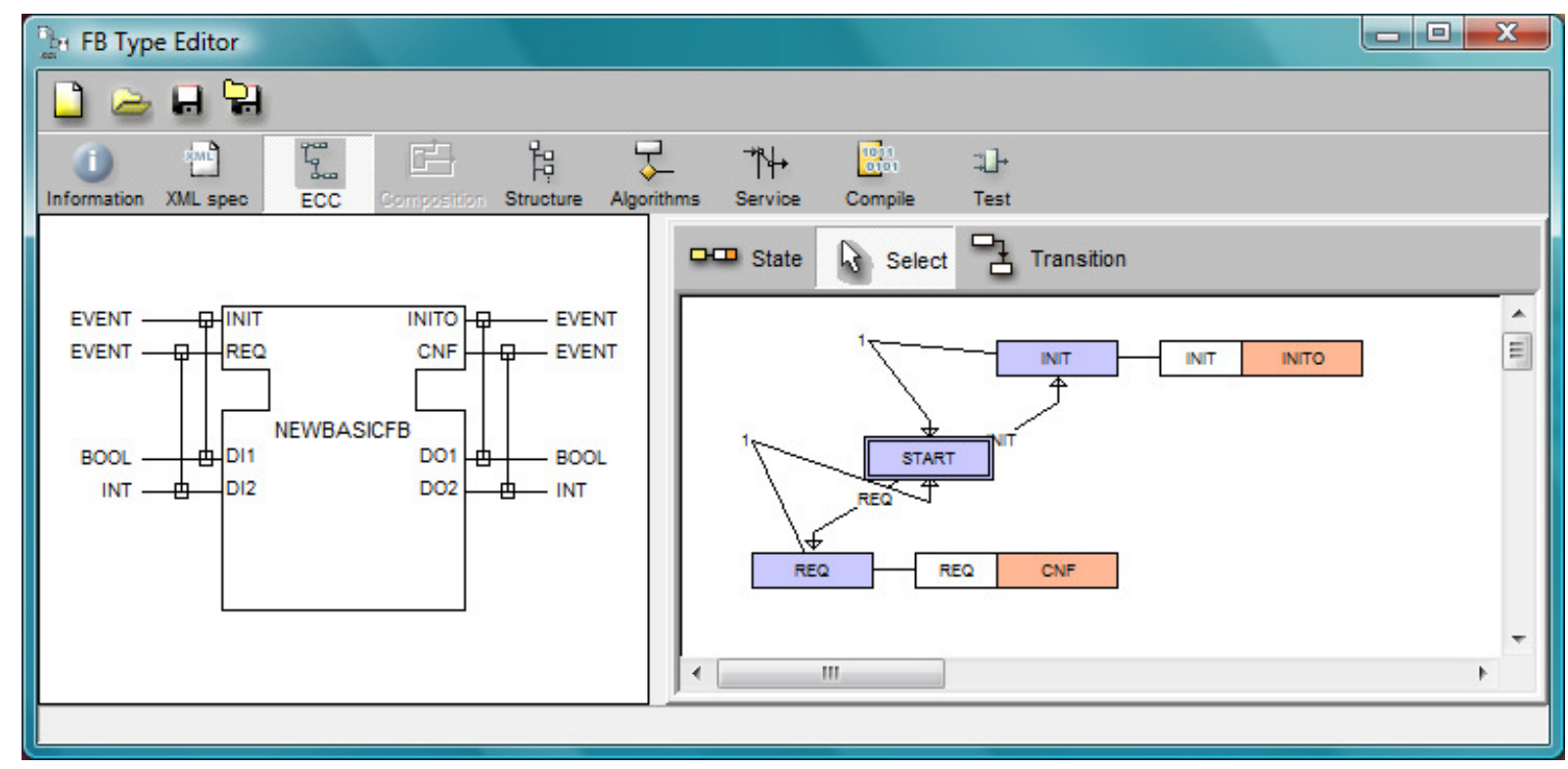

Figura 40: Editor de Tipos de Blocos Funcionais (Function Block Type Editor) da ferramenta CORFU ESS - neste caso, exibindo a interface externa e o diagrama de controle de execução (ECC) de um bloco funcional.

\subsection{Editor de Diagramas de Blocos Funcionais (Function Block Diagram} Editor)

Conforme descrito em Tranoris (2003), o editor de diagramas de blocos funcionais permite a criação ou a edição de um diagrama de blocos funcionais da norma IEC 61499.

As principais funcionalidades oferecidas por essa ferramenta são:

- Adicionar instâncias de blocos funcionais (básicos ou compostos) a um diagrama, a partir dos tipos disponíveis na biblioteca de blocos funcionais do CORFU ESS (que também pode incluir tipos especificados pelo usuário, além dos pré-existentes);

- Inserir blocos funcionais de eventos (Event Function Blocks) a um diagrama, os quais podem ser exibidos através da notação tradicional ou de forma simplificada;

- Editar características dos blocos funcionais pertencentes a um diagrama (como seus nomes, tipos, descrições e os valores iniciais das variáveis de dados de entrada), recarregar a definição do bloco funcional ou chamar o editor de blocos funcionais;

- Adicionar um Industrial Process Parameter (IPP) pré-existente ao diagrama 
de blocos funcionais - ou seja, uma variável de entrada ou de saída de um Industrial Process Terminator (IPT) dado no diagrama de camada de sistema, o qual representa uma entidade existente na planta;

- Mostrar ou permitir a interconexão entre as instâncias de blocos funcionais e entre IPP da rede de blocos funcionais;

- Exibir de maneira gráfica os tipos de dados das variáveis de interface de um bloco funcional (recurso ativado opcionalmente para facilitar a interligação dos blocos);

- Mostrar a relação de determinadas conexões do diagrama visualizado com outros diagramas de blocos funcionais (referências cruzadas);

- Modificar as propriedades de visualização do gráfico (como o zoom), adicionar notas e comandar a impressão do diagrama de blocos funcionais;

- Unificar um diagrama de blocos funcionais a outros diagramas (merge); e

- Testar (executar) o diagrama de blocos funcionais, que abrange:

- Selecionar os eventos a disparar a execução, os valores iniciais dos dados e as variáveis de entrada e saída a serem monitoradas; e

- Observar as conexões ativas do diagrama de blocos funcionais (que indicam visualmente o momento da transmissão de eventos e dados entre blocos funcionais), a seqüência temporal de eventos e a ordem cronológica da chamada aos blocos funcionais do diagrama de acordo com a execução da rede (que pode ser feita por passos ou continuamente);

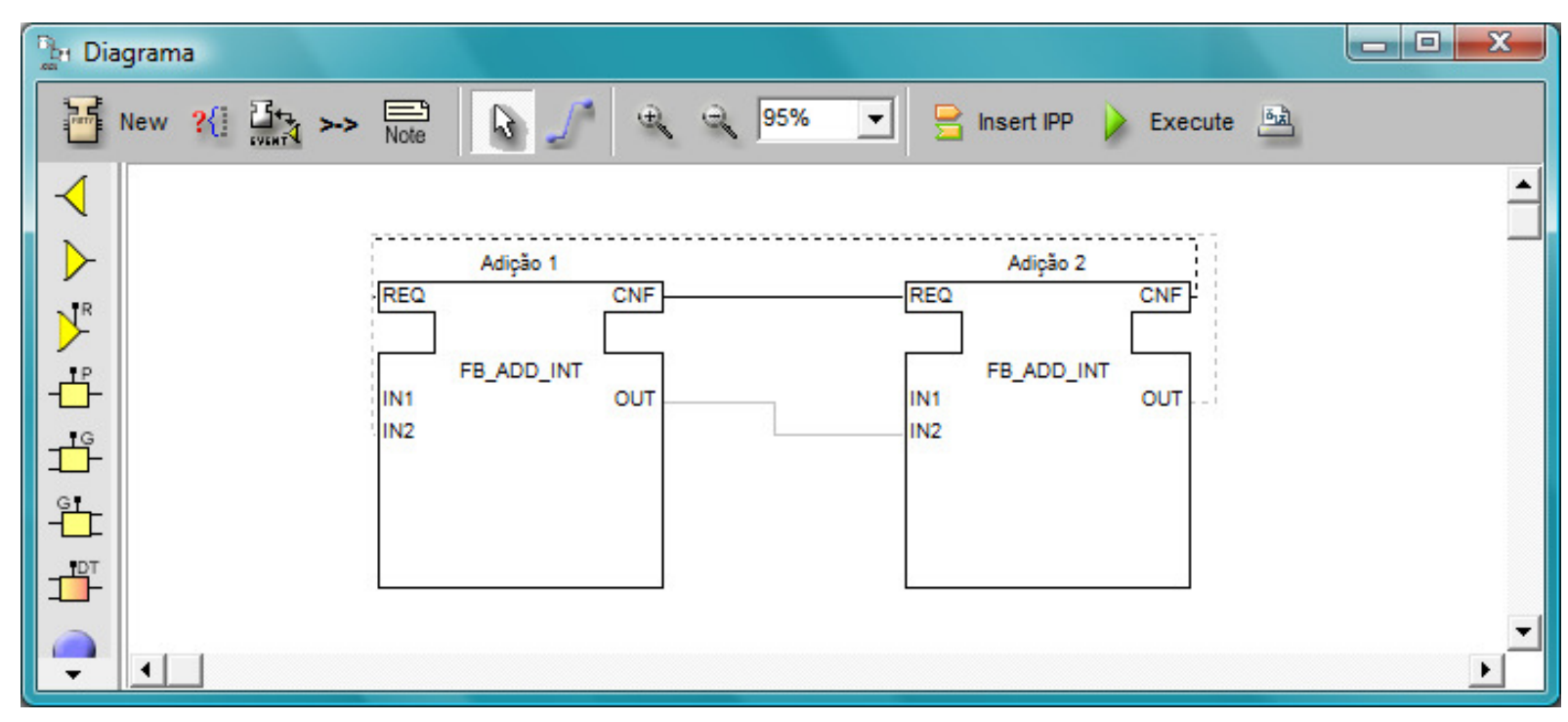

Figura 41: Rede de blocos funcionais descrita no Editor de Diagramas de Blocos Funcionais (Function Block Diagram Editor) da ferramenta CORFU ESS. 


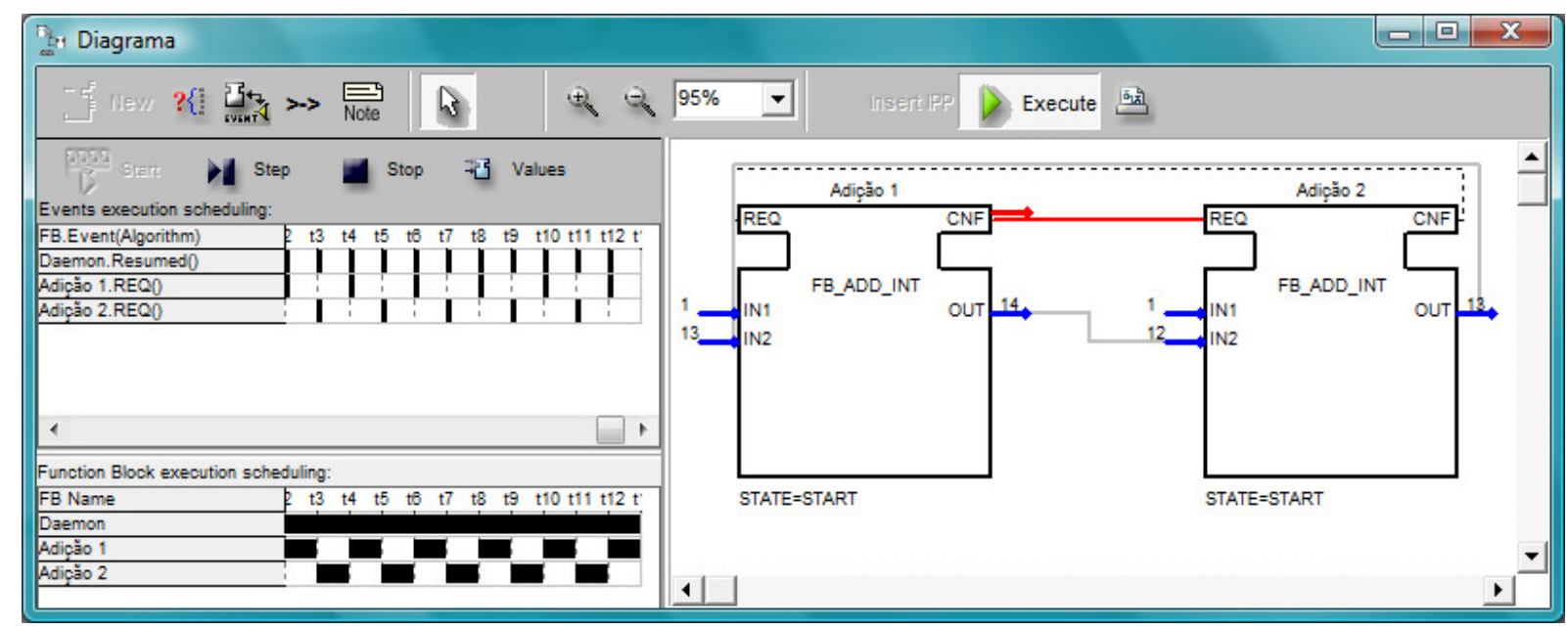

Figura 42: Execução da rede de blocos funcionais através do Editor de Diagramas de Blocos Funcionais (Function Block Diagram Editor) da ferramenta CORFU ESS.

\subsubsection{Editor da Camada de Sistema (System Layer Editor)}

O editor da camada de sistema permite realizar, segundo Tranoris (2003), um primeiro desenho da estrutura física para a qual o sistema de automação é projetado, incluindo os dispositivos da planta e a sua interconexão por meio de redes. A cada dispositivo podem ser designados IPT (as abstrações para representar os elementos físicos do sistema, que agem como fonte ou receptores de dados e interagem com o mundo real), aos quais, por sua vez, podem ser atribuídos os blocos funcionais da aplicação (configurando o processo de distribuição dos módulos).

Em um diagrama da camada de sistema, podem ser postos:

- Redes compatíveis com a norma IEC 61499 - às quais são dados um nome, um tipo (como LonWorks, por exemplo) e uma descrição, e para as quais se determina os dispositivos ligados a elas (e se é possível colocar nessas redes dispositivos não aderentes à IEC 61499);

- Redes não compatíveis com a norma IEC 61499, contando com os mesmos dados básicos descritos acima (exceto a especificação de possibilidade de suporte a dispositivos não aderentes à IEC 61499, já que isso é implícito);

- Dispositivos aderentes à norma IEC 61499, aos quais se pode especificar o nome, a descrição e as propriedades do dispositivo (como nome e descrição do fabricante, quais entradas e saídas estão disponíveis - inclusive citando seus tipos e descrições e quais os blocos funcionais da aplicação atribuídos 
a esses dispositivos). Também é possível estabelecer comunicação via TCP/IP com o dispositivo, caso o mesmo seja compatível com redes Ethernet, e desenhar o diagrama de blocos funcionais de interface de processo (Process Interface Function Block Diagram), cuja função é determinar como as entradas e saídas de um dispositivo (IPP) poderiam ser transformadas em nível lógico, com o uso de blocos funcionais para tratamento dos sinais, de forma que as aplicações ficassem independentes do encapsulamento físico do dispositivo (por exemplo, transformação de uma variável dada pelo valor booleano atribuído a quatro portas de entrada (zero para ausência de tensão, e um para presença de tensão) em um valor em representação decimal (ou seja, passagem de "0000" a "1111" das portas para 0 a 15, dado por uma única variável de tipo inteiro, por exemplo);

- Dispositivos aderentes ao padrão Object-Linking and Embedding (OLE) for Process Control (OPC), para os quais são especificados nome, descrição, tipo (OPC Data Access 1.0, 2.0 ou 3.0), dados do fornecedor, diagrama de blocos funcionais de interface de processo, qual o servidor OPC, como mapear IPP em itens OPC e e quais blocos funcionais da aplicação foram carregados nesse dispositivo;

- Dispositivos genéricos, para os quais se determina o nome, a descrição, as propriedades do dispositivo, os dados do fabricante e as entradas e saídas disponíveis (inclusive com tipos e descrições de uso);

- IPT, sejam pré-definidos ou personalizados, para os quais se pode escolher um ícone que os represente, um tipo (como esteira ou interface homemmáquina, dentre uma lista fixa de opções) e os IPP correspondentes (cada qual com nome, tipo, descrição, especificação se se trata de um IPP de evento ou de dado, e se ele é de entrada (sensor) ou saída (atuador)); e

- Outros elementos de sistema (como computador, "nuvem" de rede e unidades de intercomunicação), meramente ilustrativos.

Após o projeto do sistema físico, atribuição dos IPT e distribuição dos blocos funcionais entre os dispositivos, a ferramenta de gestão do carregamento da aplicação (Download Application Manager) ajudaria a estabelecer conexão com os mesmos e carregar seus blocos funcionais. Como ainda está em fase experimental, os comandos são enviados em XML, e se um dispositivo puder interpretá-los, a comunicação pode ser estabelecida (TRANORIS, 2003). 


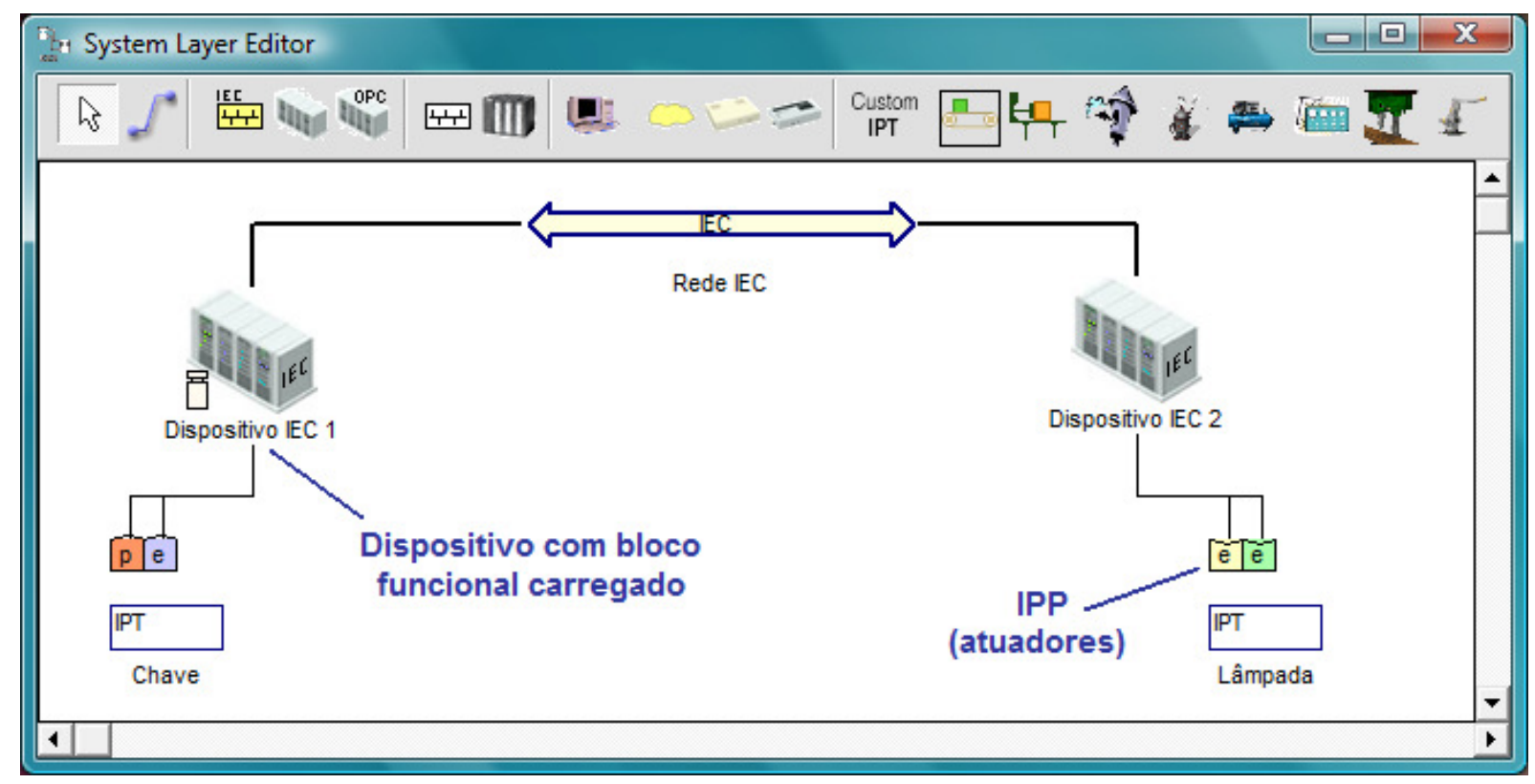

Figura 43: Sistema de dispositivos e IPT projetado por meio do Editor da Camada de Sistema (System Layer Editor) da ferramenta CORFU ESS.

\subsection{Gerenciador do Recurso de Transformação (Transformation Facility Manager)}

Tranoris (2003) apresenta o gerenciador do recurso de transformação como a ferramenta responsável pela passagem das abstrações em UML para as abstrações da norma IEC 61499: assim, ela estabelece comunicação entre o software IBM Rational Rose, retira informações dos Diagramas de Classes, Diagramas de Casos de Uso e Diagramas de Interação e aplica as regras de transformação UML-FB propostas por Thramboulidis, vistas no capítulo 3, para a criação de tipos de blocos funcionais e suas interconexões.

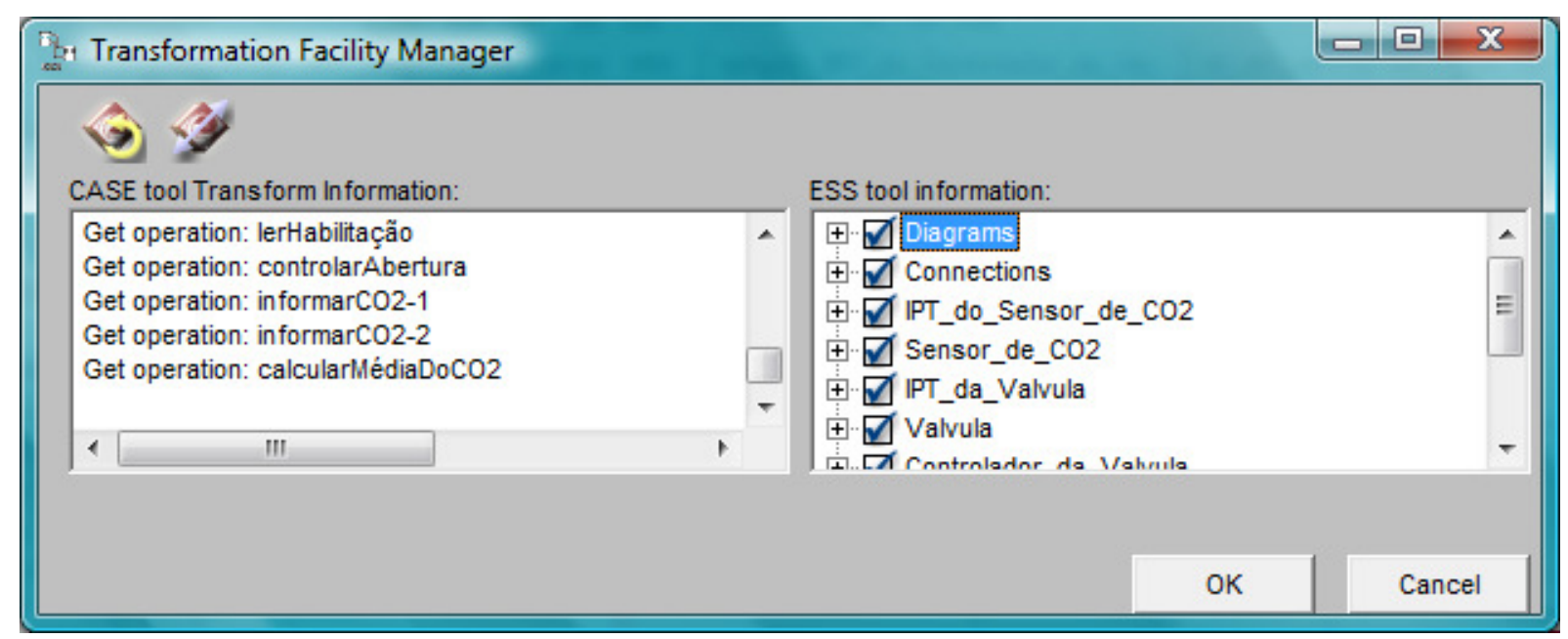

Figura 44: Gerenciador do Recurso de Transformação (Transformation Facility Manager) da ferramenta CORFU ESS. 


\subsubsection{Análise do CORFU ESS}

O CORFU ESS apresenta as seguintes características positivas:

- É uma ferramenta acadêmica, e, para uso nesse âmbito, é gratuita;

- Cobre o ciclo de vida de desenvolvimento de sistemas do levantamento de requisitos à implementação (embora esta última fase seja parcialmente resolvida);

- Consegue realizar a passagem de diagramas UML para diagramas de blocos funcionais de maneira relativamente fácil;

- Utiliza o IBM Rational Rose, ferramenta amplamente conhecida e aceita para modelagem de sistemas em UML;

- Possui editores de blocos funcionais e de diagramas em geral que contam com uma interface simples e acessível, facilitando o entendimento dos conceitos da norma IEC 61499 e da abordagem de Thramboulidis em relação a ela;

- Salva todos seus arquivos (de blocos funcionais, diagramas e de sistema) em formato XML (o que permite sua importação para outras ferramentas); e

- Possui manual reduzido, mas com exemplos significativos, e conta com ampla quantidade de artigos para sua divulgação e explicação (o que torna seu uso fácil e atraente);

Por outro lado, o uso do CORFU ESS oferece ainda alguns entraves, que devem ser superados nas novas versões:

- Ao utilizar o IBM Rational Rose como software de modelagem, impede que usuários que não possuam acesso a essa ferramenta criem diagramas UML a serem transformados pelo CORFU ESS;

- Os modelos UML guardam muita relação com os conceitos de blocos funcionais da norma IEC 61499, inclusive por usar estereótipos dessa área (ou seja, o usuário deve conhecer esse padrão e entender como a transformação é feita para que ele possa gerar diagramas passíveis de transformação - o que dificulta o uso da ferramenta por pessoas envolvidas somente com a área de engenharia de sistemas e software);

- Algumas funcionalidades ainda estão desabilitadas (em construção), como a descrição do funcionamento interno de um bloco funcional por meio de diagramas escada e o uso de adaptadores na interface do bloco funcional, 
ou ainda são feitas por protótipos muito simples, como a ferramenta de carga da aplicação (que somente gera os comandos em XML, de forma genérica, sem aplicação em uma rede comercial de ampla aceitação); e

- Apresenta erros intermitentes de programação, gerais, que forçam o usuário a encontrar, por tentativa e erro, formas de contorná-los.

\subsubsection{Conversores UML-FB}

4.1.2.1. Conversor da UML para blocos funcionais IEC 61499 (Converter from UML to IEC 61499 function blocks)

O conversor da UML para blocos funcionais IEC 61499 (ALSHIN; DUBININ, 2004) é um software muito simples, em que modelos de um sistema de automação distribuídos, especificados em UML por meio da ferramenta IBM Rational Rose, são transformados em diversos arquivos que representam tipos e instâncias de blocos funcionais, recursos, dispositivos e sistemas da norma IEC 61499 (DUBININ; VYATKIN; PFEIFFER, 2005). Vale ressaltar que esses arquivos são descritos em formato XML, de acordo com o que é especificado nessa norma.

Os diagramas da UML utilizados são os Diagramas de Classe, Diagramas de Seqüência, Diagramas de Cooperação e Diagramas de Estados, dados segundo as convenções estabelecidas por Dubinin e Vyatkin em sua linguagem UML-FB.

As restrições da ferramenta são listadas a seguir (CONVERTER..., 2004):

- As ligações de transição não são implementadas. Somente as conexões entre módulos do mesmo nível hierárquico ou entre níveis diretamente relacionados (relação entre bloco funcional composto e uma instância de bloco funcional componente) são identificadas para a realização da transformação;

- Não são gerados nomes hierárquicos para os blocos funcionais (ou seja, os nomes completos desses blocos, compostos pelo aninhamento dos nomes de todas as instâncias de blocos funcionais superiores);

- Somente as conexões entre instâncias de blocos funcionais definidas nos Diagramas de Interação são aceitos para a geração dos arquivos de saída do software; e 
- A alocação de blocos funcionais pode ser realizada somente em tipos de recursos e dispositivos, mas não em suas instâncias.

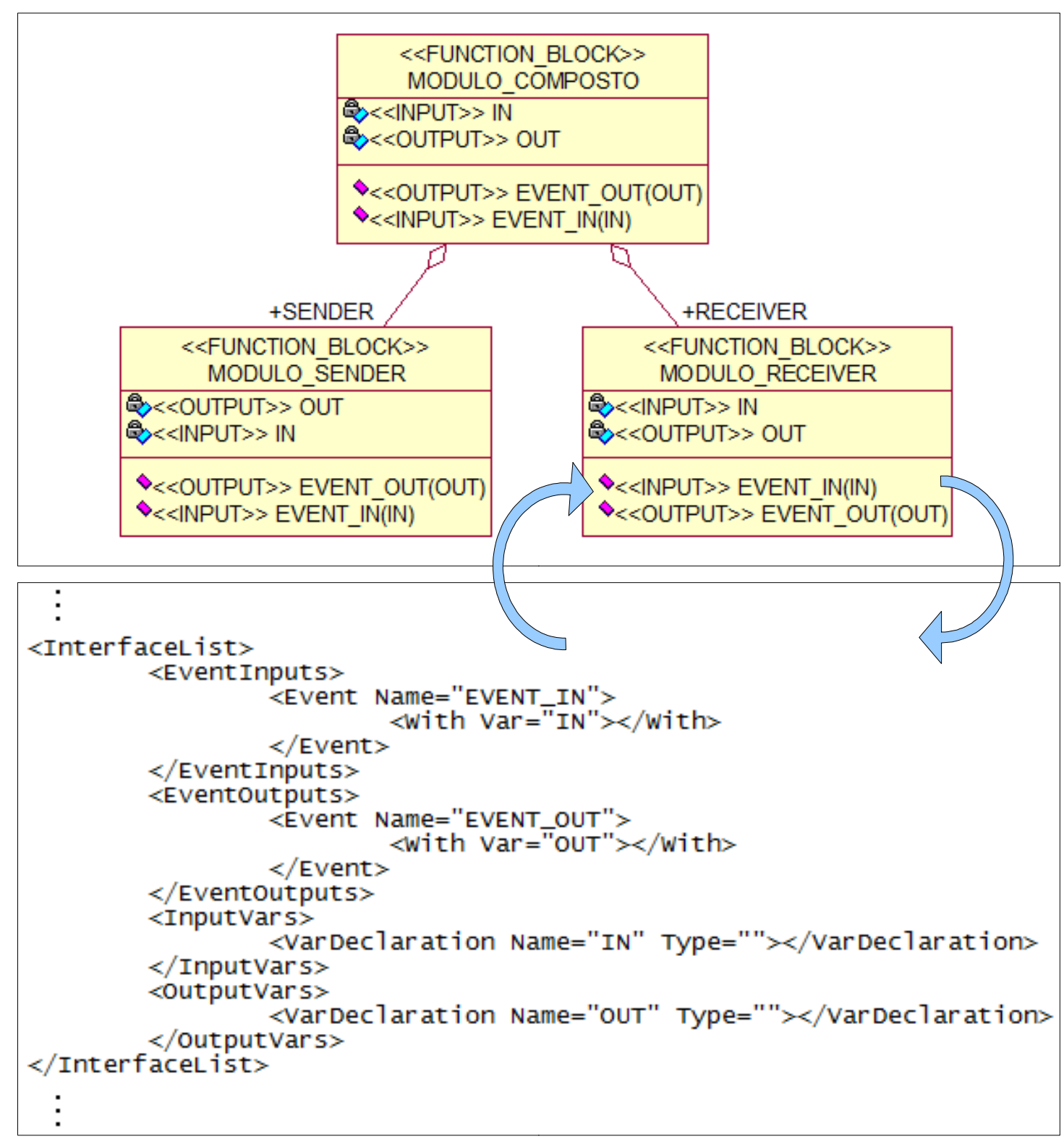

Figura 45: Representação do efeito dos conversores UML-FB.

4.1.2.2. Conversor dos blocos funcionais IEC 61499 para UML (Converter from IEC 61499 function blocks to UML)

O conversor dos blocos funcionais IEC 61499 para UML (RASKIN; DUBININ, 2004) é um software complementar ao anteriormente descrito, já que ele executa a transformação de representações em arquivos XML correspondentes a blocos 
funcionais, recursos, dispositivos e sistemas da norma IEC 61499, que devem estar concentrados em uma única pasta, para modelos UML da ferramenta IBM Rational Rose (DUBININ; VYATKIN; PFEIFFER, 2005).

Os diagramas da UML utilizados são os Diagramas de Classe, Diagramas de Seqüência, Diagramas de Cooperação e Diagramas de Estados, dados segundo as convenções estabelecidas por Dubinin e Vyatkin (2004) em sua linguagem UMLFB.

\subsubsection{Análise dos Conversores UML-FB}

Os conversores UML-FB apresentam as seguintes características positivas:

- São ferramentas acadêmicas e gratuitas;

- Cobrem o ciclo de vida de desenvolvimento de sistemas da análise ao projeto;

- Conseguem realizar a passagem de diagramas UML para arquivos em XML representantes das abstrações da norma IEC 61499 (e vice-versa) de forma muito fácil;

- Utiliza o IBM Rational Rose, ferramenta amplamente conhecida e aceita para modelagem de sistemas em UML; e

- Os arquivos XML gerados para as abstrações relativas a blocos funcionais são compatíveis com a norma IEC 61499 (o que permite sua importação em outras ferramentas).

Por outro lado, o uso dos conversores UML-FB oferecem algumas dificuldades:

- Ao utilizar o IBM Rational Rose como software de modelagem, impede que usuários que não possuam acesso a essa ferramenta criem diagramas UML a serem transformados pelos conversores UML-FB;

- Os modelos UML guardam muita relação com os conceitos de blocos funcionais da norma IEC 61499, de forma ainda mais acentuada do que ocorre na ferramenta CORFU. Isso é muito claro ao se perceber que na linguagem UML-FB, em uma classe, um evento é sempre dado por um método, uma variável de dados é sempre correspondente a um atributo e que ambos sempre precisam de estereótipos $<<\mid$ INPUT $>$ e $<<$ OUTPUT $>$. Assim, a possibilidade da UML isolar os engenheiros de sistemas e de 
software do ambiente puro da automação torna-se inviável;

- A documentação dessas ferramentas é praticamente inexistente. Não foi encontrado um manual que ajude o usuário a modelar os diagramas UML da forma devida, o que torna muito difícil que a sua transformação para os arquivos XML seja correta. De maneira geral, a não ser quando da utilização e observação do modelo pronto, não se consegue obter conexões entre os blocos funcionais, mas apenas a especificação de sua interface. Caso semelhante ocorre para a conversão de arquivos referentes às abstrações da norma IEC 61499 para diagramas UML, em que não há manual e o seu comportamento é observável somente através do exemplo de testes; e

- Pela data do último projeto dos conversores (2005), eles parecem estar descontinuados.

\subsubsection{FBench}

A ferramenta OOONEIDA FBench (INTELLIGENT MECHATRONICS AND AUTOMATION GROUP, 2007) é um editor de blocos funcionais, adaptadores, recursos, dispositivos e sistemas especificados pela norma IEC 61499 e permite, adicionalmente, a compilação e a execução desses modelos.

Dessa maneira, pode-se, através da interface gráfica do FBench:

- Criar, visualizar ou editar um tipo pré-existente de:

- Bloco funcional: além das informações de sua interface (entradas e saídas de eventos e dados, incluindo seu tipo), exibidos de maneira gráfica, pode-se também modificar seus atributos gerais, como nome, comentários, vinculação a uma determinada norma (como IEC 61499), elementos de controle de versão e informações para compilação (formatados textualmente). Os blocos funcionais devem seguir algum dos modelos abaixo, com características adicionais particulares:

- Básico: o diagrama de controle de execução (Execution Control Chart - ECC) pode ser editado graficamente, por meio da alteração ou criação de novos estados (cujos parâmetros são seu nome, comentário, determinação se é ou não estado inicial, e vinculação a algoritmos e eventos de saída) ou novas transições (que necessitam de especificação de condição de transição (com evento ou condição 
booleana de guarda) e seus estados de origem e destino, e podem conter um comentário). Por sua vez, os algoritmos devem ser dados textualmente, nos formatos das linguagens $C$ ou Java, em texto estruturado ou em linguagem livre;

- Composto: admite edição de sua rede interna de blocos funcionais (à qual podem ser alterados ou adicionados blocos funcionais e conexões entre estes);

- Proxy: comporta modificação das seqüências de interação;

- Interface de Serviço (Service Interface Function Block): aceita modificação das seqüências de primitivas de interação e de sua interface;

- Simples: permite a modificação de sua interface e do algoritmo vinculado à chegada de um evento;

- Adaptadores: ademais de permitir a alteração de sua interface, a ferramenta estabelece uma forma pela qual as seqüências de comunicação entre soquetes e plugues podem ser especificadas;

- Recursos: permite a edição de sua rede de blocos funcionais;

- Dispositivos: permite a designação de seus recursos associados;

- Sistemas: comporta a representação de um sistema completo (com dispositivos, recursos e blocos funcionais).

- Visualizar a representação em XML de qualquer abstração da norma IEC 61499, alterá-la e inclusive ativar a função Parse XML para transformar o texto XML em representação gráfica do modelo (caminho inverso ao normalmente visto);

- Compilar os blocos funcionais para a linguagem Java; e

- Executar os sistemas que tenham seus componentes previamente compilados.

Um artigo que faz referência a esta ferramenta de forma bem completa é o de Dai, Shih e Vyatkin (2006), o qual pode ser utilizado para uma visão global de seu funcionamento e das metas futuras a respeito deste projeto 


\subsubsection{Análise do FBench}

Apesar de ser uma ferramenta interessante para iniciar os estudos sobre a norma IEC 61499, infelizmente o FBench apresenta algumas falhas de programação que o tornam, por vezes, complicado de usar. Um exemplo simples é, por exemplo, que, ao se apagar o diagrama de controle de execução de um bloco funcional através da interface gráfica, a única forma de adicionar outro diagrama desse tipo é alterando o texto XML referente ao bloco e ativando a função Parse XML.

No entanto, tais falhas de programação devem ser superadas nas próximas versões, o que é uma perspectiva muito alentadora, dado que a ferramenta realmente permite expressar, por meio das abstrações da norma IEC 61499, todo o projeto lógico de um sistema de automação. Adicionalmente, com a sua possibilidade de compilação e execução dos modelos, pode-se testar o sistema antes de uma provável implementação em campo.

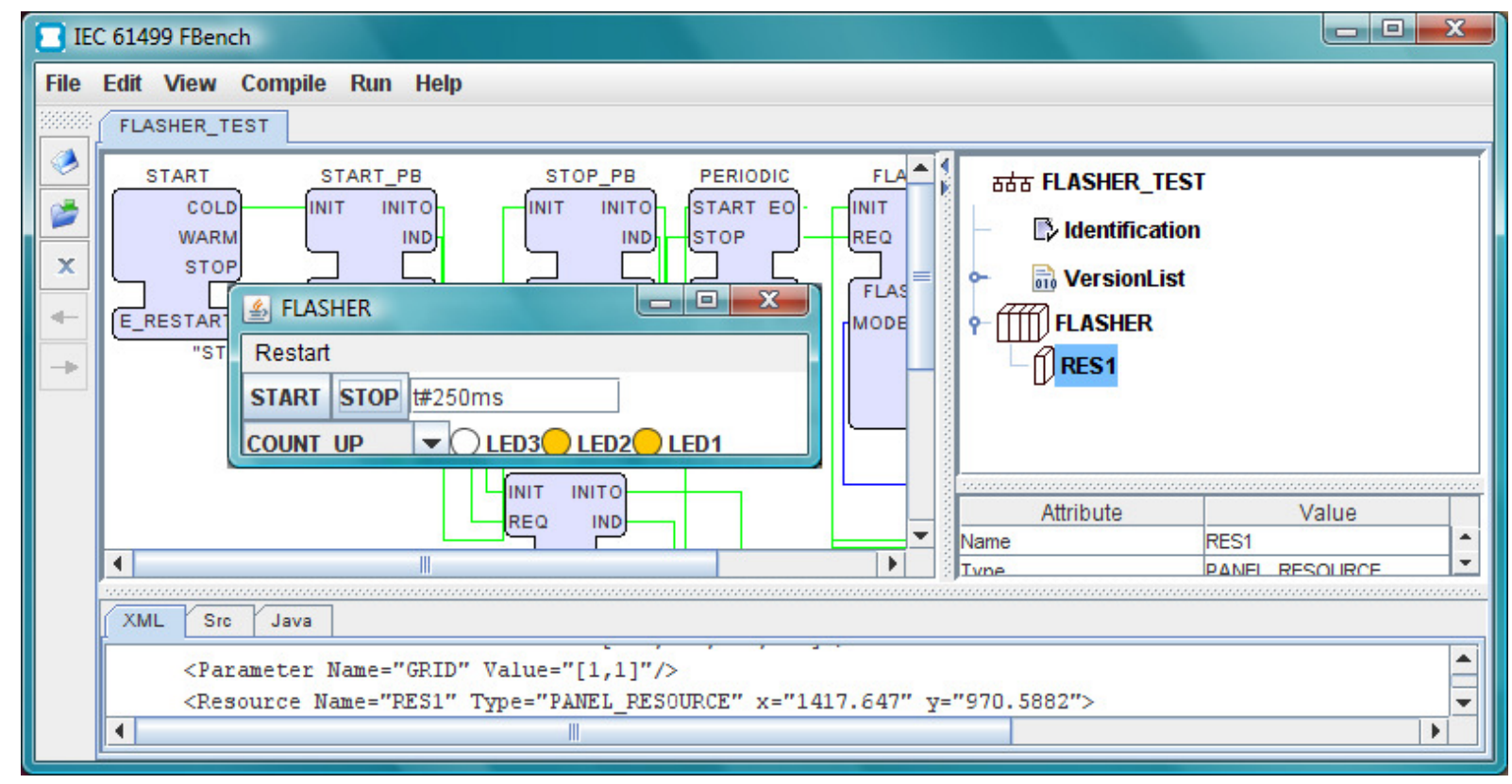

Figura 46: Interface da ferramenta FBench (exibindo a execução de um sistema).

\subsubsection{FBDK}

A ferramenta FBDK (HOLOBLOC, INC., 2006), embora seja implementada por outra instituição, tem funcionalidades e aspecto muito semelhantes em relação à ferramenta FBench. Um dos motivos pelos quais isso pode ter ocorrido é que esta 
ferramenta parece ter sido a predecessora das demais, já que um de seus principais contribuidores é o pesquisador James $\mathrm{H}$. Christensen (envolvido desde o início na normatização IEC 61499). Assim, a ferramenta FBDK e seu ambiente de execução Function Block Run-Time (FBRT) - também baseado na linguagem Java - podem ter servido como inspiração ou base para outros trabalhos.

Assim como a ferramenta FBench, no entanto, o FBDK ainda apresenta algumas inconsistências do ponto de vista de falhas de programação. No entanto, mesmo com essas restrições, é possível construir a representação de sistemas completos e executá-los.

Por fim, destaca-se que uma boa alternativa para estudar essa ferramenta, assim como muitos outros aspectos da norma IEC 61499 (inclusive por meio de tutoriais e transparências), é consultar a página da empresa Holobloc, Inc. (HOLOBLOC, INC., 2006b).

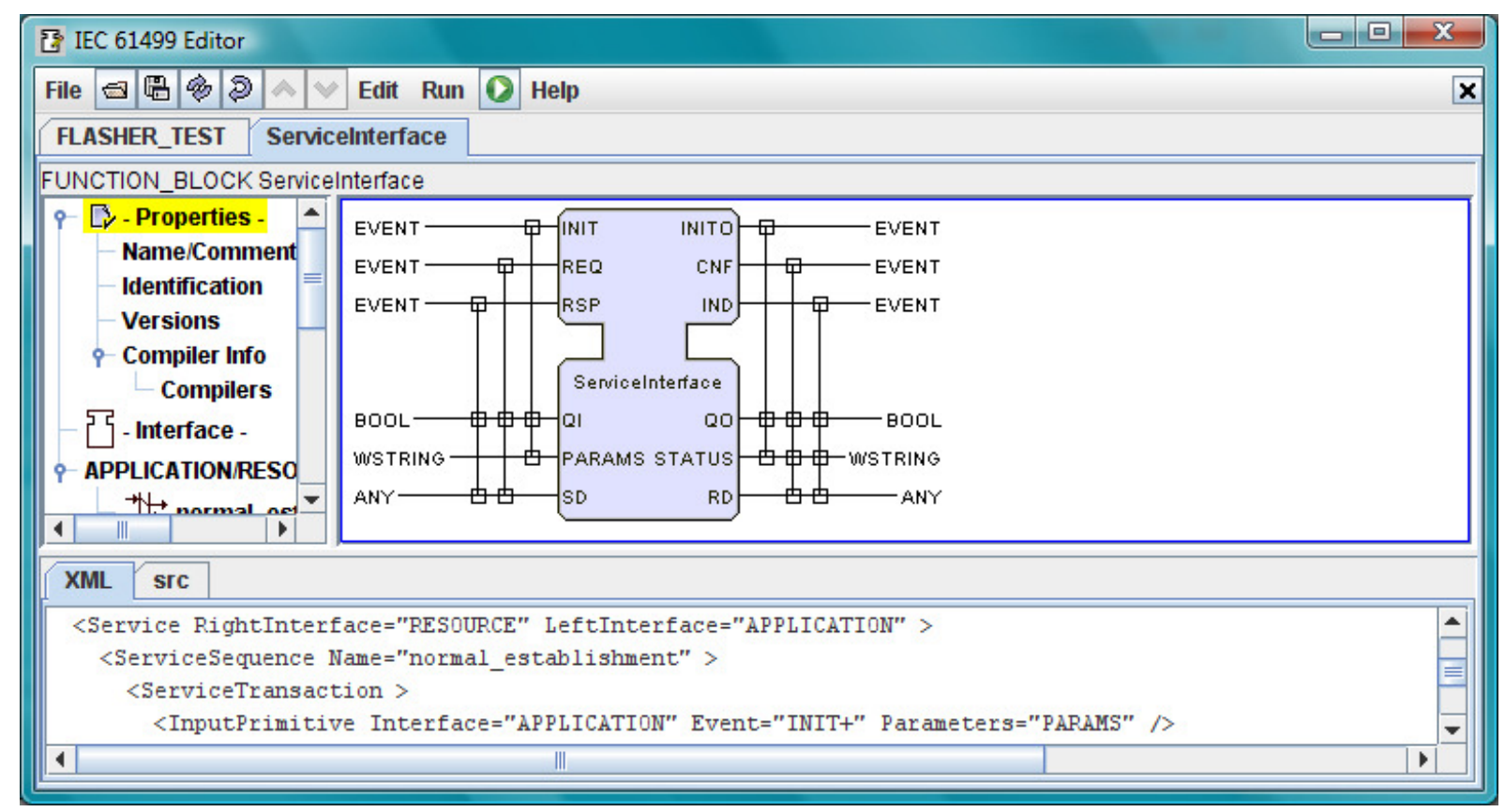

Figura 47: Interface da ferramenta FBDK (exibindo um bloco funcional de interface de serviços).

\subsubsection{DIAC-IDE}

A ferramenta 4DIAC-IDE (ECEDAC CONSORTIUM, 2007), baseada na interface gráfica do ambiente de desenvolvimento Eclipse, permite a realização de projetos de sistemas compatíveis com a norma IEC 61499 (usando, para isso, as 
suas abstrações, e permitindo, além disso, a definição do ambiente de hardware do sistema) (ZOITL; STRASSER, 2007).

As principais funções dessa ferramenta são (4DIAC CONSORTIUM, 2007):

- Fornecer e gerenciar os blocos funcionais de uma biblioteca de tipos;

- Importar tipos de dados e aplicações da ferramenta FBDK;

- Exibir e permitir a edição de características e parâmetros da interface externa e do comportamento de tipos de blocos funcionais (inclusive o diagrama de controle de execução, interno a um bloco funcional básico, e a rede de blocos funcionais, interna a um bloco funcional composto);

- Criar sistemas (com aplicações, dispositivos, recursos e distribuição das aplicações nos recursos);

- Criar aplicações, compostas por blocos funcionais e/ou subaplicações, por meio da interconexão de entradas e saídas de eventos e de dados;

- Criar subaplicações, compostas por redes de blocos funcionais, cujos blocos podem ser distribuídos em recursos;

- Configurar o hardware dos dispositivos do sistema a partir de modelos fornecidos (os quais podem inclusive mostrar a interconexão com segmentos de rede, tais como Ethernet - usado, por enquanto, somente para documentação);

- Configurar aspectos como a porta e o endereço IP de um dispositivo para que a ferramenta consiga gerenciar o dispositivo (como, por exemplo, ordenar a criação de blocos funcionais quando ocorre a carga de uma aplicação);

- Visualizar e configurar aspectos dos dispositivos como os recursos, a interface de processos e a interface de comunicação que eles contêm;

- Fazer o mapeamento de blocos funcionais em recursos dos dispositivos;

- Carregar uma aplicação em dispositivos de campo, segundo o projeto realizado anteriormente. (vale lembrar que para instanciar ou executar as redes de blocos funcionais é necessário ter um ambiente de execução compatível com a IEC 61499). Algumas opções estão disponíveis:

- Carregar a configuração completa do sistema (ou seja, todas as redes de blocos funcionais, independentemente do dispositivo ou recurso em que estejam);

- Carregar a configuração de um dispositivo (somente os blocos funcionais 
dos recursos desse dispositivo);

- Carregar a configuração de um recurso (somente os blocos funcionais de um recurso).

A ferramenta 4DIAC-IDE é compatível com dois ambientes de execução de blocos funcionais: o 4DIAC-RTE (FORTE) - implementado para PC e processador embarcado (ARM7), e o FBRT. Somente os dispositivos que suportem esses ambientes poderão ser carregados com as aplicações.

Essa ferramenta faz parte de um grande projeto (com um planejamento ambicioso), de um consórcio de empresas. Isso já faz com que, de certa forma, ela saia adiante das demais, já que implica um esforço conjunto de pesquisa e indústria. Tal ferramenta tenta cobrir desde o projeto com blocos funcionais até a implementação, e, embora seus recursos ainda sejam restritos (especialmente a carga de aplicações e a quantidade de ambientes de execução que suporta), parece ser apenas uma questão de tempo até que mais funcionalidades sejam adicionadas.

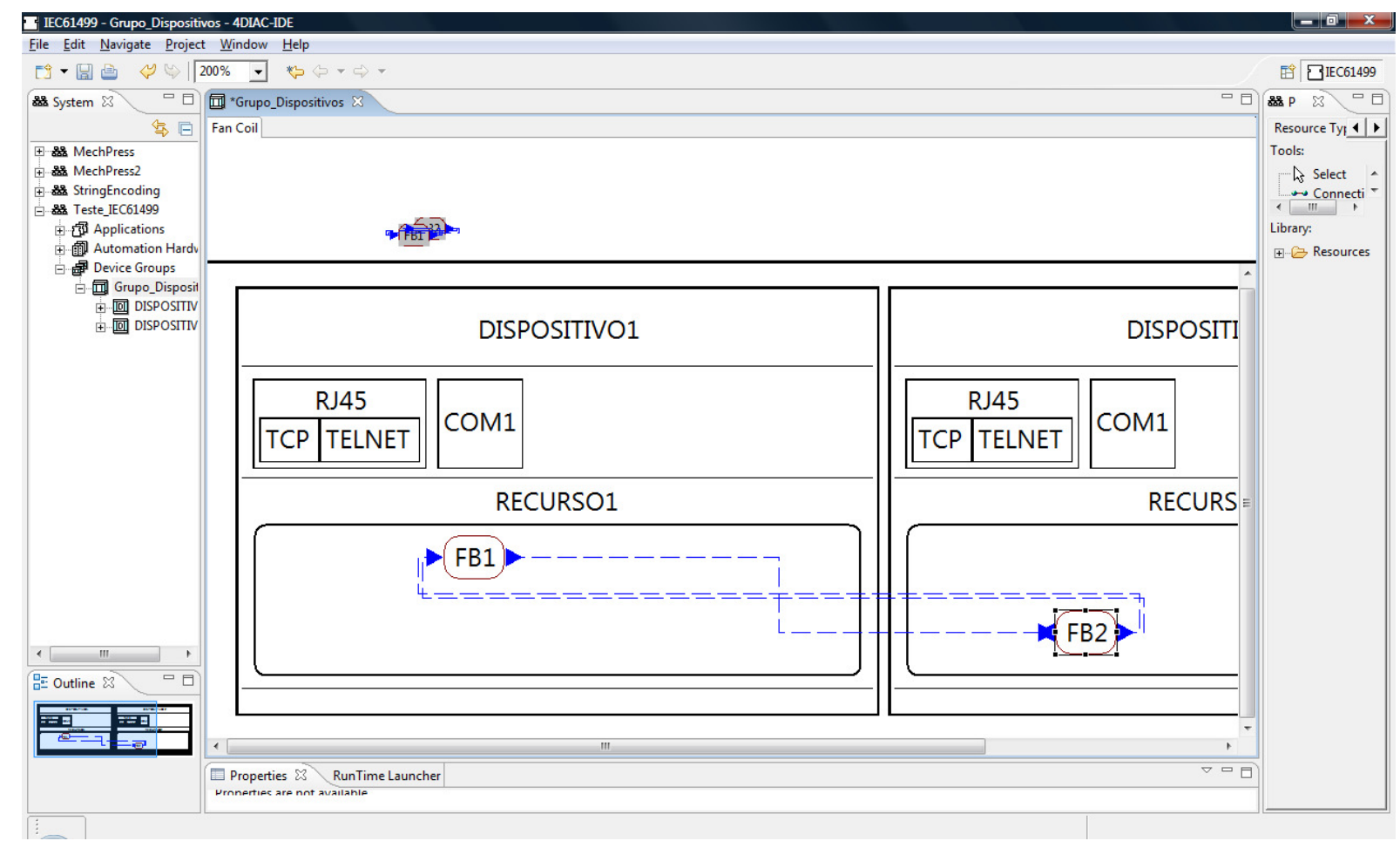

Figura 48: Distribuição de uma aplicação em dois dispositivos através da ferramenta 4DIAC-IDE. 


\subsubsection{ISaGRAF}

A ferramenta ISaGRAF 5.0 (produzida pela empresa ICS Triplex) é a primeira ferramenta comercial para auxílio ao desenvolvimento de projetos de sistemas de automação distribuídos que utiliza as abstrações da norma IEC 61499 como meios principais para a geração de modelos, e, a partir daí, para a implementação e testes dos sistemas.

Segundo Chouinard e Brennan (2006), o usuário pode, através da ferramenta ISaGRAF, separar a tarefa de projeto segundo a organização hierárquica dos conceitos fundamentais da norma IEC 61499, trabalhando em diferentes níveis, ou seja, desde os modelos de blocos funcionais até o modelo geral de sistema (cujas abstrações são dispositivos, recursos e blocos funcionais). Ao invés de construir aplicações de controle tradicionais, as interações entre os dispositivos vão ser reguladas automaticamente e sincronizadas pelos diagramas de blocos funcionais da IEC 61499 (já que as aplicações constituídas por redes de blocos funcionais são distribuídas entre recursos, e estes entre dispositivos distintos, conforme descrito pela norma). Para ajudar na verificação de uma aplicação de controle, a mesma também pode ser simulada na presente ferramenta.

Dada a necessidade de adaptação do pessoal já acostumado com a definição de sistemas de blocos funcionais descritos segundo as linguagens previstas pela norma IEC 61131-3, a ferramenta ISaGRAF permite a especificação do comportamento (algoritmos) dos blocos funcionais básicos através das linguagens definidas nessa norma, como em texto estruturado (Structured Text-ST) ou diagramas em escada (Ladder Diagrams - LD). Com esse mesmo intuito, adicionalmente, a ferramenta permite o uso opcional de diagramas de funções seqüenciais (Sequential Function Chart - SFC) para a especificação dos diagramas de controle de execução de um bloco funcional.

Uma vez que a aplicação completa tenha sido desenvolvida na ferramenta, a mesma pode ser gerada em linguagem $\mathrm{C}$ ou em código independente de plataformaalvo (chamado Target Independent Code - TIC). No primeiro caso, o código-fonte deve ser compilado e ligado (linked) às bibliotecas necessárias para ser executado em um dispositivo. Já através do uso do TIC, o software pode ser executado (e até corrigido em tempo real) em qualquer ambiente que implemente a máquina virtual necessária para interpretação desse código-fonte. Assim, o código da aplicação 
pode ser carregado em elementos com hardware diferente (processadores embarcados, Motorola, Intel e ARM, por exemplo) e em distintos sistemas operacionais (Microsoft Windows XP, Microsoft Windows CE, Microsoft Windows 2000, Linux, VxWorks e QNX, entre outros). O TIC também pode ser usado para construir dispositivos de automação como pequenos controladores, desde que os mesmos consigam interpretar essa linguagem.

Finalmente, um ambiente de execução e testes previsto pela ferramenta ISaGRAF é o seu kit de desenvolvimento: ele inclui controladores, interconectados via Ethernet, que internamente possuem um ambiente de execução ISaGRAF e um driver de entradas e saídas. Através de um repetidor sem fio (hub wireless), os mesmos podem ser acessados por qualquer computador que tenha o ambiente de desenvolvimento ISaGRAF.

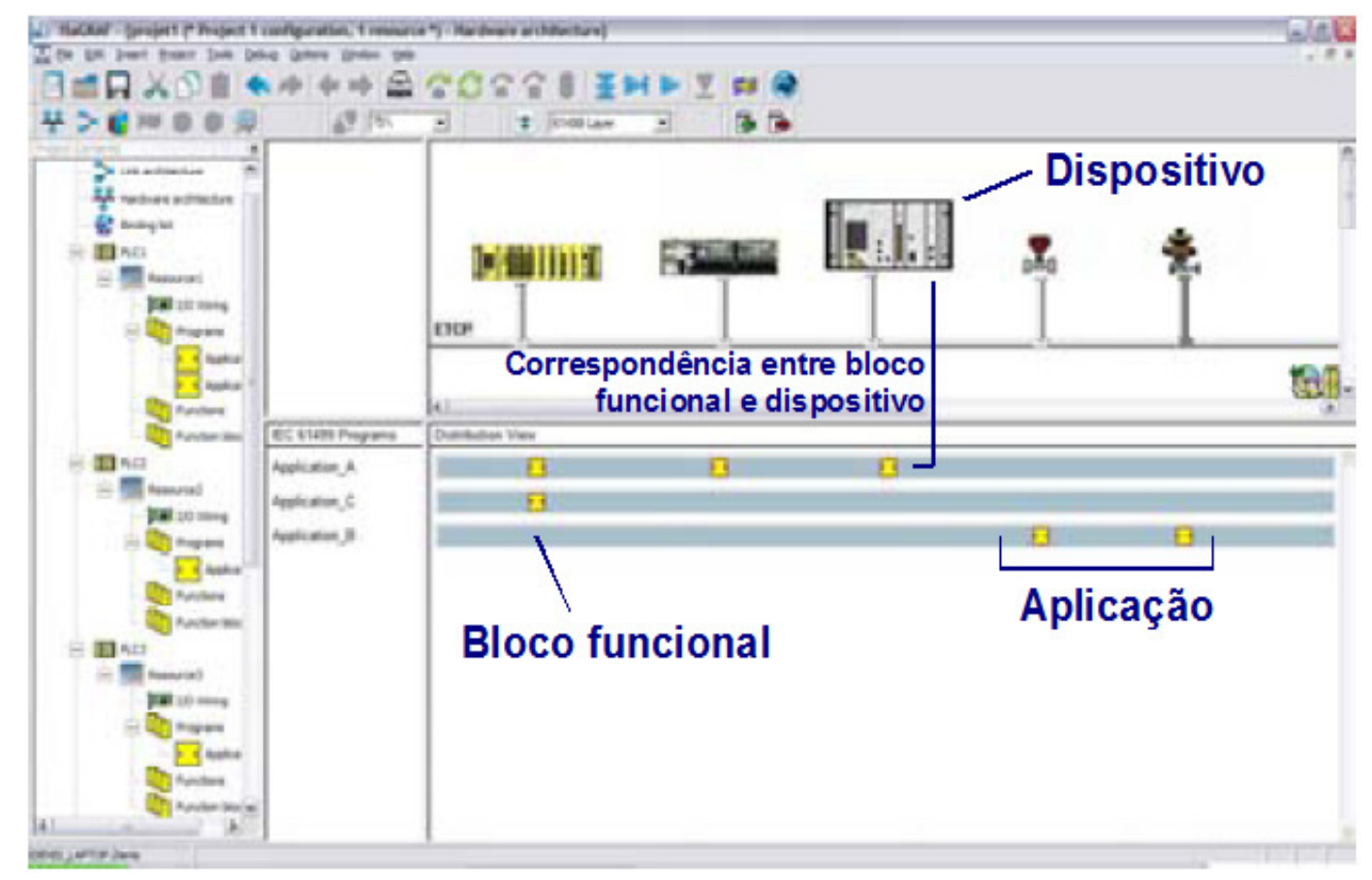

Figura 49: Distribuição de uma aplicação da norma IEC 61499 na ferramenta ISaGRAF - adaptado de Chouinard e Brennan (2006).

Um dos pontos mais relevantes a serem destacados sobre a ferramenta ISaGRAF é que a mesma configura uma das primeiras apostas comerciais da indústria na norma IEC 61499 (o que pode sugerir uma tentativa séria de inserção dessa norma no mercado). Mais importante do que isso, no entanto, é o fato de que essa ferramenta tenta cobrir as etapas de desenvolvimento de sistemas de 
automação distribuídos que vão do projeto aos testes, fornecendo uma possibilidade de implementação dos sistemas por meio da compilação de código, seja em TIC, seja em linguagem C. Assim, tem-se a possibilidade de construir um sistema real e executar testes sobre ele - como o que pode ser visto através do kit de desenvolvimento da ferramenta, por exemplo, projetando as expectativas do uso da IEC 61499 em ambientes de campo.

\subsubsection{Fuber}

Čengić, Ljungkrantz e Åkesson (2006) mostraram interesse na verificação formal das aplicações da IEC 61499. Para isso, está sendo desenvolvido um ambiente de execução da IEC 61499, chamado Fuber, que tem um modelo bem definido, e, portanto, analisável.

O Fuber é desenvolvido em Java, possui código aberto, e consegue executar diversas aplicações compatíveis com a norma IEC 61499. Na verdade, o Fuber se diferencia dos demais ambientes de execução pois não compila os algoritmos, e sim os interpreta, o que torna possível atualizar o comportamento da aplicação durante a execução. Assim, o Fuber modifica os tipos de blocos funcionais, instâncias e suas conexões enquanto a aplicação está sendo executada, o que torna fácil a reconfiguração do software - uma característica que pode ser útil tanto para testes quanto para aplicações que precisem de grande disponibilidade.

As principal vantagem do Fuber está justamente no fato dele prover uma ferramenta para realizar a execução das redes de blocos funcionais básicos da norma IEC 61499. Apesar disso, a ferramenta precisa superar diversas limitações:

- Os algoritmos dos blocos funcionais devem ser obrigatoriamente implementados em Java;

- Os tipos de blocos funcionais compostos não são avaliados;

- Não há suporte à distribuição de aplicação entre diversos recursos;

- Não há interface gráfica para essa ferramenta (a mesma é controlada por uma interface de linha de comandos);

- Não há como garantir que a execução tenha vínculo temporal estrito, nem são considerados aspectos de tempo real (restrições) do ambiente de execução; e

- Não é possível disparar as atualizações de blocos funcionais e conexões a 
partir de uma interface externa do Fuber.

Outro aspecto a ressaltar é que seria interessante se houvesse uma versão executável da ferramenta Fuber, já que isso é mais prático para quem deseja analisar a ferramenta (e não modificá-la ou codificá-la através de seu código-fonte, de acordo a como é disponibilizada atualmente).

Finalmente, tal ferramenta não aparenta cobrir outras partes de projeto que não os testes de redes de blocos funcionais já constituídas em outras ferramentas.

\subsubsection{Archimedes ESS}

A ferramenta Archimedes ESS, segundo Software Engineering Group (2005), é uma plataforma compatível com a norma IEC 61499 para o desenvolvimento de IPMCS baseados em blocos funcionais. A partir de modelos construídos em base às abstrações dessa norma, a ferramenta permite sua transformação para sistemas executáveis em ambientes específicos. Atualmente, os ambientes de execução suportados pela ferramenta CORFU são:

- RTSJ-Archimedes eXecution Environment (AXE): ambiente que se utiliza da tecnologia Real-Time Java;

- RTAI-AXE: ambiente baseado em uma variante do sistema operacional Linux para tempo real;

- CCM-AXE: ambiente que explora a especificação de modelos de componentes do Common Object Request Broker Architecture (CORBA).

As características mais relevantes dessa ferramenta são o fato dela possuir ambientes de execução de tempo real (que poderiam ser utilizados para automação, dependendo das restrições temporais a que estes estejam sujeitos) e, adicionalmente, permitir interface com a ferramenta CORFU ESS. Dessa maneira, seriam cobertas desde a fase de levantamento de requisitos até a fase de implementação de sistemas de automação. 


\subsection{COMPARAÇÃO ENTRE AS FERRAMENTAS}

As ferramentas apresentadas neste capítulo conseguem cobrir, em conjunto, diversas fases do ciclo de vida de projeto de sistemas de automação distribuídos. O fato da norma IEC 61499 estabelecer regras para o intercâmbio de informações entre ferramentas de software, inclusive, permite que muitas delas possam trabalhar cooperativamente (mesmo não fazendo parte de um único pacote, fornecido por um só fabricante). Do ponto de vista dos usuários das ferramentas, fica claro que isso é uma grande vantagem, já que pode haver liberdade de escolha entre elas no momento da aquisição, e se pode substituição umas pelas outras sem perda do material anteriormente gerado. Neste ponto, uma das poucas ressalvas que se deve fazer é o atrelamento das ferramentas CORFU ESS e Conversores UML-FB (as duas únicas que implementam a passagem de UML para modelos da norma IEC 61499) à ferramenta comercial IBM Rational Rose: apesar da sua utilização ser eficiente, percebe-se que, dessa forma, restringe-se o número de pessoas a terem acesso a realizar a transformação UML-IEC61499 (o que deveria ser revisto, haja vista que tanto o CORFU ESS quanto os conversores UML-FB são gratuitos).

Tabela 4: Cobertura das ferramentas estudadas quanto às fases de desenvolvimento do projeto de sistemas de automação.

\begin{tabular}{|c|c|c|c|c|c|c|c|}
\hline & \multicolumn{6}{|c|}{ Fases do desenvolvimento do projeto de um sistema de automaçăo } \\
\hline & & $\begin{array}{l}\text { Levantamento } \\
\text { de Requisitos }\end{array}$ & Análise & Projeto & Implementaçăo & Testes & Manutençăo \\
\hline \multirow{8}{*}{ 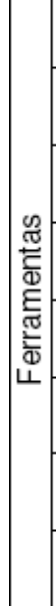 } & CORFU ESS & $\bullet$ & $\bullet$ & $\bullet$ & • & & \\
\hline & $\begin{array}{l}\text { Conversores } \\
\text { UML-FB }\end{array}$ & & $\bullet$ & $\bullet$ & & & \\
\hline & FBench & & & $\bullet$ & $\bullet$ & $\bullet$ & \\
\hline & FBDK & & & $\bullet$ & $\bullet$ & $\bullet$ & \\
\hline & 4DIAC-IDE & & & $\bullet$ & $\bullet$ & $\bullet$ & \\
\hline & ISaGRAF & & & $\bullet$ & $\bullet$ & $\bullet$ & \\
\hline & Fuber & & & $\bullet$ & • & & \\
\hline & $\begin{array}{c}\text { Archimedes } \\
\text { ESS }\end{array}$ & & & $\bullet$ & $\bullet$ & $\bullet$ & \\
\hline
\end{tabular}


Deve-se notar, no entanto, que apesar de haver diversas iniciativas indo em direção à implementação de sistemas de automação através do auxílio dessas ferramentas, esses ambientes de execução são muito específicos, e não parecem abranger tecnologias de automação para sistemas distribuídos bastante populares, como LonWorks, por exemplo. Neste sentido, vê-se possibilidade de contribuição acadêmica, a ser esclarecida no capítulo seguinte. 


\title{
5. PROPOSTA DE EXTENSÕES AOS MAPEAMENTOS UML-IEC61499 E FERRAMENTAS
}

\begin{abstract}
Neste capítulo serão apresentadas propostas de extensões aos mapeamentos UML-IEC61499 (discutidos no capítulo 3) e às ferramentas computacionais para suporte às atividades de engenharia voltadas ao desenvolvimento de sistemas de automação distribuídos baseadas em modelagens dadas através de abstrações da norma International Electrotechnical Commission 61499 (vistas no capítulo 4). Dentre os principais assuntos discutidos, estão a sugestão de um mapeamento UML-IEC61499 simplificado, a representação de parâmetros temporais em modelagens de sistemas de automação e a discussão da viabilidade de implementação de sistemas representados pela norma IEC 61499 por meio da tecnologia LonWorks.
\end{abstract}

\subsection{EXTENSÕES AOS MAPEAMENTOS UML-IEC61499}

Tendo em consideração os mapeamentos UML-IEC61499 estudados no capítulo 3, vê-se duas principais possibilidades de contribuição nesse âmbito:

- Sugestão de um mapeamento UML-IEC61499 simplificado; e

- Indicação de mecanismos para representação de parâmetros temporais nos modelos de sistemas de automação (dados tanto em UML quanto em abstrações da norma IEC 61499).

\subsubsection{Mapeamento UML-IEC61499 simplificado}

Posto que a utilização de vocabulário associada à norma IEC 61499 em modelos da Unified Modeling Language (UML) tende a dificultar a geração de modelos de sistemas de automação distribuído por parte de engenheiros de sistemas e software que não conheçam em detalhes essa padronização, propõe-se um novo mapeamento UML-IEC61499, simplificado no sentido de dispensar o uso 
de estereótipos vinculados ao vocabulário específico da norma IEC 61499 e por usar um pequeno número de diagramas da UML para realizar de fato a transformação UML-IEC61499.

Nesta proposta de mapeamento UML-IEC61499 simplificado, supõe-se que os usuários da UML irão utilizar essa linguagem para descrever sistemas de automação distribuídos. Dessa maneira, fica subentendido que, mesmo que não conheçam especificamente a norma IEC 61499, tenham conceitos gerais de automação, como a composição de um sistema por sensores, atuadores, controladores, gateways (elementos de interface para comunicação entre sistemas) e interfaces homem-máquina (utilizados para viabilizar a interação entre operadores e o sistema de automação).

Para que seja possível realizar a conversão UML-IEC61499, torna-se necessário impor algumas condições às descrições de sistemas feitas em UML:

- A fim de permitir a representação dos componentes de um sistema de automação, alguns elementos da UML poderão ter os seguintes estereótipos:

- Sensor, Atuador, Sensor-Atuador, Gateway e IHM: utilizados para indicar que uma classe representa uma abstração lógica de um sensor, de um atuador, de um dispositivo sensor e atuador (ao mesmo tempo), de um gateway ou de uma interface homem-máquina, respectivamente; e

- Controlador: empregado para indicar que um nó da UML representa um controlador de um sistema de automação;

- Todos os atributos de uma classe devem ser obrigatoriamente acessados através de métodos, mesmo que sua visibilidade seja pública;

- As máquinas de estados detalhadas nos seus respectivos diagramas devem ser compostas por estados simples (ou seja, sem subestados), e sempre deve haver indicação de seu estado inicial; e

- Cada objeto representado através da UML deve receber um número de identificação único, com a finalidade de ajudar na geração da nomenclatura de elementos dos modelos baseados em abstrações da norma IEC 61499. 
5.1.1.1. Diagramas da UML usados no mapeamento UML-IEC61499 simplificado

Apesar de que todos os diagramas da UML podem ser usados para representar o sistema de automação da forma mais completa possível, num primeiro momento apenas os dados referentes aos diagramas de Classes, de Seqüência, de Colaboração/Comunicação (Diagramas de Interação), de Máquinas de Estados e de Atividades serão usados para a extração de informações sobre o software, enquanto o Diagrama de Distribuição (Deployment) fornecerá dados sobre o hardware do sistema de automação. A seguir, detalham-se as funções dos elementos de cada diagrama para a conversão UML-IEC61499.

\subsection{Diagrama de Classes}

No Diagrama de Classes, usado para mostrar a visão estática da aplicação de um sistema de automação, as classes podem ser convertidas em tipos de blocos funcionais pertencentes à norma IEC 61499. Cada método público ou protegido de uma classe designa o nome de entradas e saídas de eventos, enquanto que seus parâmetros (inclusive o valor de retorno) especificam as entradas e saídas de dados (conforme detalhado na seção referente a Diagramas de Interação). Aos métodos privados, em geral, cabe a função de expressar atividades internas aos objetos, e devem ser traduzidos para a norma IEC 61499 como algoritmos. Por sua vez, os atributos de uma classe devem representar apenas as variáveis internas, de entrada e de saída do bloco funcional, mas não devem gerar ligações entre entradas e saídas de dados de blocos funcionais (o que deve ser feito exclusivamente pelos parâmetros dos métodos). Como todo e qualquer atributo deve ser acessado através de métodos correspondentes, além de serem mantidas boas práticas de orientação a objetos, implementa-se a distinção entre uma variável de dados (atributo) e uma entrada ou saída de dados (parâmetro ou valor de retorno de um método) - apesar de terem uma relação semântica clara, determinada pela IEC 61499.

De acordo com os tipos de estereótipos que podem serem aplicados às classes - Sensor, Atuador, Sensor-Atuador, IHM e Gateway - discriminam-se os blocos funcionais de interface de serviços (service interface function block - SIFB) da norma IEC 61499, já que os mesmos são responsáveis por permitir a interação entre a aplicação e o processo controlado ou a rede de comunicação. 


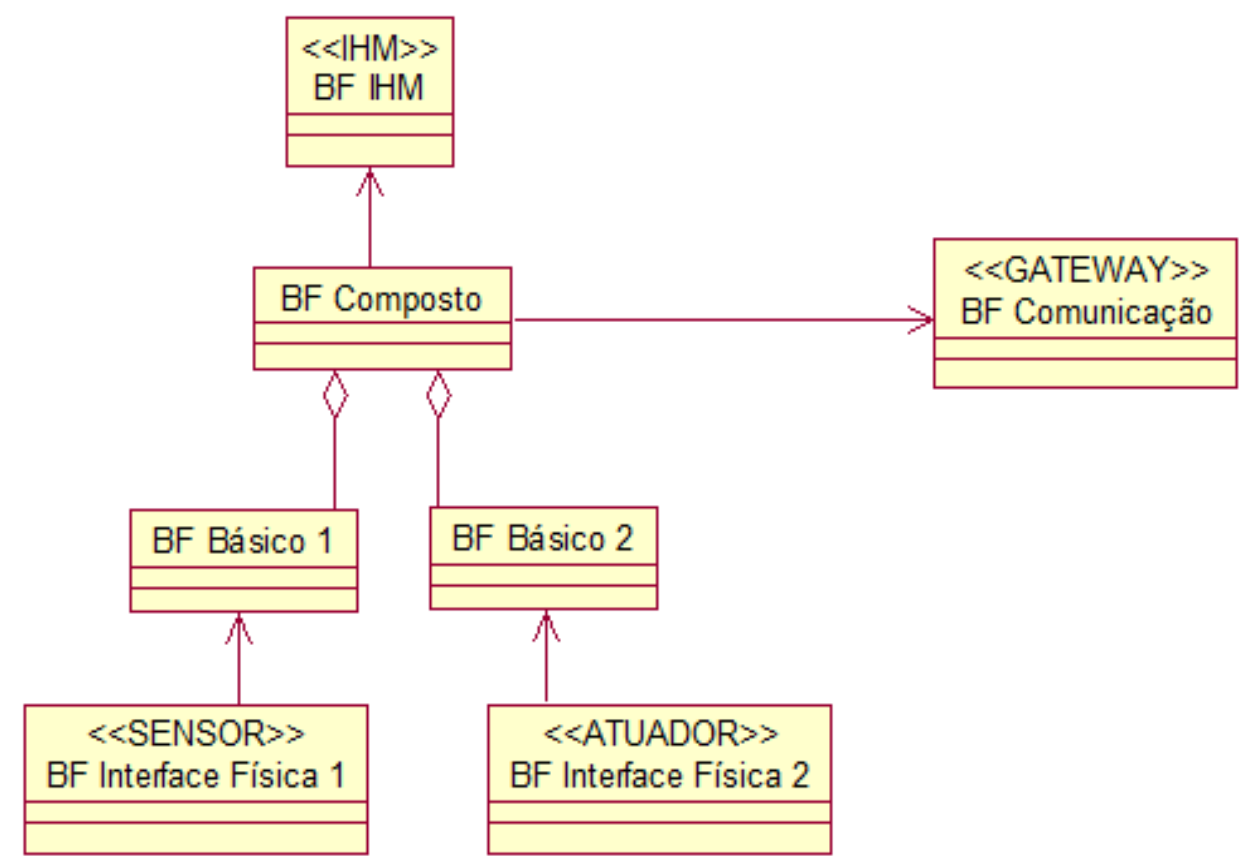

Figura 50: Exemplo de Diagrama de Classes segundo o mapeamento UML-IEC61499 simplificado.

Uma interface, por sua vez, cumpre o papel de um adaptador da norma IEC 61499 (já que ambas abstrações conseguem reduzir a representação da interface de uma classe ou bloco funcional, e ajudam no reuso de definições). Quando uma classe indicar um relacionamento de realização em relação a uma interface (seja na notação reduzida (plugue), seja na notação expandida), denota-se que o tipo de adaptador representado pela interface está incluído no tipo de bloco funcional determinado pela classe, cumprindo a função de adaptador plugue. Por sua vez, quando houver um relacionamento de dependência entre uma classe e uma interface (seja na notação reduzida (soquete), seja na notação expandida), também é inferido que o tipo de adaptador representado pela interface está incluído no tipo de bloco funcional determinado pela classe, mas desta vez cumprindo a função de adaptador soquete.

Quanto aos relacionamentos estabelecidos entre classes, têm significado especial os relacionamentos de agregação (que indicam a existência de blocos funcionais compostos) e os relacionamentos de generalização, que podem ser usados entre classes de um diagrama para que um tipo de bloco funcional herde as características de outro (para fins de reutilização de especificações) - assim, tornase mais fácil compor novos tipos de blocos funcionais a partir de blocos funcionais pré-existentes. 


\subsubsection{Diagrama de Interação}

Para designar as conexões de eventos e dados entre instâncias de blocos funcionais, podem ser usados alternativamente o Diagrama de Seqüência ou o Diagrama de Colaboração/Comunicação, de acordo com o tipo de visão que se queira ter dessas interações: para o ponto de vista da relação temporal entre as interações, recomenda-se o uso do primeiro; e para o entendimento da estrutura usada para as interações, aconselha-se o uso do segundo.

Tanto no Diagrama de Seqüência quanto no Diagrama de Colaboração, os objetos designam instâncias de um tipo de bloco funcional (já que este é representado por uma classe, conforme dito anteriormente). Por sua vez, as mensagens intercambiadas entre os objetos estipularão as conexões entre eventos e dados de instâncias de blocos funcionais, conforme disposto abaixo:

- Uma chamada de método configura uma conexão entre uma saída de evento do bloco funcional (objeto) chamador e uma entrada de evento do bloco funcional (objeto) chamado. O nome da entrada e da saída de evento deve corresponder ao nome do método invocado (adicionado do número identificador os objetos chamador e chamado);

- Se houver algum parâmetro no método chamado, este deve gerar uma ligação entre uma saída de dado do bloco funcional (objeto) chamador e uma entrada de dado do bloco funcional (objeto) chamado. Neste caso, a entrada ou saída de dado deve ser conectada a sua respectiva entrada ou saída de evento (referente à chamada do método) pelo qualificador WITH. O nome da entrada e da saída de dado deve corresponder ao nome do parâmetro passado na mensagem (adicionado do número identificador os objetos chamador e chamado);

- Caso o método possua um parâmetro de valor de retorno, deve-se adicionar uma ligação entre uma saída de evento do bloco funcional (objeto) chamado e uma entrada de evento do bloco funcional (objeto) chamador (correspondente à indicação de retorno do método), e, adicionalmente, uma saída de dado do bloco funcional (objeto) chamado e uma entrada de dado do bloco funcional (objeto) chamador (correspondente ao valor de retorno). Neste caso, a entrada ou saída de dado deve ser conectada a sua respectiva entrada ou saída de evento (referente à chamada do método) 
pelo qualificador WITH. O nome das entradas e saídas de eventos e de dados deve ser composto de acordo com as regras descritas anteriormente, inclusive mantendo-se a numeração original do objeto chamador e do objeto chamado nessa ordem (assim, pode-se identificar uma ligação de eventos e dados correspondentes a um retorno de valor). Como normalmente não há um nome para um parâmetro de retorno, pode-se atribuir a qualquer retorno um nome padrão (como "retorno", por exemplo, acrescido de um número seqüencial).

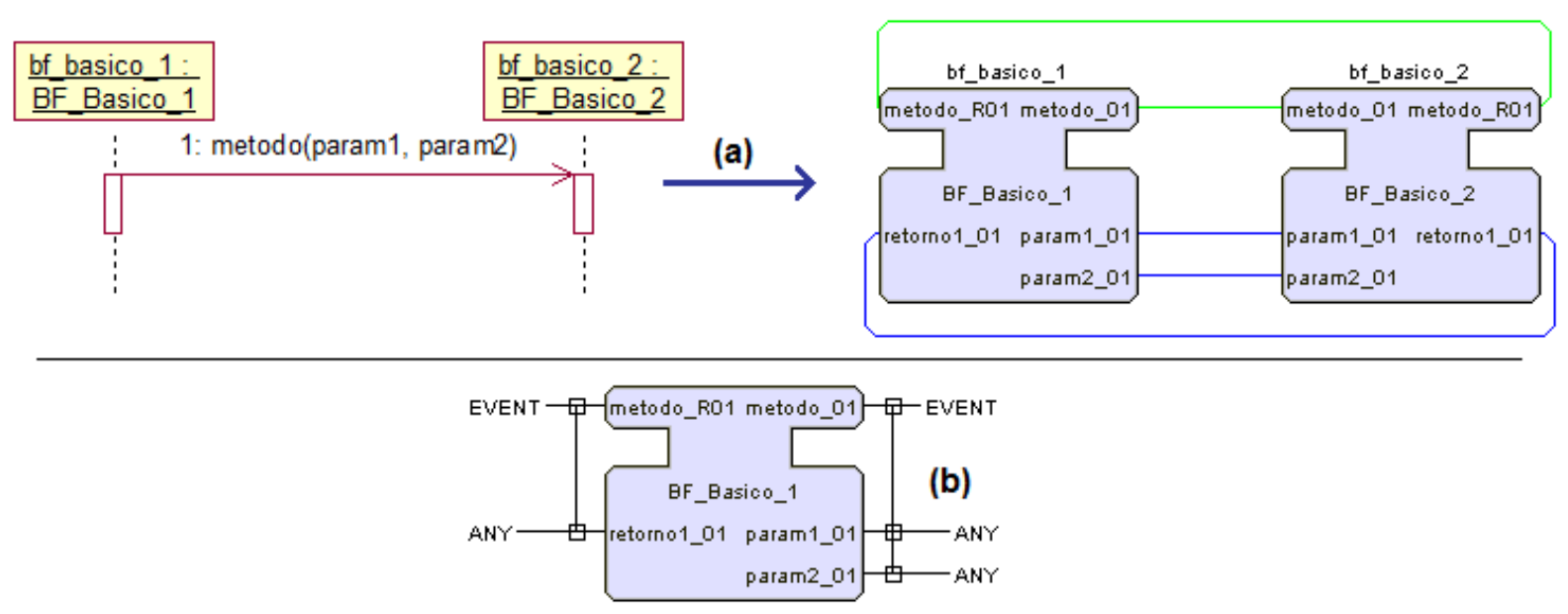

Figura 51: Exemplo de conversão de método com parâmetros e valor de retorno para uma rede de blocos funcionais (a) e detalhe da interface externa de um dos blocos funcionais (b), segundo o mapeamento UML-IEC61499 simplificado.

Uma chamada a um método próprio da classe será interpretado como algoritmo interno, e não vai gerar saídas de dados e eventos externas (já que o objeto tem controle sobre seu próprio estado e variáveis)

Neste ponto, para uma boa representação das abstrações da norma IEC 61499 quando da execução da conversão UML-IEC61499, deve-se observar quais métodos das classes corresponderiam a implementações de operações indicadas por interfaces. Dessa maneira, é possível agrupar as entradas e saídas de dados e eventos correspondentes em adaptadores adequados, cujos nomes devem corresponder ao nome da interface que representa esse tipo de adaptador (conforme descrito na parte referente a Diagramas de Classes). Vale destacar que, mesmo que uma relação de dependência não tenha sido explicitada entre a interface e a classe representante do tipo de bloco funcional aceitador, o seu adaptador 
soquete deve ser criado, a fim de que uma ligação entre adaptadores desses blocos funcionais possa ser estabelecida.

O relacionamento entre as instâncias contidas em um bloco funcional composto, e a ligação das mesmos à interface externa de seu bloco contenedor também deve ser dada por Diagramas de Seqüência ou de Colaboração/Comunicação, que devem ser estruturados da mesma forma como descrito anteriormente. Portanto, as mensagens trocadas entre 0 objeto representante do bloco funcional composto com os objetos que designam os blocos funcionais contidos estabelece a conexão entre os seus elementos de interface.

Por fim, como um bloco funcional de interface de serviços possui entradas e saídas de dados e eventos específicas (ditadas pela norma IEC 61499), deve-se ressaltar que no caso de haver troca de mensagens com um objeto que represente uma instância desse tipo de bloco funcional, as seguintes restrições na nomenclatura dos eventos e métodos devem ser tomadas em consideração (destaca-se que todas as regras vistas anteriormente permanecem mantidas caso não se explicite o contrário):

- A invocação de métodos de um objeto representante de um bloco funcional de interface de serviços por parte de um objeto representante de um bloco funcional qualquer da aplicação deve gerar no bloco funcional de interface de serviços uma entrada de evento obrigatoriamente denominada REQ (ao qual a saída de eventos do bloco funcional da aplicação deve ser conectado). Por fim, se houver valor de retorno para esse método, deve-se gerar uma saída de eventos obrigatoriamente chamada CNF no bloco funcional de interface de serviços, conectada à entrada de eventos do bloco funcional da aplicação; e

- A invocação de métodos de um objeto representante de um bloco funcional qualquer da aplicação por parte de um objeto representante de um bloco funcional de interface de serviços deve gerar no bloco funcional de interface de serviços uma saída de evento obrigatoriamente denominada IND (ao qual a entrada de eventos do bloco funcional da aplicação deve ser conectado). Por fim, se houver valor de retorno para esse método, deve-se gerar uma entrada de eventos obrigatoriamente chamada RSP no bloco funcional de interface de serviços, conectada à saída de eventos do bloco funcional da aplicação; e 
- No caso em que se queira inicializar as funções de um objeto referente a um bloco funcional de interface de serviços, um nome específico de método de inicialização deve ser estipulado (como init(), por exemplo). Assim, quando houver necessidade de fazer uma chamada a esse método do objeto, tal chamada poderá ser traduzida para as abstrações da norma IEC 61499 através da criação de uma conexão de eventos entre os blocos funcionais relacionados aos objetos em comunicação, ligada à entrada de eventos do bloco funcional de interface de serviços que deve obrigatoriamente ser chamada INIT. Caso haja parâmetros para este método, estes devem ser transformados em dados estruturados, passados por meio da entrada de dados denominada mandatoriamente PARAMS. Por fim, se houver valor de retorno para esse método, a saída de eventos relacionada deve ser chamada INITO.

Caso um objeto representante de um bloco funcional de interface de serviços tenha mais de um método a oferecer aos objetos da aplicação (interação REQ-CNF), uma alternativa possível para distinguir uma chamada a um desses métodos em especial é atribuir a cada um deles um número de identificação. Quando for detectado que um objeto está invocando um desses métodos, a transformação UML-IEC61499 gerará uma entrada de dados no bloco funcional de interface de serviços, que servirá para receber o número identificador do método, de acordo com seu nome.

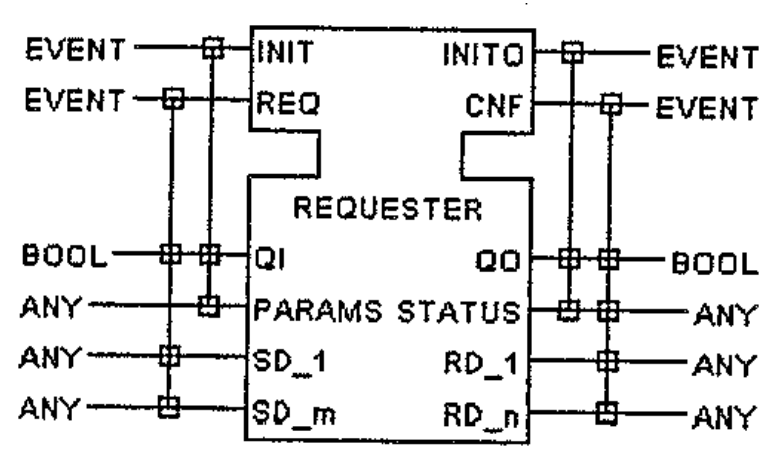

(a)

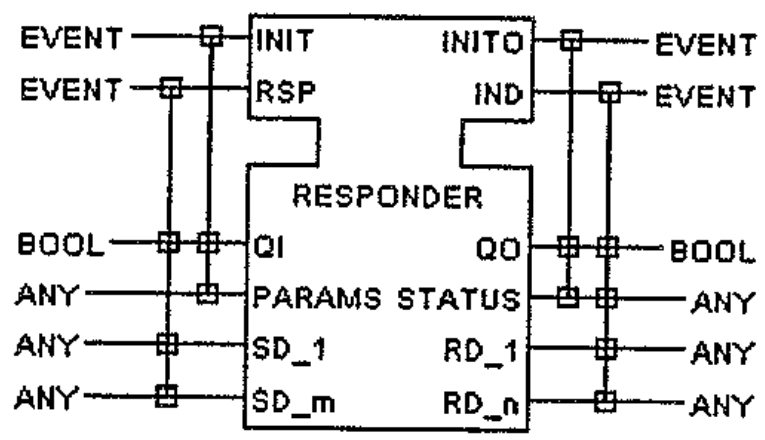

(b)

Figura 52: Exemplos de blocos funcionais de interface de serviços, para interações iniciadas pela aplicação (a) e para interações iniciadas pelo recurso (b) - retirado de International Electrotechnical Commission (2005a). 


\subsection{Diagrama de Máquinas de Estados}

O Diagrama de Máquinas de Estados deve ser utilizado para designar o comportamento interno dos objetos que representam blocos funcionais básicos de uma aplicação da norma IEC 61499.

Os estados (simples), transições, eventos, condições de guarda e ações de uma máquina de estados encontram correspondentes diretos no diagrama de controle de execução (Execution Control Chart - ECC) de um bloco funcional básico. No entanto, deve-se destacar, quanto a tal conversão UML-IEC61499:

- Conforme as condições dadas às modelagens em UML, todos os estados desse tipo de diagrama devem ser simples para que o mapeamento seja possível (já que não há estados compostos no diagrama de controle de execução da norma IEC 61499);

- Sempre deve haver um estado inicial em uma máquina de estados da UML, a ser transformado no estado chamado START do diagrama de controle de execução da norma IEC 61499;

- As atividades indicadas para execução dentro de um estado da UML (normalmente dadas em termos de métodos privados do objeto) devem ser transformadas em algoritmos associados a uma ação de um estado da norma IEC 61499;

- Caso o evento de saída de um estado da UML implique a chamada a um método de um objeto externo, deve-se vincular à ação referente ao estado da IEC 61499 uma indicação de evento de saída (cujo nome é determinado pelo nome do método, como visto anteriormente);

- Se o gatilho de uma transição entre estados da UML for justamente a chamada a um método do objeto em questão, deve-se colocar como gatilho da transição do diagrama de controle de execução (ECC) o evento de entrada do bloco funcional associado, cujo nome é determinado pelo nome do método, conforme visto anteriormente; $\mathrm{e}$

- Da mesma maneira, se na ação associada a uma transição entre estados da UML houver uma chamada a um método de um objeto externo ao que está sendo considerado, a mesma deve ser substituída, na ação da transição entre estados do diagrama de controle de execução, por uma referência a um evento de saída do bloco funcional. 


\subsubsection{Diagrama de Atividades}

Os Diagramas de Atividades podem ser utilizados para especificar em maiores detalhes os algoritmos referentes às atividades citadas nos estados dos Diagramas de Estados da UML.

No entanto, apesar de relativamente simples dada a estrutura geral dos diagramas da UML, a conversão destes para a especificação de algoritmos prevista pela norma IEC 61499 depende de que as ações descritas no diagrama já estejam em uma linguagem padronizada pela norma (como texto estruturado, por exemplo). Caso contrário, os algoritmos obtidos após a tradução servirão como documentação do comportamento esperado, mas não como código compilável para aplicações da norma IEC 61499.

\subsection{Diagrama de Distribuição (Deployment)}

O Diagrama de Distribuição deve ser utilizado para expressar uma visão geral do sistema de automação, em que se dá ênfase a quais devem ser os principais dispositivos físicos usados nesse projeto (inclusive controladores) - ainda que isso sirva apenas como uma primeira sugestão, a ser refinada pela equipe de engenharia de controle e automação responsável pelo projeto de baixo nível e implementação do sistema.

Os nós da UML devem ser convertidos para dispositivos da norma IEC 61499. Por sua vez, os relacionamentos de associação entre eles designarão os links e segmentos da rede de comunicação a compor o sistema de automação distribuído. Finalmente, se for necessário que a equipe de engenharia de software indique em que nós certos objetos devem ser processados, tais nós deverão ter o estereótipo Controlador e deverão ser mapeados em dispositivos da norma IEC 61499 em que haja um só recurso (já que esta abstração da IEC 61499 não poderá ser designada explicitamente pela UML). Posteriormente, os blocos funcionais referentes aos objetos citados (vinculados aos nós por relacionamentos de dependência) deverão ser atribuídos à configuração desse recurso, segundo a norma IEC 61499. 


\subsubsection{Comentários}

O método de mapeamento UML-IEC61499 simplificado tem como influência principal o mapeamento UML-IEC61499 sugerido por Thramboulidis, já que este mantém o foco da representação de sistemas por parte dos engenheiros de sistemas e software justamente na sua maior especialidade: a aplicação. Apesar disso, a principal desvantagem que se tentou contornar em relação a esse mapeamento foi o uso excessivo de estereótipos vinculados estritamente à IEC 61499, dando maior liberdade aos usuários da UML ao projetar um sistema de automação segundo conceitos mais facilmente acessíveis do que aqueles da norma IEC 61499 (que exigem conhecimento específico dessa padronização). Por outro lado, ressalta-se que, apesar do sistema de automação distribuído poder ser projetado por meio de diversos diagramas, apenas um pequeno subconjunto de elementos da UML deve ser usado para a conversão entre abstrações dessa linguagem para aquelas próprias da norma IEC 61499.

A partir dessa conversão, adicionalmente, o projeto deve ser verificado, refinado e complementado por especialistas da área de engenharia de controle e automação, que conheçam a norma IEC 61499 e se utilizem de ferramentas compatíveis com a mesma, para que esse desenvolvimento possa chegar à etapa de implementação e testes. Por exemplo, os blocos funcionais gerados podem ser agrupados em subaplicações (já que estas não têm representação prevista em UML) e devem ser redistribuídos entre recursos e dispositivos (dado que a descrição física e de distribuição da aplicação necessariamente deve ser revisada).

\subsubsection{Mecanismos para representação de parâmetros temporais em modelos de sistemas de automação}

Segundo Bordbar, Derrick e Waters (2002), métodos tradicionais de engenharia de sistemas não focalizam o desenvolvimento de sistemas distribuídos, particularmente com respeito a questões de desempenho e suas restrições associadas de qualidade de serviço (Quality of Service - QoS). Quando aplicado no âmbito computacional, QoS está relacionado a características de desempenho de elementos de um sistema (quanto a atrasos e erros em suas funções, por exemplo) que afetam o serviço desse sistema como um todo - contrapondo-se, dessa forma, à 
descrição de aspectos meramente funcionais. Alguns atributos de QoS de interesse no contexto de aplicações multimídia, por exemplo, são atraso e variação de atraso na transmissão de pacotes de dados - dimensões relacionadas à temporização, e vazão de uma rede de comunicação - dimensão relacionada a volume.

Um sistema de automação distribuído, é, em grande parte dos casos, um sistema de tempo real: conforme a definição de Booch, Rumbaugh e Jacobson (1998), nesse tipo de sistema certos comportamentos devem ser executados em momentos precisos (absoluto ou relativo), dentro de períodos predizíveis (e, na maior parte das vezes, restritos).

Muito embora o grau de exigência de especificação dos requisitos temporais possa variar, dependendo da aplicação do sistema considerado (segundo Booch, Rumbaugh e Jacobson (1998), podem existir desde sistemas de tempo real estritos (hard real time), que requerem a execução de comportamentos de forma completa e repetível dentro de nanossegundos ou milissegundos, até outros sistemas que comportam a execução de comportamentos em períodos da ordem de segundos ou até maiores), é necessário, para que um sistema distribuído alcance o desempenho desejado, que sentenças sobre os parâmetros de QoS associados a tempo sejam enunciadas.

Apesar da importância do tema, percebe-se que nenhum dos mapeamentos UML-IEC61499 prevê a expressão de tais requisitos, nem primeiramente na UML, nem posteriormente sua tradução para atributos das abstrações da norma IEC 61499.

Assim, sugere-se neste trabalho a utilização de restrições (contraints), mecanismos de extensão da semântica de um elemento da UML, para a enunciação de requisitos de temporização dos modelos de sistemas de automação distribuídos feitos nessa linguagem (segundo a forma descrita na seção referente ao mapeamento UML-IEC61499 simplificado). Com tais restrições disponíveis, os requisitos de temporização poderão ser transferidos para as representações do sistema de automação dados em abstrações da norma IEC 61499, dada a execução da conversão UML-IEC61499. 
5.1.2.1. Parâmetros temporais relevantes para o projeto de sistemas de automação distribuídos dados segundo a norma IEC 61499

Uma lista reduzida mas significativa de parâmetros temporais relevantes para o projeto de sistemas de automação modelados segundo a norma IEC 61499 inclui:

- Marcos de tempo e períodos de duração da comunicação entre blocos funcionais; e

- Estimativa da duração da execução dos algoritmos de um bloco funcional básico.

Apesar de tal relação ficar muito aquém do necessário para exaurir o tema da expressão de requisitos de QoS em sistemas de automação distribuídos, a mesma serve como base para início dos trabalhos relacionados a essa área, devendo ser expandida em trabalhos posteriores.

5.1.2.1.1. Especificação de marcos de tempo e períodos de duração da comunicação entre blocos funcionais

Uma das opções para a especificação de marcos de tempo e períodos de duração da comunicação entre blocos funcionais em UML é a colocação de restrições e observações de tempo e de duração nos Diagramas de Seqüência.

As restrições e observações de tempo e de duração são recursos específicos da UML 2.X para estabelecer parâmetros de temporização:

- Uma observação de tempo (TimeObservation) estipula uma referência para a marcação do tempo;

- Uma restrição de tempo (TimeConstraint) é uma condição sobre o limite de tempo em que determinado comportamento do sistema deva se manifestar;

- Uma observação de duração (DurationObservation) estipula uma referência para a mensuração de um período de tempo; e

- Uma restrição de duração (DurationConstraint) é uma condição sobre o período de tempo em que determinado comportamento do sistema deva ocorrer.

Qualquer restrição da UML pode ser dada em um texto feito em linguagem natural ou em alguma linguagem passível de interpretação computacional (machine 
readable language) - por exemplo, uma sentença em linguagem de programação Java ou mesmo linguagens especiais para a descrição de restrições em diagramas UML (como a Object Constraint Language (OCL), em que, segundo Bordbar, Derrick e Waters (2002), os blocos básicos de construção das expressões são os objetos e suas propriedades).

Em um Diagrama de Seqüência a ser mapeado em um modelo de abstrações da IEC 61499, observações e restrições de tempo e de duração poderiam ser colocados nos diagramas para condicionar a temporização da troca de mensagens entre objetos representantes de blocos funcionais: portanto, tais restrições, no momento de uma conversão UML-IEC61499, deveriam ser aplicadas às conexões de eventos e dados das instâncias de blocos funcionais envolvidas na comunicação, e, do ponto de vista prático, colocadas como texto em um atributo associado a essas conexões. Vale lembrar que a declaração de atributos específicos de aplicação está prevista no Anexo G da Parte 1 da norma IEC 61499.

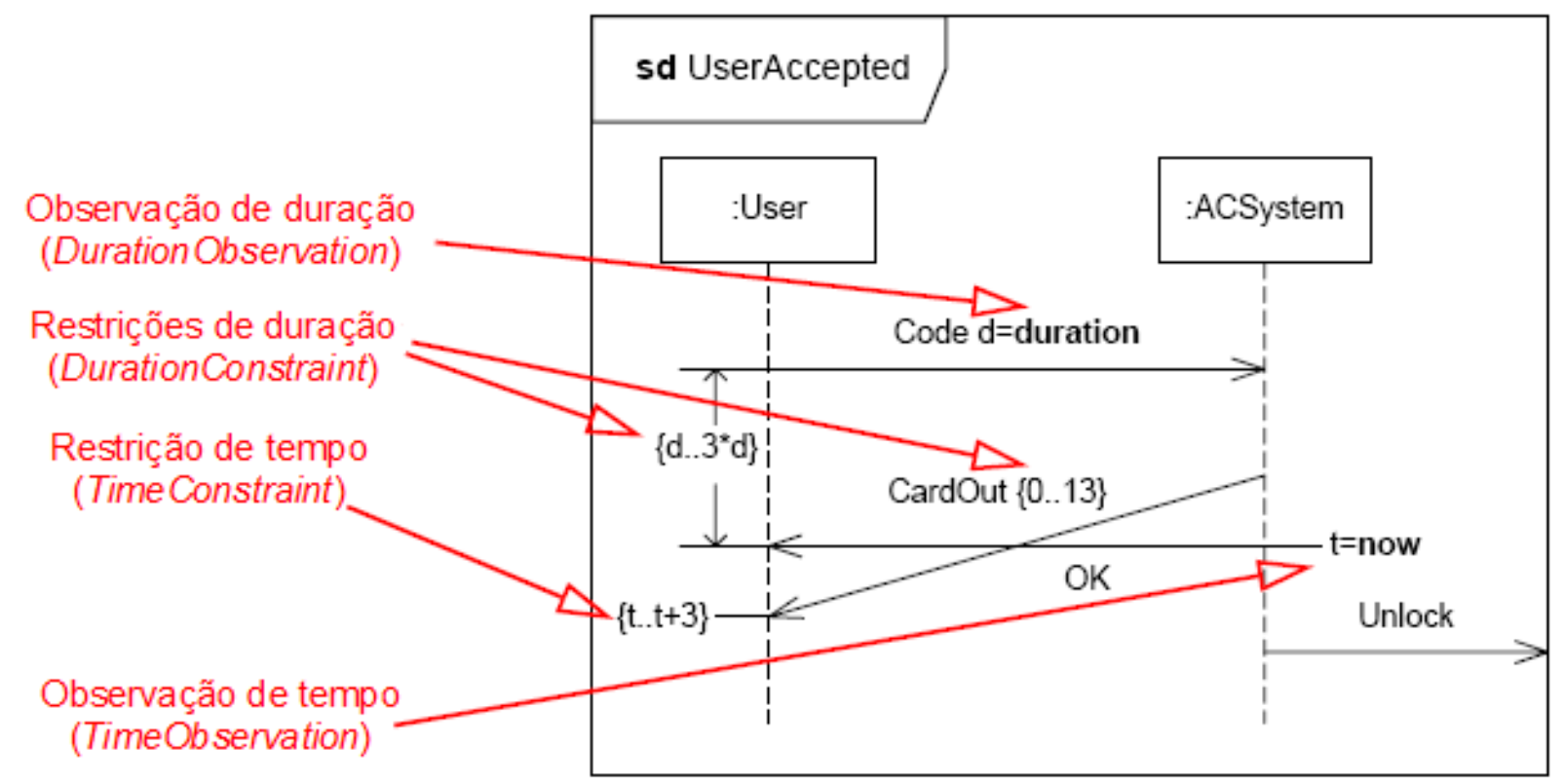

Figura 53: Diagrama de Seqüência (da UML 2.X) com ênfase nas observações de tempo e duração, e nas restrições de tempo e duração - traduzido de Object Management Group (2007). 
Outro tipo de diagrama da UML 2.X que poderia ser utilizado seria 0 Diagrama de Temporização.

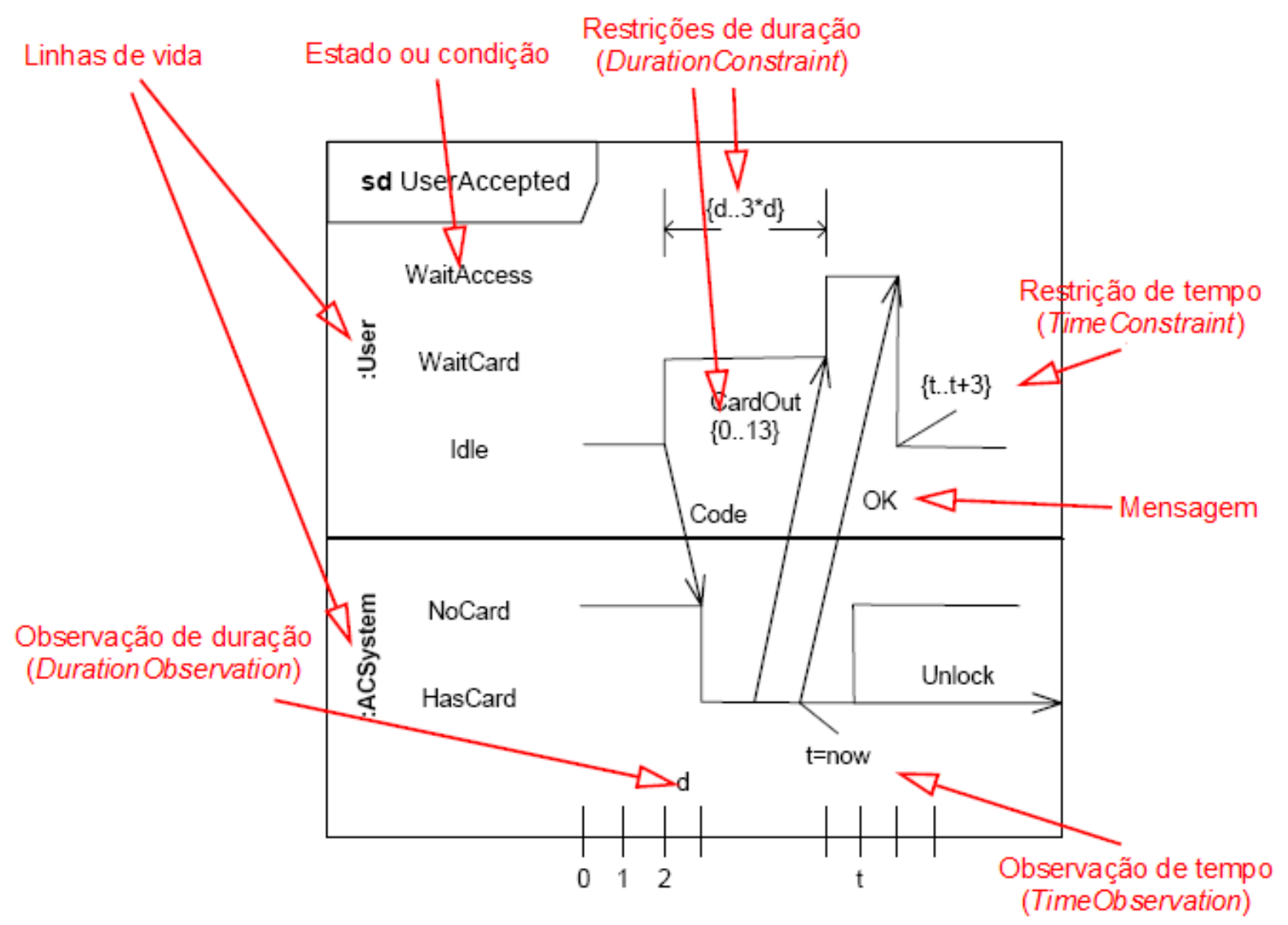

Figura 54: Diagrama de Temporização (da UML 2.X) com ênfase nas observações de tempo e duração, e nas restrições de tempo e duração - traduzido de Object Management Group (2007).

Alguns exemplos de restrições temporais para a transmissão de eventos e blocos funcionais incluiriam, por exemplo, a duração máxima de tempo entre a emissão de um evento e sua recepção por parte de um bloco funcional, a duração de tempo (atraso) entre a chegada do evento a um bloco funcional e a amostragem de seus dados correspondentes e o limite de tempo entre a recepção de um evento e a resposta a esse evento por parte de um bloco funcional.

A notação específica a ser utilizada para expressar essas idéias dependeria da linguagem escolhida para as restrições. O uso de um formato adequado para as expressões e de uma linguagem como a Real-Time Logic (RTL), por exemplo lógica formal para expressão de comportamento de sistemas - ajudaria inclusive em que os modelos gerados pudessem ser verificados por meio de ferramentas de interpretação e simulação baseadas nas expressões das restrições. 
5.1.2.1.2. Especificação de estimativa da duração da execução dos algoritmos de um bloco funcional básico

De maneira semelhante, mecanismos de extensão gerais da UML (como restrições e valore rotulados) podem ser usadas para especificar dados de temporização quanto à duração de um método privado de uma classe, que seria interpretado como um algoritmo de um bloco funcional básico no caso de uma conversão UML-IEC 61499.

Segundo Booch, Rumbaugh e Jacobson (1998), por exemplo, o valor rotulado semantics, que permite a inserção de uma descrição sobre a semântica de um elemento, poderia ser vinculado a uma operação qualquer. Colocando-se uma expressão de tempo nesse valor, seria possível modelar a complexidade temporal da operação (tipicamente, o período máximo, mínimo e/ou médio de tempo em que a operação deveria ter sido finalizada). Tal artifício poderia ser usado, assim, para estimar e comparar os tempos de execução projetados e obtidos com a implementação de uma operação, e também para obter a complexidade temporal de uma transação computacional completa.

Vale destacar que um atributo já previsto pela norma IEC 61499 chama-se ExecutionTime, e é justamente relacionado ao tempo de execução, no pior caso, de um algoritmo de um certo tipo de bloco funcional em um determinado tipo de recurso (INTERNATIONAL ELECTROTECHNICAL COMMISSION, 2005a).

\subsection{Comentários}

No campo de requisitos de temporização aplicados a sistemas de automação distribuídos, apesar da contribuição apresentada acima para mapeamentos UML-IEC61499, ainda há muito espaço para a realização de trabalhos.

Em primeiro lugar, seria necessário estipular um conjunto de medidas de interesse prático sobre os requisitos de QoS (em especial os de temporização). A seguir, seria interessante estipular o formato e a linguagem de cada expressão desses requisitos, de preferência prevendo a criação ou a utilização de ferramentas computacionais para avaliá-las e, com isso, simular o comportamento dinâmico do sistema. Em caso de uso da UML como meio para o projeto de sistemas, uma outra 
área de estudos correlata seria a avaliação de perfis (profiles) UML para a expressão específica de sistemas de tempo real. Como esse é um tema bastante vasto, suspende-se por aqui a sua discussão, sugerida como uma possível continuação deste trabalho.

\subsection{EXTENSÕES DAS FERRAMENTAS COMPUTACIONAIS PARA SUPORTE ÀS ATIVIDADES DE ENGENHARIA VOLTADAS AO DESENVOLVIMENTO DE SISTEMAS DE AUTOMAÇÃO DISTRIBUÍDOS}

Tendo em vista as ferramentas computacionais analisadas no capítulo 4, entende-se que uma possível contribuição neste âmbito possa ser a sugestão da construção de uma ferramenta que permita a implementação de um sistema de automação distribuído baseado na tecnologia LonWorks a partir dos modelos de sistema dados pelas abstrações da norma IEC 61499. Dessa maneira, considerando também a aplicação de conversões UML-IEC61499 quando necessário, conseguirse-ia cobrir todo o ciclo de desenvolvimento de um sistema de automação, desde o levantamento de requisitos até a implementação, testes e manutenção de um sistema, concretizado por meio de uma tecnologia muito bem aceita e difundida no mercado de automação.

Para mostrar a viabilidade da construção dessa ferramenta, analisa-se nesta seção, primeiramente, a compatibilidade entre as abstrações da norma IEC 61499 e das abstrações previstas pela tecnologia LonWorks. Uma vez constatada a capacidade de aproximar esses diferentes modelos lógicos, parte-se para a indicação de possíveis formas de construção de uma nova ferramenta computacional para suporte às atividades de engenharia voltadas ao desenvolvimento de sistemas de automação distribuídos. 
5.2.1. Compatibilidade entre as abstrações da norma IEC 61499 e das abstrações previstas pela tecnologia LonWorks para o projeto de sistemas de automação distribuídos

Nesta parte, apresentam-se inicialmente os conceitos sobre os modelos lógicos de sistemas de automação distribuídos aceitos no âmbito de sistemas LonWorks. A seguir, comparam-se essas abstrações às da norma IEC 61499.

Para evitar a repetição desnecessária de referências, destaca-se que todas as informações sobre a tecnologia LonWorks expostas no presente item foram baseadas em Echelon Corporation (1999, 2005).

5.2.1.1. Elementos lógicos dos sistemas LonWorks (com ênfase na representação de aplicações de sistemas distribuídos)

\subsection{Instâncias dos elementos das aplicações LonWorks}

\subsection{Bloco funcional}

As aplicações de um dispositivo LonWorks são subdivididas em blocos funcionais (Functional Blocks - fblock).

Um bloco funcional recebe dados de entrada (operacionais e de configuração, provenientes da rede, do hardware do dispositivo ou de outros blocos funcionais), executa o processamento de tais dados, e, como conseqüência, pode gerar dados de saída (enviados, da mesma maneira, para a rede, o hardware ou outros blocos funcionais).

As entradas e saídas de um bloco funcional são feitas por meio de variáveis de rede (Network Variables - NV), as quais são os dados operacionais do bloco funcional, ou por propriedades de configuração (Configuration Properties - CP), sendo estas os dados para configuração de variáveis de rede, de blocos funcionais ou do dispositivo como um todo. Segundo Echelon Corporation (2005), o bloco funcional é um conceito orientado a objetos, para o qual as variáveis de rede e as propriedades de configuração representam o papel de membros.

Um bloco funcional deve ser implementado sempre quando for necessário que uma determinada função executada por um dispositivo seja acessada por outros 
dispositivos ou deva ser configurada externamente. Dessa forma, o bloco funcional cumpre a tarefa de oferecer uma interface externa para permitir que o dispositivo possa interagir com outros elementos do sistema LonWorks.

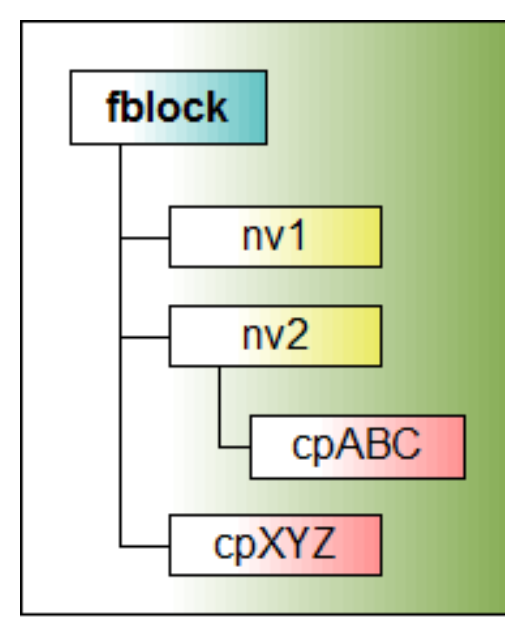

\author{
O bloco funcional é representado pelo \\ bloco fblock \\ As variáveis de rede são membros do \\ bloco fblock \\ Esta propriedade de configuração \\ aplica-se à nv 2 \\ Esta propriedade de configuração \\ aplica-se a todo o bloco fblock
}

Figura 55: Representação teórica de um bloco funcional LonWorks.

\title{
5.2.1.1.1.2. Variável de rede
}

Uma variável de rede (NV) permite ao bloco funcional ao qual está associada (sendo este um e apenas um bloco) intercambiar dados com os demais blocos funcionais de uma aplicação LonWorks. Cada variável de rede possui, como atributos principais, uma direção (variável de entrada, caso seja usada para receber dados, ou variável de saída, caso seja usada para enviar dados) e segue um determinado modelo ou tipo (que define as unidades, as escalas e a estrutura dos dados contidos na variável).

Variáveis de rede de mesmo tipo e direções opostas podem ser conectadas para permitir que seus blocos funcionais intercambiem dados: tal operação é denominada binding (termo do inglês que poderia ser traduzido como "interligar"), e pode ocorrer tanto no projeto da rede de dispositivos LonWorks (fase de engenharia do sistema) quanto no momento de sua instalação (fase de implementação), através de ferramentas computacionais de gerenciamento da rede LonWorks.

Uma única variável de rede de saída pode ser logicamente conectada a apenas uma ou a múltiplas variáveis de rede de entrada (nesse último caso, trata-se de uma conexão fan-out). Por sua vez, uma única variável de entrada pode receber apenas uma ou múltiplas variáveis de rede de saída (o que é denominado conexão 
fan-in). Assim, através do binding, quando há modificações no valor de uma variável de saída, a(s) variável(is) de entrada conectada(s) a ela recebe $(\mathrm{m})$ a atualização do dado em questão.

Para exemplificar este ponto, um binding se dá quando um dispositivo que possui um bloco funcional representando uma chave (switch), com uma variável de rede de saída chamada switch on/off, é ligado a outro dispositivo que possui um bloco funcional relacionado a uma lâmpada (lamp), com uma variável de rede de entrada chamada lamp on/off. ao se criar uma conexão entre essas duas variáveis de rede, tem-se o mesmo efeito funcional de conectar um cabo (físico) entre a chave e a lâmpada.

\subsection{Propriedade de configuração}

Uma propriedade de configuração (CP) é um item de dados que caracteriza o comportamento de um dispositivo em um sistema, já que ele descreve um valor de configuração para uma ou mais variáveis de rede, para um ou mais blocos funcionais ou mesmo para o próprio dispositivo como um todo. Ela é a implementação de um determinado modelo ou tipo de propriedade de configuração (que define as unidades, as escalas e a estrutura dos seus dados).

Um propriedade de configuração que pode ser tomada como um exemplo chama-se cpMaxSendTime. Sua função é especificar o tempo máximo de envio de uma variável através da rede LonWorks após uma alteração em seu valor.

\subsection{Tipos ou modelos para os elementos das aplicações LonWorks}

\subsection{Perfil funcional}

Um perfil funcional ou modelo de perfil funcionais (Functional Profile - FP ou Functional Profile Template - FTP) define um tipo de bloco funcional, sendo ele especificado para viabilizar a realização de uma única tarefa em um dispositivo.

Os perfis funcionais descrevem quais são os seus membros obrigatórios e opcionais (ou seja, quais variáveis de rede e propriedades de configuração são mandatórias ou não), e contém, ainda, descrições adicionais sobre o significado semântico de cada um de seus dados internos. 
Cada bloco funcional da aplicação é a implementação de um perfil funcional determinado. Vale ressaltar que, ao instanciar um perfil funcional, o bloco funcional deve implementar todos os membros obrigatórios definidos pelo perfil funcional, e pode implementar algum, todos ou nenhum dos membros opcionais. Um bloco funcional pode também conter novos membros, que não estão pré-definidos no perfil funcional, sendo estes denominados membros específicos de implementação (implementation-specific members).

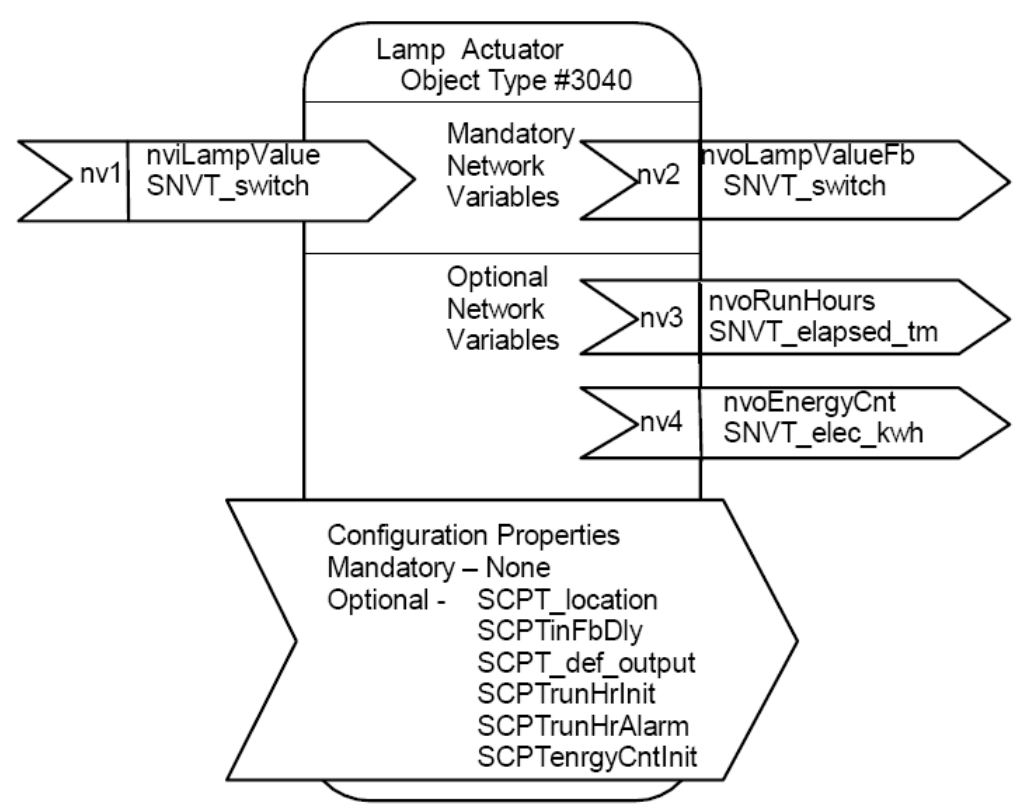

Figura 56: Representação de um perfil funcional LonWorks.

5.2.1.1.2.2. Tipo de variável de rede

Um tipo ou modelo de variável de rede (Network Variable Type - NVT) especifica as informações sobre a estrutura e formato dos dados que devem estar contidos em uma variável de rede.

Se a variável for um valor escalar (ou seja, como um valor inteiro, ou uma enumeração, por exemplo), apresentam-se, como informações principais, seu tipo, tamanho (em bytes), intervalo de valores puros (raw values - sendo esses valores especificados em inteiros, correspondentes aos bytes da variável), valores puros inválidos, fatores de escala (a serem aplicados aos valores puros, para gerar o valor final - ou processado - da variável), intervalo de valores (processados) válidos, unidade e resolução. Caso a variável seja composta por uma estrutura de dados, as 
características citadas anteriormente são especificadas para cada um de seus elementos. De maneira geral, pode-se afirmar também que um tipo de variável de rede pode herdar suas características de um outro modelo de variável de rede.

\subsection{Tipo de propriedade de configuração}

Similarmente ao caso anterior, um tipo ou modelo de propriedade de configuração (Configuration Property Type - CPT) especifica as informações sobre a estrutura e formato dos dados que devem estar contidos em uma propriedade de configuração.

Se a propriedade de configuração for um valor escalar, apresentam-se, como informações principais, seu tipo, tamanho (em bytes), intervalo de valores puros (raw values - sendo esses valores especificados em inteiros, correspondentes aos bytes da propriedade de configuração), valores puros inválidos, fatores de escala (a serem aplicados aos valores puros, para gerar o valor final - ou processado - da variável), intervalo de valores (processados) válidos, unidade, resolução e valor padrão (default value). Caso a propriedade de configuração seja composta por uma estrutura de dados, as características citadas anteriormente são especificadas para cada um de seus elementos. De maneira geral, pode-se afirmar também que um tipo de propriedade de configuração pode herdar suas características de um outro modelo de propriedade de configuração ou de um modelo de variável de rede.

\subsection{Relacionamento entre os sistemas LonWorks e suas aplicações}

Em geral, um dispositivo LonWorks contém uma aplicação, que consiste de um ou mais blocos funcionais, os quais podem ser configurados e usados de forma isolada, sendo cada um dos mesmos baseado da definição de um perfil funcional. Os blocos funcionais podem ser, então, conectados entre si, independentemente do dispositivo em que estejam alocados. 


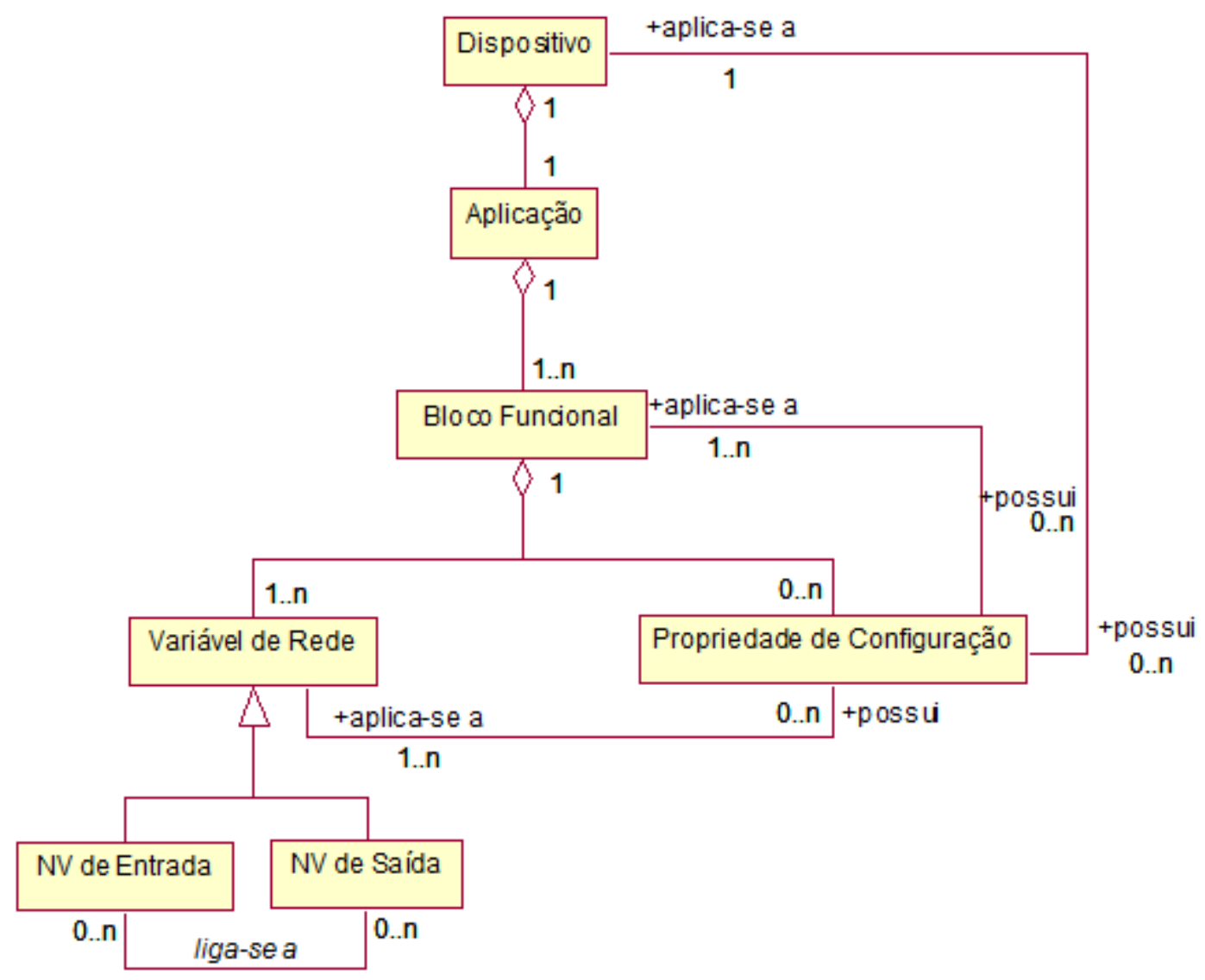

Figura 57: Relacionamento entre modelos lógicos LonWorks.

5.2.1.2. Comparação dos modelos lógicos dos sistemas LonWorks aos dos sistemas de automação projetados segundo a norma IEC 61499

Ao serem comparadas as abordagens da norma IEC 61499 e da tecnologia LonWorks quanto às suas aplicações, podemos notar diversas semelhanças:

- Em primeiro lugar, pode-se destacar que ambos modelos lógicos consideram, como ambiente de aplicação, um sistema de automação distribuído, em que dispositivos com capacidade própria de processamento executam funções específicas e modulares. Logo, a interligação lógica entre tais dispositivos (ou seja, entre suas aplicações) determinam a sua comunicação e colaboração, e permitem a execução da funcionalidade global do sistema;

- Tanto na tecnologia LonWorks quanto na norma IEC 61499 encontram-se referências ligando seus conceitos, principalmente 0 uso de blocos funcionais, aos paradigmas de orientação a objetos - o que pode ser visto, por exemplo, em Echelon Corporation (1999, p. 31), em que uma instância 
de um perfil funcional é chamado de objeto (ao invés da denominação bloco funcional), e International Electrotechnical Commission (2005c, p. 8), em que se fala diretamente da aderência dos modelos da IEC 61499 a conceitos de orientação a objetos;

- As aplicações dos dispositivos são segmentadas em blocos funcionais, os quais são elementos lógicos que fornecem uma interface externa (ou seja, variáveis de entrada e saída, visíveis, que permitem a interação com outros blocos funcionais) e que encapsulam o seu funcionamento interno. Cada bloco funcional é uma instância de um modelo (ou tipo) de bloco funcional, o que estabelece uma relação similar à de classes e objetos, conforme esperado; e

- Por fim, a obtenção da aplicação completa do sistema é dada pela interligação entre variáveis de entrada de um bloco funcional e variáveis de saída de outro bloco funcional, independentemente do dispositivo a que estes pertençam. Adicionalmente, a conexão entre elas é permitida apenas para variáveis de tipos compatíveis e direções opostas.

Apesar dessas semelhanças, não existe um mapeamento direto entre os conceitos da norma IEC 61499 e da tecnologia LonWorks. As diferenças mais significativas estão descritas a seguir:

- Pode-se afirmar que a tecnologia LonWorks não faz distinção entre dispositivos físicos e lógicos: segundo seu modelo, um dispositivo é basicamente composto por apenas um processador Neuron Chip, vinculado a algum hardware adicional (memórias, circuitos de adaptação de sinais, etc.). Já a norma IEC 61499 propõe a existência de recursos, que podem ser interpretados como dispositivos lógicos, já que cada um cuida da execução de um conjunto de blocos funcionais, embora estejam encapsulados dentro de dispositivos (físicos);

- Da mesma maneira, nos termos da tecnologia LonWorks uma aplicação está fortemente associada à idéia de dispositivo. Isso significa que uma aplicação colocada em um nó, em princípio, é utilizada apenas para implementar funções visando a tornar o dispositivo em si "inteligente", e o conjunto de dispositivos inteligentes compõem a funcionalidade do sistema de automação. Já a norma IEC 61499 tem uma abordagem um pouco mais ampla em relação a isso: o sistema de automação é composto por diversos 
dispositivos, físicos e lógicos (recursos), que servem como base para a distribuição livre de blocos funcionais, os quais juntos compõem subaplicações e aplicações. Assim, justifica-se que na tecnologia LonWorks não existam os blocos funcionais compostos e as sub-aplicações: na norma IEC 61499, estes são elementos lógicos para a agregação de blocos funcionais em um mesmo dispositivo (os primeiros) ou até em dispositivos diferentes (os segundos), o que não se faz necessário se os blocos funcionais, logica e fisicamente, forem supostos agregados simplesmente pelo dispositivo que os contém;

- Por outro lado, nos modelos da tecnologia LonWorks não existe diferença entre dados e eventos, como ocorre na norma IEC 61499 para designar os elementos para intercâmbio de informações entre blocos funcionais. Mesmo se for de interesse notificar apenas um evento em um bloco funcional LonWorks, isso deve ser feito através da transmissão de um dado, provavelmente de tipo booleano;

- Na tecnologia LonWorks, também não existem adaptadores (soquetes e plugues), embora eles possam ter alguma semelhança com as variáveis de rede no sentido de agrupar um conjunto de dados para sintetizar a interface de interação entre dois blocos funcionais (no modelo produtor-consumidor ou cliente-servidor). O modelo LonWorks para as variáveis de rede, no entanto, supera o que foi proposto até o momento para os dados de entrada e saída dos blocos funcionais na norma IEC 61499: enquanto nesta os dados são escalares ou no máximo vetores (arrays) de tipos simples (como strings, inteiros, booleanos e bytes), as variáveis de rede abrangem desde escalares a estruturas complexas (contendo outros escalares, estruturas ou variáveis de rede), as quais podem herdar características de outras variáveis de rede e possuem um significado semântico específico;

- A norma IEC 61499, além de discriminar as variáveis de entrada e saída de um bloco funcional em dados e eventos, estabelece o diagrama de controle de execução (ECC) como recurso para determinar os estados internos de um bloco funcional, as condições para a ocorrência de transições entre esses estados e os algoritmos a serem executados (inclusive com o detalhamento das variáveis afetadas). Na tecnologia LonWorks, não existe um formalismo adequado para a descrição do funcionamento interno dos 
blocos funcionais: no melhor dos casos, há recomendações gerais e explicações sobre a semântica de sua interface, mas, em última instância, o funcionamento do bloco funcional depende de seu implementador (e, muitas vezes, a própria codificação serviria como meio de sua documentação);

- Da mesma forma, não existe na tecnologia LonWorks elementos lógicos específicos que tratem da interação dos blocos funcionais com outros sistemas ou elementos físicos (o que é feito, na norma IEC 61499, pelos blocos funcionais de interface de serviço (Service Interface Function Blocks - SIFB)). Dessa forma, a construção de gateways de comunicação com outros sistemas não pode ser expressada por meio de seqüências de primitivas de serviço, assim como a interação com dispositivos físicos (muito embora na implementação através da linguagem Neuron $C$, por exemplo, o uso de entradas e saídas físicos é feito por meio de funções e variáveis pertencentes a uma biblioteca específica);

- Finalmente, vale destacar que não há um elemento na norma IEC 61499 com características semelhantes às propriedades de configuração encontradas nos modelos da tecnologia LonWorks. Apesar de haver formas de expressar essas informações segundo a norma IEC 61499 (por meio de adaptadores, eventos e dados, por exemplo), a diferenciação de dados operacionais e dados utilizados apenas para configuração de dispositivos, blocos funcionais e variáveis de entrada e saída parecem ser interessantes do ponto de vista da idealização e organização das aplicações.

Tendo em consideração os tópicos acima, percebe-se que, de maneira geral, a abordagem da norma IEC 61499 quanto aos de sistemas de automação distribuídos é muito mais abrangente que os conceitos da tecnologia LonWorks: nesse sentido, pode-se inclusive sugerir que esta última seja considerada uma especialização da primeira, contando com as seguintes restrições:

- Os dispositivos LonWorks possuem um e apenas um recurso para cada processador Neuron Chip que contenham;

- Não existem agregações de blocos funcionais, mas apenas redes de blocos funcionais; e

- Cada variável de rede LonWorks pode ser representada por uma estrutura de dados e um evento da norma IEC 61499 associados por um qualificador WITH (já que o firmware do Neuron Chip, responsável por gerenciar a 
transmissão de mensagens entre os nós, notifica a camada de aplicação sempre quando há alteração em qualquer variável de rede ou propriedade de configuração).

\subsubsection{Comentários}

Sendo assim, apesar das diferenças entre os modelos lógicos da tecnologia LonWorks e da norma IEC 61499, percebe-se que esta última pode expressar todos os recursos da primeira e ainda enriquecer a semântica dos sistemas de automação idealizados.

Além disso, devido a seus modelos lógicos serem explicitamente orientados a eventos, a norma IEC 61499 permitiu que ocorresse a sua interação com os modelos de orientação a objetos, especialmente aqueles descritos em UML, como disposto nos capítulos anteriores. Isso faz com que as abstrações da norma IEC 61499 tenham um uso ainda mais desejável do que as da tecnologia LonWorks.

Vale destacar, no entanto, que além do uso da tecnologia LonWorks ser uma alternativa tecnicamente viável para a implementação dos sistemas descritos através da norma IEC 61499 (já que esta também não restringe nenhuma tecnologia de implementação), ela pode contribuir com a norma IEC 61499 através de recursos próprios de uma tecnologia consagrada, principalmente na área de automação predial e nos mercados europeu e chinês, como por meio da definição de blocos funcionais, variáveis de rede e as propriedades de configuração publicadas pelo órgão de padronização da tecnologia LonWorks, denominado LonMark.

Assim, como será detalhado adiante, sugere-se neste trabalho o uso das abstrações da norma IEC 61499 para definir a modelagem dos sistemas de automação distribuídos e a tecnologia LonWorks como um dos meios de implementação desses sistemas. Adicionalmente, indica-se a exploração dos modelos LonWorks de blocos funcionais, variáveis de rede e propriedades de configuração padronizados para aumentar a quantidade e melhorar a expressividade dos tipos de blocos funcionais, adaptadores, dados e eventos da norma IEC 61499. Dessa maneira, pode-se aliar uma capacidade de modelagem mais representativa e o uso de uma tecnologia bem aceita, com reaproveitamento de informações e sistemas legados. 


\subsubsection{Implementação de ferramenta computacional para suporte ao desenvolvimento de sistemas de automação distribuídos LonWorks}

Vê-se, até o momento, que os sistemas de execução dos modelos da norma IEC 61499 baseiam-se em ambientes Java, Linux ou sistemas de automação de menor porte (CHOUINARD; BRENNAN, 2006; SOFTWARE ENGINEERING GROUP, 2006). A partir do que foi discutido no item anterior, uma das possíveis expansões das ferramentas para suporte ao desenvolvimento de sistemas de automação distribuídos seria que as mesmas permitissem a interação, do ponto de vista de implementação, com os sistemas LonWorks.

Assim, a idéia primordial seria ampliar as ferramentas para que as mesmas permitissem o desenvolvimento completo dos sistemas de automação, com a realização do levantamento de requisitos e análise do sistema através das abstrações da UML, o projeto do sistema por meio das abstrações da norma IEC 61499, e a implementação, os testes e a manutenção do sistema feitos através do uso de recursos da tecnologia LonWorks.

\subsubsection{Visão geral da ferramenta}

A ferramenta idealizada nesta seção deve ser composta por:

- Uma sub-aplicação para permitir o projeto de sistemas por meio de modelos da UML (como, por exemplo, o IBM Rational Rose);

- Uma sub-aplicação para a conversão de tais modelos em outros, dados segundo a norma IEC 61499 (ou seja, uma ferramenta que implemente algum dos mapeamentos UML-IEC61499, como o Transformation Facility Manager (TFM), discutido no capítulo 4);

- Uma sub-aplicação para permitir o projeto de sistemas por meio de modelos da IEC 61499 (a fim de refinar as representações obtidas através da conversão UML-IEC61499); e

- Uma sub-aplicação para, a partir das representações dadas em abstrações da IEC 61499, permitir funções de monitoração e controle, e de gerenciamento da rede (incluídas, aqui, atividades como configuração dos dispositivos, configuração de rede, execução de testes, verificação e alteração do estado dos dispositivos, observação e alteração das 
aplicações, entre outros).

Para que esta última ferramenta seja viável, um dos requisitos é que as abstrações da norma IEC 61499 possam ser transformadas em elementos de implementação LonWorks (ou seja, em configuração e código de máquina dos dispositivos, por exemplo).

5.2.2.1.1. Transformação das abstrações da norma IEC 61499 em elementos de implementação LonWorks

Em termos gerais, a transformação entre abstrações da IEC 61499 para os elementos de implementação da tecnologia LonWorks pode ser feita da seguinte maneira:

- Como restrição da modelagem, é preciso que um dispositivo da norma IEC 61499 contenha apenas um recurso para representar um dispositivo LonWorks;

- As sub-aplicações e os blocos funcionais compostos da norma IEC 61499 devem ser desmembrados até que a aplicação completa do sistema seja vista apenas em termos de instâncias de blocos funcionais básicos. Essas instâncias serão mapeadas na tecnologia LonWorks como blocos funcionais (objetos). Dado que a configuração de um sistema da norma IEC 61499 determina em qual recurso cada um desses blocos deve estar alocado, e levando em consideração a restrição vista anteriormente, obtém-se os relacionamentos entre um dispositivo LonWorks e seus blocos funcionais;

- Os tipos de blocos funcionais básicos da norma IEC 61499 determinarão a composição dos perfis funcionais LonWorks:

- Cada entrada de evento ou de dado deve ser transformada em uma variável de rede de entrada. O tipo da variável de rede corresponderá ao tipo de dado transferido ou, no caso de um evento, pode ser de um tipo qualquer, como booleano, por exemplo (neste caso, na verdade, o tipo de dado é irrelevante, já que qualquer alteração em uma variável de rede gera um evento tratável pela camada de aplicação);

- Da mesma forma, uma saída de evento ou de dado deve ser transformada em uma variável de rede de saída. O tipo da variável de rede corresponderá ao tipo de dado transferido ou, no caso de um 
evento, pode ser de um tipo qualquer;

- Um qualificador WITH entre uma entrada de eventos e uma entrada de dados pode ser simulada no nível de aplicação LonWorks pela amostragem do valor da variável de rede correspondente à entrada de dados quando a variável de rede referente ao evento indicar alteração em seu valor;

- Um qualificador WITH entre uma saída de eventos e uma saída de dados pode ser simulada no nível de aplicação LonWorks pela atualização do valor da variável de rede correspondente à saída de dados quando a variável de rede referente ao evento tiver o seu valor atualizado;

- O diagrama de controle de execução (ECC) deve ser transformado no software de um bloco funcional. Os estados e as transições podem ser transformados em uma implementação computacional de uma máquina de estados (dada em linguagem de máquina, por exemplo). Por sua vez, os algoritmos serão conjuntos de operações a serem realizadas pelo microprocessador. Por fim, os eventos de entrada e saída que forem manipulados pelo ECC podem ser traduzidos, respectivamente, como verificação ou alteração de um valor de uma variável de rede.

- Os blocos funcionais de interface de serviços, a princípio, poderão ser transformados em blocos funcionais LonWorks da mesma maneira que os blocos funcionais básicos da norma IEC 61499 quanto à sua interface. No entanto, seu comportamento, aparentemente, não pode ser traduzido sem se conhecer a aplicação do bloco funcional. Por exemplo, se for conhecido que esse diagrama é usado em certo bloco funcional para mostrar a interação da aplicação com as entradas e saídas de um Neuron Chip, isso pode ser transformado em um software que utilize a biblioteca de entradas e saídas do Neuron Chip para manipular suas entradas e saídas;

- Finalmente, um tipo de adaptador pode designar, da mesma forma que ocorre com a estrutura de um bloco funcional, quais são as variáveis de rede a serem geradas em um nó LonWorks. 


\subsection{Aspectos de implementação}

Uma opção para a implementação das idéias acima é através do uso de ferramentas de desenvolvimento LonWorks (fornecidos pela empresa Echelon Corporation).

Através do software NodeBuilder (ECHELON CORPORATION, 2006), seria possível compilar uma aplicação (referente a um dispositivo LonWorks), dada em linguagem Neuron C, para se obter um código executável em um Neuron Chip (vale ressaltar que a linguagem de máquina do Neuron Chip não é aberta, portanto não haveria, a princípio, possibilidade de compilação direta para esse processador a partir da descrição de um sistema em modelos da norma IEC 61499). Dessa maneira, os blocos funcionais da norma IEC 61499 (considerando sua estrutura e comportamento), dados em arquivos XML (conforme a norma), poderiam ser convertidos para a linguagem Neuron $\mathrm{C}$, e então compilados (para gerar os blocos funcionais e variáveis de rede da aplicação de um dispositivo LonWorks).

Por meio do kit de desenvolvimento LNS (ECHELON CORPORATION, 2004), seria possível desenvolver ferramentas que interagem com o Sistema Operacional de Rede LNS (LNS Network Operating System). Este, por sua vez, é o software responsável por realizar os serviços de rede associados a um sistema LonWorks (incluindo a configuração, a instalação e a manutenção de rede chamados coletivamente por gerenciamento de rede, e a monitoração e controle do sistema - abrangendo dispositivos e canais de comunicação). Todas as funções do LNS podem ser invocadas por meio de um controle ActiveX chamado LNS Object Server, o qual fornece uma visão da hierarquia de objetos do LNS. Tal hierarquia apresenta os componentes de rede (como dispositivos de aplicação, variáveis de rede, blocos funcionais LonMark, propriedades de configuração, roteadores e canais) como objetos padrão do Windows - cujos métodos permitem a execução de operações no componente associado; cujas propriedades viabilizam a verificação de estado e configuração do componente; e cujos eventos indicam mudanças no componente. Dessa maneira, qualquer ambiente de desenvolvimento que possa utilizar esse controle ActiveX (como, por exemplo, o Microsoft Visual Studio .NET 2003) pode viabilizar o desenvolvimento de uma ferramenta para interagir com o LNS, e, assim, gerenciar uma rede LonWorks. Dessa maneira, mostra-se uma das formas pelas quais seria possível fazer uma ferramenta para configurar os 
dispositivos da rede LonWorks, carregar suas aplicações (já compiladas pelo software NodeBuilder, por exemplo) e executar o processo de ligação (binding) das variáveis de rede. Além disso, haveria a possibilidade de visualizar o estado operacional do sistema LonWorks. Portanto, por meio dessa solução, é provável que se pudesse construir uma ferramenta computacional que, integrada à ferramenta NodeBuilder, permitisse a instalação, testes e manutenção da rede LonWorks a partir de um modelo do sistema de automação dado por meio de abstrações da norma IEC 61499. Um exemplo de uma ferramenta que realiza todas essas funções, mas com a exibição do sistema, dada de forma gráfica, por meio de blocos funcionais e dispositivos LonWorks chama-se LonMaker, e também é fornecida pela empresa Echelon Corporation: a mesma pode servir como inspiração sobre o ponto a ser atingido pela ferramenta a ser construída (no sentido de implementação, testes e manutenção de uma rede LonWorks, mas não quanto à representação de elementos relativos ao levantamento de requisitos, análise e projeto do sistema).

Finalmente, uma interface de programação (application program interface API) disponibilizada pelo órgão de padronização LonMark, permite a exploração de arquivos públicos, chamados Resource Files, que reúnem tipos padronizados de perfis funcionais, variáveis de rede e propriedades de configuração (standard FTP (SFTP), standard NVT (SNVT) e standard CPT (SCPT)). A utilização dessa interface por uma ferramenta computacional poderia ser analisada para a criação de tipos de blocos funcionais e adaptadores da norma IEC 61499 específicos para a representação daquelas abstrações LonWorks. Além de enriquecer a biblioteca de tipos de blocos funcionais de uma ferramenta da IEC 61499, a geração de código para os sistemas LonWorks seria muito mais eficiente (já que a semântica dos dados, inclusive a vinculação entre eles, estaria especificada).

\subsubsection{Comentários}

O fato de se poder implementar um sistema de automação dado por abstrações da norma IEC 61499 em tecnologia LonWorks, dentro das condições analisadas nesta dissertação, levariam a que fosse possível constituir uma ferramenta computacional para auxílio a todas as etapas de engenharia do ciclo de desenvolvimento de um sistema de automação. Segundo o que foi estudado, essa perspectiva pode ser tornada uma realidade. No entanto, outros trabalhos devem 
complementar esta dissertação no sentido de construir de fato essa ferramenta (o que, certamente, além de oferecer uma solução valiosa para as equipes de engenharia, acrescentaria contribuições acadêmicas importantes sobre as vantagens e desvantagens tanto da norma IEC 61499 quanto dos modelos lógicos da tecnologia LonWorks). 


\section{CONSIDERAÇÕES FINAIS}

\subsection{CONCLUSÕES}

Percebe-se, através do que foi exposto nos capítulos anteriores, que as pesquisas na área de projetos de automação modelados segundo a norma International Electrotechnical Commission (IEC) 61499 ainda estão em seu início, já que a norma, publicada recentemente (em 2005), não foi muito difundida até o momento, especialmente fora do âmbito acadêmico.

É interessante notar a preocupação de diversos pesquisadores (como Thramboulidis, por exemplo) em complementar as sugestões dessa norma no sentido de cobrir etapas de projeto de sistemas de automação que não estão previstas por ela, como o levantamento de requisitos e a análise do sistema. Para isso, a Unified Modeling Language (UML) tem sido usada de maneira extensiva, dado que a maioria dos engenheiros de sistemas e software estão acostumados a especificar sistemas dessa maneira. A expressividade e possibilidade de expansão da UML para outros domínios (que não os de software) também são atributos que facilitam a sua adoção para a modelagem de sistemas em diversas outras áreas.

Além de abordagens teóricas sobre a aproximação dos modelos da UML em relação àqueles oferecidos pela norma IEC 61499, encontram-se também alguns primeiros trabalhos de implementação de ferramentas para suporte às atividades de engenharia de sistemas de automação. Muito embora a existência dessas ferramentas tenha sido sugerida explicitamente pela norma IEC 61499, certas iniciativas (como a do Common Object-oriented Real-time Framework for the Unified development of distributed Industrial-Process Measurement and Control Systems (IPMCS) applications (CORFU) Engineering Support System (ESS)) empenham-se em tratar a conversão de modelos da UML para os modelos da IEC 61499 - a ser realizada previamente à continuação do projeto exclusivamente em elementos de modelagem da IEC 61499. Nota-se, também, que muitas delas estão iniciando a implementação prática dos sistemas de automação, por meio do desenvolvimento de ambientes de execução compatíveis com a norma. Neste ponto, no entanto, 
percebe-se que se têm usado ambientes Java, Linux ou tecnologias de automação para sistemas de pequeno porte como meio de implementação e testes, e não sistemas comerciais já difundidos (o que certamente seria interessante pela possibilidade de reaproveitamento de ferramentas e suporte a sistemas legados).

Dessa maneira, tentou-se contribuir com tais pesquisas no sentido de apresentar sugestões para melhorar tanto os mapeamentos UML-IEC61499 estudados quanto para viabilizar a implementação prática de sistemas de automação LonWorks. No entanto, nota-se que ainda há diversas iniciativas a serem exploradas dentro dessa área para que se chegue a métodos e ferramentas suficientemente estáveis e abrangentes a ponto de serem adotados pela indústria (mesmo porque a própria norma IEC 61499 ainda está em fase de divulgação).

\subsection{CONTRIBUIÇÕES}

As principais contribuições dadas nesta dissertação são listadas a seguir:

- Proposta de um novo mapeamento entre abstrações da UML e da norma IEC 61499 (em contraposição àqueles vistos no capítulo 3, que the serviram de base), tendo como principal objetivo a desvinculação da linguagem usada nos modelos UML dos conceitos e do próprio vocabulário específico da norma IEC 61499 - de forma a tornar a modelagem de um sistema de automação mais simples, nas fases de levantamento de requisitos e análise do sistema, para aqueles que não conheçam a padronização citada e utilizem a UML;

- Indicação sobre possíveis formas de uso de mecanismos de extensão da UML (principalmente restrições - constraints), além de diagramas da UML 2.X, para a expressão de parâmetros temporais - relacionados ao conceito de qualidade de serviço (Quality of Service - QoS) - para o projeto de sistemas de automação distribuídos dados segundo a norma IEC 61499; e

- Sugestões para a construção de uma ferramenta computacional para suporte ao desenvolvimento de sistemas de automação distribuídos que permitisse a passagem de modelos de sistemas dados através de abstrações da norma IEC 61499 para elementos de implementação da 
tecnologia LonWorks, resultado posterior à análise da compatibilidade entre as abstrações da norma IEC 61499 e das abstrações previstas pela tecnologia LonWorks para o projeto de sistemas de automação distribuídos. Como contribuições secundárias, podem-se citar:

- Elaboração de tutorial sobre conceitos fundamentais da UML, abrangendo os seus principais diagramas (inclusive aqueles introduzidos a partir da versão 2.X da norma);

- Elaboração de tutorial sobre a norma IEC 61499, relacionada ao uso de blocos funcionais orientados a eventos no projeto de sistemas distribuídos de controle e medição para processos industriais;

- Apresentação de discussão sobre a compatibilidade entre ciclos de vida de desenvolvimento de projetos, métodos de modularização e linguagens específicas para a modelagem de sistemas, segundo os pontos de vista da engenharia de sistemas e software, e da engenharia de controle e automação;

- Revisão de literatura sobre algumas das principais propostas de mapeamento entre a UML e os modelos de representação de sistemas de automação dados pela IEC 61499, e elaboração de tabelas para viabilizar a comparação sistemática das mesmas; e

- Revisão de literatura sobre algumas das principais ferramentas de suporte às atividades de engenharia do ciclo de vida de projetos de sistemas de automação distribuídos (dentro do contexto de utilização de modelos da UML e da norma IEC 61499 para a sua representação), além da vinculação das ferramentas às fases de desenvolvimento cobertas por cada uma (também apresentado em formato tabular, para facilitar sua comparação).

\subsection{MELHORIAS}

Posto que muitos dos assuntos que foram tratados nesta dissertação ainda estão aquém de serem soluções definitivas em termos de métodos e ferramentas para o projeto de sistemas de automação distribuídos, há muito espaço para melhorias. Algumas delas estão sugeridas a seguir: 
- Busca e análise de novas referências sobre tipos de mapeamento UMLIEC61499 que não tenham sido abordadas ou que possam ter surgido após a publicação desta dissertação (de forma a ampliar e atualizar o conhecimento nesta área);

- Estudo mais aprofundado das ferramentas de auxílio a projetos de sistemas de automação apresentadas no capítulo 4, especialmente após 0 encerramento deste texto - já que novas versões das ferramentas serão lançadas e provavelmente haverá interesse em verificar suas funcionalidades. Neste ponto, seria especialmente relevante estudar em detalhes aquelas que não foram abordadas de forma aprofundada nesta dissertação, como por exemplo a ferramenta Archimedes ESS, mostrando seus pontos fortes e deficiências;

- Análise do mapeamento UML-IEC61499 proposto nesta dissertação e aprimoramento do mesmo, seja pela adição de novos diagramas UML a gerarem modelos compatíveis com as abstrações da norma IEC 61499 (como por exemplo, o Diagrama de Componentes, que parece ser uma boa opção para expressar componentes de software que implementam as classes representantes de blocos funcionais), seja pela sugestão das formas pelas quais pudessem ser realizadas transformações inversas dos modelos (de representações da norma IEC 61499 para a UML, que teriam grande utilidade para o reaproveitamento de modelos de sistemas já implementados);

- Aprofundamento da proposta de utilização de restrições em modelos da UML para designar restrições temporais de sistemas de automação: neste ponto, sugere-se a determinação de um conjunto de parâmetros de interesse para sistemas de automação (incluindo sua forma de expressão nos modelos do sistema) e de uma linguagem formal adequada para permitir a geração de testes de desempenho (de forma a complementar as funcionalidades de uma possível ferramenta de suporte ao desenvolvimento de sistemas de automação), bem como a verificação do possível uso de perfis (profiles) UML voltados a sistemas de tempo real para melhorar a expressividade dos modelos da UML sobre aspectos de tempo; e

- Execução de análise crítica da proposta de mapeamento entre as abstrações da IEC 61499 e da tecnologia LonWorks, aprofundamento da 
mesma e proposição de uma conversão inversa completa de elementos lógicos e de implementação da tecnologia LonWorks para abstrações da norma IEC 61499 (o que não foi abordado neste texto por restrições de tempo, mas que seria de grande interesse para a engenharia reversa de redes LonWorks já instaladas).

\subsection{TRABALHOS FUTUROS}

Como trabalhos futuros, além das melhorias citadas acima, poderiam ser realizadas as seguintes investigações:

- Exploração do assunto sobre blocos funcionais de gerenciamento da norma IEC 61499, que permitem, em um recurso, criar, inicializar, iniciar, parar, excluir e indagar sobre os atributos e a existência de tipos de dados, de tipos e instâncias de blocos funcionais, e de conexões entre instâncias de blocos funcionais (além de notificar mudanças na disponibilidade e estado desses elementos), e, em um dispositivo, executar as mesmas funções relativamente a um recurso. Os blocos funcionais de gerenciamento parecem ser aplicáveis no caso de ferramentas de gestão de uma rede de automação, e parecem ter paralelo com blocos funcionais LonMark denominados NodeObject: essa relação poderia ser explicitada;

- Implementação de uma ferramenta de conversão UML-IEC61499 (independentemente do tipo de mapeamento escolhido) com o uso de ferramentas abertas e gratuitas para a modelagem de sistemas UML (haja vista que em todos os casos estudados a ferramenta utilizada foi o IBM Rational Rose, que é um software comercial e não está disponível a todas as pessoas da comunidade);

- Criação de uma ferramenta para executar o mapeamento UML-IEC61499 simplificado, proposto nessa dissertação, especialmente para verificar a possibilidade técnica de sua implementação e para fornecer uma ferramenta útil para a modelagem de sistemas de automação (o que também permitiria uma abordagem prática do assunto, além de conseqüentes aprimoramentos teóricos sobre o tema); 
- Idealização e implementação de uma ferramenta para simulação sobre o comportamento dinâmico, no tempo, de sistemas de automação - baseado na expressão de seus requisitos temporais tanto na UML quanto nas abstrações da norma IEC 61499;

- Estudos sobre outros requisitos de QoS que sejam de interesse para sistemas de automação distribuído (assim como de outros tipos requisitos não-funcionais), e geração de propostas para sua expressão nos modelos dos sistemas;

- Implementação de uma ferramenta completa para executar algum mapeamento entre modelos da UML e da IEC 61499, e a passagem de modelos da IEC 61499 para sistemas LonWorks, de forma a fornecer suporte a todas as etapas do ciclo de vida de desenvolvimento de projetos de automação. Esta proposta é bastante ousada, já que, a princípio, trata-se de um projeto de grande porte (considerando a necessidade de implementar não somente funções de modelagem, mas também de gestão de rede e controle e monitoração). No entanto, a mesma pode ser subdividida em projetos menores (ao estilo "dividir para conquistar"), abrindo diversas frentes de trabalho; e

- Adoção de abordagens totalmente diferentes às deste trabalho para a modelagem de sistemas de automação: por exemplo, modelagem exclusiva dos sistemas de automação em UML ou em IEC 61499 (passando-se à implementação do sistema diretamente a partir desses modelos). Esta última sugestão seria muito interessante para a comparação global das vantagens e desvantagens de se adotar modelagens puras (em uma única linguagem) ou híbridas (como as exploradas neste texto) para o projeto de sistemas de automação.

\subsection{ENCERRAMENTO}

(A partir deste ponto, a autora permite-se expressar uma visão particular sobre os resultados obtidos neste trabalho).

Pessoalmente, meu objetivo ao iniciar esta dissertação era dar uma 
contribuição à área de projetos de sistemas de automação, em que percebia uma grande lacuna (do ponto de vista de uma engenheira de software) quanto ao momento em que era necessário levantar requisitos e realizar a análise de um sistema (e, dentro dessa, a modularização das aplicações). Diversas vezes utilizeime de ferramentas para modelar o sistema em UML, e depois adaptava os modelos, de forma não-automatizada, para blocos funcionais da linguagem de implementação que estivesse utilizando.

Ao iniciar a pesquisa sobre esse tema, percebi que diversos autores tinham as mesmas insatisfações que eu, e que haviam começado a publicar trabalhos nessa área vinculando a UML a representações dos sistemas de automação em abstrações da norma IEC 61499. Mais do que isso, começavam a publicar as primeiras ferramentas para conversão automática dos modelos de sistemas (UMLIEC61499), e outras para o suporte específico ao projeto de aplicações e sistemas completos de automação com blocos funcionais daquela norma.

Tendo sugerido modificações a essas abordagens e maneiras de unir as ferramentas existentes aos sistemas LonWorks (com os quais trabalhava especialmente na área de automação predial), senti uma grande satisfação ao perceber que, embora o caminho ainda seja bastante longo para chegarmos ao ponto ideal para cobrir completamente o desenvolvimento de sistemas de automação (ou seja, por meio de ferramentas abrangentes de auxílio ao projeto), temos a perspectiva de tornar essa visão uma realidade através do desenvolvimento de diversos outros trabalhos. Assim, isso me motiva a permanecer dentro dessa área de pesquisa, a fim de realizar parte das contribuições necessárias para alcançarmos essa meta. 


\section{REFERÊNCIAS}

4DIAC CONSORTIUM. HowTo for 4DIAC-IDE Version 0.0. [S. I.]: 4DIAC Consortium, 2007. 28 p. Disponível em: <http://www.fordiac.org/fileadmin/user upload/4DIAC-IDE_HowTo_V0.0.pdf>. Acesso em: 12 nov. 2007.

AIHKISALO, T. Remote maintenance and development of home automation applications. Espoo: Technical Research Centre of Finland (VTT), 2002. 85 p. (Série VTT Tiedotteita - Meddelanden - Research Notes, 2129). Disponível em: <http://www.vtt.fi/inf/pdf/tiedotteet/2002/T2129.pdf>. Acesso em: 5 abr. 2007.

ALSHIN, D.; DUBININ, V. UML to FB converter. v. 1.0. 2004. Disponível em: <http://alice.stup.ac.ru/ dvn/fb61499/uml_fb/converters/vlasov/UMLtoFB_Vlasov_Jan _9_2005.zip>. Acesso em: 21 ago. 2007.

ARMSTRONG, D. J. The Quarks of Object-Oriented Development.

Communications of the ACM, [S. I.], v. 49, p. 123-128, fev. 2006. Número 2. Disponível em: <http://delivery.acm.org/10.1145/1120000/1113040/p123-armstrong. pdf?key1=1113040\&key2=3766990811\&coll=GUIDE\&dl=GUIDE\&CFID=20457838\& CFTOKEN=16438283>. Acesso em: 5 abr. 2007.

ÅSTRÖM, K. J. Process control - Past, present, and future. IEEE Control Systems Magazine, [S. I.], v. 5, p. 3-10, ago. 1985.

BOOCH, G.; RUMBAUGH, J.; JACOBSON, I. The Unified Modeling Language User Guide. Massachusetts: Addison-Wesley, 1998. 512 p.

BORDBAR, B.; DERRICK, J.; WATERS, G. Using UML to specify QoS constraints in ODP. Computer Networks, [S. I.], v. 40, p. 279-304, 2002. Disponível em: $<\mathrm{http}: / /$ www.sciencedirect.com/science?_ob=MImg\&_imagekey=B6VRG-45X0D602-2R\&_cdi=6234\&_user $=5674931 \&$ orig $=$ search\&_coverDate $=10 \% 2 F 07 \% 2 F 2002 \&$ sk=999599997\&view $=c \& w c h p=d G L \bar{b} V t b-z S k z S \& m d 5=23 c d f 75 c 82 b 5 a f 0181843 f a 510$ 9f9837\&ie=/sdarticle.pdf>. Acesso em: 5 abr. 2007.

CAUFFRIEZ, L. et al. Design of intelligent distributed control systems: a dependability point of view. Reliability Engineering and System Safety, [S. I.], v. 84, p. 19-32, 2004. Disponível em: <http://www.sciencedirect.com/science?_ob=M Img\&_imagekey=B6V4T-49RCGDN-1-18\&_cdi=5767\&_user=5674931\&_orig=search \&_coverDate $=04 \% 2 F 30 \% 2 F 2004 \&$ sk=999159998\&view=c\&wchp=dGL $\bar{b}$ VlbzSkWA\& md5=f7cebe9b67e48b8b96234aaed095aa01\&ie=/sdarticle.pdf $>$. Acesso em: 10 abr. 2007. 
ČENGIĆ, G.; LJUNGKRANTZ, O.; ÅKESSON, K. Formal Modeling of Function Block Applications Running in IEC 61499 Execution Runtime. In: 2006 IEEE INTERNATIONAL CONFERENCE ON EMERGING TECHNOLOGIES AND FACTORY AUTOMATION (ETFA '06), 2006, Prague. Proceedings... [S. I.]: IEEE, 2006. p. 1269-1276. Disponível em: <http://ieeexplore.ieee.org/iel5/4178170/41781 71/04178302.pdf?tp=\&isnumber=\&arnumber=4178302>. Acesso em: 14 dez. 2007 .

CHOUINARD, J.; BRENNAN, R. W. Software for Next Generation Automation and Control. In: 2006 IEEE INTERNATIONAL CONFERENCE ON INDUSTRIAL INFORMATICS, 4., 2006, [S. I.]. [S. I.]: IEEE, 2006. Disponível em: <http://ieeexplore. ieee. org/iel5/4053335/4053336/04053506. pdf?tp=\&isnumber=\&arnumber $=40535$ 06>. Acesso em: 12 nov. 2007.

CHRISTENSEN, J. H. The IEC 61499 Standard: Concepts and R\&D Resources. [S. I.: s. n.], 2002. 78 p. Documento do PowerPoint. Disponível em: <http://www.holobloc.com/papers/tut_61499.zip>. Acesso em: 23 jul. 2007.

CLEMENTS-CROOME, T. D. J. What do we mean by intelligent buildings? Automation in Construction, [S. I.], v. 6, p. 395-400, 1997. Disponível em: $<$ http://www.sciencedirect.com/science?_ob=Mlmg\&_imagekey=B6V20-3SNMSDH $-3-1 \&$ cdi $=5688$ \&_user $=5674931 \&$ orig $=$ search\&_coverDate $=09 \% 2 \mathrm{~F} 30 \% 2 \mathrm{~F} 1997$ \& sk=999939994\&view=c\&wchp=dGLbVlb-zSkWA\&md5=5638565d317e972325b9a96 6d4a5930e\&ie=/sdarticle.pdf>. Acesso em: 10 abr. 2007.

CONVERTER from UML to IEC 61499 function blocks -- forward engineering. 2004. Apresenta informações sobre a ferramenta. Disponível em: <http://alice.stup.ac.ru/ dvn/fb61499/uml_fb/converters/alshin/download.htm>. Acesso em: 21 ago. 2007.

DAI, W.; SHIH, A. C. K.; VYATKIN, V. Development of Distributed Industrial Automation Systems and Debugging Functionality Based on the Open Source OOONEIDA Workbench. In: AUSTRALASIAN CONFERENCE ON ROBOTICS AND INDUSTRIAL AUTOMATION (ACRA 2006), 2006, Auckland. [S. I.: s.n.], 2006. p. 1-7. Disponível em: <http://www.araa.asn.au/acra/acra2006/papers/paper_5_55.pdf>. Acesso em: 21 jun. 2007.

DUBININ, V.; VYATKIN, V. UML-FB - A language for modeling and implementation of industrial-process measurement and control systems on the basis of IEC 61499 standard. In: INTERNATIONAL CONFERENCE OF SCIENCE AND TECHNOLOGY "NEW INFORMATION TECHNOLOGIES AND SYSTEMS" (NITS'2004), 6., 2004, Penza. Proceedings... [S. I.: s. n.], 2004. p. 77-83. Disponível em: <http://alice.stup. ac.ru/ dvn/fb61499/docs/paper/my/Nits2004/dubinin_vyatkin_nits2004.pdf >. Acesso em: 21 ago. 2007. 
DUBININ, V.; VYATKIN, V.; PFEIFFER, T. Engineering of Validatable Automation Systems Based on an Extension of UML Combined With Function Blocks of IEC 61499. In: 2005 IEEE INTERNATIONAL CONFERENCE ON ROBOTICS AND AUTOMATION, 2005, Barcelona. Proceedings... [S. I.]: IEEE, 2005. p. 3996-4001. Disponível em: <http://ieeexplore.ieee.org/iel5/10495/33250/01570732.pdf>. Acesso em: 21 ago. 2007.

ECEDAC CONSORTIUM. 4DIAC-IDE. Version 0.0.2. 2007. Disponível em: <http://www.fordiac.org/fileadmin/user_upload/4DIAC-IDE-0.0.2.zip>. Acesso em: 12 nov. 2007.

ECHELON CORPORATION. Introduction to the LonWorks system, v. 1.0. [S. I.]: Echelon Corporation, 1999. 73 p. Disponível em: <http://www.echelon.com/support/ documentation/manuals/078-0183-01A.pdf>. Acesso em: 20 mai. 2005.

ECHELON CORPORATION. LNS® Application Developer's Kit/Turbo Edition Model 34309. [S. I.]: Echelon Corporation, 2004. 4 p. Disponível em: <http://www.echelon.com/support/documentation/datashts/34309.pdf>. Acesso em: 20 mai 2005.

ECHELON CORPORATION. LonMark Application-Layer Interoperability Guidelines, v. 3.4. [S. I]: Echelon Corporation, 2005. 130 p. Disponível em: <http://www.lonmark.com/technical_resources/guidelines/docs/LmApp34.pdf>. Acesso em: 20 mai. 2005.

ECHELON CORPORATION. Echelon's NodeBuilder Development Tool. [S. I.]: Echelon Corporation, 2006. Descrição técnica-comercial da ferramenta NodeBuilder® 3.1. Disponível em: <http://www.echelon.com/products/development/ nodebuilder/default.htm>. Acesso em: 16 mar. 2007.

GUSTIN, G. D. B. Modelagem e análise de sistemas distribuídos e abertos para automação predial. 2005. 196 p. Tese (Doutorado) - Escola Politécnica da Universidade de São Paulo, São Paulo, 2005.

HEVERHAGEN, T.; TRACHT, R.; HIRSCHFELD, R. A Profile for Integrating Function Blocks into the Unified Modeling Language. In: INTERNATIONAL WORKSHOP ON SPECIFICATION AND VALIDATION OF UML MODELS FOR REAL TIME AND EMBEDDED SYSTEMS (SVERTS'03), 2003, San Francisco. Proceedings... [S. I.: s. n.], 2003. Disponível em: <http://www-verimag.imag.fr/EVENTS/2003/SVERTS/ PAPERS-WEB/08-Heverhagen-FunctionBlockAdapters.pdf>. Acesso em: 21 ago. 2007. 
HOLOBLOC, INC. FBDK. Version 20061017. 2006. Disponível em: <http://www. holobloc.com/fbdk.zip>. Acesso em: 21 jun. 2007.

HOLOBLOC, INC. HOLOBLOC, Inc.: Resources for the New Generation of Automation and Control. [S. I.]: Holobloc, Inc., 2006. Página da Internet sobre a empresa Holobloc, sobre o projeto FBDK e sobre o padrão IEC 61499. Disponível em: <http://www.holobloc.com>. Acesso em: 21 jun. 2007.

HONEYWELL INTERNATIONAL INC. Control_Builder_PIN.pdf: Descrição técnicacomercial da ferramenta Experion ${ }^{\circledR}$ Control Builder. Phoenix, 2005. Disponível em: <http://hpsweb.honeywell.com/HPSWEBII/DownloadDocument.axd?DocumentUrl=/ NR/rdonlyres/0A391DEE-0210-4913-81A4-DC336268C5F6/24268/Control_Builder_ PIN.pdf>. Acesso em: 27 abr. 2007.

HUR, S. -H.; KIM, D.; PARK, G. -T. Building automation system via LonWorks and Linux based personal computer. Automation in Construction, [S. I.], [2005]. No prelo. Disponível em: <http://www.sciencedirect.com/science?_ob=Mlmg\&_image key=B6V20-4HGM778-1-11\&_cdi=5688\&_user $=10$ \&_orig=search\&_coverDate $=07 \%$ 2F31\%2F2006\&_sk=999849995\&view=c\&wchp=dGLzVlz-zSkzV\&md5=40579c6d97 4a46ec00646d058495880b\&ie=/sdarticle.pdf>. Acesso em: 15 mai. 2006.

INTELLIGENT MECHATRONICS AND AUTOMATION GROUP. IEC 61499 FBench. Version v0.5. 2007. Disponível em: <http://sourceforge.net/project/showfiles.php? group_id=1986 68\&package_id=235424\&release_id=546550 >. Acesso em: 21 jun. 2007.

INTERNATIONAL ELECTROTECHNICAL COMMISSION. IEC 61499-1: Function blocks - Part 1: Architecture. Geneva, 2005. 111 p.

INTERNATIONAL ELECTROTECHNICAL COMMISSION. IEC 61499-2: Function blocks - Part 2: Software tool requirements. Geneva, 2005. 41 p.

INTERNATIONAL ELECTROTECHNICAL COMMISSION. IEC 61499-3: Function blocks for industrial-process measurement and control systems - Part 3: Tutorial information. Geneva, 2005. 48 p.

MAHALIK, N. G. P. C.; LEE, S. K. A study on production line automation with LonWorks ${ }^{\mathrm{TM}}$ control networks. Computer Standards \& Interfaces, [S. I.], v. 24, p. 21-27, 2002. Disponível em: <http://www.sciencedirect.com/science?_ob=Mlmg\&_ imagekey=B6TYV-44KVXKV-1-9\&_cdi $=5628 \&$ user $=5674931 \&$ orig $=$ search\&_cover Date $=03 \% 2 F 31 \% 2 F 2002 \&$ sk=999759998\&view=c\&wchp=dGLbVtz-zSkzS\&md5= 2721fa88f8c35f76ccd998c1164c46e9\&ie=/sdarticle.pdf>. Acesso em: 10 abr. 2007. 
MAHALIK, N. G. P. C.; LEE, S. K. Design and development of system level software tool for DCS simulation. Advances in Engineering Software, [S. I.], v. 34, p. 451-465, 2003.

NERSON, J.-M. Applying Object-Oriented Analysis and Design. Communications of the ACM, [S. I.], v. 35, p. 63-74, set. 1992. Número 9. Disponível em: $<$ http://delivery.acm.org/10.1145/140000/130997/p63-nerson.pdf?key1=130997\& key2=0286990811\&coll=GUIDE\&dl=GUIDE,ACM\&CFID=20458071\&CFTOKEN $=63249700>$. Acesso em: 5 abr. 2007.

NEUMANN, P. Communication in industrial automation - What is going on?. Control Engineering Practice, [S. I.], v. 15, p. 1332-1347, nov. 2007. Disponível em: <http://www.sciencedirect.com/science?_ob=MImg\&_imagekey=B6V2H-4MJB THB-1-1\&_cdi $=5703 \&$ user $=10 \&$ orig $=$ search \&_coverDate $=11 \% 2 \mathrm{~F} 30 \% 2 \mathrm{~F} 2007 \&$ sk $=999849988 \& v i e w=c \& w c h p=d G L b V I z-z S k z S \& m d 5=c c 15 a e 606 b b 482 b 77 a 8 b 1$ f9befd eae9c\&ie=/sdarticle.pdf>. Acesso em: 28 mar. 2007.

OBJECT MANAGEMENT GROUP. Unified Modeling Language: Infrastructure. [S. I.], fev. 2007. 732 p. Disponível em: <http://www.omg.org/cgi-bin/apps/doc?formal/ 07-02-06.pdf>. Acesso em: 5 abr. 2007.

OGATA, K. Introdução a Sistemas de Controle. Tradução de André Fábio Kohn; José Carlos Teixeira de Barros Moraes. In: Engenharia de Controle Moderno. Rio de Janeiro: Prentice/Hall do Brasil, 1982, p. 1-16.

PANJAITAN, S.; FREY, G. Functional Design for IEC 61499 Distributed Control Systems using UML Activity Diagrams. In: 2005 INTERNATIONAL CONFERENCE ON INSTRUMENTATION, COMMUNICATIONS AND INFORMATION TECHNOLOGY (ICICI), 2005, Bandung. Proceedings... [S. I.: s. n.], 2005. p. 64-70. Disponível em: <http://www.eit.uni-kl.de/frey/papers/PDF/Acc01.pdf>. Acesso em: 21 ago. 2007.

PANJAITAN, S.; FREY, G. Combination of UML Modeling and the IEC 61499 Function Block Concept for the Development of Distributed Automation Systems. In: 2006 IEEE INTERNATIONAL CONFERENCE ON EMERGING TECHNOLOGIES AND FACTORY AUTOMATION (ETFA '06), 2006, Prague. Proceedings... [S. I.]: IEEE, 2006. p. 766-773, 2006. Disponível em: <http://ieeexplore.ieee.org/iel5/ 4178170/4178171/04178238.pdf?tp=\&isnumber=\&arnumber=4178238>. Acesso em: 21 jun. 2007.

PANJAITAN, S.; FREY, G. Designing Generic/Reusable Functionality Based Controllers for Distributed Control using UML. In: 2006 IEEE INTERNATIONAL CONFERENCE ON ROBOTICS AND AUTOMATION, 2006, Orlando. 
Proceedings... [S. I.]: IEEE, 2006. p. 321-326. Disponível em: <http://ieeexplore. ieee.org/iel5/10932/34383/01641731. pdf?tp=\&isnumber=\&arnumber=1641731 > . Acesso em: 20 ago. 2007.

RASKIN, S.; DUBININ, V. IEC61499 converter. v. 2.0. 2004. Disponível em: <http://alice.stup.ac.ru/ dvn/fb61499/uml_fb/converters/raskin/FBtoUMLconverter_v1 5_July_12_2004.zip >. Acesso em: 21 ago. 2007.

SAMAD, T.; MCLAUGHLIN, P.; LU, J. System architecture for process automation: Review and trends. Journal of Process Control, [S. I.], v. 17, p. 191-201, 2007. Disponível em: <http://www.sciencedirect.com/science?_ob=Mlmg\&_imagekey=B6V 4N-4MVDVG1-1-1\&_cdi $=5763 \&$ user $=5674931$ \&_orig=search\&_coverDate $=03 \% 2 F 3$ 1\%2F2007\&_sk=999829996\&view=c\& wchp=dGLbVzb-zSkzk\&md5=97831b0cfbc422 cc789ae4db43e97924\&ie=/sdarticle.pdf>. Acesso em: 29 mar. 2007.

SANTOS, J. J. H. Generalidades sobre automação. In: Automação industrial. Rio de Janeiro: Livros Técnicos e Científicos, 1979. p. 1-23.

SOFTWARE ENGINEERING GROUP. Archimedes ESS 0.8 User's Guide. Patras: Software Engineering Group, Electrical \& Computer Engineering, University of Patras, 27 jan. 2005. 17 p. Disponível em: <http://seg.ee.upatras.gr/mim/Archimedes ESSUsersGuide1_2.pdf>. Acesso em: 14 ago. 2007.

SOFTWARE ENGINEERING GROUP. CORFU ESS. Version 1.0.0. 2006. Disponível em: <http://seg.ee.upatras.gr/corfu/dev/files/corfu_ess_distribution_1.0.0.exe>. Acesso em: 21 jun. 2007.

SPARX SYSTEMS PTY LTD. UML 2.1 Tutorial. 2008. Disponível em: <http://www.sparxsystems.com.au/resources/uml2_tutorial/index.html>. Acesso em: 10 jan. 2008.

THE UNIVERSITY OF AUCKLAND, RESEARCH CENTRE FOR EMBEDDED INTELLIGENCE - CEMBI. FBench Project: Home. [S. I.]: The University of Auckland, Research Centre for Embedded Intelligence - CEMBI, 2007. Página da Internet sobre o projeto FBench. Disponível em: <http://www.ece.auckland.ac.nz/ \%7Evyatkin/fbench/index.html>. Acesso em: 21 jun. 2007.

THRAMBOULIDIS, K. Using UML for the Development of Distributed Industrial Process Measurement and Control Systems. In: 2001 IEEE INTERNATIONAL CONFERENCE ON CONTROL APPLICATIONS, 2001, México City. Proceedings... [S. I.]: IEEE, 2001. p. 1129-1134. Disponível em: <http://ieeexplore.ieee.org/iel5/ 7676/20975/00974023. pdf?tp=\&isnumber=\&arnumber=974023>. Acesso em: 30 ago. 2007 . 
THRAMBOULIDIS, K. C. Towards an Engineering Tool for Implementing Reusable Distributed Control Systems. In: EUROPEAN SOFTWARE ENGINEERING CONFERENCE / ACM SIGSOFT INTERNATIONAL SYMPOSIUM ON FOUNDATIONS OF SOFTWARE ENGINEERING, 2003, Helsinki. Proceedings... [S. I.]: ACM, 2003. p. 351-354. Disponível em: <http://portal.acm.org/ft gateway.cfm? id $=940119 \&$ type $=$ pdf $\&$ coll $=$ GUIDE $\& d l=G U I D E \& C F I D=25603290 \& C F T O K E N=825478$ 24>. Acesso em: 18 abr. 2007.

TOURANDOVERCONTROLS. Menta_forHVAC.pdf: Descrição técnica-comercial da ferramenta TAC Menta ${ }^{\text {TM }}$. [S. I.], 2006. Disponível em: <http://www.tac.com/data/ internal/data/05/01/1169217918962/Menta_forHVAC.pdf>. Acesso em: 21 jul. 2007.

TRANORIS, C. (Ed.). CORFU FBDK: Quick Start Guide, v. 0.8. Patras: Software Engineering Group, 2003. 27 p. Disponível em: <http://seg.ee.upatras.gr/corfu/dev/ CORFU_FBDK_Quick_Guide.pdf>. Acesso em: 21 jun. 2007.

TRANORIS, C.; THRAMBOULIDIS, K. From requirements to function block diagrams: a new approach for the design of industrial control applications. In: MEDITERRANEAN CONFERENCE ON CONTROL AND AUTOMATION, 10., 2002, Lisbon. Proceedings... [S. I.: s. n.], 2002. Disponível em: <http://med.ee.nd.edu/ MED10-2002/pdf/392.pdf>. Acesso em: 21 ago. 2007.

TRANORIS, C.; THRAMBOULIDIS, K. An IEC-compliant Engineering Tool for Distributed Control Applications. In: MEDITERRANEAN CONFERENCE ON CONTROL AND AUTOMATION (MED '03), 11., 2003, Rhodes. [S. I.: s. n.], 2003. p. 1-6. Disponível em: <http://seg.ee.upatras.gr/thrambo/dev/Papers/MED-03paper. pdf>. Acesso em: 21 jun. 2007.

TRANORIS, C.; THRAMBOULIDIS, K. Integrating UML and the Function Block Concept for the Development of Distributed Control Applications. In: 2003 IEEE INTERNATIONAL CONFERENCE ON EMERGING TECHNOLOGIES AND FACTORY AUTOMATION, 2003, [S. I.]. Proceedings... [S. I.]: IEEE, 2003. p. 87-94. Disponível em: <http://ieeexplore.ieee.org/iel5/8826/27958/01248674.pdf?tp=\& isnumber $=\&$ arnumber=1248674>. Acesso em: 21 jun. 2007.

VISUALCONTROL, LLC. VisualControl\%20brochure\%2002-20-03_r01.pdf: Descrição técnica-comercial da suíte de ferramentas VisualControl ${ }^{\mathrm{T}}{ }^{-}$. Fairview Heights, 2003. Disponível em: <http://www.smartcontrols.us/smartControls/scvc/ VisualControl\%20brochure\%2002-20-03_r01.pdf>. Acesso em: 3 mai. 2007.

VYATKIN, V. ViVe - the Visual Verifier. [S. I.: s. n.], 2007. 3 p. Disponível em: <http://www.ece.auckland.ac.nz/ vyatkin/tools/VisualVerifier.pdf>. Acesso em: 12 nov. 2007. 
WANG, S. et al. Investigation on intelligent building standard communication protocols and application of IT technologies. Automation in Construction, [S. I.], v. 13, p. 607-619, 2004. Disponível em: <http://www.sciencedirect.com/science?_ob= Mlmg\&_imagekey=B6V20-4CJCYBD-1-1\&_cdi=5688\&_user=5674931\&_orig=search \&_coverDate=09\%2F30\%2F2004\&_sk=999869994\&view=c\&wchp=dGLbVzWzSkzS\&md5=e965bc994e953773fd8074608343baf1\&ie=/sdarticle.pdf>. Acesso em: 10 abr. 2007.

WONG, J. K. W.; LI, H.; WANG, S. W. Intelligent building research: a review.

Automation in Construction, [S. I.], v. 14, p. 143-159, 2005. Disponível em: <http:// www.sciencedirect.com/science?_ob=MImg\&_imagekey=B6V20-4D5JYDY-1-1\& $\mathrm{cdi}=5688 \&$ \&user $=5674931 \&$ _orig $=$ search\&_coverDate $=01 \% 2 \mathrm{~F} 31 \% 2 \mathrm{~F} 2005 \&$ sk $=999$ 859998\&view=c\&wchp=dGLzVzz-zSkzV\&md5=0b64b1dc7bdca745cdd5804aa7b138 77\&ie=/sdarticle.pdf >. Acesso em: 10 abr. 2007.

XIE, C.; PU, J.-S.; MOORE, P. R. A case study on the development of intelligent actuator components for distributed control systems using LONWORK neuron chips. Mechatronics, [S. I.], v. 8, p. 103-119, 1998. Disponível em: <http://www.science direct.com/science?_ob=Mlmg\&_imagekey=B6V43-3TB05XD-2-1\&_cdi=5747\&_user $=5674931 \&$ orig=search \&_coverDate=03\%2F31\%2F1998\&_sk=999919997\&view $=c$ $\& w c h p=d G L \bar{b} V I z-z S k W A \& \overline{m d} 5=13218 \mathrm{e} 3227000 \mathrm{db} 3 \mathrm{db} 760276573636 \mathrm{df} \& \mathrm{ie}=/ \mathrm{sd}$ article.pdf>. Acesso em: 10 abr. 2007.

YOURDON, E. Análise estruturada moderna. Tradução Dalton Conde de Alencar. 13 ed. Rio de Janeiro: Campus, 1990. 836 p. (Série Yourdon Press).

YOURDON, E; ARGILA, C. Introdução. In: Análise e projeto orientados a objetos: estudos de casos. Tradução Angelita Carvalho Gomes; Alvaro Antunes. São Paulo: MAKRON Books, 1999. p. 1-18.

ZHANG, W.; DIEDRICH, C.; HALANG, W. A. Specification of Function Block Applications with UML. In: 2005 IEEE INTERNATIONAL CONFERENCE ON ROBOTICS AND AUTOMATION, 2005, Barcelona. Proceedings... [S. I.]: IEEE, 2005. p. 4002-4007. Disponível em: <http://ieeexplore.ieee.org/iel5/10495/33250/ 01570733.pdf?arnumber=1570733 >. Acesso em: 21 ago. 2007.

ZOITL, A.; STRASSER, T. Modelling Distributed Control Systems within 4DIAC based on IEC 61499. [S. I.]: 4DIAC Consortium, 2007. 68 p. Tutorial em formato de transparências. Disponível em: <http://www.fordiac.org/fileadmin/user_upload/4DIAC _Tutorial.pdf>. Acesso em: 12 nov. 2007. 


\section{ANEXO A - Figuras complementares referentes aos modelos de referência da norma IEC 61499}

As figuras a seguir foram retiradas de Christensen (2002) e traduzidas para a língua portuguesa. Essas mesmas ilustrações estão presentes na Parte 1 da norma IEC 61499 (INTERNATIONAL ELECTROTECHNICAL COMMISSION, 2005a), e são utilizadas nesta dissertação para tornar mais claros os conceitos relacionados aos modelos de referência da norma IEC 61499.

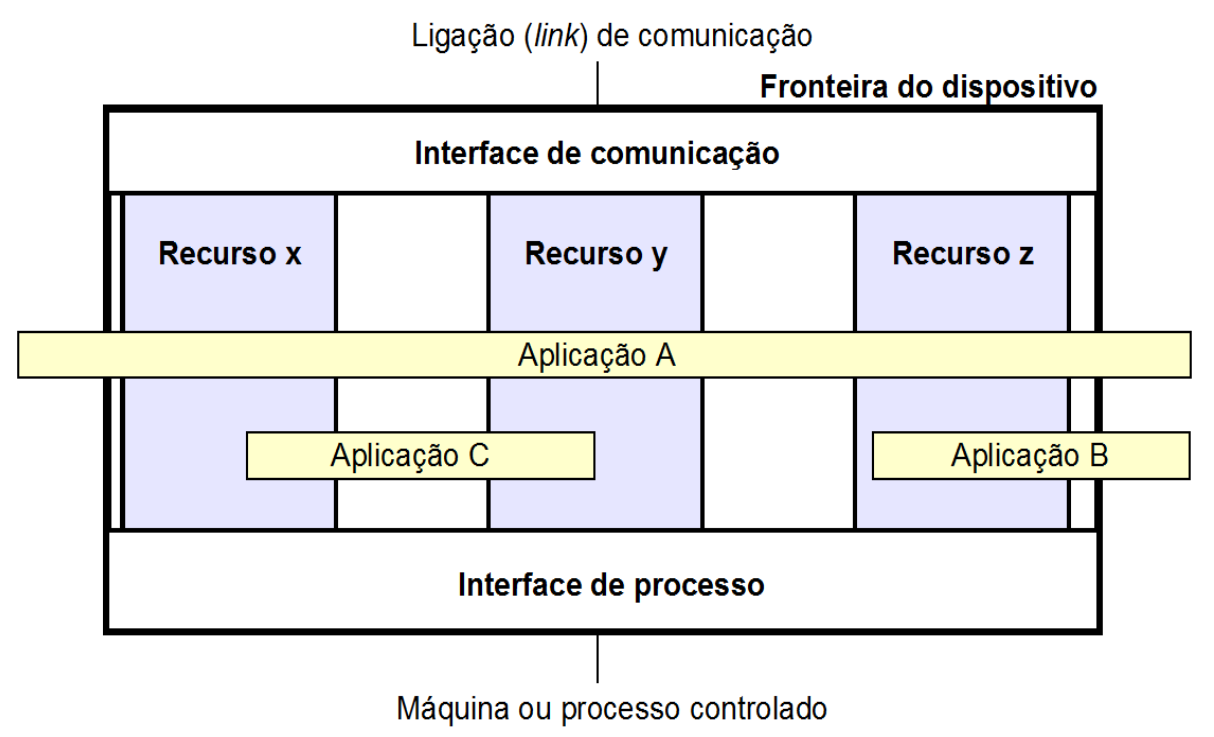

Figura 58: Arquitetura de um dispositivo.

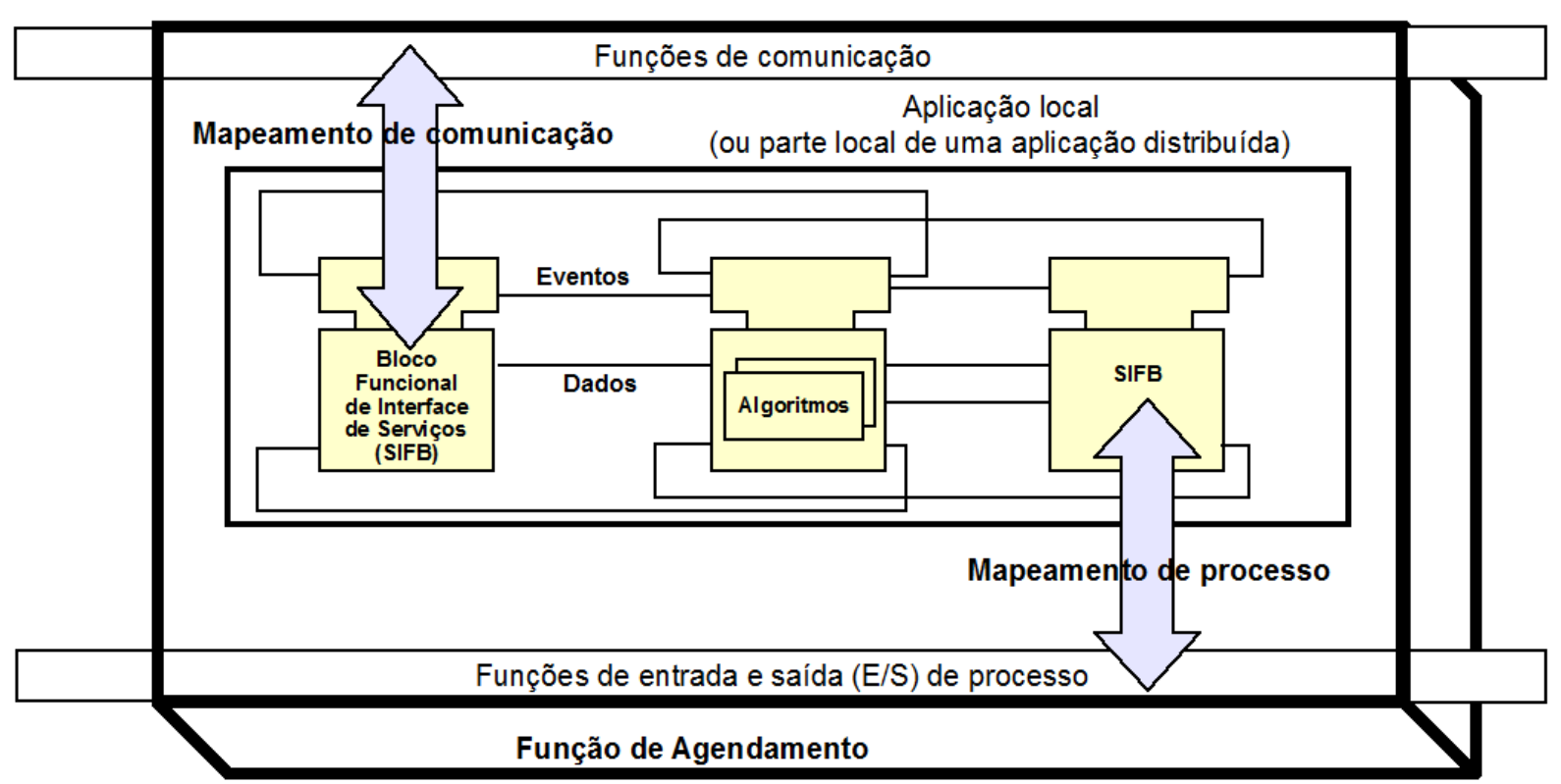

Figura 59: Arquitetura de um recurso. 


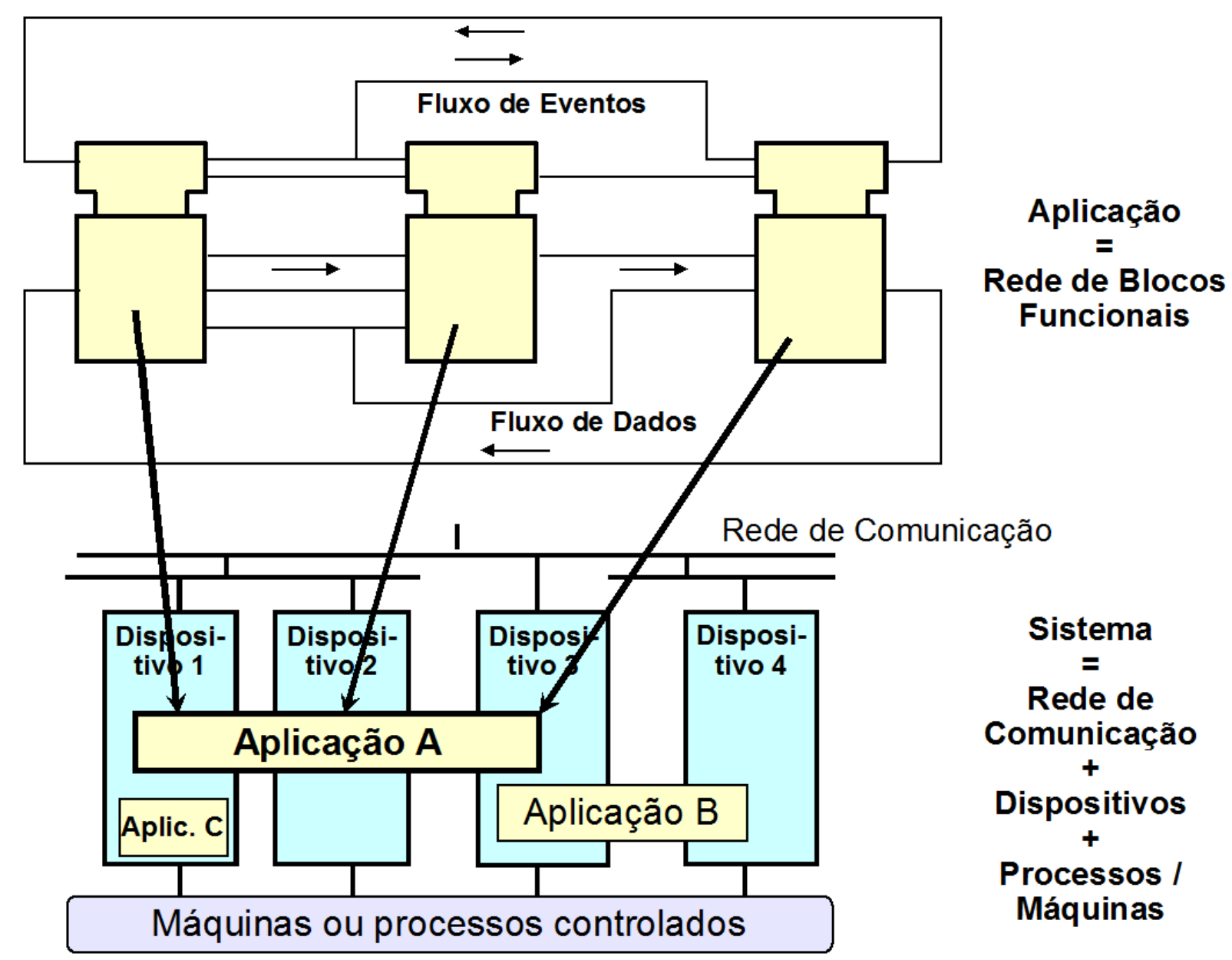

Figura 60: Arquitetura de um sistema distribuído segundo a norma IEC 61499. 